\title{
Development of Tin-Bronze and Copper Based Journal Bearing Materials with Tribaloy Alloy Additives
}

\author{
by \\ Arash Tavakoli \\ B.Sc., MSc. \\ A thesis submitted to the Faculty of Graduate Studies and Research \\ in partial fulfillment of the requirements for the degree of \\ Master of Applied Science \\ Ottawa-Carleton Institute for Mechanical and Aerospace Engineering \\ Department of Mechanical and Aerospace Engineering \\ Carleton University \\ Ottawa, Ontario \\ Canada
}

August $2007 @$ 


$\begin{array}{ll}\begin{array}{l}\text { Library and } \\ \text { Archives Canada }\end{array} & \begin{array}{l}\text { Bibliothèque et } \\ \text { Archives Canada }\end{array} \\ \begin{array}{l}\text { Published Heritage } \\ \text { Branch }\end{array} & \begin{array}{l}\text { Direction du } \\ \text { Patrimoine de l'édition }\end{array} \\ \begin{array}{l}\text { 395 Wellington Street } \\ \text { Ottawa ON K1A ON4 }\end{array} & \begin{array}{l}\text { 395, rue Wellington } \\ \text { Ottawa ON K1A ON4 } \\ \text { Canada }\end{array}\end{array}$

Your file Votre référence ISBN: 978-0-494-33670-0 Our file Notre référence ISBN: 978-0-494-33670-0

NOTICE:

The author has granted a nonexclusive license allowing Library and Archives Canada to reproduce, publish, archive, preserve, conserve, communicate to the public by telecommunication or on the Internet, loan, distribute and sell theses worldwide, for commercial or noncommercial purposes, in microform, paper, electronic and/or any other formats.

The author retains copyright ownership and moral rights in this thesis. Neither the thesis nor substantial extracts from it may be printed or otherwise reproduced without the author's permission.
AVIS:

L'auteur a accordé une licence non exclusive permettant à la Bibliothèque et Archives Canada de reproduire, publier, archiver, sauvegarder, conserver, transmettre au public par télécommunication ou par l'Internet, prêter, distribuer et vendre des thèses partout dans le monde, à des fins commerciales ou autres, sur support microforme, papier, électronique et/ou autres formats.

L'auteur conserve la propriété du droit d'auteur et des droits moraux qui protège cette thèse. $\mathrm{Ni}$ la thèse ni des extraits substantiels de celle-ci ne doivent être imprimés ou autrement reproduits sans son autorisation.
In compliance with the Canadian

Privacy Act some supporting forms may have been removed from this thesis.

While these forms may be included in the document page count, their removal does not represent any loss of content from the thesis.
Conformément à la loi canadienne sur la protection de la vie privée, quelques formulaires secondaires ont été enlevés de cette thèse.

Bien que ces formulaires aient inclus dans la pagination, il n'y aura aucun contenu manquant.

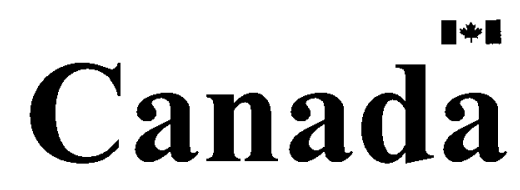




\begin{abstract}
Three groups of lead-free bronze based and copper based composites with the newly developed Tribaloy alloy additives, designated as $\mathrm{T}-401$ and $\mathrm{T}-400 \mathrm{C}$, are developed for journal bearing applications. Two types of bronze are tested, one is in a premixed state, the other prealloyed. The copper is added with $15 \%$ bismuth. Different from conventional Tribaloy alloys, T-401 has better ductility owing to the primary solid solution rather than Laves phase and both T-401 and T-400C have improved corrosion resistance due to the increased chromium content. The specimens are fabricated using the powder metallurgy (PM) and hot isostatic pressing (HIP) consolidation techniques. The sintering/HIPping cycles are designed based on the differential scanning calorimetry (DSC) analyses of the specimen powders. The material characterization includes optical and scanning electron microscope (SEM) microstructual examination, determination of mechanical properties under macro hardness, nano indentation, and tensile tests. Evaluation of wear resistance is conducted on a pin-on-disc tribometer. The experimental results demonstrate that the Tribaloy alloy $\mathrm{T}-401$, as the additive, increases the wear resistance and mechanical properties of the bronze and the copper materials, but $\mathrm{T}-400 \mathrm{C}$ has a detrimental effect on the wear resistance due to its brittleness. In the copper based materials excessive content of bismuth causes the copper grain boundaries brittle, resulting in cracking. It is also found that the presence of the Tribaloy particles reduces the grain size of the matrices and refines the microstructures. The potential new materials for journal bearing applications will be prealloyed bronze with 15-20\% T-401 which exhibit the best wear resistance and mechanical properties among the developed materials.
\end{abstract}




\section{Acknowledgments}

I would like to gratefully acknowledge the contributions of this research made by several groups and individuals. I greatly appreciate the support given to this project by NSERC, jointed with three industrial organizations, Pratt \& Whitney Canada, Canadian Babbitt Bearings Ltd. and Deloro Stellite Inc. which provided the funding for this project. I also would like to acknowledge National Research Council Canada, SMPL group for their kind support and help. I would like to express my sincere gratitude to my supervisor Dr. Rong Liu, for her unwavering support and guidance during this research, I will forever be thankful to her. I would like to acknowledge my co-supervisor, Dr. Xijia Wu from NRC for his kind support during this research. I also would like to appreciate Dr. Qi Yang from NRC for his in-kind support in wear and nano indentation tests. I wish to thank David D. (Dave) Morphy and Ryan MacNeil for their sincere cooperation in manufacturing. I would also like to thank Olga Lupandina and David Chow from NRC for their kind help in metallography and SEM analysis. 


\section{Table of Contents}

ABSTRACT ….........................................................................................................................................II

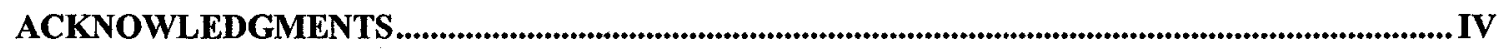

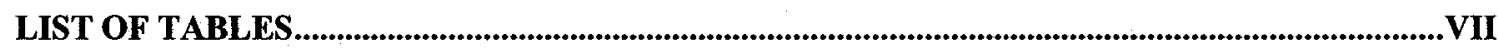

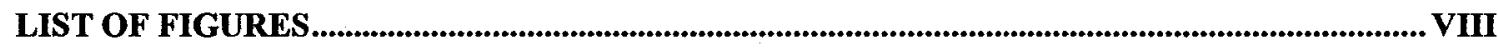

NOMENCLATURE ...........................................................................................................................XII

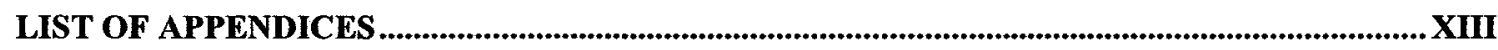

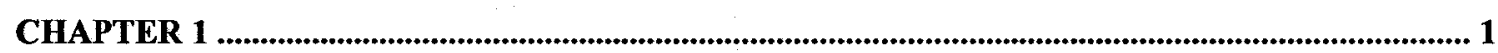

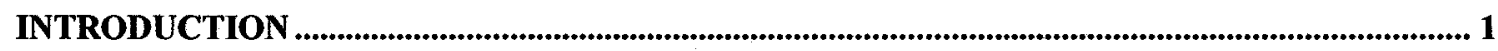

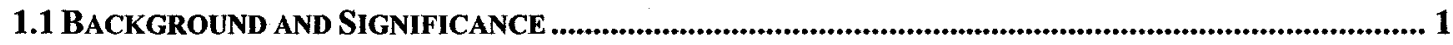

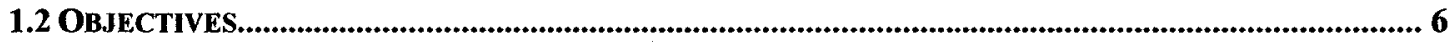

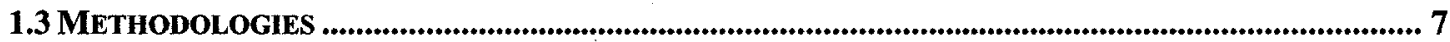

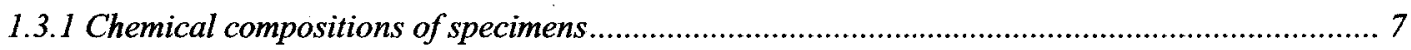

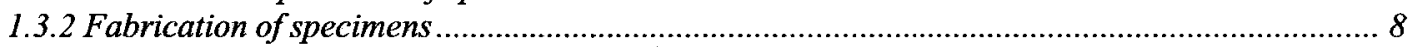

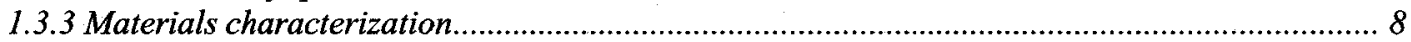

1.4 STRUCTURE OF THE THESIS.............................................................................................................................. 9

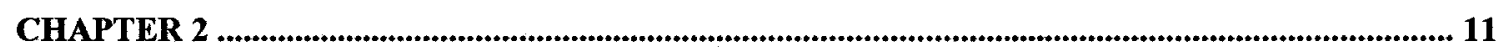

LITERATURE REVIEW .................................................................................................................... 11

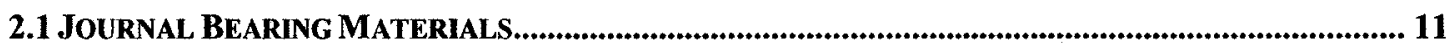

2.1.1 Requirements for journal bearing materials ................................................................ 11

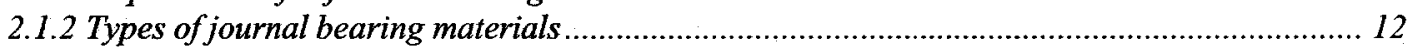

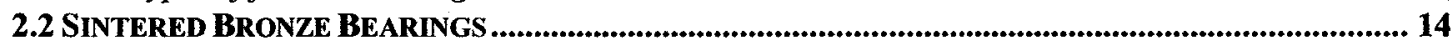

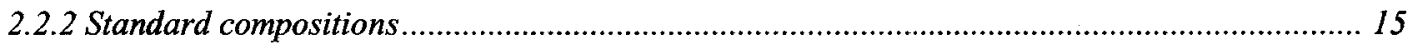

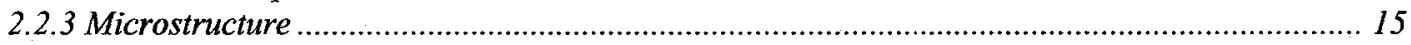

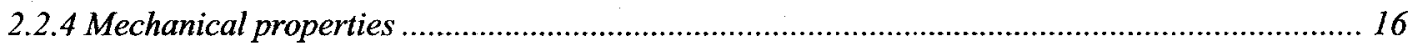

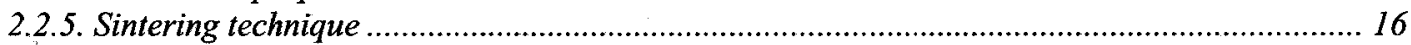

2.2.6. Densification and dimensional change …………............................................................ 19

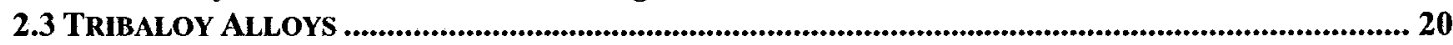

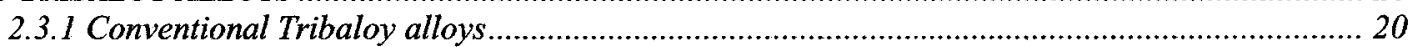

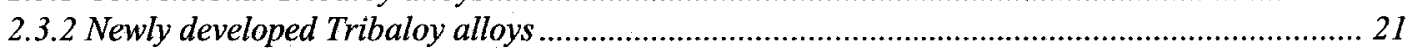

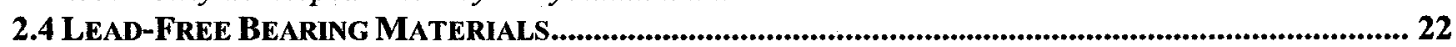

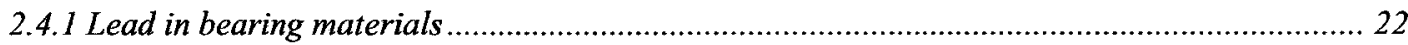

2.4.2 Development of lead-free bearing materials................................................................... 24

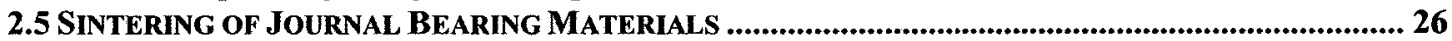

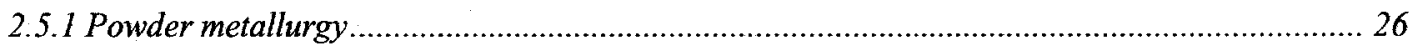

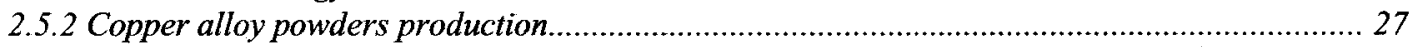

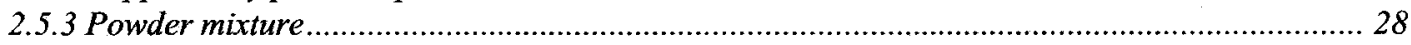

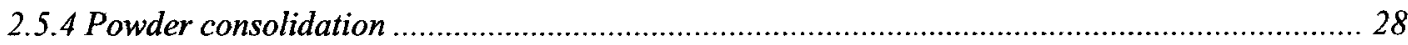

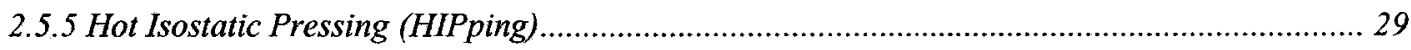

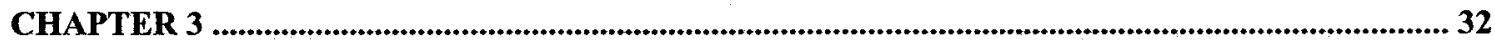

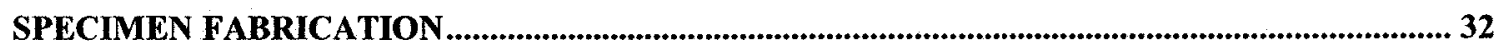

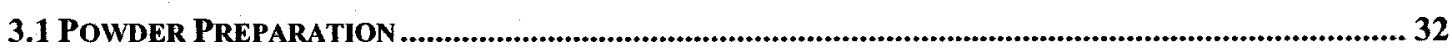

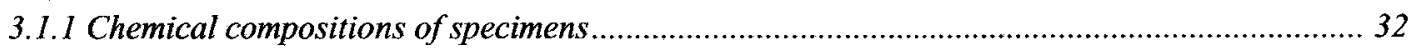

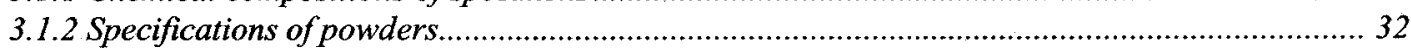

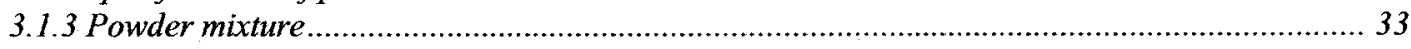

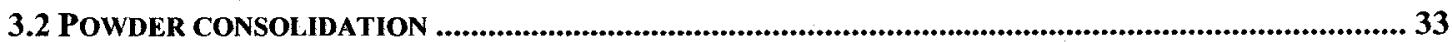




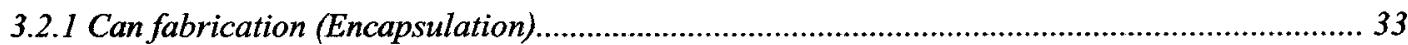

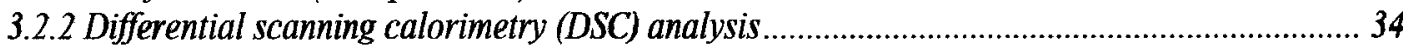

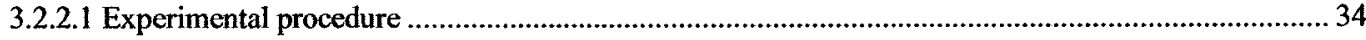

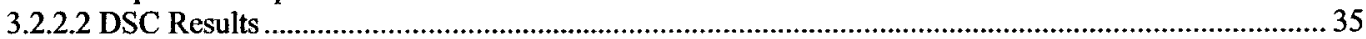

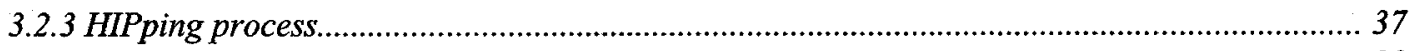

3.2.4 Sintering process

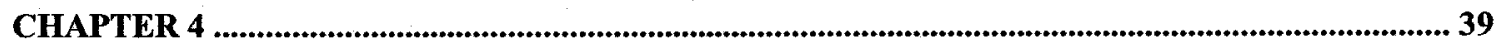

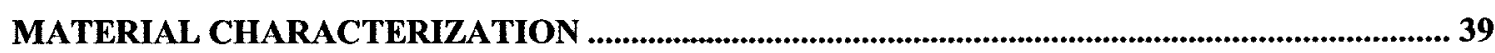

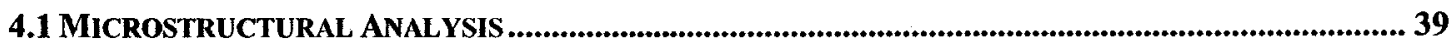

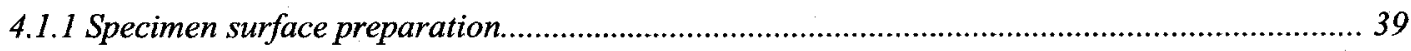

4.1.2 Microstructures of sintered specimens.................................................................................. 40

4.1.3 Microstructures of HIPped specimens ............................................................................... 41

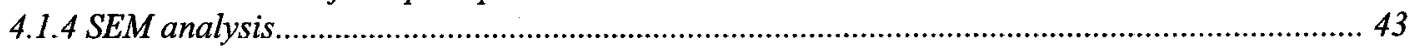

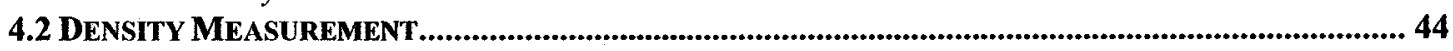

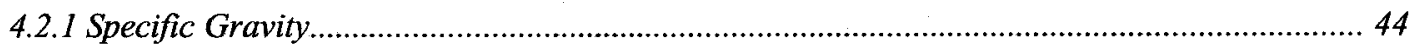

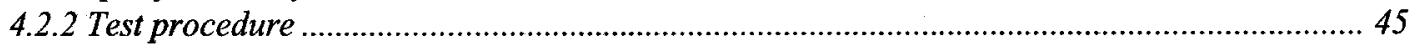

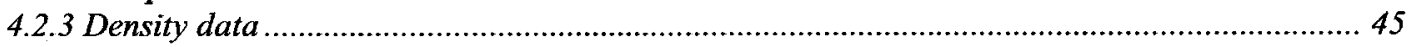

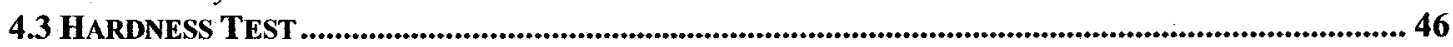

4.3.1 Test procedure ……………………………………....................................................... 46

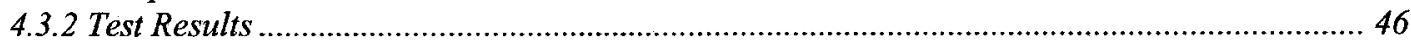

4.4 NANO INDENTATION TEST ............................................................................................................................... 47

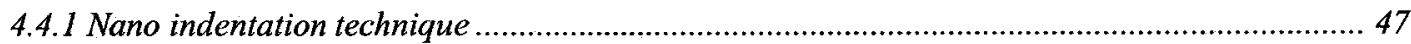

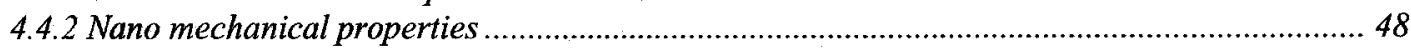

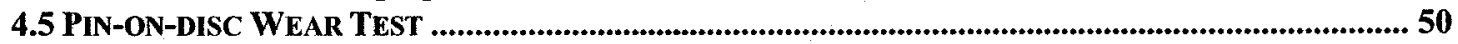

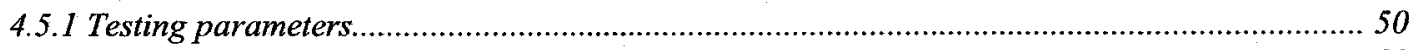

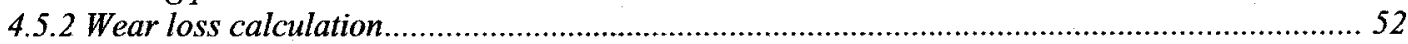

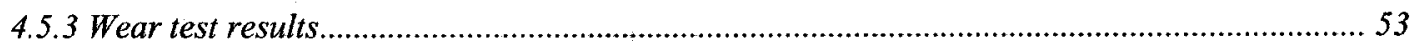

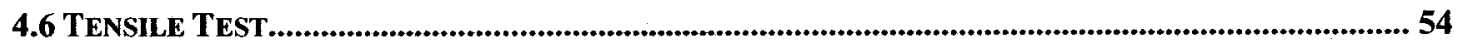

4.6.1 Test process

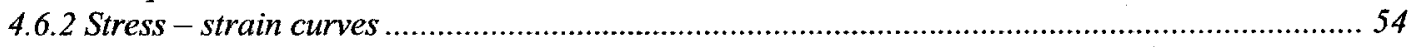

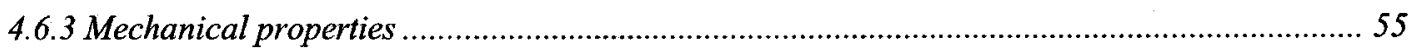

4.7 TESTS OF AN INDUSTRIAL SINTERED BRONZE BEARING ...........................................................5

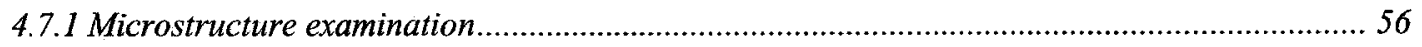

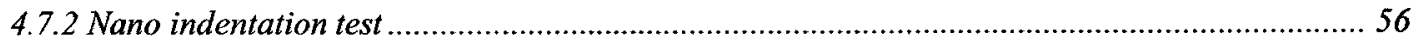

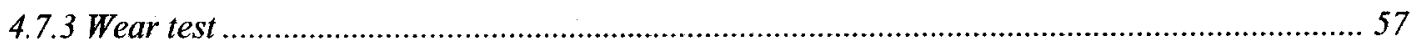

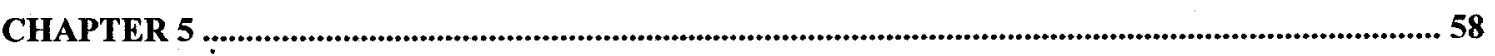

DISCUSSION AND CONCLUSIONS.............................................................................................. 58

5.1 DISCUSSION ON THE EXPERIMENTAL RESULTS ..................................................................................... 58

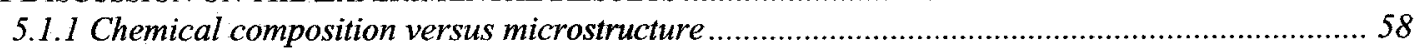

5.1.2 Effects of Tribaloy alloys on the wear resistance...................................................................... 60

5.1 .3 Effects of Tribaloy alloys on the mechanical properties .............................................................62 62

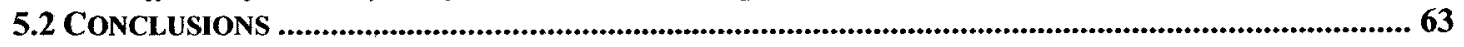

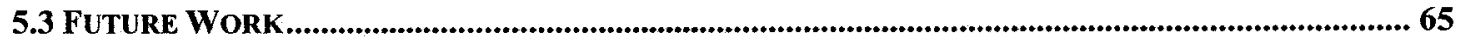

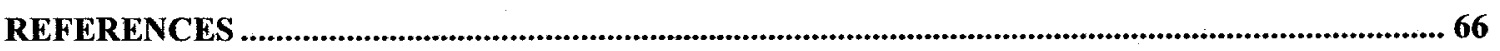

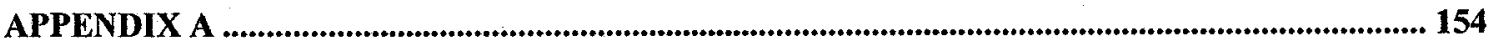

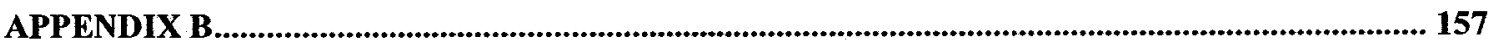

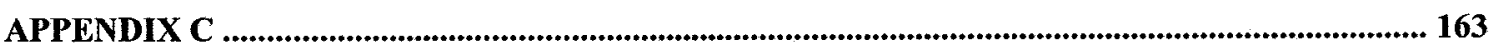

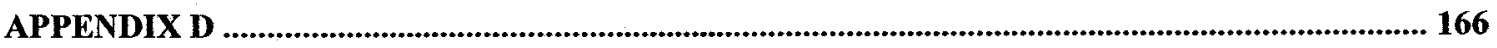




\section{List of Tables}

Table 1.1 Compositions of Tribaloy alloys $[25,27]$ 72

Table 2.1 Chemical requirements (composition, wt\%) for sintered bronze bearings [2] . 72

Table 2.2 Density requirements for oil impregnated sintered bronze bearings [2] ......... 72

Table 2.3 Density requirements for oil impregnated sintered bronze bearings [2] ......... 73

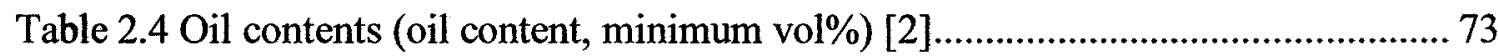

Table 2.5 Etchants used for examination of PM materials [45] ..................................... 73

Table 2.6 Mechanical properties of sintered bronze bearings [46] ............................... 74

Table 2.7 Effect of copper powder oxide thickness on the strength of press-and-sintered

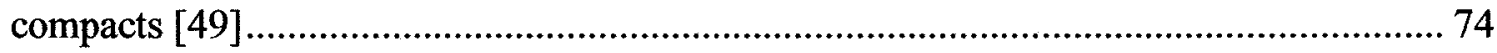

Table 2.8 Nano mechanical properties of Tribaloy alloys [27] …................................ 74

Table 2.9 Major historical development in powder metallurgy [55] ............................ 75

Table 2.10 Physical properties of typical bronze alloy [56] ......................................... 75

Table 3.1 Powder compositions of the developed materials........................................ 76

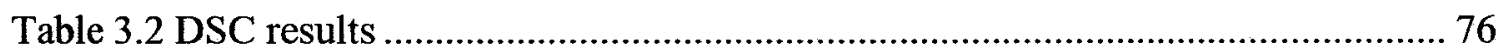

Table 4.1 EDX data of composition analyses of copper-15\% bismuth specimen ........... 77

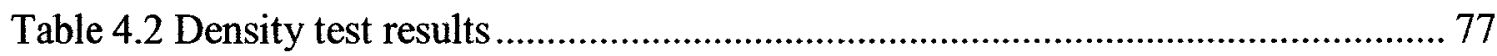

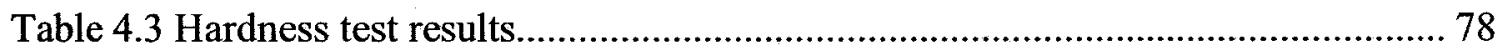

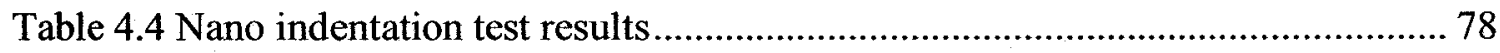

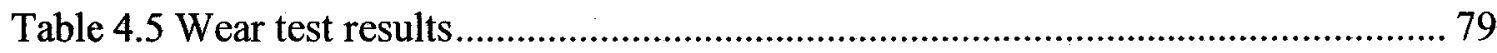

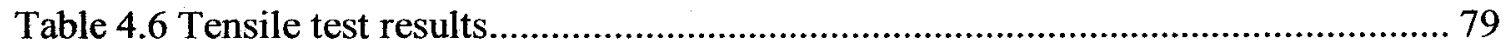

Table 4.7 Nano indentation test results for an industrial sintered bronze bearing in comparison with specimens MG1 and B-409 ...................................................... 80

Table 4.8 Wear test results for an industrial sintered bronze bearing in comparison with specimens MG1 and B-409. 80

vii 


\section{List of Figures}

Figure 1.1 Supplementary lubrication of porous bearings: (a) oil reservoir created in the space between two bearing ends, (b) oil reservoir around bearing, (c) oil reservoir above bearing, (d) oil reservoir below bearing, (e) oil-soaked felt washer to provide additional lubrication, (f) oil-soaked felt washer with self-aligning bearing [1] ............................. 81

Figure 1.2 Typical self-lubricating bronze bearings ........................................ 82

Figure 2.1 Alpha bronze microstructure in $90 \% \mathrm{Cu}-10 \% \mathrm{Sn}$ PM bearing alloy: (a) Low

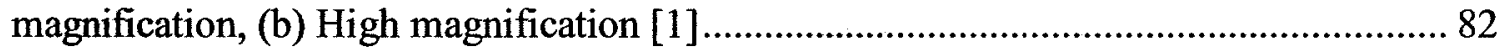

Figure 2.2 Distribution of original particle boundaries in undersintered specimens from a diffusion-alloyed steel $\left(6.7 \mathrm{~g} / \mathrm{cm}^{3}\right)$, pressed at $480 \mathrm{MPa}$ and sintered in dissociated ammonia in hot zone at $1120^{\circ} \mathrm{C}$ : (a) material sintered for $5 \mathrm{~min}$. Numerous particle boundaries (arrows P) are indicative of undersintering. Arrows $\mathrm{G}$ are undiffused, gray flakes of graphite in pores, (b) material sintered for $15 \mathrm{~min}$. Pores are rounded (arrows R). Arrows $\mathrm{P}$ indicates persistence of original particle boundaries; as-polished. [45] .......... 83

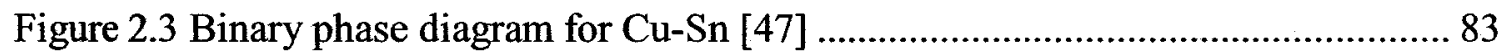

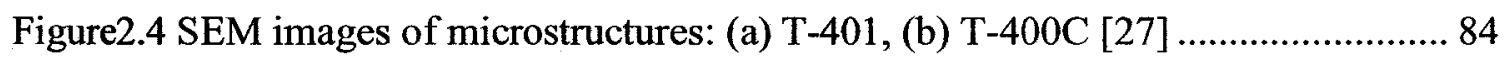

Figure2.5 Wear losses of cylinder and flat pairs after $400 \mathrm{~m}$ sliding at $482^{\circ} \mathrm{C}[29] \ldots \ldots . .85$

Figure2.6 Wear losses of disc and flat pairs after $800 \mathrm{~m}$ sliding at $482^{\circ} \mathrm{C}[29] \ldots \ldots \ldots \ldots . . . .85$

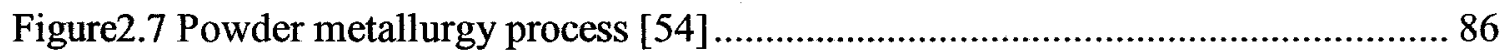

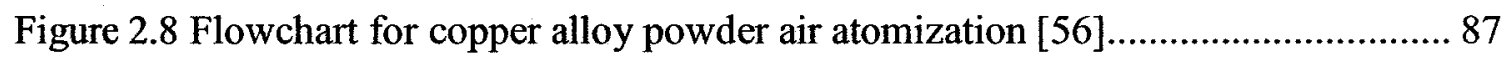

Figure 2.9 SEM images of copper powder: (a) air atomized, (b) water atomized [57] ... 87

Figure 2.10 Density as a function of pressure for isostatic and unidirectional pressing of

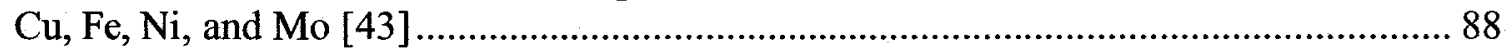

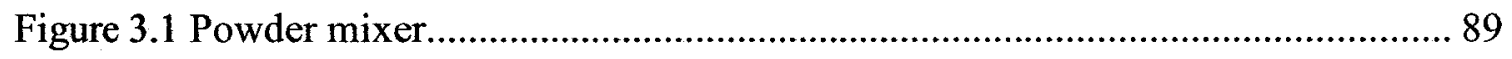

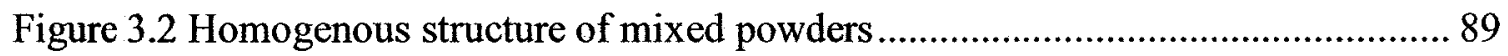

Figure 3.3 Distribution of Tribaloy alloy particles in the matrix................................ 89

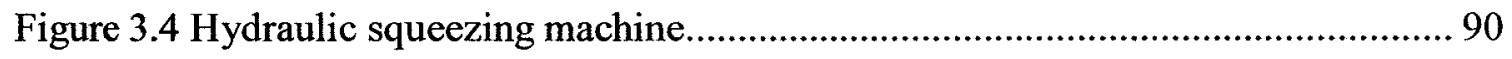

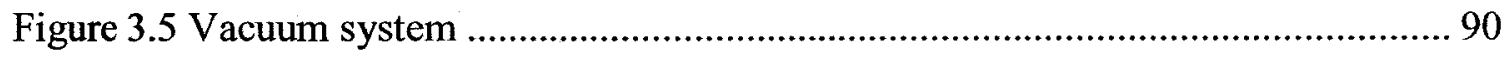

viii 
Figure 3.7 DSC curves for Group 1 specimens (premixed bronze based): (a) premixed $90 / 10$ bronze powder under the ultimate temperature of $1100^{\circ} \mathrm{C}$, (b) premixed $90 / 10$ bronze with $10 \%$ T401 under the ultimate temperature of $1300^{\circ} \mathrm{C}$, (c) premixed $90 / 10$ bronze powder under the ultimate temperature of $870^{\circ} \mathrm{C}$, (d) premixed $90 / 10$ bronze with $20 \% \mathrm{~T} 401$ under the ultimate temperature of $1500^{\circ} \mathrm{C}$

Figure 3.8 DSC curve for Group2 specimens (prealloyed bronze based), prealloyed 90/10 bronze with $20 \% \mathrm{~T} 401$ under the ultimate temperature of $1400^{\circ} \mathrm{C}$

Figure 3.9 DSC curve for Group3 specimens (copper based), Cu-15\%Bi with 20\% T401 under the ultimate temperature of $870^{\circ} \mathrm{C}$. 93

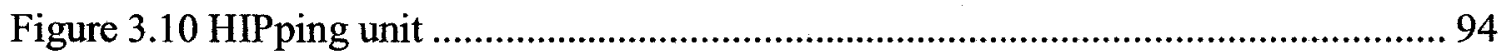

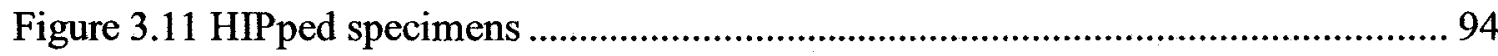

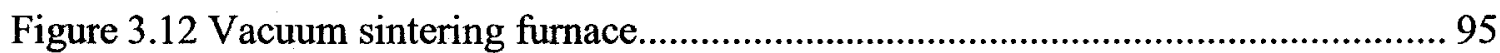

Figure 4.1 Microstructures of $\mathrm{Cu}-15 \% \mathrm{Bi}$ with $10 \% \mathrm{~T}-401$ sintered for $30 \mathrm{~min}$ at $870^{\circ} \mathrm{C} 96$

Figure 4.2 Microstructures of HIPped bronze based alloy (first HIPped specimen), 90/10 premixed bronze with $10 \% \mathrm{~T}-401$, HIPped for $20 \mathrm{~min}$ at $840^{\circ} \mathrm{C}$

Figure 4.3 Microstructures of HIPped copper based alloy (second HIPped specimen), $\mathrm{Cu}-15 \% \mathrm{Bi}$ with $10 \% \mathrm{~T}-401$, HIPped for $30 \mathrm{~min}$ at $870^{\circ} \mathrm{C}$

Figure 4.4 Microstructures of HIPped bronze based alloy (third HIPped specimens), Cu$10 \% \mathrm{Sn}, \mathrm{HIP}$ ped at $870^{\circ} \mathrm{C}$ for $120 \mathrm{~min}$ under $206 \mathrm{MPa}$ pressure 98

Figure 4.5 Microstructures of premixed bronze (specimen MG1) ............................ 100

Figure 4.6 Microstructures of premixed bronze with 10\% T-401 (specimen 7) ........... 102

Figure 4.7 Microstructures of premixed bronze with 15\% T-401 (specimen 8) ........... 103

Figure 4.8 Microstructures of premixed bronze with 20\% T-401 (specimen 9) ........... 104

Figure 4.9 Microstructures of premixed bronze with 15\% T-400C (specimen 13)....... 105

Figure 4.10 Microstructures of premixed bronze with 20\% T-400C (specimen 14)..... 106

Figure 4.11 Microstructures of prealloyed bronze (specimen B409) 107

Figure 4.12 Microstructures of prealloyed bronze with 10\% T-401 (specimen 10)...... 108 
Figure 4.13 Microstructures of prealloyed bronze with 15\% T-401 (specimen 11) ...... 109

Figure 4.14 Microstructures of prealloyed bronze with 20\% T-401 (specimen 12)....... 110

Figure 4.15 Microstructures of copper-15\% bismuth (specimen 6) ........................... 111

Figure 4.16 Microstructures of copper-15\% bismuth with 10\% T-401 (specimen 16) .. 112

Figure 4.17 Microstructures of copper-15\% bismuth with 15\% T-401 (specimen 17).. 113

Figure 4.18 Microstructures of copper-15\% bismuth with 20\% T-401 (specimen 18).. 115

Figure 4.19 SEM images of HIPped premixed bronze with 10\% T-401: (a) Medium magnification, (b) High magnification, (c) Very high magnification.

Figure 4.20 SEM images of HIPped copper-15\% bismuth with 10\% T-401: (a) Low magnification, (b) Medium magnification, (c) High magnification

Figure 4.21 SEM images of undersintered copper-15\% bismuth with 10\% T-401: (a) Low magnification, (b) Medium magnification, (c) High magnification 118

Figure 4.22 EDX patterns of composition analysis for entire microstructure of copper-15\% bismuth: (a) Test 1, (b) Test 2, (c) Test 3, (d) Test 4 120

Figure 4.23 EDX patterns of composition analysis for grain boundaries of copper-15\% bismuth: (a) Test 1, (b) Test 2, (c) Test 3, (d) Test $4 .$. 122

Figure 4.24 Load - displacement curves for premixed bronze (specimen MG1) ........... 123

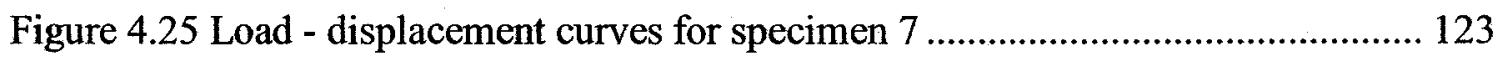

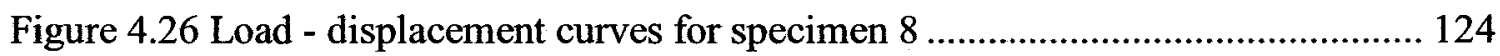

Figure 4.27 Load - displacement curves for specimen 13 ....................................... 124

Figure 4.28 Load - displacement curves for prealloyed bronze (specimen B409) ........ 125

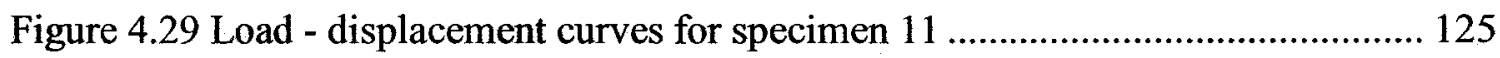

Figure 4.30 Load - displacement curves for specimen 17 ..................................... 126

Figure 4.31 Specimens for nano indentation and wear tests................................... 126

Figure 4.32 Three possible situations for differing wear of ball and flat disk specimens: (a) only the ball wears, (b) only the disc wears, (c) both the ball and disk wear.... 
Figure 4.33 Worn surfaces for premixed bronze based specimens: (a) specimen MG1, (b) specimen 7, (c) specimen 8, (d) specimen 9, (e) specimen 13, (f) specimen 14

Figure 4.34 Worn surfaces for prealloyed bronze based specimens: (a) specimen B409, (b) specimen 10, (c) specimen 11, (d) specimen 12

Figure 4.35 Worn surfaces for copper based specimens: (a) specimen 6, (b) specimen 16, (c) specimen $17,(\mathrm{~d})$ specimen 18

Figure 4.36 Variations of friction coefficient versus time for premixed bronze based materials

Figure 4.37 Variations of friction coefficient versus time for prealloyed bronze based materials

Figure 4.38 Variations of friction coefficient versus time for copper based materials... 141

Figure 4.39 Friction coefficient at $\mathrm{t}=5400 \mathrm{~s}$

Figure 4.40 Rectangular tensile test specimens [63]

Figure 4.41 Stress - strain curves for Groupl specimens (premixed bronze based): (a) specimen MG1, (b) specimen 7, (c) specimen 8, (d) specimen 13, (e) specimen 14, (f) specimens MG1, 7, and 8, (g) specimens MG1, 13, and 14

Figure 4.42 Stress - strain curves for Group 2 specimens (prealloyed bronze based): (a) specimen B-409, (b) specimen 10, (c) specimen 11, (d) specimen 12, (e) specimens B$409,10,11,12, \mathrm{MG} 1,7$, and 8

Figure 4.43 Stress - strain curves for Group 3 specimens (copper based): (a) specimen 6, (b) specimen 16 , (c) specimens 6 and 16 151

Figure 4.44 Sintered bronze bearing sample. 152

Figure 4.45 Microstructures of sintered bronze bearing sample 152

Figure 4.46 Load - displacement curves for sintered bronze bearing sample in comparison with specimens MG1 and B-409. 153

Figure 4.47 Worn surface of sintered bronze bearing sample 153 


\section{Nomenclature}

$\begin{array}{ll}\text { PM } & \text { Powder Metallurgy } \\ \text { PTFE } & \text { Polytetrafluoroethylene } \\ \text { HIP } & \text { Hot Isostatic Pressing } \\ \text { DSC } & \text { Differential Scanning Calorimetry } \\ \text { SEM } & \text { Scanning Electron Microscope } \\ \text { GTAW } & \text { Gas Tungsten Arc Welding } \\ \text { MIT } & \text { Micro Indentation Test } \\ \text { NIT } & \text { Nano Indentation Test } \\ \text { GBs } & \text { Grain Boundaries } \\ \text { UTS } & \text { Ultimate Tensile Strength } \\ \text { MPIF } & \text { Metal Powder Industries Federation } \\ \text { EDX } & \text { Energy-Dispersive X-ray spectroscopy } \\ \text { SQC } & \text { Statistical Quality Control } \\ \text { SPC } & \text { Statistical Process Control }\end{array}$

xii 


\section{List of Appendices}

Appendix A Technical and safety data sheets for premixed bronze powder (MG1)

Appendix B Technical and safety data sheets for prealloyed bronze powder (B-409)

Appendix C Technical and safety data sheets for copper powder

Appendix D Technical and safety data sheets for bismuth powder 


\section{Chapter 1}

\section{Introduction}

\subsection{Background and Significance}

Bearing is one of the most important parts in rotating equipments, which permits constrained relative motion between two rotating parts. It provides much easier movement between two rotating parts, which increases efficiency and reduces energy consumption. Bearings are used in any rotating parts such as fans, jet engines, automobile parts, industrial equipments, appliances, and so on. There are two types of bearings, namely, rolling bearings and sliding bearings. In rolling bearings loads are carried by rolling elements and sliding friction is avoided. However, in sliding bearings loads are carried via sliding actions and predominantly sliding contact occurs between relatively moving surfaces. Journal bearings are a simple type of sliding bearings in which a shaft or "journal" rotates on a layer of oil or grease to prevent any physical contacts of the journal and the bearing.

Journal bearings can be grouped into two types considering lubrication mechanism. They are either "self-lubricating" or "supplementary-lubricating". In the case of self-lubricating there is no need to apply high pressure oil between the shaft and bearing. Self-lubricating bearings can be considered as one of the oldest industrial applications for porous powder metallurgy (PM) parts, dated back to eighty years ago [1]. The main advantage of porous PM bearings is that porosity can act as oil reservoir so that 
the bearings get impregnated with oil or a lubricant which comprises about $25 \%$ of material volume [1-3]. During the rotation of a journal in an impregnated bearing, the temperature rises because of friction development and lubricant material is drown out of porosities due to the greater expansion coefficient of the lubricant compared to the bearing material. As soon as the journal stops, the oil gets absorbed by capillary action. For heavy-duty bearings an extra oil reservoir may be provided outside of the bearings for supplementary lubrication. Figure 1.1 [1] shows typical examples of the supplementary lubrication system. Figure 1.2 shows typical self-lubricating bronze bearings [4].

For efficient operation and long service life journal bearings have to meet several requirements. Copper Development Association (CDA) and Non-Ferrous Founders' Society (NFFS) have made the following requirements for journal bearings which must be satisfied simultaneously [5].

- Position and support a shaft or journal and permit motion with minimum energy consumption

- Support a fixed load and be able to withstand occasional shock loads

- Run quietly and suppress externally generated vibrations

- Act as a guide to support reciprocating or oscillating motion

- Withstand temperature excursions

- Accommodate some degree of shaft misalignment

- Accommodate dirt particle strapped in the lubricant 
- Resist corrosion - under normal service conditions as well as during storage or extended down-time

- Provide easy maintenance

Three critical performance parameters in journal bearings can be expressed as the following [5]:

- Friction coefficient

- Wear coefficient, which reflects material loss during the sliding

- Local bearing temperature, which is an important parameter in seizure

Main causes for journal bearing failure can be summarized as below:

- Excessive loads

- Over heating

- Lubricant failure

- Corrosion

- Misalignment

- Seizure

Journal bearings can be manufactured by several manufacturing processes such as PM, casting, coating and so on. In the presented research PM process has been selected, although the developed compositions can be manufactured with other manufacturing processes. PM sintered bearings can be divided into four groups [1]: 
- Sintered bronze bearings

- Iron-based sintered bearings

- Iron-bronze (diluted bronze) sintered bearings

- Iron-graphite sintered bearings

Among these four groups, sintered bronze bearings are very common and most widely used. The conventional bronze bearing composition is $90 \% \mathrm{Cu}-10 \% \mathrm{Sn}$ named tin-bronze. Lead, graphite and iron are additives to this group of bearings. Tin-based white metal has always been regarded as superior to lead-based materials. However, the price of tin has soared so drastically that lead-based white metal is now being much more widely used because of its lower cost and almost equivalent bearing properties. It is also well known that lead is more effective than tin as a soft phase alloying addition, which confers the necessary anti-scoring and anti-frictional properties with low wear. Lead-containing aluminum alloys, copper-lead alloy and lead bronze (tin combines with copper to form bronze) are found in many applications, typically in the automobile industry. In these alloys lead remains in a free state dispersed in the aluminum, copper or bronze matrix. This free lead provides the bearing properties, while the aluminum-based and copper-based matrices supply the strength. A low modulus of elasticity is required in a bearing alloy to ensure good compatibility with the journal surface. Apart from indium, lead has the lowest modulus of elasticity of all the soft phases alloying with aluminum, copper and bronze. Lead acts as a solid lubricant with better antifriction properties which improves wear and seizure resistance. Lead has low shear strength so that it can fill in 
irregularities of journals and provide emergency lubrication in case of temporarily interrupted oil supply. Lead also improves machining properties [6-10].

However, lead is toxic and because of its harmful effects on environment and public health, therefore, based on environmental regulations it should be removed from products including bearings [11]. To eliminate and replace this material many researches have been done and are in process, especially elimination of lead in solder materials used in microelectronics applications [12-18]. Lead containing bearings are currently still used widely in industry, just in vehicles the amount of lead in bearings is estimated to be in the range of $50-1000$ grams per vehicle [11]. Although many researchers are attempting to eliminate lead and develop totally lead-free bearing materials, this task is still at early stage compared to the development of lead-free solders. So far no effective new materials can replace and surpass the lead-containing journal materials being used in industry.

From a recent survey in a few bearing manufacturers and users, for example, Canadian Babbitt Bearings Ltd. and Pratt \& Whitney Canada, the environmental issue due to lead inherent toxicity has been highlighted. There is a strong demand from the bearing industry that lead-containing bearing materials should be replaced by equivalent, comparable or superior new materials. As known from Pratt \& Whitney Canada, in terms of a "Green Engine" Directive, lead must be replaced on new engine models by January 1 st, 2007. 


\subsection{Objectives}

This research is aimed to develop lead-free bronzed- and copper-based journal bearing materials with newly developed Tribaloy alloy additives. The project is sponsored by NSERC, jointed with three industrial organizations, Pratt \& Whitney Canada, Canadian Babbitt Bearings Ltd. and Deloro Stellite Inc. Three groups of new alloys are developed using a PM jointed with hot isostatic press (HIP) technique in this research: premixed bronze-based alloys, prealloyed bronze-based alloys and copper-based alloys.

One of the elements which has been found to act similar or even better than lead as a lubricant in bronze bearings is bismuth. It is a white, crystalline, and brittle metal. Bismuth with the atomic number 83 , density of $9.8 \mathrm{gr} / \mathrm{cm}^{3}$, and melting temperature of $271^{\circ} \mathrm{C}$ is considered as one of the less toxic heavy metals among its neighbors in periodic table such as lead, thallium, and antimony. Bismuth unlike other heavy metals is not considered as toxic metal and poses minimum hazard to the environment so that it has replaced toxic lead in many industrial applications such as soldering and bearing.

In the present research, bismuth is employed as one of the additives in the copper-based alloys. Another type of additives is Tribaloy alloys. Tribaloy intermetallic materials contain a large volume fraction of a hard and brittle, intermetallic Laves phase in a much softer matrix [19-26]. It is the presence of this Laves phase that enables these materials to achieve their good wear resistance. Commercially used Tribaloy alloys for wear applications are T-400 and T-800, which are cobalt based, containing chromium, 
molybdenum and silicon. The Tribaloy alloys used in this research are newly developed at Deloro Stellite Inc., designated as $\mathrm{T}-401$ and $\mathrm{T}-400 \mathrm{C}$ [27-28]. Different from conventional Tribaloy alloys, T-401 is a hypoeutectic alloy due to the lowered Mo and $\mathrm{Si}$ contents, which has improved ductility owing to the primary solid solution, while both T-401 and T-400C have better corrosion resistance [29], due to the increased chromium content compared with T-400 and T-800. The chemical compositions of conventional and developed Tribaloy alloys are given in Table $1.1[25,27]$.

\subsection{Methodologies}

\subsubsection{Chemical compositions of specimens}

The compositions of the three groups of alloys being developed in this research are described below:

1. Pre-mixed tin-bronze-based alloys

1.1. $\mathrm{Cu}-10 \% \mathrm{Sn}+0 \% \mathrm{~T}-401$ (or $\mathrm{T}-400 \mathrm{C}$ )

1.2. $\quad \mathrm{Cu}-10 \% \mathrm{Sn}+10 \% \mathrm{~T}-401$

1.3. $\quad \mathrm{Cu}-10 \% \mathrm{Sn}+15 \% \mathrm{~T}-401$

1.4. $\mathrm{Cu}-10 \% \mathrm{Sn}+20 \% \mathrm{~T}-401$

1.5. $\mathrm{Cu}-10 \% \mathrm{Sn}+15 \% \mathrm{~T}-400 \mathrm{C}$

1.6. $\mathrm{Cu}-10 \% \mathrm{Sn}+20 \% \mathrm{~T}-400 \mathrm{C}$

2. Pre-alloyed tin-bronze-based alloys

2.1.

$\mathrm{Cu}-10 \% \mathrm{Sn}+0 \% \mathrm{~T}-401$

2.2.

$\mathrm{Cu}-10 \% \mathrm{Sn}+10 \% \mathrm{~T}-401$ 
2.3. $\quad \mathrm{Cu}-10 \% \mathrm{Sn}+15 \% \mathrm{~T}-401$

2.4. $\quad \mathrm{Cu}-10 \% \mathrm{Sn}+20 \% \mathrm{~T}-401$

3. Copper-based alloys

3.1. $\quad \mathrm{Cu}+15 \% \mathrm{Bi}+0 \% \mathrm{~T}-401$

3.2. $\quad \mathrm{Cu}+15 \% \mathrm{Bi}+10 \% \mathrm{~T}-401$

3.3. $\quad \mathrm{Cu}+15 \% \mathrm{Bi}+15 \% \mathrm{~T}-401$

3.4. $\quad \mathrm{Cu}+15 \% \mathrm{Bi}+20 \% \mathrm{~T}-401$

\subsubsection{Fabrication of specimens}

Fourteen specimens with different chemical compositions are fabricated using PM jointed with HIPping consolidation technique, respectively. Differential scanning calorimetry (DSC) analyses of the mixed powders of each composition are conducted to determine the phase transformation temperatures which are the bases for the design of the sintering cycles.

\subsubsection{Materials characterization}

The following tests are performed on the fabricated specimens for material characterization:

1. Microstructural analyses via an optical microscope and a scanning electron microscope (SEM)

2. Density measurement using the Archimedes method

3. Macro hardness test 
4. Nano indentation test to investigate mechanical behaviors such as hardness, Young's modulus, elasticity and plasticity of individual phases of the specimens

5. Pin-on-disc wear test to determine tribological properties.

6. Tensile test to determine mechanical properties.

\subsection{Structure of the Thesis}

This thesis consists of five chapters. The contents of each chapter are summarized as below:

Chapter 1 is an introduction of this research, which includes an introduction to journal bearings, the materials currently used for journal bearings, background and significance, objectives of this research as well as the methodologies adopted to complement this research.

Chapter 2 is the literature review of previous studies related to the present research. They cover five aspects: journal bearing materials, sintered bronze bearings, Tribaloy alloys, lead-free bearing materials, and sintering of journal bearing materials.

Chapter 3 describes the details of experimental procedure for specimen fabrication including preparation of raw materials, mixing of powders, DSC test, powder consolidation, specimen sintering and HIPping. 
- Chapter 4 describes the details of experimental procedure for material characterization and test results including microstructural examination (optical and SEM), density measurement, hardness test, nano indentation test, wear test and tensile test. The determination of the mechanical and tribological properties of an existing lead-free journal bearing material is also described in this chapter.

* Chapter 5 is discussion on experimental results accompanied with the conclusions drawn from this research and the suggestions for future work. 


\section{Chapter 2}

\section{Literature Review}

\subsection{Journal Bearing Materials}

\subsubsection{Requirements for journal bearing materials}

Damage to journal bearings can occur in a number of different ways [30-31]. Failure of the bearing materials is caused mainly by plastic deformation, fatigue, wear, corrosion and thermal expansion [30]. Due to high bearing pressure, soft bearing materials may extrude or otherwise deform unacceptably. Fatigue cracking of the bearing metal can occur either due to heavy vibration or by cavitation in the lubricating-oil film. Cavitation occurs with a severely restricted oil supply; the restriction may be in the external supply, or in the bearing itself due to the supply groove being unsuited to the journal attitude under the applied load. Wear occurs mainly with an oil film of very small minimum film thickness or with boundary lubrication. The conditions leading to wear are: contact of asperities on the imperfect journal and bearing surfaces; scoring by solid particles; development of excessive local pressure or temperature; and electrical pitting. Corrosion is due to oxidizing agents in the oil or to contamination by sea water. With varying temperature, thermal expansion of the material is important to maintain appropriate clearance. 
Among all the damage factors, wear is the most important for journal bearings. Therefore, tribological properties including friction, wear, and seizure can be considered as the main and the most important requirement for journal bearing materials.

\subsubsection{Types of journal bearing materials}

The materials used for bearings are ranging from various steels to a multitude of non-ferrous alloys. Whitemetals, which are tin-based or lead-based, and both aluminumbased and copper-based alloys usually containing lead, are used for journal bearings and the lining materials of plain bearings. This is due to the following advantages [32]:

1. When properly applied as lining materials, they have excellent adhesion to steel, cast iron and bronze.

2. They 'wet' well with all ordinary oils, and thus tend to remain oily after standing for some time.

3. They are better than harder materials in tolerating slight journal misalignment or deflection under load.

4. They are not corroded by the acid introduced into the lubricants of engines by the combustion of sulphur containing fuels.

5. Thick-walled bearings lined with these materials can be relined when worn or damaged.

6. They are better than harder materials at withstanding lubrication starvation at starting, or when subjected to momentary overloads.

7. In the case of thick-walled bearings, they can be 'scraped' to adjust for slight misalignment or the like. 
8. Their embeddability is better than that of any other existing lining material, which means that foreign matter readily embeds or sinks into the bearing surface, especially under the near metal-to-metal contact conditions at starting, instead of remaining proud and scoring the journal.

Tin-based whitemetal has always been regarded as superior to lead-based materials. However, the price of tin has soared so drastically that lead-based whitemetal is now being much more widely used because of its lower cost and almost equivalent bearing properties.

In recent years, polytetrafluoroethylene (PTFE) and its composites have been developed and used extensively for journal bearing components [33-36], due to the excellent thermal insulation, high temperature capability, low coefficient of friction and corrosion resistance, particularly in applications where dirty conditions prevail and lubrication is difficult or impossible. The main reinforcements in PTFE composites are glass-fiber, $\mathrm{Al}_{2} \mathrm{O}_{3}, \mathrm{CeO}_{2}, \mathrm{CeF}_{3}, \mathrm{La}_{2} \mathrm{O}_{3}, \mathrm{PbS}, \mathrm{Cu}_{2} \mathrm{O}, \mathrm{CuS}, \mathrm{MoS}_{2}$ and $\mathrm{CuS}$ [37-41]. However, due to the high hardness and brittleness of the reinforcements, the interface bonding in the composites are very weak, resulting in low fracture toughness. 


\subsection{Sintered Bronze Bearings}

\subsubsection{Features}

There are three main groups of journal bearings: cast, sintered and plated powder on steel backing. Sintered bronze bearings are one of most common used bearings.

Sintered bearings were introduced initially in the United States in 1930, and were initiated in Japan by Prof. Tatsuo Matsukawa in 1934. It was around 1950 that large-scale manufacturing of sintered bearings began [42]. Sintered bronze bearings are widely used because of their good wear resistance, low friction coefficient, and good mechanical properties.

Sintered bronze is porous self-lubricating bearing material which the self-lubrication property is achieved by oil impregnation process. The most common composition of this material is $90 \% \mathrm{Cu}-10 \% \mathrm{Sn}$ with or without the addition of lead, graphite or iron. Sintered bronze bearings are included in American Society for Testing and Materials (ASTM) standard B 438.

PM bronzes are typically divided in two main groups [43]: premixed and prealloyed. Premixed PM bronzes consist of elemental copper and tin powders plus 0.5 to $0.75 \%$ dry organic lubricants such as stearic acid or zinc stearate. Prealloyed powders have higher yield strengths and work-hardening rates than premixed powders and are used where densities higher than $7.0 \mathrm{~g} / \mathrm{cm}^{3}$ are required [43]. Because of higher 
work-hardening rates prealloyed powders require higher pressure during compaction to achieve given green density compared to premixed powders.

Prealloyed powders have improved properties, but premixed powders show better compaction properties [44]. Premixed powders are usually recommended for self-lubricating applications as they have enough porosity to keep oil in oil impregnation process. Most sintered bronze bearings have densities in the range of 5.8 to $6.6 \mathrm{~g} / \mathrm{cm}^{3}$ in dry condition, or 6.0 to $6.8 \mathrm{~g} / \mathrm{cm}^{3}$ in oil impregnated condition [43].

\subsubsection{Standard compositions}

According to ASTM standard B438 sintered bronze bearings are available in four grades based on chemical composition and in four types based on density requirements and are oil impregnated in the range of 7 to 27 vol\%. Tables $2.1-2.4$ represent the requirements for chemical composition, density requirements and oil contents of these alloys.

\subsubsection{Microstructure}

The common microstructure of bronze bearings is alpha $(\alpha)$ phase bronze, as shown in Figure 2.1, which has the face-centered cubic (fcc) lattice [1]. During sintering, the elemental tin melts and forms a series of high temperature intermetallic compounds which finally dissolves in the copper at the temperature range of 785 to $845^{\circ} \mathrm{C}$. A well sintered bronze should not show free tin or blue-gray copper-tin intermetallic compounds. 
In incomplete sintering, the rounded gray copper-tin compounds could be seen in the unetched microstructure, but after etched with $\mathrm{K}_{2} \mathrm{Cr}_{2} \mathrm{O}_{7}$ solution, they are preferentially attacked and disappeared. In this case the etchant in Table 2.5 should be used to reveal the grain structure [45]. For this research it is necessary to examine sintered parts in an unetched condition. On the other hand, when the sintering is incomplete, the original particle boundaries are present in the fine polished, unetched microstructure, as seen in Figure 2.2 [45].

\subsubsection{Mechanical properties}

The mechanical properties of three leaded and lead-free bronze bearing materials are presented in Table 2.6 [46] as examples. The different mechanical properties between these materials are due to the different chemical compositions which enables each material for specific application.

\subsubsection{Sintering technique}

Sintering is the process which transforms the green PM part into a metallurgically bonded alloy. The elemental copper and tin transform into a true $\alpha$ bronze alloy during a sintering process. Figure 2.3 shows the binary phase diagram for $\mathrm{Cu}-\mathrm{Sn}$ [47]. In liquid-phase sintering the sintering temperature is above the melting temperature of tin $\left(232^{\circ} \mathrm{C}\right)$, but below the melting temperature of copper $\left(1085^{\circ} \mathrm{C}\right)$; it is usually in the range of 830 to $900^{\circ} \mathrm{C}$ [48-49]. Sintering is a three phase process, the first phase is neck growth between particles which proceeds rapidly, but the identities of particles are retained. In 
the second phase grain growth occurs while most densification takes place and the pores are getting rounded. In this phase the particles lose their separate identities and diffusion takes place. In the third phase densification proceeds, but at a lower rate as the isolated round pores shrink. The decrease in free surface area (solid/gas interface) as particles grow together and voids shrink because of surface tension or capillary forces, is considered as the principal driving force for these changes [49].

Material transition during sintering occurs in one or more mechanisms listed below [49]:

- Diffusion flow

- Evaporation/condensation

- Viscous flow

- Plastic flow

Among mentioned mechanisms, diffusion is the most likely mechanism which occurs through a lattice volume, along free surface, or along a grain boundary. Fick's law describes this diffusion which is expressed as the following [49]:

$$
D=D_{0} \exp (-Q / R T)
$$

where

$D=$ diffusion coefficient

$D_{0}=$ material constant, jump frequency

$Q=$ activation energy 
$R=$ gas constant

$T=$ absolute temperature

With decreasing the activation energy for diffusion the sintering rate will increase and this process is called "activated sintering". Through this process, the sintering can proceed at lower temperatures, and for shorter times with better properties such as strength and electrical conductivity. Activated sintering was observed in copper powders with thin films of 40-60 $\mathrm{nm}$ oxide on particles, which resulted in improved properties of sintered parts, as shown in Table 2.7 [49]. The mechanism for this is based on partial solubility of the copper oxide in the copper matrix. The oxygen from the oxide film diffused into the copper and left highly active copper surfaces, which enhanced the sintering. In the meanwhile, as known from Table 2.7 , there is a limit in the oxide film thickness for improved properties. Addition of small amount of copper oxide into the copper powders has shown the same activation in sintering [49]. In a copper-tin system (bronze), elemental tin forms a liquid phase during sintering because of its low melting temperature, and activates the sintering process [44]. In this system, tin melts and alloys with copper forming bronze. Higher densification was reported in plasma sintered powders. It was suggested that diffusion was activated by the sputtered atoms impinging the compact surfaces. Sinka et al. [50] conducted a study on plasma sintering of $90 \mathrm{Cu}-10 \mathrm{Sn}$ bronze in premixed powders, to investigate the densification process. The formation of large pores present in the microstructure after sintering was suggested to be caused by the transient liquid phase which formed due to melting of the tin particles with low melting temperature of $232^{\circ} \mathrm{C}$. Because of capillary forces, tin penetrates into the 
pores between copper particles, thus leaving a network of interconnected pores behind. Therefore, higher densification could be achieved in this sintering process. Average porosity in an industrially sintered bearing is $36 \%$, but $26.3 \%$ is achieved via plasma sintering.

\subsubsection{Densification and dimensional change}

During sintering the compacted powders undergo dimensional changes. In the initial phase, as the temperature increases, the compacts expand, the vaporized lubricant and the entrapped gas in the pores contribute to this expansion. As sintering proceeds, the compacts start shrinking up to the maximum at the peak sintering temperature. In the last phase, the compacts contract during cooling. Total dimensional change in the three phases of the sintering process would result in high shrinkage and high density of the compacts. The principal factors for densification of PM parts during sintering are listed below [49]:

- Sintering temperature

- Sintering time

- Powder particle size

- Green density of the compact, as a function of compacting pressure

In a copper-tin system, carbon, as an additive, present in the form of graphite, can alter dimensional change during the sintering process. Dimensional change in the sintering process of bronze bearings is of critical aspects, which should be minimized as 
there are usually tight tolerances for bearing parts. In industrial-scale manufacturing, another processing called sizing is usually taken to size sintered bearings.

\subsection{Tribaloy Alloys}

\subsubsection{Conventional Tribaloy alloys}

Tribaloy alloys are cobalt-based or nickel-based alloys which are primarily strengthened by intermetallic Laves phases dispersed in a softer eutectic matrix, and are corrosion and wear resistant. The eutectic solid solution provides high mechanical strength, fracture toughness, and ductility, while the Laves phase which are formed by molybdenum and silicon, gives the materials wear resistance under poor or unlubricated conditions. Molybdenum and silicon improve the wear resistance and the corrosion resistance comes from adding chromium to the alloy. Conventional Tribaloy alloys usually have low strength and fracture toughness in comparison with ductile materials, owing to the large volume fraction of Laves phase [27-29]. The hard primary phase is a ternary Laves phase of the $\mathrm{C}-14\left(\mathrm{MgZn}_{2}\right)$ type having a melting point of about $1560^{\circ} \mathrm{C}$, and its compositions are approximately $\mathrm{Co}_{3} \mathrm{Mo}_{2} \mathrm{Si}$ or $\mathrm{CoMoSi}$ for the $\mathrm{Co}-\mathrm{Mo}-\mathrm{Cr}-\mathrm{Si}$ Tribaloy family. The advantage of Tribaloy alloys over carbide-strengthened alloys (for example, Stellite alloys) is that Laves phase is softer than the carbides (hardness about half) so that it would not act as a cutting tool to wear away a mating surface. The carbon content in Tribaloy alloys is kept low to prevent carbides forming in preference to the Laves phase. These alloys are usually hypereutectic with $30-70$ vol\% primary intermetallic phase evenly dispersed in a softer eutectic matrix [19-26]. 
$\mathrm{T}-400$ and T-800 Tribaloy alloys with the overall hardness of Laves phase and solid solution of $54-60 \mathrm{HRC}$ are typical Tribaloy alloys for wear applications. Laves phase contents are $50 \%$ and $55 \%$ for $\mathrm{T}-400$ and $\mathrm{T}-800$ respectively $[20,22,23]$. The main

differences between these two types are higher intermetallic Laves phase and higher chromium content in T-800, which makes this alloy harder with excellent wear properties and corrosion resistance. Both T-400 and T-800 exhibit excellent wear and corrosion resistance and are used widely in various industrial applications such as bushings and bearings, but suffer from little plastic flow capacity $[21,22,25]$.

\subsubsection{Newly developed Tribaloy alloys}

In order to improve ductility and enhance corrosion resistance of Tribaloy alloys, two new Tribaloy alloys, designated as $\mathrm{T}-401$ and $\mathrm{T}-400 \mathrm{C}$, as a modification of $\mathrm{T}-400$, were developed recently at Deloro Stellite Inc [27-29]. Chemical compositions of Tribaloy alloys T-400, T-401 and T-400C are presented in Table 1.1 [27] and the SEM images of their microstructures are illustrated in Figure 2.4 [27].

Different from conventional Tribaloy alloys, T-401 has a hypoeutectic microstructure (due to the lowered molybdenum and silicon contents) with the cobalt solid solution as the primary phase, and the eutectic phase being a mixture of cobalt solid solution and Laves phase. The Laves phases are ternary Laves phase, $\mathrm{Co}_{3} \mathrm{Mo}_{2} \mathrm{Si}$ or CoMoSi, of the C-14 $\left(\mathrm{MgZn}_{2}\right)$ type, [27-29]. Although T-401 has lower hardness and wear resistance due to reduction of the volume fraction of Laves phase compared to $\mathrm{T}-400$, it is still wear resistant [27]. Nano mechanical properties of the newly developed 
Tribaloy alloys, T-401 and T-400C, are presented in Table 2.8 [27], with the data of $\mathrm{T}-400$ as a conventional Tribaloy alloy for comparison. The most important is that previous research has showed that T-400C has excellent high-temperature metal on metal wear resistance, as tested at $482^{\circ} \mathrm{C}$. The experimental results are illustrated in Figures 2.5 and 2.6 [29]. In both cases T-400C suffers less wear compared to T-400. In addition, T401 and $\mathrm{T}-400 \mathrm{C}$ exhibit excellent corrosion resistance to $65 \% \mathrm{HNO}_{3}$ oxidizing acid at $66^{\circ} \mathrm{C}, 10 \% \mathrm{H}_{2} \mathrm{SO}_{4}$ reducing acid at $102^{\circ} \mathrm{C}$, and $5 \% \mathrm{HCl}$ reducing acid at $66^{\circ} \mathrm{C}[29]$.

\subsection{Lead-Free Bearing Materials}

\subsubsection{Lead in bearing materials}

Lead has been used for a long time as an additive to bearings because of its outstanding lubrication properties. The superior antifriction properties of lead result in improved wear and seizure resistance, and low shear strength provides emergency lubrication in case of interrupted oil supply. Improvement of machining properties is also reported for leaded bearings [6-10].

Lead-containing aluminum alloys, copper-lead alloy and lead bronze (tin combines with copper to form bronze) are found in many applications, typically in the automobile industry. In these alloys lead remains in a free state dispersed in the aluminum, copper or bronze matrix. This free lead provides bearing properties, while the aluminum-based and copper-based matrices supply the strength. A low modulus of elasticity is required in a bearing alloy to ensure good compatibility with the journal 
surface. Apart from indium, lead has the lowest modulus of elasticity of all the soft phases alloying with aluminum, copper and bronze.

Leaded tin bronze bearings are popular and they can be divided into two main groups based on lead percentage as the following [51]:

- Leaded tin bronzes

- High- leaded tin bronzes

In the first group lead is mainly added to improve machinability, and the lead percentage is not at the level that changes bearing properties. The maximum lead concentration in this group is $2.5 \%$.

In the second group, lead concentration can reach to $25 \%$, with the minimum of 6\%. SAE 660 (C93200) and SAE 64 (C93700) have wide range of applicability with $8-10 \%$ lead. In highly leaded bronze bearings, high strength is sacrificed for superior embedability and lubricity. Those alloys containing $15-25 \%$ lead embed dirt particles very well and are used where particles in lubrication can really damage the shaft.

As a conclusion, lead is added to tin bronze bearings to improve wear properties and seizing in the case of interrupted lubrication supply, and increase embedability of bearings. On the other hand, as lead reduces strength, selection of suitable leaded tin bronze alloy should be based on service requirements. The lead-containing tin bronze bearing materials currently used in industry are listed below:

- Tin bronzes: Alloy Nos. C90300, C90500, C90700 
- Leaded tin bronzes: Alloy Nos. C92200, C92300, C92700

- High-leaded tin bronzes: Alloy Nos. C93200, C93400, C93500, C93700, C93800, C94300

\subsubsection{Development of lead-free bearing materials}

One of the elements which has been found to act similar or even better than lead as a lubricant in bronze bearings is bismuth. Whitney et al. developed a lead free bearing material which lead was replaced with bismuth and phosphorus [6]. The material developed by them is a copper based powder consisting of 8 to $12 \mathrm{wt} \%$ of tin, 1 to less than $5 \mathrm{wt} \%$ of bismuth, 0.03 to $0.08 \mathrm{wt} \%$ of phosphorus, which is bounded to a steel backing. The mechanical properties of developed material are as the following:

- Tensile strength $\geq 400 \mathrm{MPa}$

- Yield strength $\geq 290 \mathrm{MPa}$

- Elongation $\geq 10 \%$

- Hardness $\geq 130 \mathrm{HV}$

It was reported that the developed material had better mechanical properties compared to traditional copper-tin-lead bearing materials having $10 \mathrm{wt} \%$ of tin, and 10 $\mathrm{wt} \%$ of lead. The wear and seizure resistance of the developed material are as good as the traditional copper-tin-lead engine bearings or superior to. It was also found that migration of tin from the matrix to the bearing surface as a result of tin-bismuth reaction under the 
load/friction conditions of bearing usage produced a tin-reach layer on the bearing surface which served as lubricant and provided wear and seizure resistance [6].

Ono et al. [52] conducted similar research on this topic, replacing lead with bismuth. This material is also a backing type bearing. The developed material is copper-tin-bismuth-molybdenum carbide bearing on a steel back with bismuth/silver dual layers as an overlay. It was found that bismuth/silver dual overlay had high seizure resistance, and the new developed material had high fatigue strength, low wear and good overall performance.

Sudhari [46] has performed another research on bismuth additive to sintered bronze-based bearing material. The developed material is castable bronze alloy with 7 $w t \%$ tin, $5 \mathrm{wt} \%$ bismuth and $0.1 \mathrm{wt} \%$ phosphorus. Mechanical properties of the developed material are

- Tensile strength : $207-276 \mathrm{MPa}(30,000-40,000 \mathrm{psi})$

- Yield strength : $131-193 \mathrm{MPa}(19,000-28,000$ psi)

- Elongation : $10.0-25.0 \%$

- Hardness : $65-95 \mathrm{HB}$

It was reported that the developed material had comparable mechanical properties and wear resistance with the standard leaded bronze bearings C932 and C936.

Sato [53] has developed a lead-free bronze-based material with silver (Ag.) additive. The developed bearing is steel backing type and the material chemical 
composition is bronze-based with 7-13 wt\% of $\mathrm{Sn}$ and $0.7-2 \mathrm{wt} \%$ of $\mathrm{Ag}$. The hardness of the material is over $100 \mathrm{HV}$. It is also reported that if a solid lubricant such as molybdenum disulfide and graphite was added to the developed material, even more superior bearing properties could be achieved.

Polytetrafluoroethylene (PTFE)-based bearings and bronze-based bearings impregnated with graphite are new trends of lead-free bearing materials. They are found and available on market for industrial applications.

\subsection{Sintering of Journal Bearing Materials}

\subsubsection{Powder metallurgy}

Powder Metallurgy or PM is a metal forming process which is achieved by heating compacted powders to a temperature below the melting temperature. It is widely recognized as a superior manufacturing process with highlighted advantages such as near-net-shape dimensional control with minimum required machining, applicable to wide verity of materials, good surface finish of final products, controlled porosity for self lubrication and filtering applications, and cost efficiency. Parts with complex shapes can be easily manufactured via this process. Figure 2.7 illustrates the PM process [54].

Bronze bearings are mainly fabricated by casting or PM, although new technologies are being used in these days to make multi-layer bearings on steel backings 
with different coating processes such as electroplating or metal spray techniques. In PM, sintering and HIPping techniques are often employed for consolidation of the powders.

Table 2.9 summarizes the major history of the PM development [55]. PM principles were developed around 3000 B.C. by Egyptians. One of the most important stages of modern PM development was in $18^{\text {th }}$ and $19^{\text {th }}$ centuries in Europe when metallurgy of platinum was practiced [55]. For the first time a high-temperature sintering process was applied to compacted platinum powders in Russia in 1826 on a commercial basis [55]. The Wollaston process to produce compact platinum is considered as the beginning of modern PM techniques [55]. In 1870, the first patent was issued in the United States on the development of self-lubricating bearing materials from metal powders. The modern type of bearings, copper-tin-graphite, was first developed by Loewendahl and Gilson in the early of 1990s and further studied by Boegehold et al. [55].

\subsubsection{Copper alloy powders production}

Typical physical properties of bronze alloy with nominal mesh size -60 are given in Table 2.10 [56]. Figure 2.8 illustrates the flowchart for copper alloy powder air atomization, SQC and SPC steps in this process refer to statistical quality control and statistical process control [56]. Similar to a foundry process, high-purity virgin metals are charged into a melting furnace set to specific heating rate, temperature and time. For homogeneity and uninterrupted atomization, melts are then transferred to the holding furnace which has greater holding capacity. At least one of these furnaces should be of induction heating type to insure homogeneity and especially lead dispersion in leaded- 
bearing alloys. Air and water may be used for atomization. Large-scale of copper powder atomization is usually conducted in air. Figure 2.9 illustrates the scanning electron micrographs of air-atomized and water-atomized copper powders [57]. Water-atomized powders have a more irregular particle shape, while air-atomized powders are more spherical.

\subsubsection{Powder mixture}

The production of PM parts usually needs mixing of different powders. Dry mixing is very common to produce powder mixes. For this purpose metal powders and additives are charged to a blender and mixed until a homogeneous mixture is achieved. When mixing powders of different densities, proper mixing time is required to insure well dispersion with minimum segregation. For bronze bearings the mixture of atomized copper and tin is used. The recommended particle size distribution of the copper powder is $100 \%-100$ mesh and between $40-70 \%-325$ mesh, and for tin is $95 \%-325$ mesh [48]. Proper mixing provides uniform strength, density, and dimensional control during sintering, and it is necessary for uniform melting and diffusion of low melting constituents such as tin in bronze alloys.

\subsubsection{Powder consolidation}

Copper and copper alloy powders are generally cold compacted. In this process powder particles are interlocked mechanically with density of up to $80-90 \%$ of the theoretical density of the material. At this stage, the strength of the compacted part is just 
enough for handling. For complete metallurgical bonding with good mechanical properties a sintering process is required. The density is a function of the compaction pressure. Figure 2.10 illustrates the density as a function of the pressure for isostatic and unidirectional pressing [43]. For higher densities, other consolidation processes such as hot pressing, extrusion, HIP, and hot forging are required.

\subsubsection{Hot Isostatic Pressing (HIPping)}

Hot Isostatic Pressing (HIP) is a process involving the use of high-pressure gas isostatically applied to a part or work piece at an elevated temperature, performed in a specially constructed pressure vessel [58]. In a HIP process, powders deform plastically, which closes up porosity and results in $100 \%$ theoretical density in the part. The range of pressure for HIP is 20 to $300 \mathrm{MPa}$, in which $100 \mathrm{MPa}$ is the most common pressure.

The HIP technique was invented in 1955 at Battelle Memorial Institute for diffusion bonding of dissimilar materials of nuclear fuel elements. With further development, other applications such as consolidating encapsulated powders in PM were discovered. In 1970s, the HIP process was used on industrial scale.

One of superiorities of HIP to casting is that the as-cast ingot exhibits variations in chemical composition, porosity, and non-uniform microstructure which contains equiaxed and columnar grains. In PM parts higher alloyed compositions without segregation can be achieved, and once fully densified by a HIP process, the microstructure would be of fine and equiaxed grains. This uniform microstructure leads 
to isotropic mechanical and physical properties. In the meanwhile, because of the finer grain size and fine dispersion of alloy elements, higher mechanical properties can be achieved compare to as-cast materials. Machinability of PM products is also improved owing to uniform and fine microstructures. HIP and PM characteristics can be summarized as the following [58]:

- Full density of highly alloyed materials (usually can not be achieved by casting)

- Near-net-shape

- Fine grain size

- Isotropic mechanical and physical properties

- Improved mechanical properties

- Extended life cycle

- Cost-effective

- Wide range of part sizes from 1 to $>10,000 \mathrm{lb}$

Typically, spherical powders are used for HIP with a broad particle size distribution for higher packing density. Similar to sintering, HIP is a three phase process as listed below:

- Powder consolidation

- Neck growth

- Final densification 
The cycle to apply pressure and heat in a HIP process can be classified as the following. There are three basic cycles:

- Heat up first, and then pressurize

- Pressurize first, and then heat

- Pressurize and heat simultaneously

Container or can fabrication is one of the important issues in a HIP process. The container can be metal, glass, or ceramic. Powder should be carefully poured into the container with one end squeezed and welded. Then the container is connected to the vacuum system while heating up to remove moisture. This step is very important so that minimum level of oxygen is trapped. After proper time of vacuum, while the container is still under vacuum, the other end of container should get squeezed and welded. Sealed encapsulated powder will be charged into the HIPping furnace for HIPping at a proper pressure with a thermal cycle for a set time. As the powders are not compacted in a HIP process, processing time for complete metallurgical bonding is longer than that in a sintering process in which pre-compacted powders have already mechanically interlocked and need less time for diffusion. 


\section{Chapter 3}

\section{Specimen Fabrication}

\subsection{Powder Preparation}

\subsubsection{Chemical compositions of specimens}

The chemical compositions of the three groups of materials developed in this research are listed in Table 3.1. Group 1 is premixed bronze based with $0-20 \% \mathrm{~T}-401$ and $15-20 \% \mathrm{~T}-400 \mathrm{C}$ as the additives, the specimens are designated as MG1, 7, 8, 9, 13, and 14, respectively. Group 2 is prealloyed bronze based with $0-20 \% \mathrm{~T}-401$ as the additive, the specimens are designated as B-409, 10, 11, and 12, respectively. Group 3 is copper based with $0-20 \% \mathrm{~T}-401$ and $15 \%$ bismuth as the additive simultaneously, the specimens are designated as $6,16,17$, and 18 , respectively.

\subsubsection{Specifications of powders}

Powders used in this research are listed below:

- Water atomized Premixed 90-10 Tin-Bronze (MG1)

- Air atomized Prealloyed 90-10 Tin-Bronze (B-409)

- Water atomized Copper

- Water atomized Bismuth

- Tribaloy powder T-401 
- Tribaloy powder T-400C

Copper, bismuth and bronze powders were provided by USBronze Co., and Tribaloy powders were provided by Delero Stellite Inc. Technical and safety data sheets of the powders being used are provided in Appendices A - D.

\subsubsection{Powder mixture}

The first step in a PM process is to mix the powders. Constitutes of each composition in the powder form were poured in a glass jar, sealed and got mixed in a powder mixer, as shown in Figure 3.1. Because the densities of the powder constitutes are very close, as shown in Figure 3.2, the mixed powders showed homogenous structures, that is, no significant segregation was found. The powders of all compositions were mixed for at least three hrs to make sure that Tribaloy particles were well distributed. Microstructures showed proper distribution of Tribaloy particles in the matrix as shown in Figure 3.3.

\subsection{Powder consolidation}

\subsubsection{Can fabrication (Encapsulation)}

Cans are required for a HIPping consolidation process. The cans used in this research were fabricated from 304 stainless tubes with $5 / 8$ in. of outer diameter and 18 wall thickness gauge (equal to 0.049 in.). The tubes were cut to 16 in long, squeezed at one end and sealed with Gas Tungsten Arc Welding (GTAW), see Figure 3.4, which 
shows the hydraulic squeezing machine used. The tubes were filled with mixed powders to a length of 6 in. and a glass wool plug was inserted to the other end, which was used to prevent the powder from being drawn into the vacuum system in the next step. The filled tubes were then hooked to the vacuum system shown in Figure 3.5. In the meanwhile, an oven was set to $300^{\circ} \mathrm{C}$ to heat up the powders to remove any moisture. The tubes were under vacuum for a minimum of twenty four hours and mostly for forty-eight hours so that a vacuum as low as $10^{-5}$ mbar could be achieved. While the tubes were still under vacuum, they were squeezed from the other end, cut and sealed with GTAW to get ready for HIPping. Figure 3.6 shows a sealed encapsulated powder ready for HIPping.

\subsubsection{Differential scanning calorimetry (DSC) analysis}

DSC test was conducted on the mixed powder of each composition to obtain the phase transformation temperatures, which are the useful information for the design of the sintering/HIPping cycles. Although sintering/HIPping temperatures were supposed to be under the melting temperature of the Tribaloy alloys (which is around $1400^{\circ} \mathrm{C}$ ), any possible reactions between the Tribaloy alloys and the matrix (copper-15\% bismuth and bronze) to form new phases and investigation of the solidus/liquidus properties of the new materials were of interest in DSC analysis.

\subsubsection{Experimental procedure}

DSC can be defined as "a technique for measuring the energy necessary to establish a nearly zero temperature difference between a substance and an inert reference 
material, as the two specimens are subjected to identical temperature regimes in an environment heated or cooled at a controlled rate" [59]. As another definition, "DSC measures the temperature and heat flows associated with transitions in materials as a function of time and temperature in a controlled atmosphere" [60]. A mode of DSC 404C was used in this research. Heating and cooling rates were $10^{\circ} \mathrm{C} / \mathrm{min}$ which were recommended for bronze sintering [61-62]. The specimens were heated to $100^{\circ} \mathrm{C}$ and kept for $5 \mathrm{~min}$. and then heated up again to the ultimate temperature, kept for $10 \mathrm{~min}$., and cooled down to room temperature with the same rate of $10^{\circ} \mathrm{C} / \mathrm{min}$. Different ultimate temperatures were tested based on the solidus-liquidus temperature of bronze and melting points of individual constituents in the mixed powders such as $870^{\circ} \mathrm{C}$ for bronze solidusliquidus temperature, $1100^{\circ} \mathrm{C}$ for the melting of copper, and $1400^{\circ} \mathrm{C}$ for the melting of Tribaloy alloys. The mass of each powder specimen tested was about $30 \mathrm{mg}$ and aluminum oxide powder was chosen as reference. Alumina crucibles were used as the sample and reference containers. Vacuum and argon back filling was performed for several times to make the chamber clean and oxygen free up to the vacuum level of -2.5 mbar. The test was run under a flow of pure argon gas to minimize the oxidation during the test.

\subsubsection{DSC Results}

The DSC results are illustrated in Figures $3.7-3.9$ and the temperatures corresponding to each phase transformation which is represented by the peaks on the DSC curves are summarized in Table 3.2. For the premixed bronze without T-401, tested under the ultimate temperature of $1100^{\circ} \mathrm{C}$, three sharp peaks are observed in Figure 3.7(a), 
the first peak at $233.4^{\circ} \mathrm{C}$ corresponds to the tin melting, the second peak which is around $800^{\circ} \mathrm{C}$ corresponds to the solidus temperature of bronze formation, and the third peak around $1017^{\circ} \mathrm{C}$ corresponds to the liquidus temperature of bronze formation, in terms of Cu-Sn binary phase diagram, shown Figure 2.3. Regarding the premixed bronze with $10 \% \mathrm{~T}-401$, see Figure 3.7(b), the DSC curves are similar to those of the premixed bronze without $\mathrm{T}-401$, since with the ultimate temperature used of $1300^{\circ} \mathrm{C}, \mathrm{T}-401$ particles did not melt. Two minor peaks between $400^{\circ} \mathrm{C}$ to $600^{\circ} \mathrm{C}$ on both the curves correspond to $\eta \rightarrow \varepsilon+$ liquid transformation and $\gamma$ phase formation, based on the previous study on liquid-phase sintering in a Cu-Sn system [63]. With the ultimate temperature of $870^{\circ} \mathrm{C}$ for the pure premixed bronze, since this temperature is higher than the solidus temperature and lower than the liquidus temperature of bronze formation, the third peak, corresponding to liquidus temperature, present on the previous two curves is missing, see Figure 3.7(c). Finally, as concerns the premixed bronze with $20 \% \mathrm{~T}-401$ tested under the ultimate temperature of $1500^{\circ} \mathrm{C}$, the same three sharp peaks and two minor peaks as discussed above are presented on the curve, but plus an extra sharp peak around $1283^{\circ} \mathrm{C}$ which corresponds to the solid $\rightarrow$ liquid transformation or melting of the T-401 Tribaloy alloy particles, see Figure 3.7(d). The DSC curve of the prealloyed bronze with $20 \%$ T-401 tested under the ultimate temperature of $1400^{\circ} \mathrm{C}$ is presented in Figure 3.8. Since the bronze powder is of prealloyed type and no free tin is present in the mixture, no peak for tin melting is observed on the DSC curve. Figure 3.9 presents the DSC curve of the copper with $15 \%$ bismuth and $20 \%$ T- -401 tested under the ultimate temperature of $870^{\circ} \mathrm{C}$. The only sharp peak around $280^{\circ} \mathrm{C}$ corresponds to bismuth melting. No significant peaks corresponding to the melting of copper and Tribaloy particles are observed. 
Based on these DSC results the Sintering/HIPping temperatures between $840^{\circ} \mathrm{C}$ and $870^{\circ} \mathrm{C}$ were selected in this research, assuming that Tribaloy alloy $\mathrm{T}-401$ would not melt during the Sintering/HIPping processes.

\subsubsection{HIPping process}

The maximum operating temperature and pressure of the HIP unit used in this research, shown in Figure 3.10, are $2000^{\circ} \mathrm{C}$ and $206 \mathrm{MPa}$ respectively. The HIPping cycles were designed based on the DSC test results. In order to investigate the influences of temperature, pressure, time and heating rate on the HIPing products and thereby to obtain the optimum HIPing parameters for each composition, the following four cycles were tested:

1. HIPping at $840^{\circ} \mathrm{C}$ and $206 \mathrm{MPa}$ for 20 minutes. Heating rate was $10^{\circ} \mathrm{C} / \mathrm{min}$ and cooling was based on furnace cooling rate which was about $12.5^{\circ} \mathrm{C} / \mathrm{min}$

2. HIPping at $870^{\circ} \mathrm{C}$ and $206 \mathrm{MPa}$ for 30 minutes. Heating rate was $10^{\circ} \mathrm{C} / \mathrm{min}$ and cooling was based on furnace cooling rate which was about $12.5^{\circ} \mathrm{C} / \mathrm{min}$

3. HIPping at $870^{\circ} \mathrm{C}$ and $206 \mathrm{MPa}$ for 120 minutes. Heating rate was $10^{\circ} \mathrm{C} / \mathrm{min}$ and cooling was based on furnace cooling rate which was about $12.5^{\circ} \mathrm{C} / \mathrm{min}$

4. HIPping at $870^{\circ} \mathrm{C}$ and $103 \mathrm{MPa}$ for 120 minutes. Heating rate was $10^{\circ} \mathrm{C} / \mathrm{min}$ and cooling was based on furnace cooling rate which was about $12.5^{\circ} \mathrm{C} / \mathrm{min}$

In all the HIPping cycles above, heating rate was $10^{\circ} \mathrm{C} / \mathrm{min}$, because it is an industrial heating rate for bronze sintering [61-62]. 
The sealed encapsulated powders were placed in a ceramic pot with the capacity of 20 specimens surrounded with sands to keep the tubes straight during the HIPping process and then loaded into the chamber of the HIPping unit. The chamber was first cleaned via purging with high purity argon gas for three times to make sure that no oxygen was present. After that, the chamber was pressurized at room temperature with high purity argon gas up to half of the ultimate HIPping pressure. The ultimate HIPping pressure was achieved via heating cycle. Figure 3.11 shows the HIPped specimens.

\subsubsection{Sintering process}

In this research the sintering technique was also employed for the consolidation of the mixed powders, in order to compare with the HIPping technique. Two compositions were tested: Premixed bronze with 10\% T-401, and copper-15\% bismuth with $10 \%$ T-401. The following two sintering cycles were designed for the consolidation, performed in a vacuum sintering furnace shown in Figure 3.12.

1. Sintering at $840^{\circ} \mathrm{C}$ for 20 minutes with heating and cooling rate of $10^{\circ} \mathrm{C} / \mathrm{min}$ (for bronze based compositions)

2. Sintering at $870^{\circ} \mathrm{C}$ for 30 minutes with heating and cooling rate of $10^{\circ} \mathrm{C} / \mathrm{min}$ (for copper based compositions)

The facilities for powder compaction before sintering, in order to get a semi dense compact, were not available in the present research, therefore squeezed vacuum encapsulated powders were sintered. 


\section{Chapter 4}

\section{Material Characterization}

\subsection{Microstructural Analysis}

\subsubsection{Specimen surface preparation}

The sintered and HIPped specimens were cut using an abrasive cutter and a precision saw and hot mounted for metallographic analyses. The surfaces of the specimens were first ground with sand papers of grit $180,240,320,600,800$ and 1200 successively, followed by two polishing stages of $3 \mu \mathrm{m}$ and $0.05 \mu \mathrm{m}$, respectively. Before each polishing stages, the specimens were cleaned ultrasonically. Polished and ultrasonically cleaned specimens were first studied in as polished condition for sintering evaluation. The purpose of this study was to examine the distributions of the Tribaloy alloy particles in the copper or bronze matrices. Also, the porosity could be evaluated.

The specimens were then etched with different etchant solutions as the following:

- $2 \mathrm{~g} \mathrm{~K}_{2} \mathrm{Cr}_{2} \mathrm{O}_{7}, 4 \mathrm{~mL}$ saturated $\mathrm{NaCl}$ solution, $8 \mathrm{~mL} \mathrm{H}_{2} \mathrm{SO}_{4}, 100 \mathrm{~mL} \mathrm{H} \mathrm{H}_{2} \mathrm{O}$

This etchant solution was mainly used for copper based alloys, which reveals microstructures better than for bronze based alloys.

- $5 \mathrm{~g} \mathrm{FeCl}_{3}, 50 \mathrm{~mL} \mathrm{HCl}, 100 \mathrm{~mL} \mathrm{H}_{2} \mathrm{O}$

This etchant solution was mainly used for bronze based alloys, which reveals microstructures better than for copper based alloys. 
- $15 \mathrm{~mL} \mathrm{HNO}_{3}, 15 \mathrm{~mL}$ Acetic acid, $60 \mathrm{~mL} \mathrm{HCl}, 15 \mathrm{~mL} \mathrm{H}_{2} \mathrm{O}$

This etchant solution was used to reveal the microstructures of Tribaloy alloys.

Each specimen was immersed in the etchant solution for about $20 \mathrm{~s}$, followed by immediate rinsing under running water and acetone or alcohol rinsing, respectively. Finally, the specimens were carefully dried. A minimum of two specimens of each composition were prepared for microstructure analysis under an optical microscope. The same specimens were also used for SEM studies.

The specimens were examined for microstructure under an optical microscope in two conditions, before etch and after etch.

\subsubsection{Microstructures of sintered specimens}

The Microstructural images show that the sintering of bronze based alloys was not successful; the mixed powder was not even consolidated. The reason for this was that compaction was required before sintering; otherwise it would take several hours for diffusion. Different from a HIPping process, in a sintering process there is no external pressure to accelerate diffusion. Copper based alloys were not sintered completely although consolidation was almost completed. As shown in Figure 4.1 for the sintered copper based alloy with $10 \% \mathrm{~T}-401$, the presence of particle boundaries in unetched condition is a proof of undersintering. The microstructure consists of copper grains, spherical particles which are Tribaloy alloy (T-401), and free bismuth penetrating along the copper grain boundaries or around the Tribaloy alloy particles. 


\subsubsection{Microstructures of HIPped specimens}

Figure 4.2 shows the microstructure of the premixed bronze based alloy with $10 \%$ T-401 HIPped in the first HIPping cycle condition. The presence of particle boundaries in unetched condition indicates that sintering was not completed. The grey spherical particles are T-401, and the matrix is $\alpha$ phase bronze.

Figure 4.3 shows the microstructure of the copper based alloy with $10 \% \mathrm{~T}-401$ HIPped in the second HIPping cycle condition. Particle boundaries are also observed in unetched condition, which demonstrates that sintering was not completed. Again, the grey spherical particles are $\mathrm{T}-401$.

Figure 4.4 shows the microstructure of the premixed, and prealloyed bronze based alloys with $10 \% \mathrm{~T}-401$ HIPped in the third HIPping cycle condition; it is obvious that no particle boundaries exist. This means that the sintering was complete in theses specimens. The microstructures contain $\alpha$ phase bronze with T-401 particles well distributed in the matrix. The microstructures look very dense and contain little quantity of pores. The premixed bronze based alloy shows more pores compared to pre-alloyed type, see Figures 4.4 (c) and (e). As discussed earlier, pores are good sites for lubricants where the bearing is oil impregnated. Since the microstructures of the third HIPping cycle are good, all the compositions were finally HIPped with this cycle, except that pressure was lowered to $103 \mathrm{MPa}$ to increase pores. The pressure of $103 \mathrm{MPa}$ is the most common HIPping pressure used in industry [58]. 
Figures $4.5-4.18$ show the microstructures of the fourteen specimens. It is demonstrated that the microstructures of all bronze based composites contain $\alpha$ phase bronze and free Tribaloy alloy (T-401 or $\mathrm{T}-400 \mathrm{C})$ particles. It is obvious from the microstructures that adding Tribaloy alloy particles to the compositions decreases the grain sizes. Comparing grain sizes in high magnification in Figures $4.5-4.8$ for the premixed bronze based materials, one may see that $\mathrm{T}-401$ additive decreases the size of bronze grains, also with increasing the $\mathrm{T}-401$ percentage in the compositions the grain sizes decreases more. The same results are obtained from Figures $4.11-4.14$ for the prealloyed bronze based materials. T-400C exhibits the same effect as T-401 to decrease the grain size. In addition, it is found that the Tribaloy alloy additives could reduce pores, as the pores might be suitable sites for free solid Tribaloy particles. It should be noticed that T-401 and T-400C Tribaloy alloys have much higher melting temperatures than the HIPping temperature $\left(870^{\circ} \mathrm{C}\right)$. Their melting temperatures are around $1400^{\circ} \mathrm{C}$ so that they did not melt during the HIPping process, which is similar to graphite powder when it is added to conventional bronze bearings. Also, it is clear that the premixed bronze microstructure contains more pores compared to the prealloyed type with or without Tribaloy alloy additives.

The microstructure of the copper-15\% bismuth specimen, as shown in Figure 4.15, contains copper grains and free bismuth penetrating along the copper GBs. It is dense with very few pores, but in Figure 4.15 (b), one may see the sintering is incomplete at the edge of the specimen due to insufficient compaction of the powder. This problem may be 
avoided by increasing the HIPping temperature or time. It is also noticeable that more bismuth is solidified or penetrated in these areas compared to the center of the specimen.

Figures $4.16-4.18$ show the microstructures of the specimens of copper- $15 \%$ bismuth plus $10-20 \%$ T-401. Again, it is seen that T-401 particles exist in the microstructures as a free phase because they did not melt during the HIPping. In addition, cracking is observed in the microstructures of these specimens, see Figure $4.16-4.18$. Comparing grain sizes under the higher magnification in Figures 4.15 - 4.18, one may see that T-401 additive decreases the size of copper grains, as what is observed in the bronze based microstructures.

\subsubsection{SEM analysis}

In addition to optical microscope analyses, the microstructure analyses of the specimens were also conducted on a Hitachi Model S-570 scanning electron microscope (SEM) with backscatter electron imaging and energy dispersive X-ray (EDX) spectrum, in order to investigate the interface behaviors between the Tribaloy alloy particles and the matrices in high magnifications. The EDX composition analysis was performed on the copper-15\% bismuth specimen via an Ultra Rapid Spectrum Analyzer. The bright phase in the grain boundaries of the specimen was of interest in this analysis.

The SEM images of the specimens are shown in Figures $4.19-4.21$. The aim of SEM examination was to study the bonding of Tribaloy alloy particles to the matrix and analyze the white areas in copper GBs of the copper based materials. It is demonstrated 
that the interface between the Tribaloy alloy particle and the matrix is solid bonded, and no cracks are observed. The white areas in copper GBs and around Tribaloy particles in the copper based materials are identified clearly. The EDX analysis shows either high percentage of bismuth or the penetration of bismuth along the copper GBs.

The patterns of EDX composition analysis of the whole specimen and the grain boundaries for the copper-15\% bismuth composition are illustrated in Figures 4.22 - 4.23. Table 4.1 presents the data. It is shown that high content level of copper is in the overall microstructure but high bismuth is at the copper GBs.

\subsection{Density Measurement}

\subsubsection{Specific Gravity}

Density, the ration of mass to volume, is measured according to Archimedes' principle. Density measurement is standardized in ASTM B 328, MPIF test method 42, and ISO 2738. It is recommended in ASTM B 328 that the sample weight is $2 \mathrm{~g}$ in minimum, otherwise relatively high error rate will be induced [64]. Specific gravity is the density of a substance divided by the density of water. Assuming that water has a density of $1 \mathrm{gram} / \mathrm{cm}^{3}$, since all of the units are counteracted, specific gravity equals density in magnitude but without units. 


\subsubsection{Test procedure}

In this research the specific gravity measurement was conducted on a Startorius 6080 Specific Gravity Determination Kit at room temperature. The first step was to weigh the specimen in air, and then in the water. The following equation was used to calculate the specific gravity of the specimen [65]:

$$
\rho_{k}=W_{a} \cdot \rho_{f t} / A
$$

where:

$\rho_{k}=$ Specific gravity of the specimen

$W_{a}=$ Weight of the specimen in air

$\rho_{f l}=$ Density of water

$A=$ Buoyancy (weight of the specimen in water)

\subsubsection{Density data}

The density test was conducted on the pure premixed bronze and prealloyed bronze specimens (specimens MG1 and B-409) and two prealloyed bronze and premixed bronze based specimens (specimens 8 and 11). The experimental results are presented in Table 4.2. Specimens B-409 and 11 with the density of 8.1618 and $8.5172 \mathrm{~g} / \mathrm{cm}^{3}$, respectively, show higher density $(11-16 \%)$ in comparison with specimens MG1 and 8 which have density of 7.0096 and $7.6885 \mathrm{~g} / \mathrm{cm}^{3}$, respectively. Although both specimens 8 and 11 contain $15 \% \mathrm{~T}-401$, the prealloyed bronze composite has higher density than the premixed type. 


\subsection{Hardness Test}

\subsubsection{Test procedure}

A Wilson Series 2000 Rockwell Hardness Tester was employed to measure the hardness of the specimens. HRH scale was used for the softer materials such as copper- $15 \%$ Bismuth composition and pure premixed bronze alloys. HRB scale was used for the other compositions which are harder. The specimens were prepared with smooth and parallel surfaces. A minimum of four specimens for each composition were tested in both cross section and longitudinal section, respectively, and the average of five tests in each section was taken as the hardness of the material.

\subsubsection{Test Results}

The experimental results show that the hardness in cross section and longitudinal section are very close, which confirms the isotropic mechanical properties of the HIPped specimens produced by uniform pressure in all directions during the HIPping process.

Table 4.3 represents the hardness values of all the specimens. Significant increase in hardness is observed by adding Tribaloy additives to the material. Prealloyed bronze based materials show higher hardness compared with premixed ones. Copper-bismuth based materials show much lower hardness compared to bronze based materials, even with Tribaloy additives. Also, the hardness increases with the increase of Tribaloy content (T-401 \& T-400C) in both the copper based and bronze based materials, but 
$\mathrm{T}-400 \mathrm{C}$ increases the hardness more than $\mathrm{T}-401$. This is obvious by comparing hardness of specimens 8 and 9 with specimens 13 and 14.

\subsection{Nano Indentation Test}

\subsubsection{Nano indentation technique}

Micro and nano indentation tests (MIT \& NIT) are of the new techniques to study the hardness and elastic modulus of thin films and composites, based on the loading/unloading curve. With this new technique, the interface properties of composite materials can be studied. This technique relies on the fact that the displacement recovered during unloading is elastic so that from the load-displacement data the modulus of elasticity can be calculated [66-67].

In this research, in addition to macro hardness, nano hardness of individual phases of the developed materials was determined via the nano indentation technique on a CSM nano hardness machine. The nano indentation effective Young's modulus $E^{*}=E /\left(1-v^{2}\right)$ and hardness $H$ are calculated based on the loading/unloading curves which are measured with a Berkovich indenter using the Oliver-Pharr method [68], where $E$ and $v$ are the Young's modulus and Poisson ratio of the tested material, respectively. The load displacement curves of loading and unloading are recorded automatically during the indentation. The area enclosed by the loading and unloading curves represents the dissipated energy due to plastic deformation [69]. In this research, the maximum load employed in each indentation was $50 \mathrm{mN}$ with a load and unload rate of $100 \mathrm{mN} / \mathrm{min}$. 
The machine is equipped with an optical microscope with which a specific point in the microstructure can be selected for nano indentation test. It is very important that the tested specimen has parallel surfaces and is in final polished condition; otherwise the test data are not reliable.

\subsubsection{Nano mechanical properties}

The nano indentation test was performed on the following specimens as representatives of the three groups of developed materials.

- Pre-Mixed Tin-Bronze Based Materials

- Specimen MG1 (Cu-10\% Sn+ 0\% T-401)

- Specimen $7 \quad(\mathrm{Cu}-10 \% \mathrm{Sn}+10 \% \mathrm{~T}-401)$

O Specimen $8 \quad(\mathrm{Cu}-10 \% \mathrm{Sn}+15 \% \mathrm{~T}-401)$

- Specimen 13 (Cu-10\% Sn $+15 \% \mathrm{~T}-400 \mathrm{C})$

- Pre-Alloyed Tin-Bronze Based Materials

○ Specimen B409 (Cu-10\% Sn + 0\% T-401)

- Specimen $11 \quad(\mathrm{Cu}-10 \% \mathrm{Sn}+15 \% \mathrm{~T}-401)$

- Copper Based Materials

- Specimen $17 \quad(\mathrm{Cu}+15 \% \mathrm{Bi}+15 \% \mathrm{~T}-401)$

A minimum of three tests were conducted on each phase and the interface of a material and the average of the experimental data was taken as the mechanical properties of the phases and matrices. 
Figures $4.24-4.30$ present the load - displacement curves of the tested specimens under loading and unloading. The area enclosed by the loading curve represents the total deformation energy and that enclosed by the unloading curve the elastic deformation. Thus $\eta_{e}$ is defined as the ratio of the elastic deformation energy to the total deformation energy, representing elasticity of the tested component, while $\eta_{p}$ is the ratio of the plastic deformation energy to the total deformation energy, representing plasticity of the tested component.

The nano mechanical properties of the tested specimens such as hardness, Young's modulus, elasticity and plasticity are presented in Table 4.4. It is found that there is no significant difference of nano mechanical properties of the matrices between the alloys with and without Tribaloy alloys. The slight difference in hardness and Young's modulus is due to the sensitivity of nano scale test to the specimen finishing, but in general no meaningful difference in the nano mechanical properties is observed. It is clear that Tribaloy alloy particles are much harder and have more than twice higher Young's modulus than the matrices. Also these particles exhibit higher elastic deformation rate. Between the $\mathrm{T}-401$ and $\mathrm{T}-400 \mathrm{C}$ particles, the latter shows higher hardness and Young's modulus with slightly higher elasticity.

In addition, the load - displacement curves of the pure premixed and prealloyed bronzes (specimens MG1 and B409) demonstrate similar deformation behaviors with very close elastic and plastic deformation rates, but the latter exhibits slightly higher 
Young's modulus. In general, these two types of bronze have very close mechanical properties on nano scale, see Figure 4.28.

As mentioned in the microstructure analysis, cracks are observed in the specimens of copper-15\% bismuth plus $10-20 \% \mathrm{~T}-401$ (specimens 16,17 and 18 ). In order to investigate the cracking mechanism, the nano indentation test was performed on the matrix and the particle near the cracks of the specimen with copper-15\% bismuth plus $15 \% \mathrm{~T}-401$ (specimen 17). It is found that there is no significant difference of the nano mechanical properties between the particle near the cracks and far from the cracks, but the matrices in the two areas exhibit different nano mechanical behaviors. Near the cracks, the matrix seems slightly softer and exhibits lower Young's modulus, compared with the matrix far from the cracks.

\subsection{Pin-on-disc Wear Test}

\subsubsection{Testing parameters}

To investigate the tribological properties and evaluate the wear resistance of the developed materials, wear test was conducted on a pin-on-disc tribometer. The wear test specimens require special preparation as the test is very sensitive to specimen surface conditions. The test specimens should be flat with a polished surface; the maximum thickness of the specimen should be $5 \mathrm{~mm}$ according to the holder of the wear test machine. Figure 4.31 shows the specimens for pin-on-disc wear test. They were polished and ultrasonically cleaned (in acetone) before the test with the thickness of $5 \mathrm{~mm}$. 
Different ball (pin) materials, alumina, WC-6\%Co and hardened steel, were tested to find which one would be suitable for the developed materials. The hardness of the balls is described below:

- Alumina ball: $1700 \mathrm{HV}$

- WC-6\%Co ball: $1633-1787 \mathrm{HV}$

- Hardened steel ball: $697-900 \mathrm{HV}$

It was found that the steel ball was too soft, but alumina and WC-6\%Co balls were both hard enough against the developed materials with negligible wear of the ball in a pin-on-disc test. In this research WC-6\%Co ball was selected for the wear test.

The wear test was performed on the polished surface of the specimen (the disc) which was spinning during the wear process under a contact load applied through the ball. As a result, there would be a wear track or pit formed in the specimen surface. The wear tracks were examined under an optical microscope after the wear test. The wear loss of the material was evaluated by calculating the volume of the wear track. The testing parameters selected are listed below:

- Pin: $5 \mathrm{~mm}$ diameter $\mathrm{WC}-6 \%$ Co ball

- Wear track diameter: $6.7 \mathrm{~mm}$

- Load level: $2 \mathrm{~N}$

- Friction force capacity: $10 \mathrm{~N}$ in maximum

- Rotational speed of the disc: $500 \mathrm{rpm}$

- Linear speed: $175 \mathrm{~mm} / \mathrm{s}$ 
- Test duration: $5400 \mathrm{~s}$

- Accuracy: reading $+/-0.1 \%$

\subsubsection{Wear loss calculation}

ASTM G 99-95a Standard covers the pin-on-disc tribometer test. This standard determines the wear loss by measuring appropriate linear dimensions of both ball and disk. Depending on the ball and disc materials, the wear of the ball and disc may occur in three modes, illustrated in Figure 4.32 [70]. Assuming that there is no significant ball wear in the present test because the ball material is much harder than the tested materials, the volume loss of the disk can be calculated using the following formula [70]:

Disk volume loss $=2 \pi R\left[r^{2} \sin ^{-1}(d / 2 r)-(d / 4)\left(4 r^{2}-d^{2}\right)^{1 / 2}\right]$

where:

$R=$ Wear track radius (which is $6.7 \mathrm{~mm}$ in the performed tests)

$d=$ Wear track width

$r=$ Ball radius

The width of each track was measured at five positions along the wear track under an optical microscope in the magnification of X50 with the associated measurement software installed. 


\subsubsection{Wear test results}

Two specimens were under the wear test for each composition and the average of the test results was taken as the wear loss of the material. Figures $4.33-4.35$ show the optical photos of the worn surfaces of the specimens; with the wear tracks being measured. The friction coefficients varying with time are illustrated in Figures 4.36 - 4.39. Table 4.5 represents the wear track widths, volume losses and friction coefficients of the specimens. It is shown that there is no significant difference in friction coefficient between the bronze based materials with and without Tribaloy, but significant increase in friction coefficient of the copper based alloys with Tribaloy is observed; the friction coefficient is almost tripled. The wear track width and volume loss is significantly reduced when T-401 is added to the bronze and copper-bismuth materials. The effect of T-401 in improving the wear resistance is higher in the premixed bronze than in the prealloyed bronze based materials. Increasing T-401 additive from $10 \%$ to $20 \%$ has increased the wear resistance. The volume loss of the premixed bronze material containing $20 \% \mathrm{~T}-401$ is only one third $(1 / 3)$ of that of the pure premixed bronze. For the prealloyed bronze, the volume loss of the material with $20 \% \mathrm{~T}-401$ is about half $(1 / 2)$ of that of the material without T-401. But no significant wear resistance improvement is observed in the bronze with T-400C. The copper based materials also show the improvement in wear resistance when T-401 is added, but compared to the bronze based materials their wear resistance is much lower. The volume losses of the copper based materials are higher than those of the bronze based materials by four or five times, but the effect of Tribaloy alloy $\mathrm{T}-401$ in improving wear resistance seems much higher in the copper based materials compared to the bronze based materials. 


\subsection{Tensile Test}

\subsubsection{Test process}

The tensile test was conducted on an MTS tensile testing machine according to the ASTM E 8-03 Standard, Test Methods for Tension Testing of Metallic Materials. In the Metal Powder Industries Federation (MPIF) Standard 10, Methods for Determination of the Tensile Properties of Powder Metallurgy Materials, ASTM E 8 is referred as the Tensile Test Standard for Powder Metallurgy Materials. The standard tensile test specimens, as shown in Figure 4.40 [71], were manufactured for each composition except for copper-15\% bismuth plus 15\% T-401 and plus 20\% T-401 (specimens 17 and 18). These two specimens are too brittle and they cracked during the machining. The tensile test was performed in a strain-controlled mode with a loading rate of $0.05 \mathrm{~min}^{-1}$.

\subsubsection{Stress - strain curves}

The stress - strain curves of the specimens, obtained from the tensile tests are presented in Figure $4.41-4.43$. It is obvious that the bronze materials without Tribaloy alloy additives are much more ductile compared to the materials with Tribaloy alloy additives, characterized by the different elongations. Between the premixed bronze specimen and the prealloyed bronze specimen, the latter exhibits higher ductility with $7 \%$ elongation and the former only about $2 \%$, see Figure 4.42 (e). For the copper-15\% bismuth with and without T-401 materials (specimens 6 and 16), as shown in Figure 4.43, both the specimens exhibit brittle behavior with very small plastic deformation and no obvious yielding. 


\subsubsection{Mechanical properties}

Tensile test results including yield strength, ultimate tensile strength and elongation, obtained from the stress - strain curves, are presented in Table 4.6. The yield stresses are calculated in correspondence to $0.2 \%$ residual strain. It is clear that the Tribaloy alloy additives increase the yield stresses and tensile strengths of tin-bronze and copper-bismuth significantly but decrease the elongations dramatically, as most reinforcements do in composite materials. Also, the yield stresses and tensile strengths are increased with the content of the Tribaloy alloy additives, but the elongations seem not influenced very much by the additive content.

Between the premixed bronze based and the prealloyed bronze based materials the latter exhibits higher yield stress and tensile strength as well as larger elongation. Regarding the effects of $\mathrm{T}-401$ and $\mathrm{T}-400 \mathrm{C}$ on the mechanical properties of the developed composites, one may see that specimen 13 containing $15 \% \mathrm{~T}-400 \mathrm{C}$ has slightly lower yield stress and tensile strength as well as elongation compared to specimen 8 containing 15\% T-401. Comparing the copper based materials with the bronze based materials, the former exhibits much lower yield stress and tensile strength as well as elongation. This may be due to the presence of bismuth instead of tin in the copper based materials. This issue will be discussed in next chapter. However, the reinforcement effect of the Tribolay alloy on the mechanical properties of the copper- $15 \%$ bismuth specimen is more remarkable than on those of the bronze specimens. 


\subsection{Tests of an Industrial Sintered Bronze Bearing}

For comparison an industrial sintered lead-free bronze bearing sample (specimen Sava), shown in Figure 4.44, was studied under metallographic examination, nano indentation and wear test.

\subsubsection{Microstructure examination}

The same procedure of surface preparation for metallographic examination made on the developed materials was taken on this industrial sample. The microstructure study was performed on an optical microscope and the photos are shown in Figure 4.45. The microstructure in unetched condition shows that the sintering is complete, but pores are seen obviously. As a necessity for self lubricant bearings, the specimen contains about $25 \%$ porosity which is used for oil impregnation.

\subsubsection{Nano indentation test}

The same nano indentation test made on the developed materials was performed on this industrial bearing. Figure 4.46 shows the load - displacement curve determined in the NIT. The mechanical properties obtained from the load - displacement curve are presented in Table 4.7, accompanied with the data of specimens MG1 (pure premixed bronze) and B-409 (pure prealloyed bronze) for comparison. It is shown that the bearing sample has slightly higher hardness but lower Young's modulus and less plastic deformation. 


\subsubsection{Wear test}

Again, the same pin-on-disc wear test made on the developed materials was conducted on this industrial bearing. The loading condition was the same as for the matrices of the developed materials. The worn surface with the wear track is shown in Figure 4.47.

The test results including volume loss and friction coefficient are presented in Table 4.8 with data of specimens MG1 and B-409 for comparison. It is shown that the wear resistance of the bronze bearing sample is close to that of specimens MG1 and B409, but there is significant difference in friction coefficient. The bearing sample has much lower friction coefficient. This is because the bearing material is oil impregnated. Compared with this industrial bearing material, the developed bearing composites with Tribaloy alloy additives have much higher wear resistance. 


\section{Chapter 5}

\section{Discussion and Conclusions}

\subsection{Discussion on the Experimental Results}

\subsubsection{Chemical composition versus microstructure}

The microstructural analyses show that the premixed and prealloyed bronzes without Tribaloy alloy additives have a microstructure containing $\alpha$ phase bronze. Since the sintering/HIPping temperatures were much below the melting points of Tribaloy alloys T-401 and T-400C, these particles remained solid state and did not melt during the specimen fabrication processes. Therefore, in the microstructures the Tribaloy alloys (T-401 and T-400C) exist as free particles. Also, from the DSC test results, no new phases formed due to the presence of the Tribaloy alloys, that is, there is no chemical reaction between the Tribaloy alloy particles and the bronze matrices. The nano indentation test results demonstrate that the bronze matrices of the composite specimens with Tribaloy alloy additives have the same mechanical properties with the pure bronze specimens, which further confirms that the Tribaloy alloy particles do not react chemically with the bronze matrices thus do not affect the properties of the matrices.

However, it is found that adding the Tribaloy alloy particles to the bronze matrices reduces the bronze grain size and refines the microstructures. This is because the Tribaloy alloy particles are uniformly distributed in the matrices, which retards the 
growth of the bronze grains. Refined microstructures commonly provide better mechanical properties.

In the copper based materials containing bismuth, besides the same behavior of the Tribaloy alloy particles as discussed for the bronze based materials, the effect of bismuth is not negligible. As well known, bismuth has similar characteristics to lead and has beneficial effect in journal bearing materials. However, it was found that the content level of bismuth (15\%) used in the materials developed in this research was too high, which resulted in cracking of the specimens, as shown in the microstructures and discussed in last chapter. This is because free bismuth penetrates along the copper grain boundaries, as illustrated in Figure 4.20, which makes the materials brittle. The nano indentation test results of the copper- $15 \%$ bismuth with $15 \% \mathrm{~T}-401$ specimen show that the matrices near the cracks are softer than those far from the cracks and they have lower Young's modulus. This can be explained as in the areas near the cracks there is bismuth concentration which causes the copper GBs brittle leading to cracking. Bismuth is softer than copper and also has lower Young's modulus.

Previous research also reported the detrimental effect of bismuth when alloyed with copper. It is a common sever detrimental phenomenon in some alloy systems. Ductile metals when exposed to specific metallic environments may become brittle; one of the examples of such systems is copper-bismuth system [72-73]. Therefore, proper selection of bismuth content in copper-bismuth materials is very important. 
Comparing the premixed bronze with prealloyed bronze, their microstructures are the same, all containing $\alpha$ phase bronze. During the sintering/HIPping process, copper and tin in the premixed powder alloyed to form bronze, while the $\alpha$ phase bronze in the prealloyed powder melted and then recrystallized. From the experimental results, the prealloyed bronze (HRB 43.5) is harder than the premixed bronze (HRH 78.3); also the wear resistance, yield strength and tensile strength of the prealloyed bronze are all higher than those of the premixed bronze, as presented in Tables 4.5 and 4.6. Two reasons may be responsible for the difference of these properties between these two types of bronze. One is that the premixed bronze microstructure contains more pores compared to the prealloyed type, as seen in Figures 4.5 and 4.11. It is known from the powder supplier that the premixed bronze powder contains lubricant, as shown in the technical and safety sheets attached in Appendix A. The lubricant would vapor during the sintering/HIPping process and had left pores in the microstructures. The other is that the $\alpha$ phase bronze in the prealloyed powder might not totally melt during heating in the sintering/HIPping process thus some of the $\alpha$ phase bronze experienced grain refinement in the process.

\subsubsection{Effects of Tribaloy alloys on the wear resistance}

It is evident that the Tribaloy alloy additives enhance the hardness of the pure bronzes and copper-15\% bismuth, as demonstrated in Table 4.3. For most metallic materials, the harder a material, the higher the wear resistance of the material is. However, for composite materials this convention may not apply, because the interface bonding between the matrix and the reinforcement plays an important role in the material properties. Although the reinforcement particle is hard and wear resistance, if the 
interface bonding is not strong enough and the particle is pull out of the matrix during wear, the wear resistance of the material will be decreased.

As known from Table 4.3, the bronze composites with T-400C particles are much harder than those with T-401 particles, comparing the hardness test results of specimens 7 , 8 and 9 with specimens 13 and 14 . However, the wear test results in Table 4.5 demonstrate that the wear resistance of the bronze and copper-bismuth alloys is increased significantly by the reinforcement of T-401 particles, but the T-400C particles make a detrimental effect on the wear resistance of the bronzes; they do not enhance the wear resistance but reduce it.

As introduced in the previous chapters, the major difference between $\mathrm{T}-401$ and $\mathrm{T}-400 \mathrm{C}$ is that $\mathrm{T}-401$ is a hypoeutectic alloy with better ductility compared to conventional Tribaloy alloys because its primary phase is cobalt solid solution instead of Laves phase, while T-400C is a hypereutectic alloy which is brittle as conventional Tribaloy alloys are. As a result, the compatibility of T-401 with the soft bronze matrix would be better than that of T-400C. Comparing the worn surfaces in Figure 4.33, it is obvious that the surface damage of specimens 13 and 14, which contain T-400C particles, is much more severe than that of specimens 7, 8 and 9, which contain T-401 particles. Many holes can be observed in the worn surfaces of specimens 13 and 14, which were left when the T-400C were pull out from the surfaces during the wear process. This confirms the weak bonding strength between the T-400C particles and the bronze matrix. 


\subsubsection{Effects of Tribaloy alloys on the mechanical properties}

As shown in Table 4.6, Tribaloy alloys have beneficial effects enhancing the yield strength and tensile strength of the bronze and copper based materials when added to these materials. Also both $\mathrm{T}-401$ and $\mathrm{T}-400 \mathrm{C}$ increase the yield strength and tensile strength of the bronzes. The mechanisms for this may be two; one is the Tribaloy alloys selves have much higher mechanical strength than bronze; the other is the Tribaloy alloy particles refine the microstructures of the bronzes when present in the materials as additives. Again, as most composite materials do, the Tribaloy alloy reinforcements worsen the ductility of the bronze materials, characterized by the reduction in elongation.

Comparing the tensile test results between specimen 8 (containing 15\% T-401) and specimen 13 (containing 15\% T-400C), one may see that T-401 has larger effect on enhancing the mechanical strength of the bronze than T-400C. This is also attributed to the better ductility of T-401, which benefits the interface bonding between the bronze matrix and the T-401 particles. Strong interface bonding would reduce cracking in the specimen thus enhancing the mechanical properties of the material, including yield strength, tensile strength and elongation.

It is also interesting to notice that for a same reinforcement increasing its content in the composite would increase the mechanical properties of the material. In general, higher content of the reinforcement in a composite material would create more interfaces between the reinforcement and the matrix, thus the material would become more brittle, resulting in decrease of the elongation. However, for the materials developed in this 
research, since addition of the Tribaloy alloy particles reduces the grain size of the bronze, the refined microstructure would provide improved ductility of the material with increased elongation.

As concerns the copper based materials, due to the high content of bismuth, the specimens with or without T-401 all exhibit typical brittle behavior, see Figure 4.43. However, the additive of T-401 increased the tensile strength and elongation of the copper- $15 \%$ bismuth specimen more than twice. This is because the presence of the more ductile, with higher strength T-401 can compensate some effect of the brittle, with lower strength bismuth in the microstructure, thus enhance the overall mechanical properties of the specimen.

\subsection{Conclusions}

Based on the experimental results and above discussions, the following conclusions can be achieved from this research:

1. Three groups of novel lead-free tin-bronze based and copper based composites with newly developed Tribaloy alloys as the reinforcements have been developed through sintering/HIPping process for journal bearing applications.

2. The presence of Tribaloy alloy particles does not change the properties of the matrix because there is no chemical reaction between the particle and the matrix at the sintering/HIPping temperature which is much below the melting point of the Tribaloy alloy. 
3. Both $\mathrm{T}-401$ and T-400C Tribaloy alloys exhibit beneficial effect in enhancing the mechanical properties of tin-bronze, but due to the brittleness of $\mathrm{T}-400 \mathrm{C}$ the interface bonding between the reinforcement particle and the matrix may not be very strong, thus cracks would be induced at the interface areas, leading to failure of the material.

4. Addition of Tribaloy alloy particles into tin-bronze and copper-bismuth increases the hardness of these materials. T-401 can enhance the wear resistance of the materials, but $\mathrm{T}-400 \mathrm{C}$ not, because the weak interface bonding causes the $\mathrm{T}-400 \mathrm{C}$ particles pull out of the material surface during wear, leading to high material loss.

5. The beneficial effect of $\mathrm{T}-401$ on the mechanical properties and wear resistance of tin-bronze and copper-bismuth increases with the content level of T-401 in the composites. In this research, the content was tested up to $20 \mathrm{wt} \%$ and it was demonstrated to be good.

6. Prealloyed bronze possesses better properties such as hardness, mechanical strength and ductility than premixed bronze.

7. The presence of Tribaloy alloy particles reduces the grain size and refines the microstructures of tin-bronze and copper-bismuth, thus improve the properties of the materials.

8. Bismuth has beneficial effect in journal bearing materials, but excessive content would cause the copper grain boundaries brittle, resulting in micro cracks.

9. The potential new materials for journal bearing applications will be prealloyed bronze with $15-20 \% \mathrm{~T}-401$ which exhibit the best wear resistance and mechanical properties among the developed materials. 


\subsection{Future Work}

The following studies are suggested for future work:

- Grain refinement was observed in Tribaloy containing materials in this research, which improved mechanical properties of developed materials, therefore the study of grain refinement mechanisms in the developed materials is suggested.

- Bismuth as a non toxic heavy metal is a replacement for lead in case of improving friction properties and seizure resistance. Adding bismuth to bronze as the second additive to study the mechanical and tribological properties of the developed materials is suggested.

- Due to the catastrophic phenomenon of copper-bismuth brittleness, especially with high content level of bismuth, reducing the content of bismuth in copper-bismuth system to study brittleness and crack initiation behavior is suggested.

- Fabrication of coatings on low-carbon steel substrates with the developed materials using both thermal and cold spray techniques for new industrial applications such as jet engine bearings is suggested. 


\section{References}

[1] ASM Hand Book, Volume 7, "Powder Metal Technologies and Applications", First Printing, Dec. 1998, pp. 1051-1057.

[2] Standard ASME B438.

[3] Standard MPIF 35.

[4] http://www.qualisinter.com.br/page-1.htm.

[5] Bearing Selection Guide, http://www.copper.org/resources/pub_list/pdf/sleevebearing_a1063_06.pdf.

[6] W.J. Whitney, R.L. Greene, J.M. Carpenter, United States Patent 6746154, http://www.patentstorm.us/patents/6746154.html, June 2004.

[7] http://www.copper.org/applications/industrial/bronze_bearing.html.

[8] Prasad, B.K. (Regional Res. Lab., CSIR, Bhopal, India), "Sliding wear behavior of bronzes under varying material composition, microstructure and test conditions", Wear, v 257, n 1-2, July 2004, pp 110-23.

[9] Haoran Geng (Dept. of Mater. Eng., Shandong Polytech. Univ., Jinan, China); Jiaji Ma, "Friction and wear of Al-Zn-Pb bearing alloy", Wear, v 169, n 2, 15 , Oct. 1993, p 201-207.

[10] Ozsarac, Ugur (Department of Metal Education, Technical Education Faculty, Sakarya University); Findik, Fehim; Durman, Mehmet, "The wear behaviour investigation of sliding bearings with a designed testing machine", Materials and Design, v 28, n 1, 2007, pp. 5-350.

[11] J. Gearhart, D. Menke, C. Griffith, K. Mills, "Getting the Lead Out, A report by: Environmental Defense, Ecology Center, Clean Car Campaign", http://www.environmentaldefense.org/documents/2887_leadbatteries.pdf, July 2003.

[12] C. M. L. Wu, D. Q. Yu, C. M. T. Law and L. Wang, "Properties of lead-free solder alloys with rare earth element additions" Materials Science and Engineering R: Reports, 44(1), 2004, pp. 44.

[13] S. K. Kang, J. Horkans, P. C. Andricacos, R. A. Carruthers, J. Cotte, M. Datta, P. Gruber, J. M. E. Harper, K. Kwietniak, C. Sambucetti, L. Shi, G. Brouillette and D. Danovitch, "Pb-free solder alloys for flip chip applications", Proceedings Electronic Components and Technology Conference, 1999, pp. 283. 
[14] D. Qi Lu, C. P. Wong, "Development of conductive adhesives for solder replacement", IEEE Transactions on Components and Packaging Technologies, 23(4), 2000, pp. 620.

[15] S. Jin, M. McCormack, "Dispersoid additions to a Pb-free solder for suppression of microstructural coarsening", Journal of Electronic Materials, 23(8), 1994, pp. 735.

[16] M. McCormack, S. Jin, "Design and properties of new, Pb-free solder alloys", Proceedings of the IEEE/CPMT International Electronics Manufacturing Technology (IEMT) Symposium, 1, 1994, pp. 7.

[17] Zhao, Jie, Qi, Lin, Wang, Xiu-Min, Wang, Lai, "Influence of Bi on microstructures evolution and mechanical properties in $\mathrm{Sn}-\mathrm{Ag}-\mathrm{Cu}$ lead-free solder", Journal of Alloys and Compounds, v 375, n 1-2, Jul 28, 2004, pp. 196201.

[18] M.L. Huang, L. Wang, "Effects of $\mathrm{Cu}, \mathrm{Bi}$, and In on microstructure and tensile properties of $\mathrm{Sn}-\mathrm{Ag}-\mathrm{X}(\mathrm{Cu}, \mathrm{Bi}$, In) solders", Metallurgical and Materials Transactions A (Physical Metallurgy and Materials Science), v 36A, n 6, June 2005, pp. 1439-46.

[19] A. Halstead, R. D. Rawlings, "Structure and hardness of Co-Mo-Cr-Si wear resistant alloys (Tribaloys)", Metal Science, 18 (10), 1984, pp.491-500.

[20] C. B. Cameron, D. P. Ferriss, "Tribaloy intermetallic materials: New wear- and corrosion-resistant alloys", Anti-Corrosion Methods and Materials, 22 (4), 1975, pp. 5-8.

[21] A. Halstead, R. D. Rawlings, "Fracture behavior of two Co-Mo-Cr-Si wear resistant alloys", Journal of Materials Science, 20 (4), 1985, pp. 1248-1256.

[22] R. D. Schmidt, D. P. Ferriss, "New materials resistant to wear and corrosion to $1000^{\circ} \mathrm{C} "$, Wear, $32(3), 1975$, pp. 279-289.

[23] A. Halstead, R. D. Rawlings, "The effect of iron additions on the microstructure and properties of the Tribaloy Co-Mo-Cr-Si wear resistant alloys", Journal of Materials Science, 20 (5), 1985, pp. 1693-1704.

[24] Anon, Unique intermetallics combat wear and corrosion, Metal Progress, 107 (5), 1975, pp. 90.

[25] C. B. Cameron, R. A. Hoffman, R. W. Poskitt, "Tribaloy intermetallic alloy compositions - New materials or additives for wear resistant applications", Progress in Powder Metallurgy, 31, 1975, pp. 41-51. 
[26] M. Fujita, Y. Saito, K. Matsuo, "Effects of Co-base alloy powder addition on wear-resistance and anti-seizure property of $\mathrm{Cu}-\mathrm{Sn}-\mathrm{Pb}$ alloys", Funtai Oyobi Fummatsu Yakin/Journal of the Japan Society of Powder and Powder Metallurgy, 44(6), 1997, pp. 585.

[27] W. Xu, R. Liu, P. C. Patnaik, M. X. Yao and X. J. Wu (2007), "Mechanical and tribological properties of newly developed Tribaloy alloys", Materials Science and Engineering A, 452-453, pp. 427-436.

[28] R. Liu, W. Xu, M. X. Yao, P. C. Patnaik and X. J. Wu (2005), "A newly developed Tribaloy alloy with increased ductility", Scripta Materialia, 53(12), pp. 1351-1355.

[29] M. X. Yao, J. B. C. Wu, S. Yick, Y. S. Xie and R. Liu (2006), "High Temperature Wear and corrosion resistance of a Laves phase strengthened Co-Mo-Cr-Si alloy", Materials Science and Engineering A, 435-436, pp. 78-83.

[30] W. B. Rowe, "Hydrostatic and Hybrid Bearings Design", Butterworth \& Co. Ltd., UK, 1983.

[31] E. M. Stansfield, "Hydrostatic Bearings", The Machinery Publishing Co. Ltd., UK, 1970.

[32] R. J. Welsh, Plain Bearing Design Handbook, The Thetford Press Ltd., UK, 1983.

[33] S. B. Glavatskih, "Evaluating thermal performance of a PTFE-faced tilting pad thrust bearing", Journal of Tribology, 125(2), 2003, pp.319.

[34] A. Leger, "Selection of polymer-based materials", South African Mechanical Engineer, 39(6), 1989, pp. 263.

[35] M. Kasahara, "Long life oilless bearing", Journal of Japan Society of Lubrication Engineers, 32(7), 1987, pp.469.

[36] R. S. Mahalaha, A. N. Dhodapkar and V. P. Deshpande, "Use of PTFE in sliding bridge bearings", Indian Highways, 14(3), 1986, pp. 29.

[37] T. Li, J. Tao, P. Cong and X. Liu, "Study on the tribological characteristics of solid lubricants embedded tin-bronze bearings", Journal of Applied Polymer Science, 80(13), 2001, pp. 2394.

[38] T. Tevruz, "Tribological behaviors of bronze-filled polytetrafluoroethylene dry journal bearings", Wear, $230(1), 1999$, pp. 61. 
[39] Z. Z. Zhang, Q. J. Xue, W. M. Liu and W. C. Shen, "Effect of rare earth compounds as fillers on friction and wear behaviors of PTFE-based composites", Journal of Applied Polymer Science, 72(3), 1999, pp. 361.

[40] I. Bishop, "New materials extend bearing applications", Tin and Its Uses, 158, 1988, pp. 11.

[41] Z. Z. Zhang, W. C. Shen and J. Z. Zhao, "Tribological properties of several kinds of PTFE-based self-lubricating composite bearings under oil lubrication", Mocaxue Xuebao/Tribology, 13(3), 1993, pp. 228.

[42] Youichiro Hayashi, "Trends in Oil-Impregnated Sintered Metal Bearings: Mainly about Hybrid Sintered Metal Bearing Material", Japanese Journal of Tribology, Volume 42, Number 12, 1997, pp1403-1408.

[43] ASM Hand Book, Volume 7, "Powder Metal Technologies and Applications", First Printing, Dec. 1998, pp.859-873.

[44] V. Mamedov, "Microstructure and mechanical properties of PM Fe-Cu-Sn alloys containing solid lubricants", Powder Metallurgy, v. 47, n. 2, 2004, pp. 173-179.

[45] ASM Hand Book, Volume 9, "Metallography and microstructures of powder metallurgy alloys", First Printing, Dec. 2004, pp.995-1019.

[46] Sahu, Sudhari (Glendale, WI, US), United States Patent 5413756, http://www.freepatentsonline.com/5413756.html, May 1995.

[47] ASM Handbook, Volume 3, “Alloy Phase Diagrams", First Printing, Dec.1992, p. 2.178.

[48] ASM Specialty Hand Book, “Copper and Copper alloys", 2001, pp. 105-112.

[49] Specialty Hand Book, "Copper and Copper alloys", 2001, pp. 235-238.

[50] V.Sinka, C.Alves JR., and G. Janak, "Plasma sintering of Cu90Sn10 bronze", Journal of Materials Science Letters 21, 2002, pp427-429.

[51] http://www.copper.org/applications/industrial/bronze_bearing.html.

[52] A. Ono, S. Takayanagi, H. Ishikawa, and T. Tanaka (Dido Metal Co. Ltd.), "Lead-Free Bearing Material for Highly Loaded Engines", Auto Technology, Jan. 2006, pp 60-63. 
[53] I. Sato, N. Sato, United States Patent 20020142186, http://www.freepatentsonline.com/20020142186.html, Oct. 2002.

[54] http://www.mpif.org/IntroPM/intropm.asp?linkid=1.

[55] ASM Hand Book, Volume 7, "Powder Metal Technologies and Applications", First Printing, Dec. 1998, pp.3-7.

[56] ASM Hand Book, Volume 7, "Powder Metal Technologies and Applications", First Printing, Dec. 1998, pp.143-145.

[57] ASM Hand Book, Volume 7, "Powder Metal Technologies and Applications", First Printing, Dec. 1998, pp.132-142.

[58] ASM Hand Book, Volume 7, "Powder Metal Technologies and Applications", First Printing, Dec. 1998, pp.605-619.

[59] H. K. D. H. Bhadeshia, "Differential Scanning Calorimetry", lecture notes, University of Cambridge, Materials Science \& Metallurgy, http://www.msm.cam.ac.uk/phase-trans/2002/Thermal2.pdf

[60] Stephen Collins, "Differential Scanning Calorimetry", University of Durham, www.dur.ac.uk/n.r.cameron/Assets/Group\%20talks/DSC\%20presentation.ppt

[61] V.Sinka, C.Alves JR., and G. Janak, "Plasma sintering of Cu90Sn10 bronze", Journal of Materials Science Letters 21, 2002, pp427-429.

[62] G.I. Aksenov and I. A. Drozdov, "Theory and technology of sintering, Heat treatment, and Chemicothermal treatment process", Poroshkovaya Metallurgiya, No.6 (30), June 1965, pp. 5-9.

[63] C. Menapace, P. Costa, A. Molinari, "Study of the liquid phase sintering in the $\mathrm{Cu}-\mathrm{Sn}$ system by thermal analysis", Proceeding of 2004 Powder Metallurgy World Congress, ed. H.Danninger et al., European Powder Metallurgy Association, Vienna, vol.2, October 2004, pp.177-183.

[64] ASM Hand Book, Volume 7, "Powder Metal Technologies and Applications", First Printing, Dec. 1998, pp.712-713.

[65] Sartorius 6080 Specific Gravity Determination Kit User's Manual.

[66] M. Desaeger, I. Verpoest, "On the use of The Micro-Indentation test Technique to Measure the Interfacial Shear Strength of Fiber-Reinforced Polymer Composites", Composites Science and technology, 48, 1993, pp.215-226. 
[67] G. M. Pharr, W. C. Oliver, F. R. Brotzen, "On the generality of the relationship among contact stiffness, contact area, and elastic modulus during indentation", J. Mater. Res., Volume 7, No.3, Mar. 1992, pp.613-617.

[68] W.C. Oliver, and G.M. Pharr, "An Improved Technique for Determining Hardness and Elastic Modulus Using Load and Displacement Sensing Indentation Experiments", J. Mater. Res., 7, 1992, p 1564-1583.

[69] J. Musil, F. Kunc, H. Zeman, and H. Polakova, "Relationships between Hardness, Young's Modulus and Elastic Recovery in Hard Nanocomposite Coatings", Surf. Coat. Technol., 154, 2002, p 304-313.

[70] CSM Instruments, "Tribology Test Standards", Applications Bulletin, No.18, Sep. 2002, http://www.csm-instruments.com/indexold.html.

[71] ASTM E 8-03, Standard Test Methods for Tension Testing of Metallic Materials

[72] B.Joseph, F.Barbier, M. Aucouturier, "Mechanism of Liquid Bi Penetration along $\mathrm{Cu}$ Grain Boundaries, Scripta materials, No. 42, 2000, pp.1151-1158.

[73] S.Divinski, M. Lohmann, C. Herzig, "Grain-boundary Melting Phase Transition in the Cu-Bi system", Physical review, B71, 2005, pp.104104. 
Table 1.1 Compositions of Tribaloy alloys $[25,27]$

\begin{tabular}{|c|c|c|c|c|}
\hline \multirow{2}{*}{$\begin{array}{c}\text { Tribaloy } \\
\text { Alloy }\end{array}$} & \multicolumn{4}{|c|}{ Composition (wt \%) } \\
\cline { 2 - 5 } T-401 & Co & $\mathrm{Cr}$ & $\mathrm{Mo}$ & $\mathrm{Si}$ \\
\hline T-400 C & Bal. & 17 & 22 & 1.2 \\
\hline T-400 & Bal. & 14 & 26 & 2.6 \\
\hline T-800 & Bal. & 17 & 28.5 & 2.6 \\
\hline
\end{tabular}

Table 2.1 Chemical requirements (composition, wt $\%$ ) for sintered bronze bearings [2]

\begin{tabular}{lllll}
\hline \multicolumn{1}{c}{ Element } & \multicolumn{1}{c}{ Grade 1 } & \multicolumn{1}{c}{ Grade 2 } & Grade 3 & Grade 4 \\
\hline Copper & $87.2-90.5$ & $65.7-90.0$ & $82.8-68.3$ & $80.0-88.0$ \\
Tin & $9.5-10.5$ & $9.5-10.5$ & $9.2-10.2$ & $9.5-10.5$ \\
Graphite & $0-0.3$ & $0.5-1.8$ & $2.5-5.0$ & $0.50-1.75$ \\
Iron, max & 1.0 & 1.0 & 1.0 & 1.0 \\
Total other elements & 1.0 & 1.0 & 1.0 & 0.5 \\
$\quad$ by difference, max & & & & \\
Lead & & & & $2.0-4.0$ \\
Zinc, max & & & & 0.75 \\
Nickel, max & & & & 0.25 \\
Antimony, max & & & & \\
\hline
\end{tabular}

Nore-Grade 4 to be used for special government needs.

Table 2.2 Density requirements for oil impregnated sintered bronze bearings [2]

\begin{tabular}{lcc}
\hline & Type & Density, g/cm \\
\hline Grades 1 and 2 & 1 & $5.8-6.2^{4}$ \\
Grades 1,2 and 4 & 2 & $6.4-6.8$ \\
Grades 1 and 2 & 3 & $6.8-7.2$ \\
Grades 1 and 2 & 4 & $7.2-7.6$ \\
\hline
\end{tabular}

Maximum densily limit of $6.2 \mathrm{~g}^{4} \mathrm{~cm}^{3}$ has been established on Type 1 to ensure meeting an oi content of $27 \%$ minimum. Satisfactory bearings can also be produced between Type and Type 2. These bearings have slighty higher strength constants and slighty lower ofl content. 
Table 2.3 Density requirements for oil impregnated sintered bronze bearings [2]

\begin{tabular}{ccc}
\hline & Type & Densily $\mathrm{g}_{\mathrm{cm}}{ }^{3}$ \\
\hline Grade 3 & 1 & $5.8-6.2$ \\
& 2 & $6.2-6.6$ \\
\hline
\end{tabular}

Table 2.4 Oil contents (oil content, minimum vol\%) [2]

\begin{tabular}{ccccc}
\hline Typo & Grade 1 & Grade 2 & Grade 3 & Grade 4 \\
\hline 1 & 27 & 25 & $11^{4}$ & $\ldots$ \\
2 & 19 & 17 & $\ldots$ & 17 \\
3 & 12 & 9 & $\ldots$ & $\ldots$ \\
4 & 9 & 7 & $\ldots$ & $\ldots$ \\
\hline
\end{tabular}

At $3 \%$ graphite, Type 1 will contain $14 \%$ min oll content.

${ }^{B}$ At $3 \%$ graphite, Type 2 will contain $8 \%$ min oil content. At $5 \%$ graphite, Type 2 will contain only a minimal amount of oll.

Table 2.5 Etchants used for examination of PM materials [45]

\begin{tabular}{|c|c|}
\hline Etchant & Procedures and applications \\
\hline $2 \%$ nital methyl alcohol plus $2 \%$ concentrated $\mathrm{HNO}_{3}$ & $\begin{array}{l}\text { For as-sintered irons and steels (best for ferrite and low-carbon } \\
\text { steels): immersed for } 10-15 \text { s; heat treated steels: } 6-7 \mathrm{~s}\end{array}$ \\
\hline $\begin{array}{l}\text { Concentrated picral: pieric acid in methyl atcohol: some } \\
\text { undissolved erystals remain in the container bottom }\end{array}$ & $\begin{array}{l}\text { For higher earbon-containing materials to develop good } \\
\text { contrast with carbides, pearlite, other eutectoid products, } \\
\text { martensite, and retained austenite; etch by immersion, } \\
15-20 \text { s }\end{array}$ \\
\hline $\begin{array}{l}\text { Glyceregia: } 10 \mathrm{~mL} \mathrm{HNO}_{3} \text { conc, } 15 \mathrm{~mL} \mathrm{HCl}, 35 \mathrm{~mL} \\
\text { glycerol(a) }\end{array}$ & $\begin{array}{l}\text { Shows grain boundaries, twin boundaries, and catbides in } \\
\text { austenitic and martensitic stainless steel: immerse for } 1-2 \\
\text { min or swab lightly }\end{array}$ \\
\hline $4 \mathrm{FeCl}$ in $\mathrm{H}_{2} \mathrm{O}$ & $\begin{array}{l}\text { Develops red color in copper-rich regions in bronze; etch by } \\
\text { swabbing. } 10-20 \text { s }\end{array}$ \\
\hline $2 \mathrm{~g} \mathrm{~K}_{2} \mathrm{Cr}_{2} \mathrm{O}_{7}, 4 \mathrm{~mL} \mathrm{NuCl}, 8 \mathrm{~mL} \mathrm{H} \mathrm{H}_{2} \mathrm{SO}_{4} 100 \mathrm{~mL} \mathrm{H}_{2} \mathrm{O}$ & $\begin{array}{l}\text { Develops grain boundaries and small grain clusters in bronze; } \\
\text { etch by swabbing. } 10-20 \mathrm{~s}\end{array}$ \\
\hline $\begin{array}{l}\text { Keller's reagent: } 2.5 \mathrm{~mL} \mathrm{HNO}_{3}, 1.5 \mathrm{~mL} \mathrm{HCl}, 10 \mathrm{~mL} \mathrm{HF} \\
95 \mathrm{~mL} \mathrm{H}_{2} \mathrm{O}\end{array}$ & $\begin{array}{l}\text { For aluminum and aluminum alloys: inmerse } 8 / 15 \mathrm{~s} \text {, wash in } \\
\text { water: do not remove etchant products from surface }\end{array}$ \\
\hline 58 nital & For as-sintered tool steels; immerse $5 \mathrm{~min}$ \\
\hline $5 \mathrm{~mL} \mathrm{HNO}_{3}$ conc. $10 \mathrm{~mL} 48 \% \mathrm{HF}, 85 \mathrm{~mL} \mathrm{H}_{2} \mathrm{O}$ & For titanium and titanium alloys; immerse $5 \mathrm{~s}$ \\
\hline 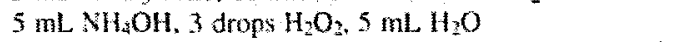 & For brasses; swab $20 \mathrm{~s}$; make fresh solution every $20 \mathrm{~min}$ \\
\hline $\begin{array}{l}450 \mathrm{~mL} \mathrm{H}_{2} \mathrm{O} .25 \mathrm{~mL} \mathrm{H}_{2} \mathrm{SO}_{3}, 25 \mathrm{~mL} \mathrm{HNO}, 25 \mathrm{~g} \text { chromic } \\
\text { oxide. } 4 \mathrm{~g} \mathrm{NH}_{4} \mathrm{Cl}\end{array}$ & $\begin{array}{l}\text { For bronzes not etching cletrly in the above } \mathrm{K}_{2} \mathrm{Cr}_{2} \mathrm{O}_{7} \text {. Just } \\
\text { before use, mix a few mL. of this etehant with equal amount } \\
\text { of } 3 \% \mathrm{H}_{2} \mathrm{O}_{2} \text { and swab for } 10 \mathrm{~s}\end{array}$ \\
\hline
\end{tabular}


Table 2.6 Mechanical properties of sintered bronze bearings [46]

\begin{tabular}{|c|c|c|c|c|c|c|c|c|c|}
\hline \multirow[b]{2}{*}{$\begin{array}{l}\text { Alloy } \\
\text { ID }\end{array}$} & \multicolumn{4}{|c|}{ Composition (wt\%) } & \multirow[b]{2}{*}{ Remark } & \multirow{2}{*}{$\begin{array}{c}\text { Tensile } \\
\text { Strength } \\
\text { (psi) }\end{array}$} & \multirow{2}{*}{$\begin{array}{l}\text { Yield } \\
\text { Strength } \\
\text { (psi) }\end{array}$} & \multirow{2}{*}{$\begin{array}{c}\text { Elongation } \\
\text { in } 2 " \\
(\%)\end{array}$} & \multirow[b]{2}{*}{$\begin{array}{c}\text { Hardness } \\
(\mathrm{BHN})\end{array}$} \\
\hline & $\mathrm{Cu}$ & Sn & $\mathrm{Pb}$ & $\mathrm{Zn}$ & & & & & \\
\hline C 932 & 83 & 7 & 7 & 3 & $\begin{array}{l}\text { leaded } \\
\text { bronze } \\
\text { leaded }\end{array}$ & 35000 & 18000 & 20.0 & 65 \\
\hline C 936 & 90 & 7 & 12 & 1 & bronze & 35000 & 21000 & 15.0 & 65 \\
\hline C 903 & 88 & 8 & 0 & 4 & $\begin{array}{c}\text { lead-free } \\
\text { bronze }\end{array}$ & 45000 & 21000 & 30.0 & 70 \\
\hline
\end{tabular}

Table 2.7 Effect of copper powder oxide thickness on the strength of press-and-sintered compacts [49]

\begin{tabular}{lcr}
\multirow{2}{*}{$\begin{array}{l}\text { Thickness of oxtde } \\
\text { nlm on powder, nm }\end{array}$} & \multicolumn{2}{c}{$\begin{array}{c}\text { Tensile strength of } \\
\text { sintered compac(a) }\end{array}$} \\
\cline { 2 - 3 } Coarse copper powder & MPa & ksi \\
0 & & \\
40 & 29 & 4.2 \\
80 & 51 & 7.4 \\
120 & 38 & 5.5 \\
160 & 21.5 & 3.1 \\
200 & 15.7 & 2.2 \\
Fine copper powder & 7.8 & 1.1 \\
0 & & \\
20 & 120 & 17.4 \\
60 & 130 & 18.8 \\
100 & 143 & 20.7 \\
140 & 137 & 19.8 \\
180 & 129 & 18.7 \\
220 & 122 & 17.7 \\
& 114 & 16.5
\end{tabular}

(a) Pressed at $414 \mathrm{MPa}\left(30\right.$ isi), sintered at $600^{\circ} \mathrm{C}\left(1110^{\circ} \mathrm{F}\right)$ for $1 / 2 \mathrm{~h} \mathrm{in}$ $\mathrm{H}_{2}$, Source: Ref 13

Table 2.8 Nano mechanical properties of Tribaloy alloys [27]

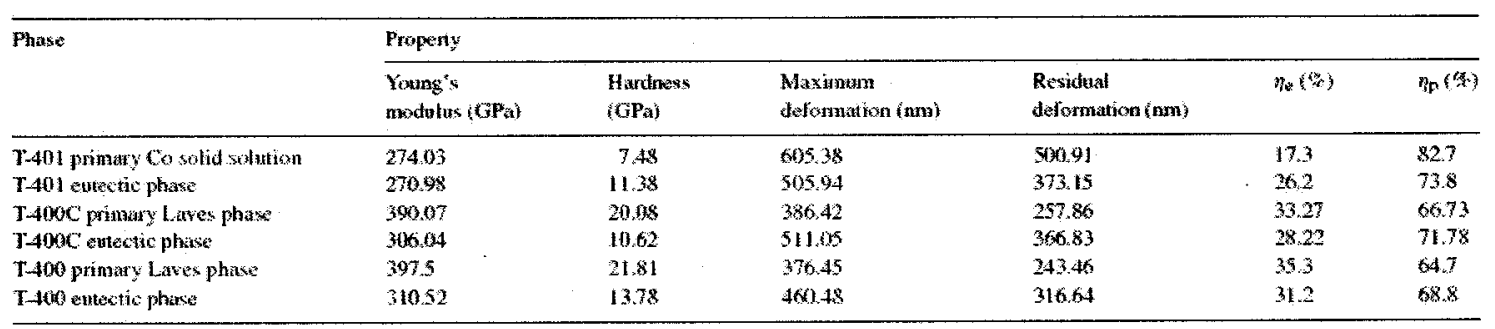


Table 2.9 Major historical development in powder metallurgy [55]

\begin{tabular}{|c|c|c|}
\hline Date & Dexolopment & Origin \\
\hline $3000 \mathrm{nc}$. & "Sponge iron" for making tools & Egypt, Africa, India \\
\hline A.D. 1200 & Cementing platinum grains & South America (Incas) \\
\hline 1781 & Fusible platinum-arsenic alloy & France, Germany \\
\hline 1790 & Production of platinum-arsenic chemical vessels commercially & France \\
\hline 1822 & Platinum powder formed into solid ingot & France \\
\hline 1826 & High-temperature sintering of platinum powder compacts on aconmercial basis & Russia \\
\hline 1829 & $\begin{array}{l}\text { Wollaston nethod of producing compact platimum from platinum sponge (basis of } \\
\text { modern P/M technique) }\end{array}$ & England \\
\hline 1830 & Sintering compacts of various metals & Europe \\
\hline 1859 & Platinum fusion process & \\
\hline 1870 & $\begin{array}{l}\text { Patent for bearing materials made from metal powders (forenuner of self-lubricating } \\
\text { bearings) }\end{array}$ & United Stales \\
\hline $1878-1900$ & Incandescent lamp fitaments & United States \\
\hline $1915-1930$ & Cemented carbides & Germany \\
\hline \multirow[t]{2}{*}{ Early 1900 s } & Composite metals & Unitod Stntes \\
\hline & Porous metals and metallic filters & United States \\
\hline $1920 \mathrm{~s}$ & Self-lubricating bearings (used comnercially) & United States \\
\hline $1940 \mathrm{~s}$ & Iron powder texhnology & Central Europe \\
\hline 1950 s and $1960 \mathrm{~s}$ & $\mathrm{P} / \mathrm{M}$ wrought and dispersion-strengthened products, including $\mathrm{P} / \mathrm{M}$ forgings & Unuted States \\
\hline $1970 \mathrm{~s}$ & Hot isastatic pressing, P/M tool steels, and superplastic superalloys & United States \\
\hline $1980 \mathrm{~s}$ & Rapid solidification and powder injection molding technology & United States \\
\hline $1990 \mathrm{~s}$ & $\begin{array}{l}\text { Intermetallies, metal-marix composites, spray foming, nanoscale powders, and wam } \\
\text { compaction }\end{array}$ & Unifed States, England \\
\hline
\end{tabular}

Table 2.10 Physical properties of typical bronze alloy [56]

\begin{tabular}{lc}
\hline Property & Bronze \\
\hline Sieve analysis, \% & \\
+100 mesh & $2.0 \mathrm{max}$ \\
$-100+200$ & $15-35$ \\
$-200+325$ & $15-35$ \\
-325 & $60 \mathrm{max}$ \\
Physical properties & \\
Apparent density & $3.3-3.5$ \\
& \\
Mechanical properties & \\
Cornpressibility(c) at 414 MPa & 7.4 \\
(300 tsi). g/cm & \\
Green strength(c) at $414 \mathrm{MPa}$ & $10-12(1500-1700)$ \\
(300 tsi), MPa (psi)
\end{tabular}


Table 3.1 Powder compositions of the developed materials

\begin{tabular}{|c|c|c|c|c|c|c|c|}
\hline \multirow{3}{*}{$\begin{array}{c}\text { Group } \\
\text { No. }\end{array}$} & $\begin{array}{c}\text { Specimen } \\
\text { ID }\end{array}$ & \multicolumn{7}{|c|}{ Composition (wt\%) } & \multirow{2}{*}{$\begin{array}{c}\text { Bronze } \\
\text { Type }\end{array}$} \\
\hline \multirow{4}{*}{1} & MG-1 & 0 & 0 & 0 & Bal. & 0 & Premixed \\
\cline { 2 - 9 } & 7 & 10 & 0 & 0 & Bal. & 0 & Premixed \\
\cline { 2 - 9 } & 8 & 15 & 0 & 0 & Bal. & 0 & Premixed \\
\cline { 2 - 9 } & 9 & 20 & 0 & 0 & Bal. & 0 & Premixed \\
\cline { 2 - 9 } & 13 & 0 & 15 & 0 & Bal. & 0 & Premixed \\
\cline { 2 - 9 } & 14 & 0 & 20 & 0 & Bal. & 0 & Premixed \\
\hline \multirow{3}{*}{2} & B-409 & 0 & 0 & 0 & Bal. & 0 & Prealloyed \\
\cline { 2 - 9 } & 10 & 10 & 0 & 0 & Bal. & 0 & Prealloyed \\
\cline { 2 - 9 } & 11 & 15 & 0 & 0 & Bal. & 0 & Prealloyed \\
\cline { 2 - 9 } & 12 & 20 & 0 & 0 & Bal. & 0 & Prealloyed \\
\hline \multirow{3}{*}{3} & 6 & 0 & 0 & 15 & 0 & Bal. & N/A \\
\cline { 2 - 9 } & 16 & 10 & 0 & 15 & 0 & Bal. & N/A \\
\cline { 2 - 9 } & 17 & 15 & 0 & 15 & 0 & Bal. & N/A \\
\cline { 2 - 9 } & 18 & 20 & 0 & 15 & 0 & Bal. & N/A \\
\hline
\end{tabular}

Table 3.2 DSC results

\begin{tabular}{|c|c|c|c|c|}
\hline $\begin{array}{l}\text { Specimen } \\
\text { ID }\end{array}$ & $\begin{array}{c}\text { Ultimate } \\
\text { Test Temperature } \\
\left({ }^{\circ} \mathrm{C}\right)\end{array}$ & $\begin{array}{l}\text { Transition } \\
\text { Temperature } \\
\left({ }^{\circ} \mathrm{C}\right)\end{array}$ & $\begin{array}{c}\text { Material } \\
\text { Transition Type }\end{array}$ & $\begin{array}{c}\text { Figure } \\
\text { No. }\end{array}$ \\
\hline \multirow{5}{*}{ MG1 } & \multirow{5}{*}{1100} & 233.2 & Sn melting & \multirow{5}{*}{3.7 (a) } \\
\hline & & 800 & solidus temperature of bronze formation & \\
\hline & & 1017 & liquidus temperature of bronze formation & \\
\hline & & $400-600$ & $\eta \rightarrow \varepsilon+$ liquid & \\
\hline & & $400-600$ & $\gamma$ phase formation & \\
\hline \multirow{5}{*}{7} & \multirow{5}{*}{1300} & 233.4 & Sn melting & \multirow{5}{*}{3.7 (b) } \\
\hline & & 800 & solidus temperature of bronze formation & \\
\hline & & 1017 & liquidus temperature of bronze formation & \\
\hline & & $400-600$ & $\eta \rightarrow \varepsilon+$ liquid & \\
\hline & & $400-600$ & $\gamma$ phase formation & \\
\hline \multirow{4}{*}{ MG1 } & \multirow{4}{*}{870} & 234 & Sn melting & \multirow{4}{*}{$3.7(\mathrm{c})$} \\
\hline & & 800 & solidus temperature of bronze formation & \\
\hline & & $400-600$ & $\eta \rightarrow \varepsilon+$ liquid & \\
\hline & & $400-600$ & $\gamma$ phase formation & \\
\hline \multirow{6}{*}{9} & \multirow{6}{*}{1500} & 236 & Sn melting & \multirow{6}{*}{$3.7(d)$} \\
\hline & & 800 & solidus temperature of bronze formation & \\
\hline & & 1027.1 & liquidus temperature of bronze formation & \\
\hline & & 1283.6 & solid to liquid transformation of T-401 & \\
\hline & & $400-600$ & $\eta \rightarrow \varepsilon+$ liquid & \\
\hline & & $400-600$ & $\gamma$ phase formation & \\
\hline \multirow{3}{*}{12} & \multirow{3}{*}{1400} & 836 & solidus temperature of bronze formation & \multirow{3}{*}{3.8} \\
\hline & & 1028.9 & liquidus temperature of bronze formation & \\
\hline & & 1290.5 & solid to liquid transformation of $\mathrm{T}-401$ & \\
\hline 18 & 870 & 281.4 & bismuth melting & 3.9 \\
\hline
\end{tabular}


Table 4.1 EDX data of composition analyses of copper-15\% bismuth specimen

\begin{tabular}{|c|c|}
\hline Grain Boundary Composition Analysis & Entire Microstructure Composition Analysis \\
\hline Detector window: Beryllium & Detector window: Beryllium \\
\hline Accelerating voltage: 20 & Accelerating voltage: 20 \\
\hline Tilt: 20 & Tilt: 20 \\
\hline Elevation: 10 & Elevation: 10 \\
\hline Azimuth: 13 & Azimuth: 13 \\
\hline Test 1 & Test 1 \\
\hline Element wt $\%$ atom $\%$ ZAF factor 3 sigma & Element wt $\%$ atom $\%$ ZAF factor 3 sigma \\
\hline 50.53 & $94.11 \quad 98.14$ \\
\hline $49.46 \quad 22.94$ & $0.42 \quad 1.05$ \\
\hline Total 99.99 & Total 99.99 \\
\hline Test 2 & Test 2 \\
\hline Element $w t \%$ atom $\%$ ZAF factor 3 sigma & Element $w t \%$ atom $\%$ ZAF factor 3 sigma \\
\hline $24.16 \quad 51.17$ & 98.11 \\
\hline $75.84 \quad 48.83$ & 0.42 \\
\hline Total 100.00 & Total 99.99 \\
\hline Test 3 & Test 3 \\
\hline Element wt $\%$ atom $\%$ ZAF factor 3 sigma & Element $w t \%$ atom $\%$ ZAF factor 3 sigma \\
\hline $\begin{array}{lllll}\mathrm{Cu} & 99.54 & 99.87 & 0.74 & 1.93 \\
\end{array}$ & $\begin{array}{lllll}\mathrm{Cu} & 92.01 & 97.43 & 0.75 & 1.74 \\
\end{array}$ \\
\hline 0.13 & 2.57 \\
\hline Total 99.98 & Total 99.99 \\
\hline Test 4 & Test 4 \\
\hline Element $w t \%$ atom $\%$ ZAF factor 3 sigma & Element wt $\%$ atom $\%$ ZAF factor 3 sigma \\
\hline $0.74 \quad 1.717$ & 98.29 \\
\hline $\begin{array}{lll}0.21 & 0.41 & 0.34\end{array}$ & $\begin{array}{rrr}5.40 & 1.71 & 0.42 \\
\end{array}$ \\
\hline Total 99.98 & Total 99.99 \\
\hline
\end{tabular}

Table 4.2 Density test results

\begin{tabular}{|c|c|c|c|c|c|c|c|}
\hline \multirow{2}{*}{$\begin{array}{c}\text { Specimen } \\
\text { ID }\end{array}$} & T-401 & T-400C & Bi & Bronze & Cu & $\begin{array}{c}\text { Bronze } \\
\text { Type }\end{array}$ & $\begin{array}{c}\text { Density } \\
\left(\mathrm{g} / \mathrm{cm}^{\wedge} 3\right)\end{array}$ \\
\hline MG-1 & 0 & 0 & 0 & Bal. & 0 & Premixed & 7.0096 \\
\hline 8 -H & 15 & 0 & 0 & Bal. & 0 & Premixed & 7.6885 \\
\hline B-409 & 0 & 0 & 0 & Bal. & 0 & Prealloyed & 8.1618 \\
\hline 11-H & 15 & 0 & 0 & Bal. & 0 & Prealloyed & 8.5172 \\
\hline
\end{tabular}


Table 4.3 Hardness test results

\begin{tabular}{|c|c|c|c|c|c|c|c|c|}
\hline \multirow{2}{*}{$\begin{array}{c}\text { Specimen } \\
\text { ID }\end{array}$} & \multicolumn{7}{|c|}{ Composition (wt\%) } & \multicolumn{2}{c|}{$\begin{array}{c}\text { Bronze } \\
\text { Type }\end{array}$} & \multicolumn{2}{c|}{$\begin{array}{c}\text { Average } \\
\text { Hardness }\end{array}$} & \multirow{2}{*}{ Scale } \\
\cline { 2 - 6 } & T-401 & T-400C & $\mathrm{Bi}$ & Bronze & Cu & \multicolumn{1}{c|}{} & \\
\hline MG-1 & 0 & 0 & 0 & Bal. & 0 & Premixed & 78.3 & HRH \\
\hline 7 & 10 & 0 & 0 & Bal. & 0 & Premixed & 50.2 & HRB \\
\hline 8 & 15 & 0 & 0 & Bal. & 0 & Premixed & 64.6 & HRB \\
\hline 9 & 20 & 0 & 0 & Bal. & 0 & Premixed & 63.8 & HRB \\
\hline 13 & 0 & 15 & 0 & Bal. & 0 & Premixed & 72.0 & HRB \\
\hline 14 & 0 & 20 & 0 & Bal. & 0 & Premixed & 77.1 & HRB \\
\hline B-409 & 0 & 0 & 0 & Bal. & 0 & Prealloyed & 43.5 & HRB \\
\hline 10 & 10 & 0 & 0 & Bal. & 0 & Prealloyed & 78.8 & HRB \\
\hline 11 & 15 & 0 & 0 & Bal. & 0 & Prealloyed & 77.9 & HRB \\
\hline 12 & 20 & 0 & 0 & Bal. & 0 & Prealloyed & 81.7 & HRB \\
\hline 6 & 0 & 0 & 15 & 0 & Bal. & N/A & 72.0 & HRH \\
\hline 16 & 10 & 0 & 15 & 0 & Bal. & N/A & 93.6 & HRH \\
\hline 17 & 15 & 0 & 15 & 0 & Bal. & N/A & 93.6 & HRH \\
\hline 18 & 20 & 0 & 15 & 0 & Bal. & N/A & 94.9 & HRH \\
\hline
\end{tabular}

Table 4.4 Nano indentation test results

\begin{tabular}{|c|c|c|c|c|c|c|}
\hline $\begin{array}{l}\text { Specimen } \\
\text { ID }\end{array}$ & $\begin{array}{c}\text { Hardness } \\
(\mathrm{GPa})\end{array}$ & $\begin{array}{l}\text { Young's } \\
\text { Modulus } \\
\text { (GPa) }\end{array}$ & $\begin{array}{c}\text { Max. } \\
\text { Deformation } \\
\text { in Loading } \\
(\mathrm{nm})\end{array}$ & $\begin{array}{c}\text { Max. } \\
\text { Deformation } \\
\text { in Unloading } \\
(\mathrm{nm})\end{array}$ & \begin{tabular}{|c} 
Plastic \\
Deformation \\
$(\%)$
\end{tabular} & $\begin{array}{c}\text { Elastic } \\
\text { Deformation } \\
(\%)\end{array}$ \\
\hline MG1 & 1.53 & 95.85 & 1291.67 & 1183.89 & 91.66 & 8.34 \\
\hline 7 - Matrix & 1.42 & 107.35 & 1360.43 & 1253.31 & 92.13 & 7.87 \\
\hline 7 -Particle & 12.19 & 233.00 & 503.65 & 348.77 & 69.25 & 30.75 \\
\hline 8 - Matrix & 1.43 & 94.29 & 1371.49 & 1258.59 & 91.77 & 8.23 \\
\hline 8 - Particle & 10.72 & 227.42 & 531.07 & 384.54 & 72.41 & 27.59 \\
\hline 13-Matrix & 1.92 & 115.55 & 1158.09 & 1051.16 & 90.77 & 9.23 \\
\hline 13 - Particle & 13.03 & 253.47 & 486.18 & 336.70 & 69.25 & 30.75 \\
\hline B409 & 1.50 & 106.67 & 1298.04 & 1196.25 & 92.16 & 7.84 \\
\hline 11 - Matrix & 2.39 & 111.38 & 1052.01 & 932.26 & 88.62 & 11.38 \\
\hline 11 - Particle & 12.18 & 222.64 & 504.11 & 347.74 & 68.98 & 31.02 \\
\hline 17 - Matrix & 1.40 & 111.83 & 1451.38 & 1253.64 & 86.38 & 13.62 \\
\hline 17-Particle & 13.19 & 228.06 & 487.64 & 331.37 & 67.95 & 32.05 \\
\hline $\begin{array}{l}17 \text { - Matrix } \\
\text { (near the crack) }\end{array}$ & 1.16 & 106.21 & 1461.42 & 1380.45 & 94.46 & 5.54 \\
\hline $\begin{array}{l}17 \text { - Particle } \\
\text { (near the crack) }\end{array}$ & 11.04 & 252.30 & 516.38 & 374.71 & 72.57 & 27.43 \\
\hline
\end{tabular}


Table 4.5 Wear test results

\begin{tabular}{|c|c|c|c|c|c|c|c|c|c|}
\hline \multirow[b]{3}{*}{$\begin{array}{l}\text { Specimen } \\
\text { ID }\end{array}$} & \multirow{2}{*}{\multicolumn{5}{|c|}{ Composition (wt\%) }} & \multirow[b]{3}{*}{$\begin{array}{c}\text { Bronze } \\
\text { Type }\end{array}$} & \multicolumn{3}{|c|}{ Wear Test } \\
\hline & & & & & & & \multirow{2}{*}{$\begin{array}{c}\text { Average } \\
\text { Wear Track } \\
\text { Width } \\
(\mathrm{mm})\end{array}$} & \multirow{2}{*}{$\begin{array}{c}\text { Volume } \\
\text { Loss } \\
\left(\mathrm{mm}^{\wedge} 3\right)\end{array}$} & \multirow[b]{2}{*}{$\begin{array}{c}\text { Friction } \\
\text { Coefficient }\end{array}$} \\
\hline & $\mathrm{T}-401$ & $\mathrm{~T}-400 \mathrm{C}$ & $\mathrm{Bi}$ & Bronze & $\mathrm{Cu}$ & & & & \\
\hline MG-1 & 0 & 0 & 0 & Bal. & 0 & Premixed & 0.444 & 0.062 & 0.809 \\
\hline 7 & 10 & 0 & 0 & Bal. & 0 & Premixed & 0.384 & 0.040 & 0.960 \\
\hline 8 & 15 & 0 & 0 & Bal. & 0 & Premixed & 0.352 & 0.031 & 0.678 \\
\hline 9 & 20 & 0 & 0 & Bal. & 0 & Premixed & 0.304 & 0.020 & 0.783 \\
\hline 13 & 0 & 15 & 0 & Bal. & 0 & Premixed & 0.510 & 0.093 & 0.965 \\
\hline 14 & 0 & 20 & 0 & Bal. & 0 & Premixed & 0.430 & 0.056 & 0.889 \\
\hline B-409 & 0 & 0 & 0 & Bal. & 0 & Prealloyed & 0.426 & 0.054 & 0.844 \\
\hline 10 & 10 & 0 & 0 & Bal. & 0 & Prealloyed & 0.371 & 0.036 & 0.653 \\
\hline 11 & 15 & 0 & 0 & Bal. & 0 & Prealloyed & 0.359 & 0.033 & 0.814 \\
\hline 12 & 20 & 0 & 0 & Bal. & 0 & Prealloyed & 0.342 & 0.028 & 0.658 \\
\hline 6 & 0 & 0 & 15 & 0 & Bal. & N/A & 2.000 & 5.905 & 0.265 \\
\hline 16 & 10 & 0 & 15 & 0 & Bal. & N/A & 0.578 & 0.136 & 0.592 \\
\hline 17 & 15 & 0 & 15 & 0 & Bal. & N/A & 0.519 & 0.098 & 0.643 \\
\hline 18 & 20 & 0 & 15 & 0 & Bal. & N/A & 0.524 & 0.101 & 0.683 \\
\hline
\end{tabular}

Table 4.6 Tensile test results

\begin{tabular}{|c|c|c|c|c|c|c|c|c|c|}
\hline \multirow[b]{2}{*}{$\begin{array}{l}\text { Specimen } \\
\text { ID }\end{array}$} & \multicolumn{5}{|c|}{ Composition (wt $\%$ ) } & \multirow[b]{2}{*}{$\begin{array}{l}\text { Bronze } \\
\text { Type }\end{array}$} & \multicolumn{3}{|c|}{ Tensile Test } \\
\hline & $T-401$ & $\mathrm{~T}-400 \mathrm{C}$ & $\mathbf{B i}$ & Bronze & $\mathrm{Cu}$ & & $\begin{array}{c}\text { Yield } \\
\text { Strength } \\
\text { (MPa) } \\
0.2 \%\end{array}$ & $\begin{array}{l}\text { Ultimate } \\
\text { Tensile } \\
\text { Strength } \\
\text { (MPa) }\end{array}$ & $\begin{array}{c}\text { Elongation } \\
(\%)\end{array}$ \\
\hline MG-1 & 0 & 0 & 0 & Bal. & 0 & Premixed & 170 & 206.77 & 2.02 \\
\hline 7 & 10 & 0 & 0 & Bal. & 0 & Premixed & 230 & 243.71 & 0.60 \\
\hline 8 & 15 & 0 & 0 & Bal. & 0 & Premixed & 280 & 331.56 & 0.94 \\
\hline 13 & 0 & 15 & 0 & Bal. & 0 & Premixed & 230 & 265.04 & 0.77 \\
\hline 14 & 0 & 20 & 0 & Bal. & 0 & Premixed & 245 & 301.90 & 1.01 \\
\hline B-409 & 0 & 0 & 0 & Bal. & 0 & Prealloyed & 215 & 297.77 & 7.07 \\
\hline 10 & 10 & 0 & 0 & Bal. & 0 & Prealloyed & 300 & 356.15 & 1.67 \\
\hline 11 & 15 & 0 & 0 & Bal. & 0 & Prealloyed & 315 & 365.58 & 1.44 \\
\hline 12 & 20 & 0 & 0 & Bal. & 0 & Prealloyed & 300 & 394.13 & 1.97 \\
\hline 6 & 0 & 0 & 15 & 0 & Bal. & n.a & $\mathbf{n} / \mathbf{a}$ & 41.98 & 0.05 \\
\hline 16 & 10 & 0 & 15 & 0 & Bal. & $\mathrm{n} / \mathbf{a}$ & $\mathbf{n} / \mathbf{a}$ & 95.74 & 0.13 \\
\hline
\end{tabular}


Table 4.7 Nano indentation test results for an industrial sintered bronze bearing in comparison with specimens MG1 and B-409

\begin{tabular}{|l|r|r|c|c|c|c|}
\hline $\begin{array}{c}\text { Specimen } \\
\text { ID }\end{array}$ & $\begin{array}{c}\text { Hardness } \\
(\mathrm{GPa})\end{array}$ & $\begin{array}{c}\text { Young's } \\
\text { Modulus } \\
(\mathrm{GPa})\end{array}$ & $\begin{array}{c}\text { Max. } \\
\text { Deformation } \\
\text { in Loading } \\
(\mathrm{nm})\end{array}$ & $\begin{array}{c}\text { Max. } \\
\text { Deformation } \\
\text { in Unloading } \\
(\mathrm{nm})\end{array}$ & $\begin{array}{c}\text { Plastic } \\
\text { Deformation } \\
(\%)\end{array}$ & $\begin{array}{c}\text { Elastic } \\
\text { Deformation } \\
(\%)\end{array}$ \\
\hline Sava* & 2.03 & 66.34 & 1170.15 & 1004.33 & 85.83 & 14.17 \\
\hline MG1 & 1.53 & 95.85 & 1291.67 & 1183.89 & 91.66 & 8.34 \\
\hline B409 & 1.50 & 106.67 & 1298.04 & 1196.25 & 92.16 & 7.84 \\
\hline
\end{tabular}

* Sava specimen is an industrial bronze bearing without lead.

Table 4.8 Wear test results for an industrial sintered bronze bearing in comparison with specimens MG1 and B-409

\begin{tabular}{|c|c|c|c|c|c|c|c|c|c|}
\hline \multirow[b]{2}{*}{$\begin{array}{c}\text { Speciemn } \\
\text { ID }\end{array}$} & \multicolumn{5}{|c|}{ Composition $(\mathrm{wt} \%)$} & \multirow[b]{2}{*}{$\begin{array}{c}\text { Bronze } \\
\text { Type }\end{array}$} & \multicolumn{3}{|c|}{ Wear Test } \\
\hline & $\mathrm{T}-401$ & $\mathrm{~T}-400 \mathrm{C}$ & $\mathrm{Bi}$ & Bronze & $\mathrm{Cu}$ & & $\begin{array}{l}\text { Track } \\
\text { Width } \\
(\mathrm{mm})\end{array}$ & $\begin{array}{c}\text { Volume } \\
\text { Loss } \\
\text { (mm3) }\end{array}$ & $\begin{array}{c}\text { Friction } \\
\text { Coefficient }\end{array}$ \\
\hline Sava* & 0 & 0 & 0 & Bal. & 0 & Premixed & 0.460 & 0.068 & 0.189 \\
\hline MG-1 & 0 & 0 & 0 & Bal. & 0 & Premixed & 0.444 & 0.062 & 0.809 \\
\hline B-409 & 0 & 0 & 0 & Bal. & 0 & Prealloyed & 0.426 & 0.054 & 0.844 \\
\hline
\end{tabular}




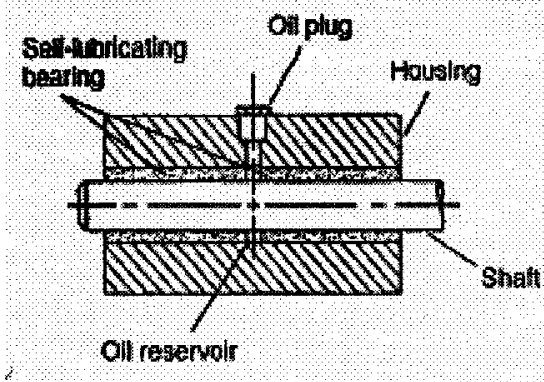

(a)

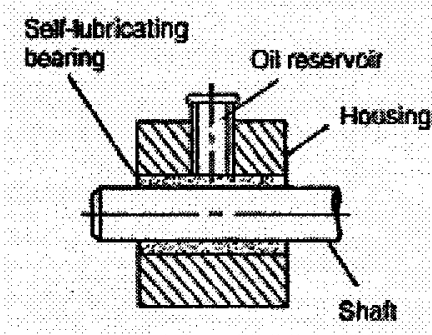

(c)

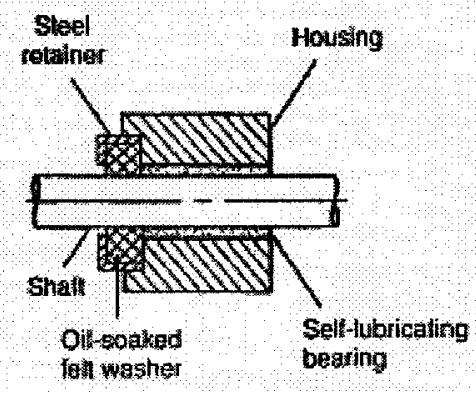

(6)

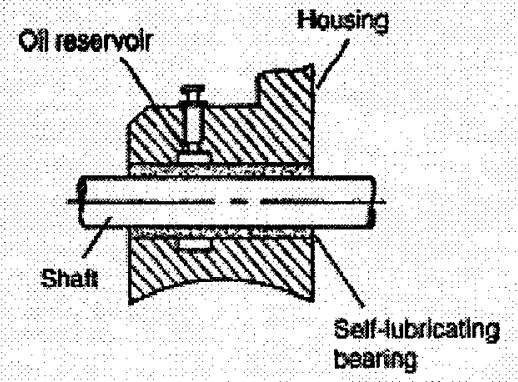

(b)

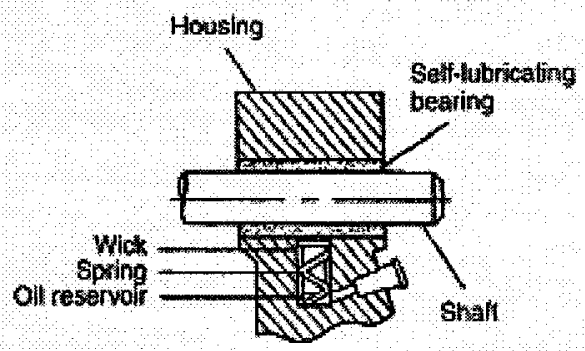

(d)

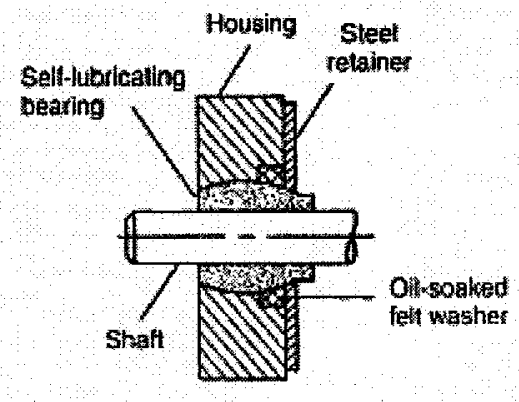

(f)

Figure 1.1 Supplementary lubrication of porous bearings: (a) oil reservoir created in the space between two bearing ends, (b) oil reservoir around bearing, (c) oil reservoir above bearing, (d) oil reservoir below bearing, (e) oil-soaked felt washer to provide additional lubrication, (f) oil-soaked felt washer with self-aligning bearing [1] 


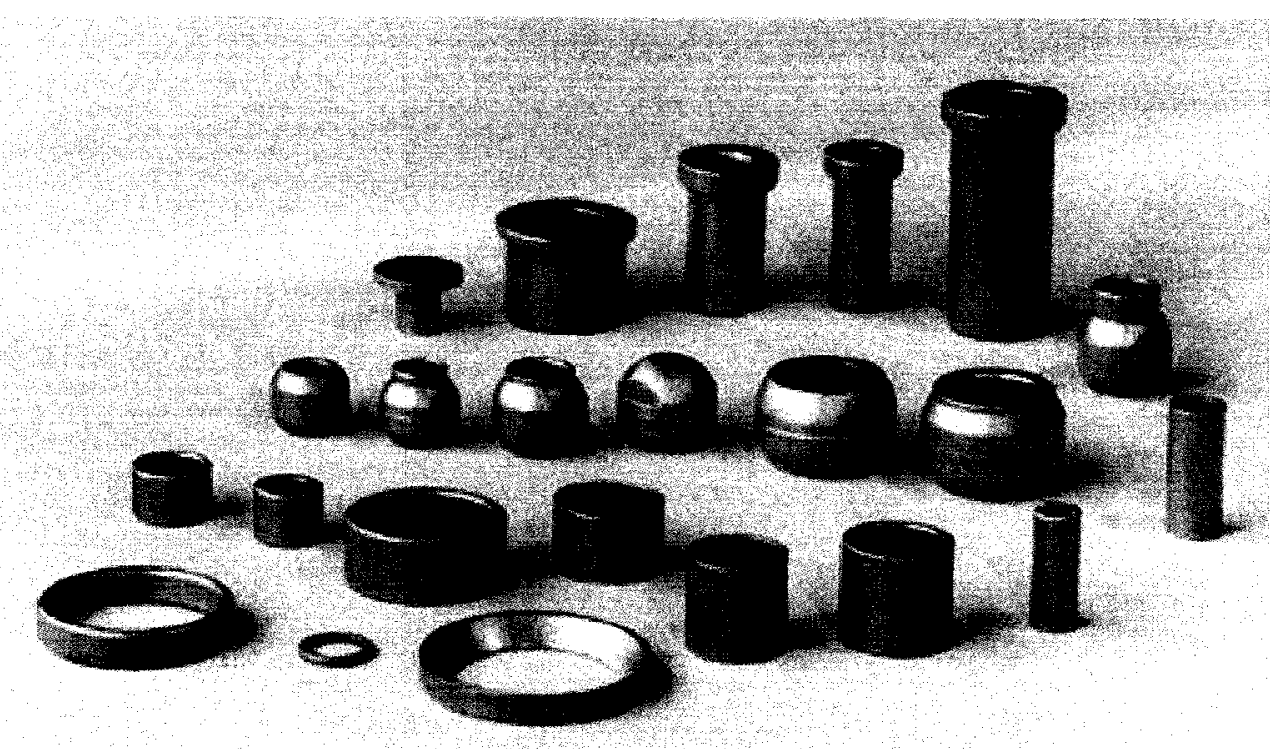

Figure 1.2 Typical self-lubricating bronze bearings

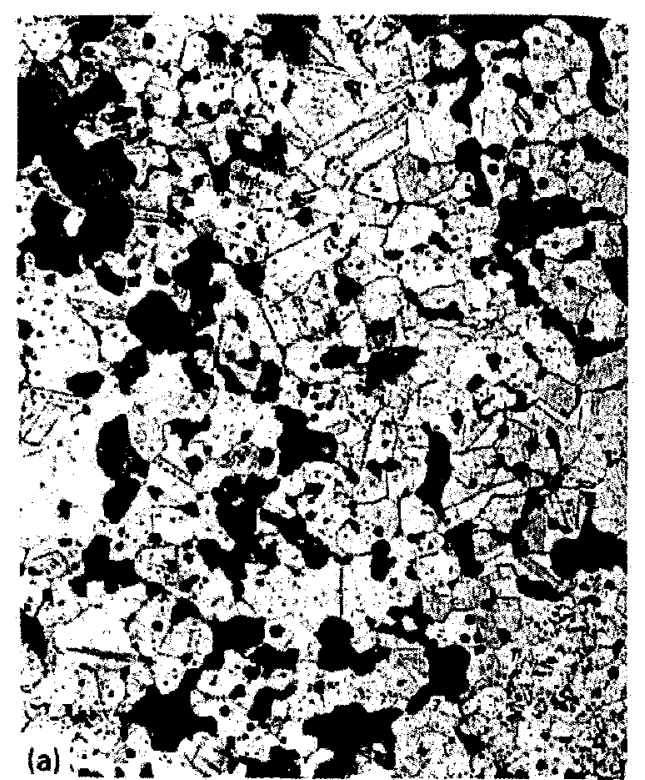

(a)

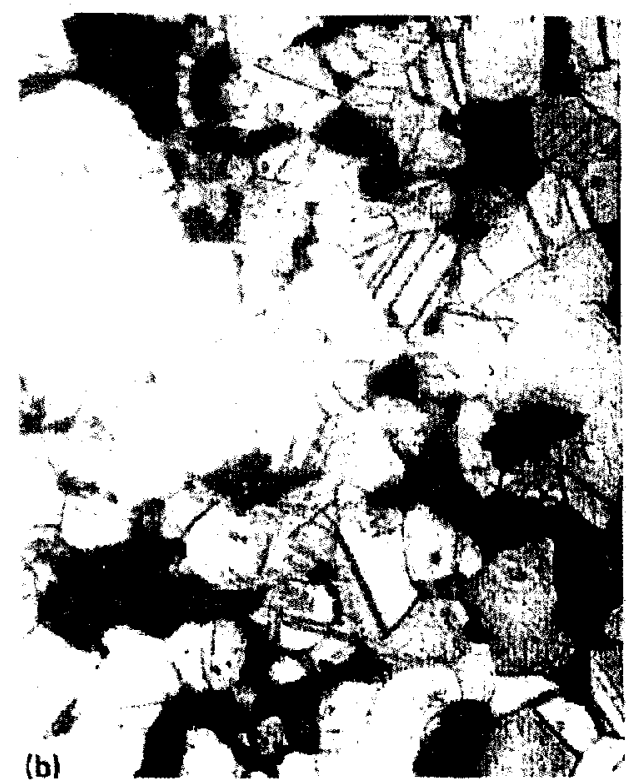

(b)

Figure 2.1 Alpha bronze microstructure in 90\%Cu-10\% Sn PM bearing alloy: (a) Low magnification, (b) High magnification [1] 


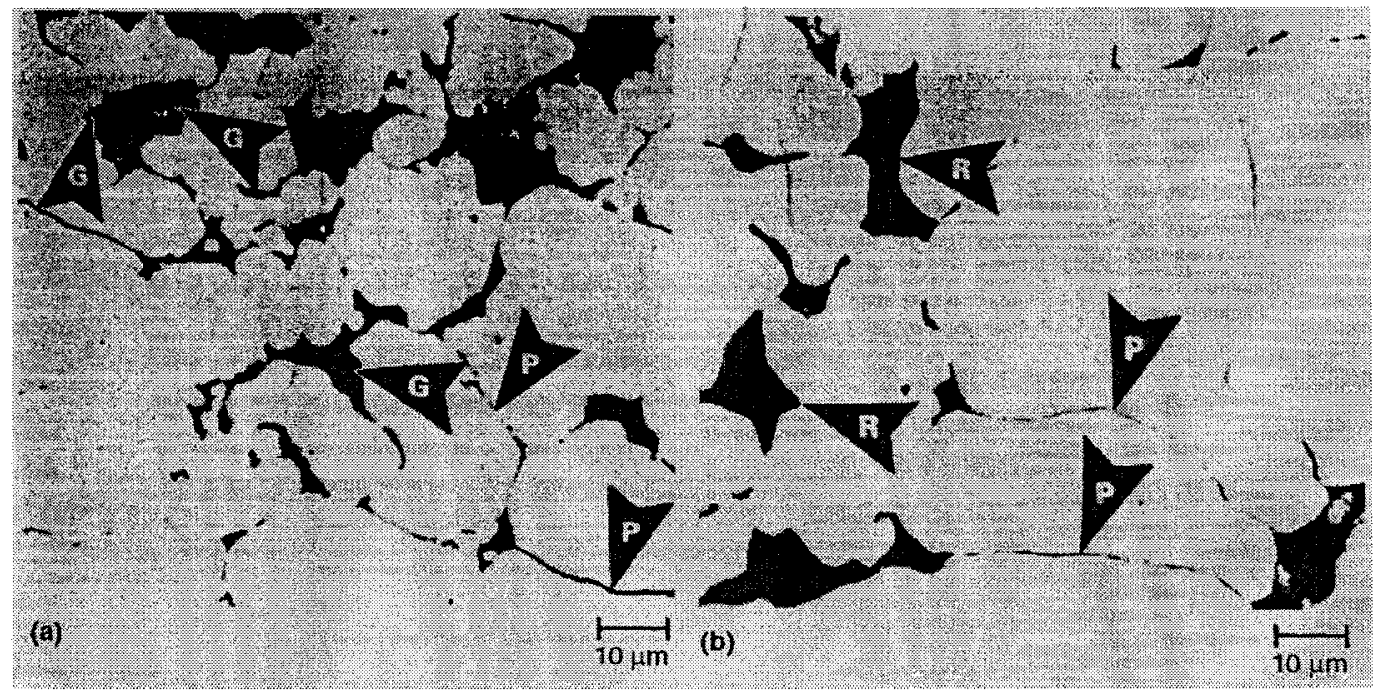

Figure 2.2 Distribution of original particle boundaries in undersintered specimens from a diffusion-alloyed steel $\left(6.7 \mathrm{~g} / \mathrm{cm}^{3}\right)$, pressed at $480 \mathrm{MPa}$ and sintered in dissociated ammonia in hot zone at $1120^{\circ} \mathrm{C}$ : (a) material sintered for $5 \mathrm{~min}$. Numerous particle boundaries (arrows P) are indicative of undersintering. Arrows $\mathrm{G}$ are undiffused, gray flakes of graphite in pores, (b) material sintered for $15 \mathrm{~min}$. Pores are rounded (arrows R). Arrows P indicates persistence of original particle boundaries; as-polished. [45]

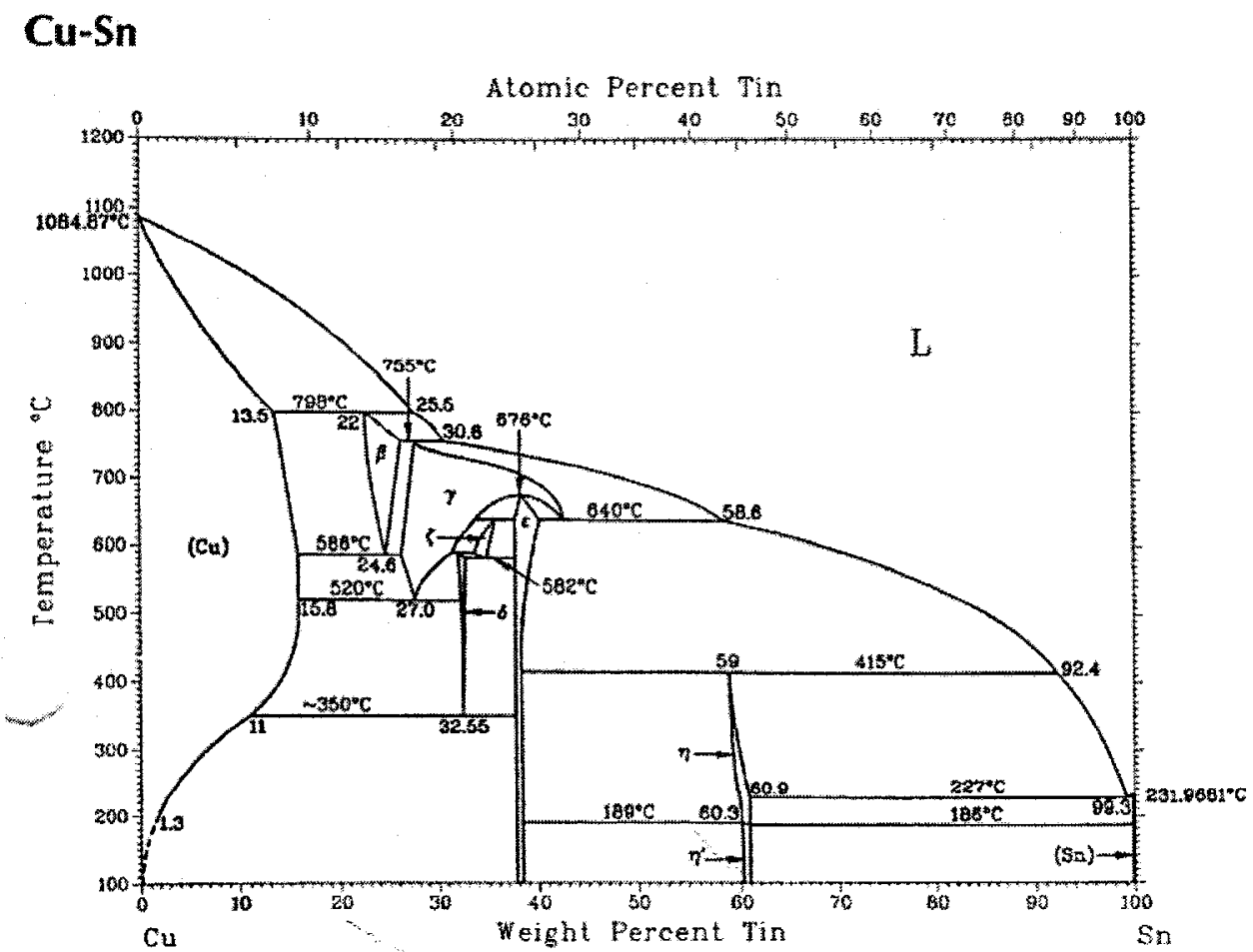

Figure 2.3 Binary phase diagram for $\mathrm{Cu}-\mathrm{Sn}[47]$ 


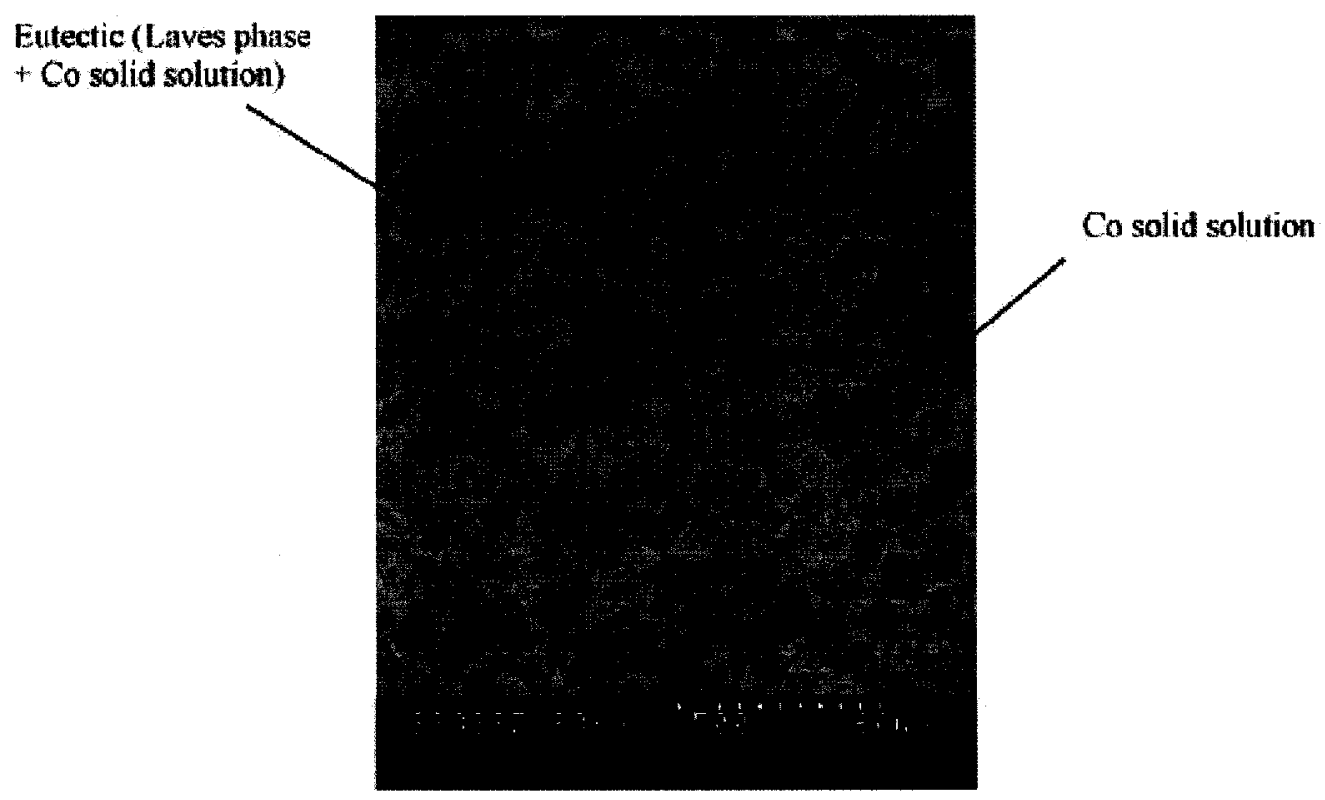

(a)

Laves phase

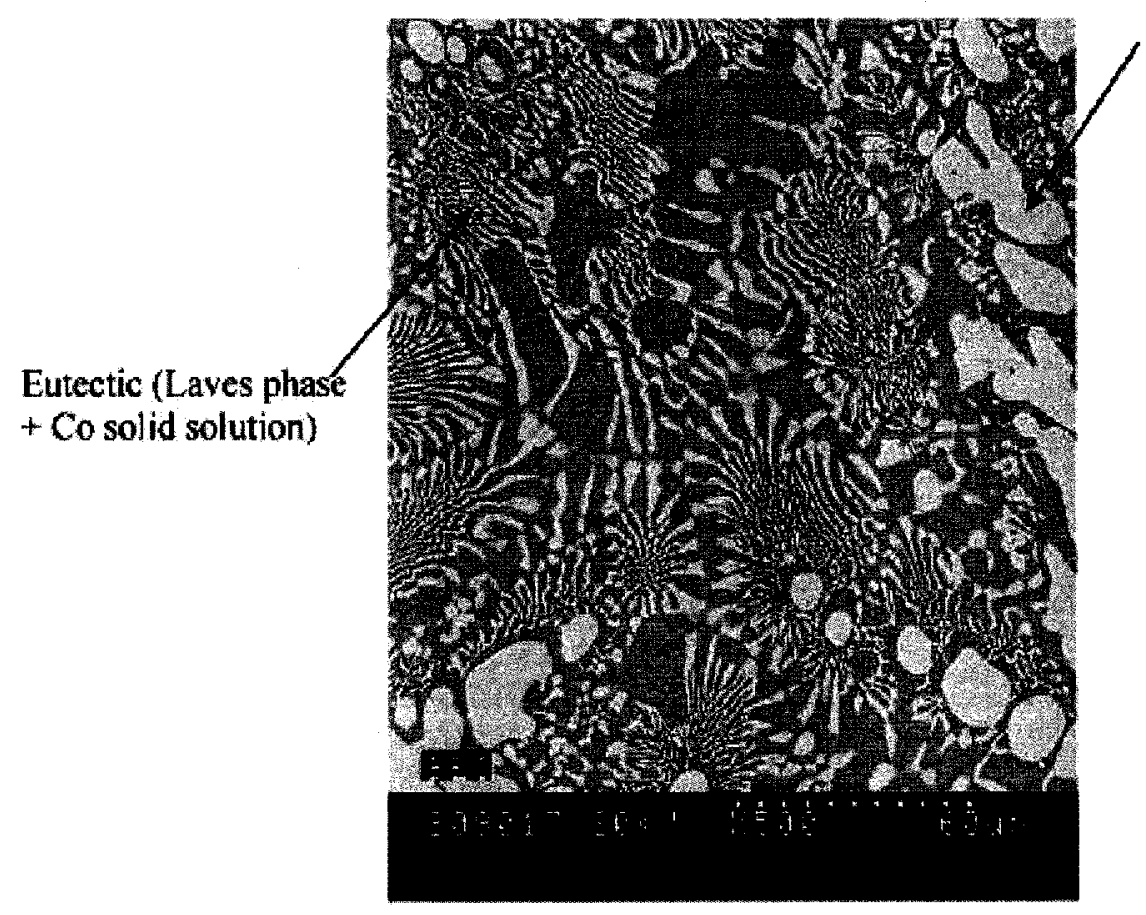

(b)

Figure2.4 SEM images of microstructures: (a) T-401, (b) T-400C [27] 


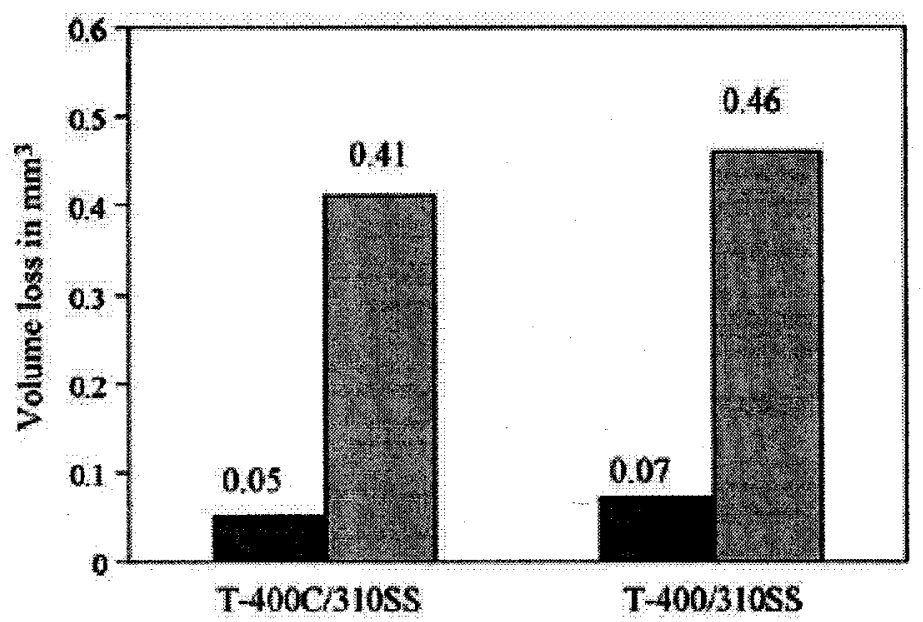

Figure2.5 Wear losses of cylinder and flat pairs after $400 \mathrm{~m}$ sliding at $482^{\circ} \mathrm{C}$ [29]

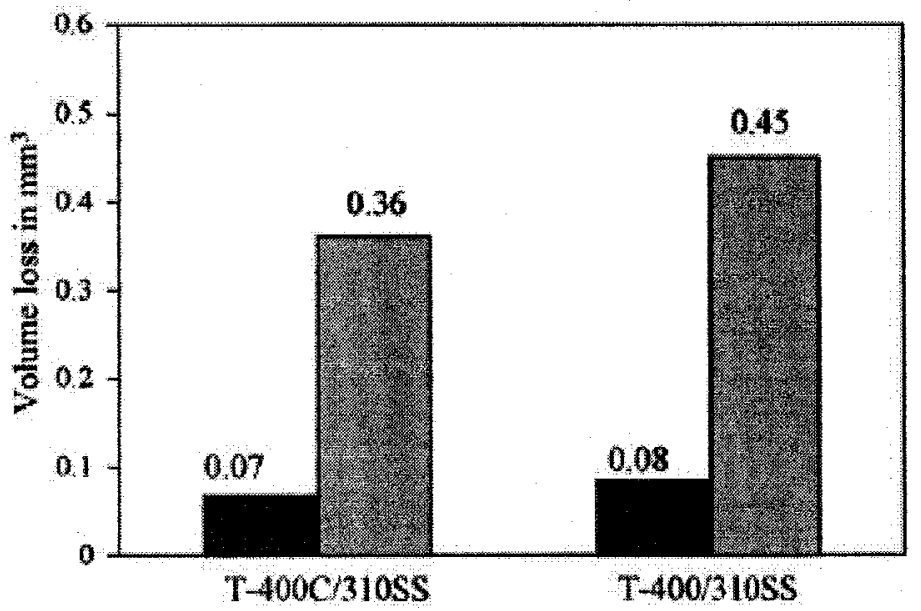

Figure2.6 Wear losses of disc and flat pairs after $800 \mathrm{~m}$ sliding at $482^{\circ} \mathrm{C}$ [29] 


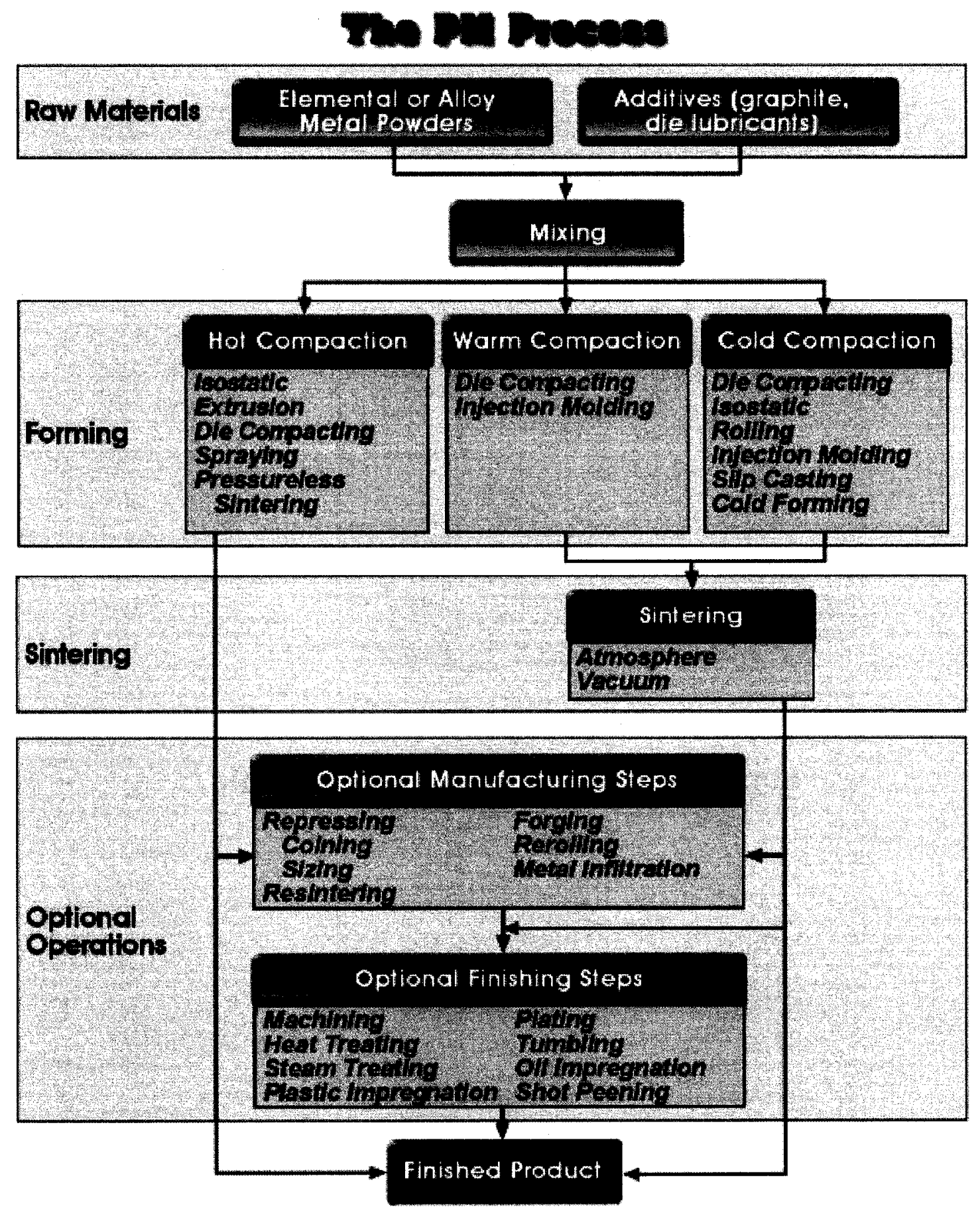

Figure2.7 Powder metallurgy process [54] 


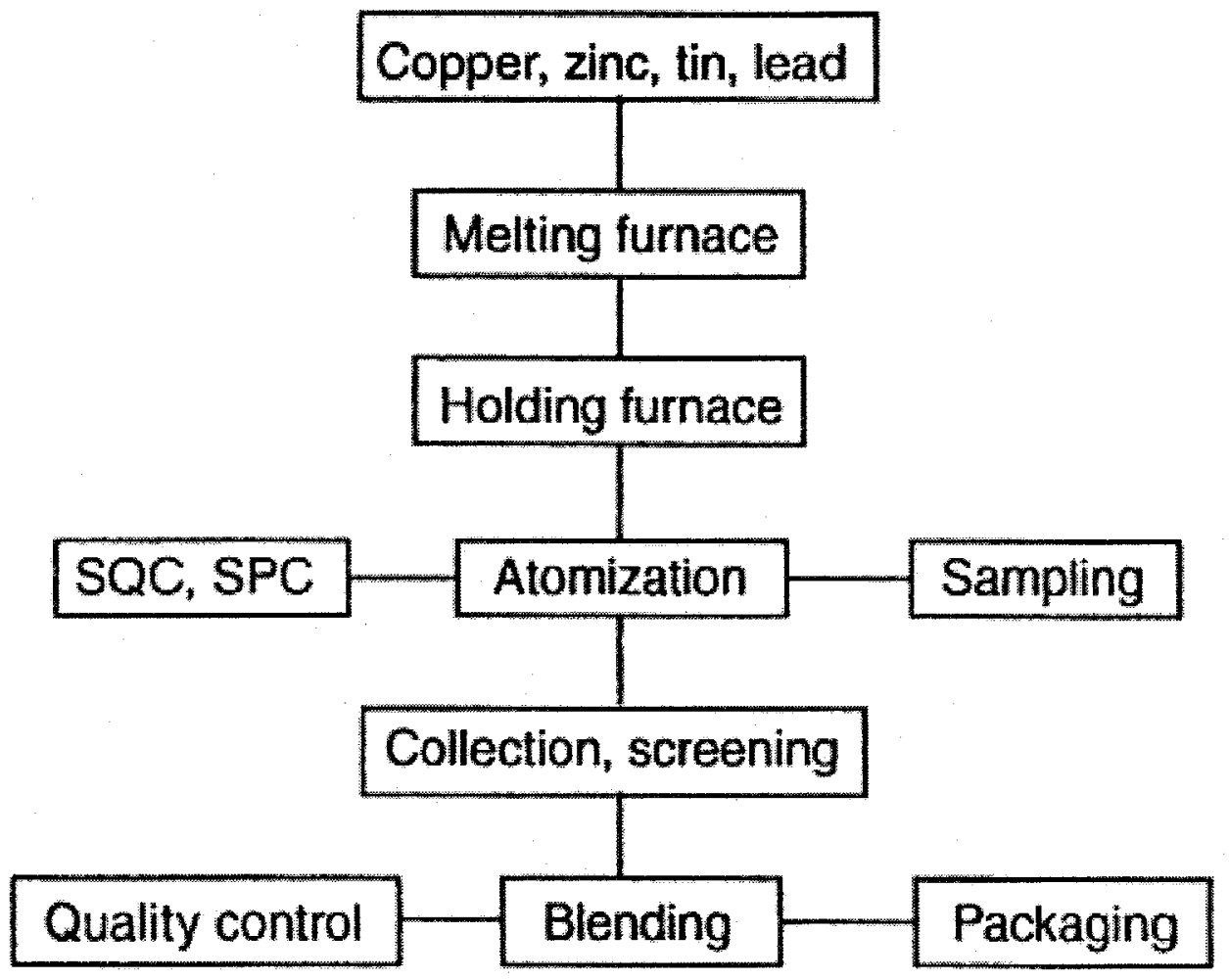

Figure 2.8 Flowchart for copper alloy powder air atomization [56]
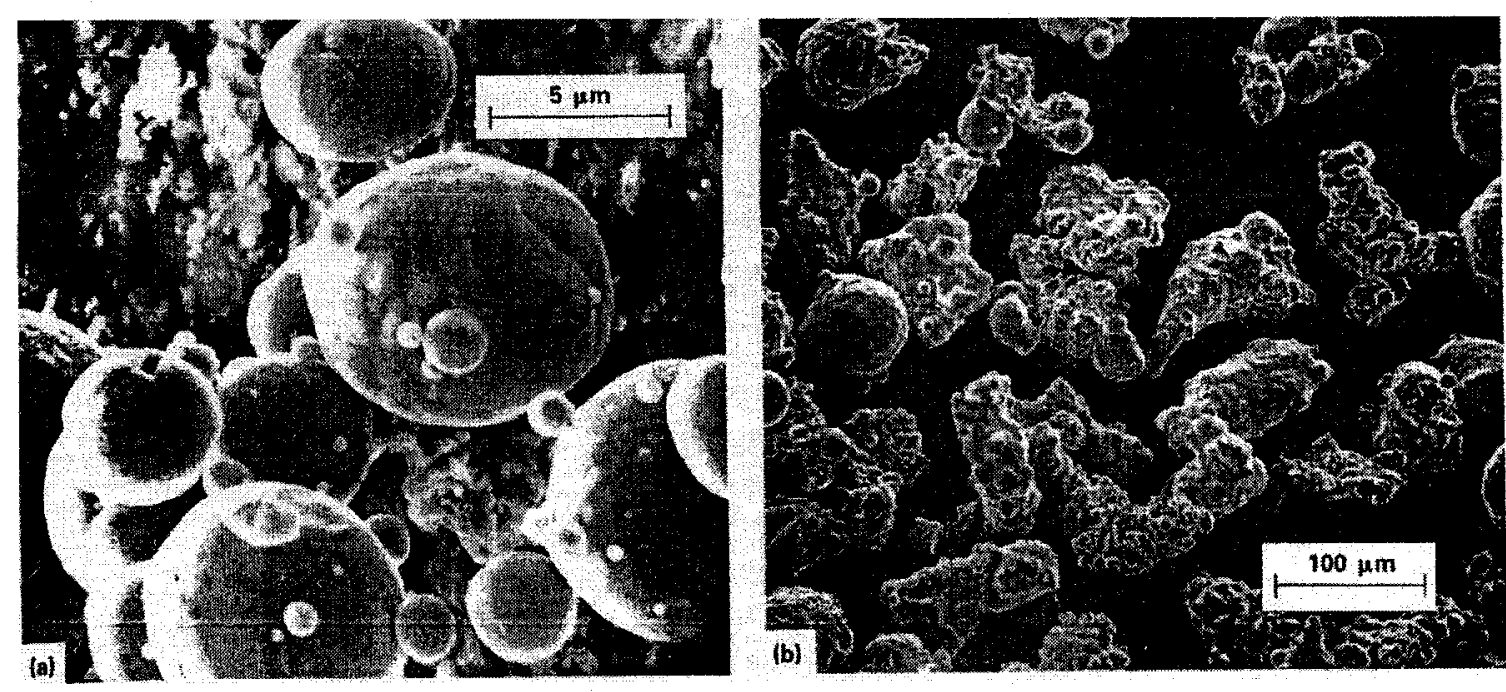

Figure 2.9 SEM images of copper powder: (a) air atomized, (b) water atomized [57] 


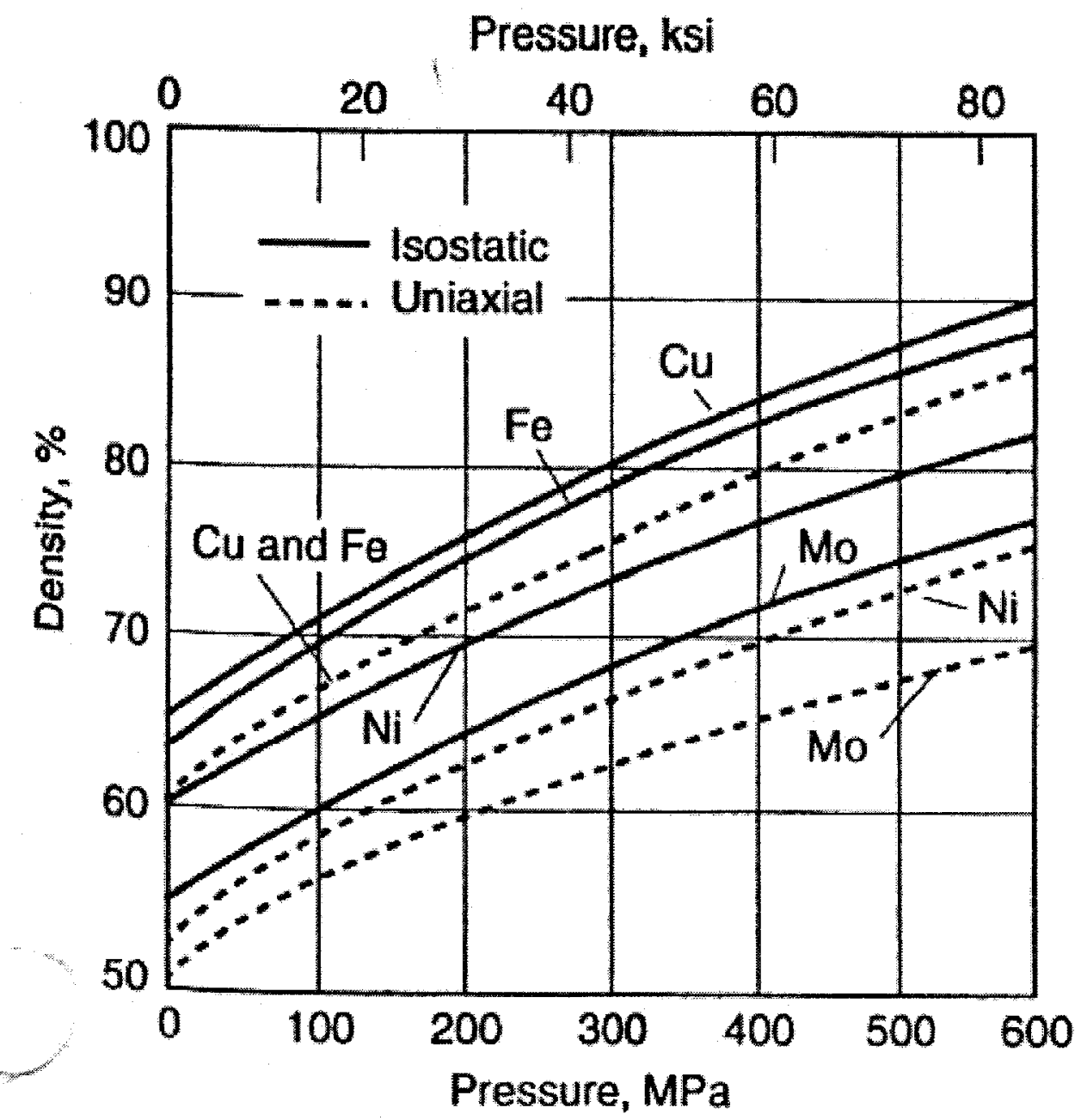

Figure 2.10 Density as a function of pressure

for isostatic and unidirectional pressing of $\mathrm{Cu}, \mathrm{Fe}, \mathrm{Ni}$, and $\mathrm{Mo}$ [43] 


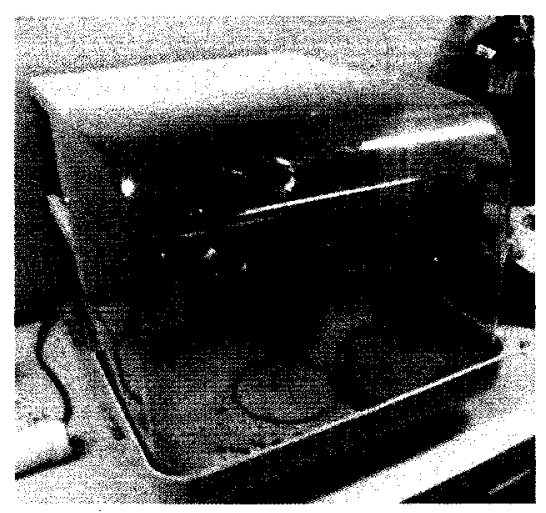

Figure 3.1 Powder mixer

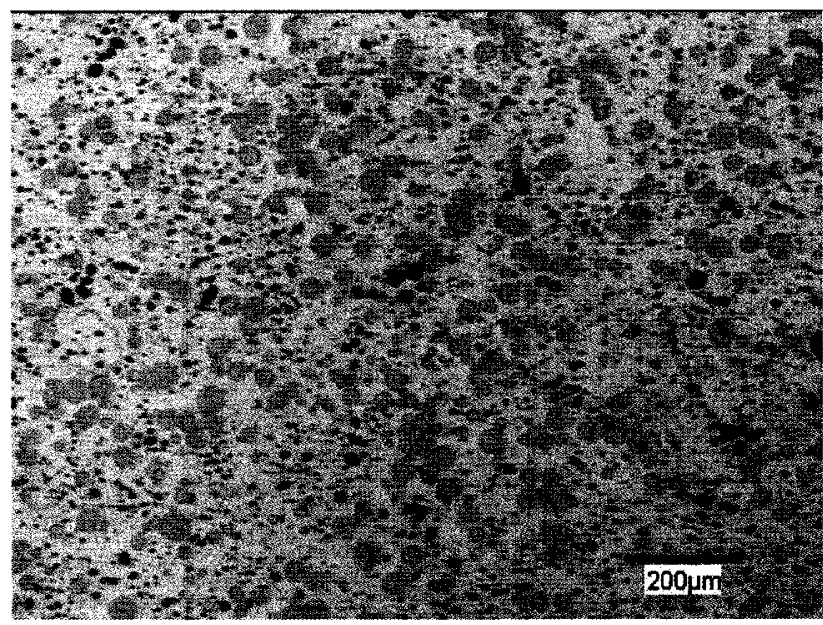

Figure 3.2 Homogenous structure of mixed powders

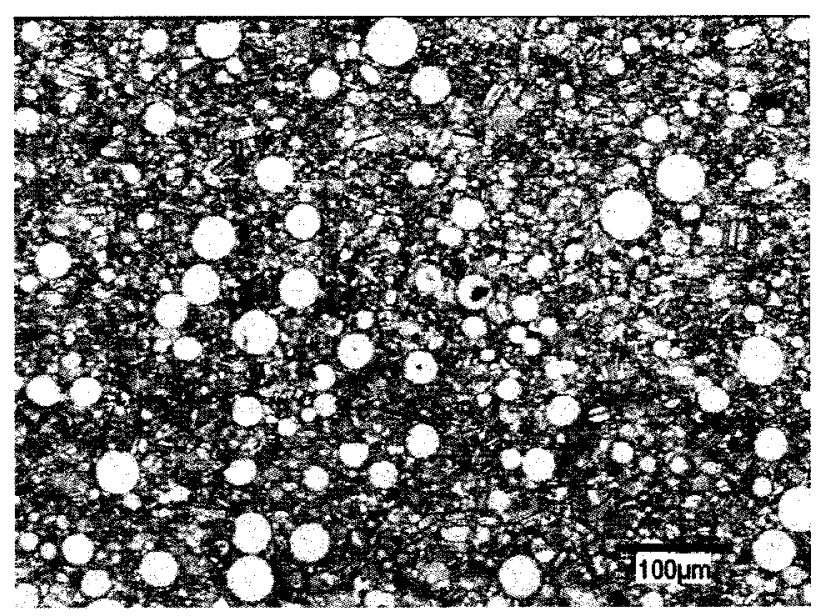

Figure 3.3 Distribution of Tribaloy alloy particles in the matrix 


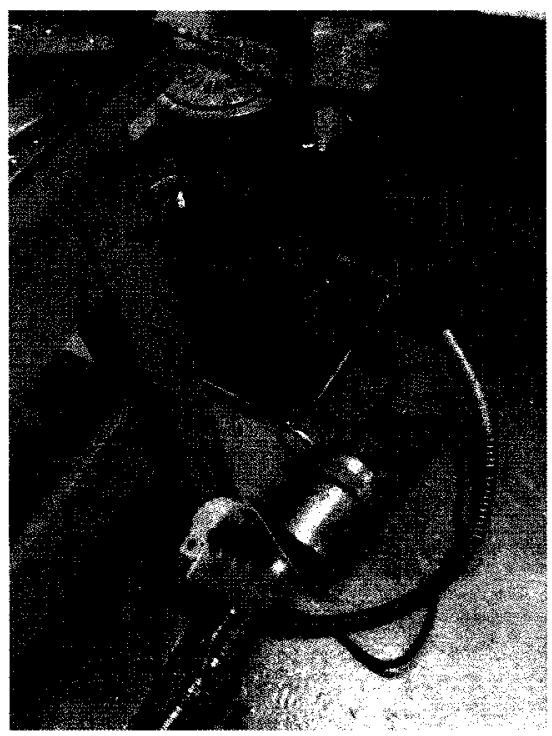

Figure 3.4 Hydraulic squeezing machine
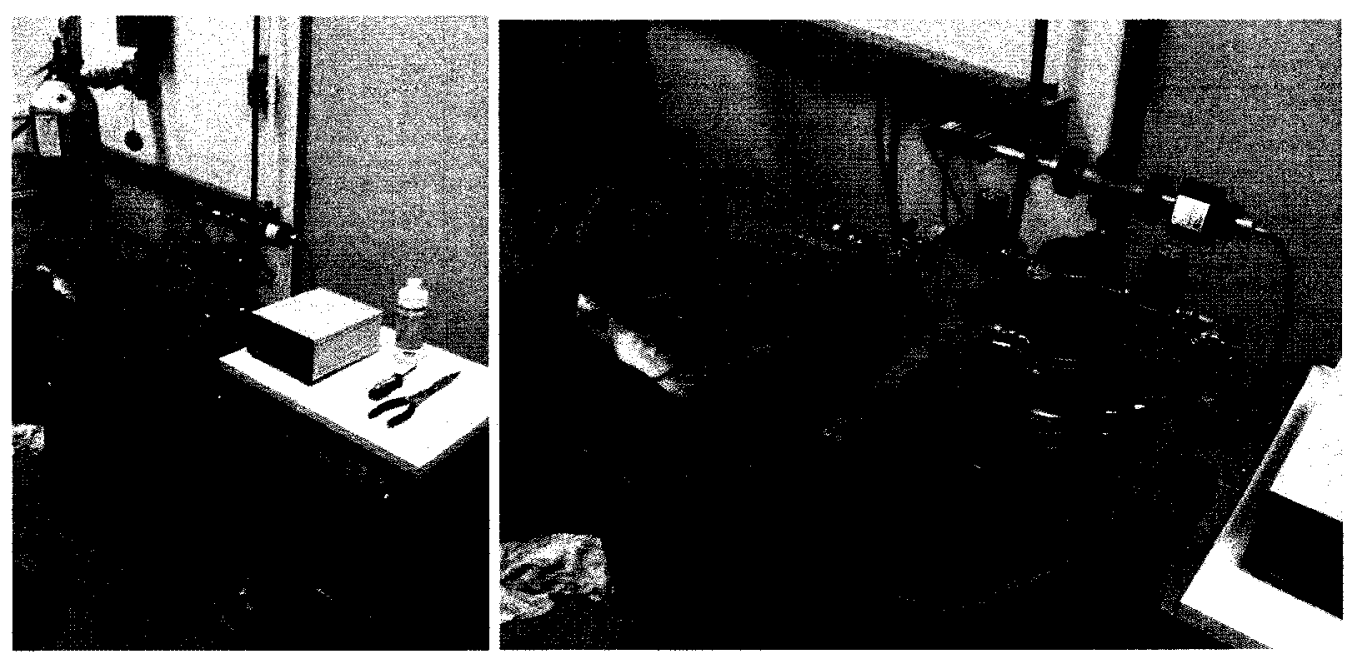

Figure 3.5 Vacuum system

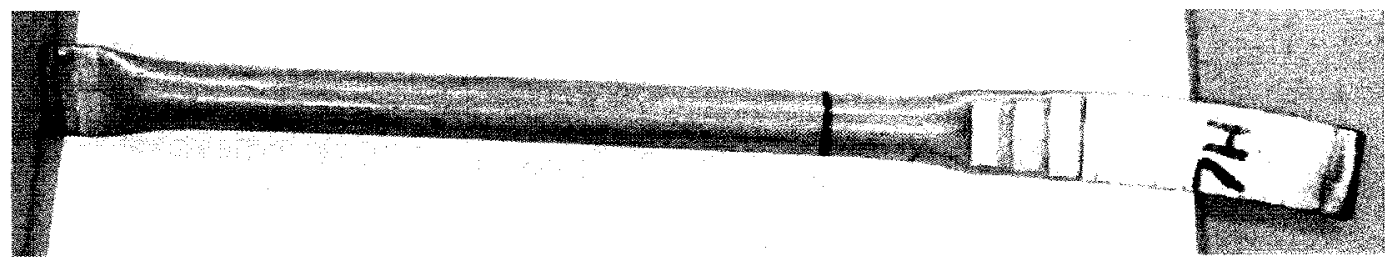

Figure 3.6 Sealed encapsulated powder for HIPping 


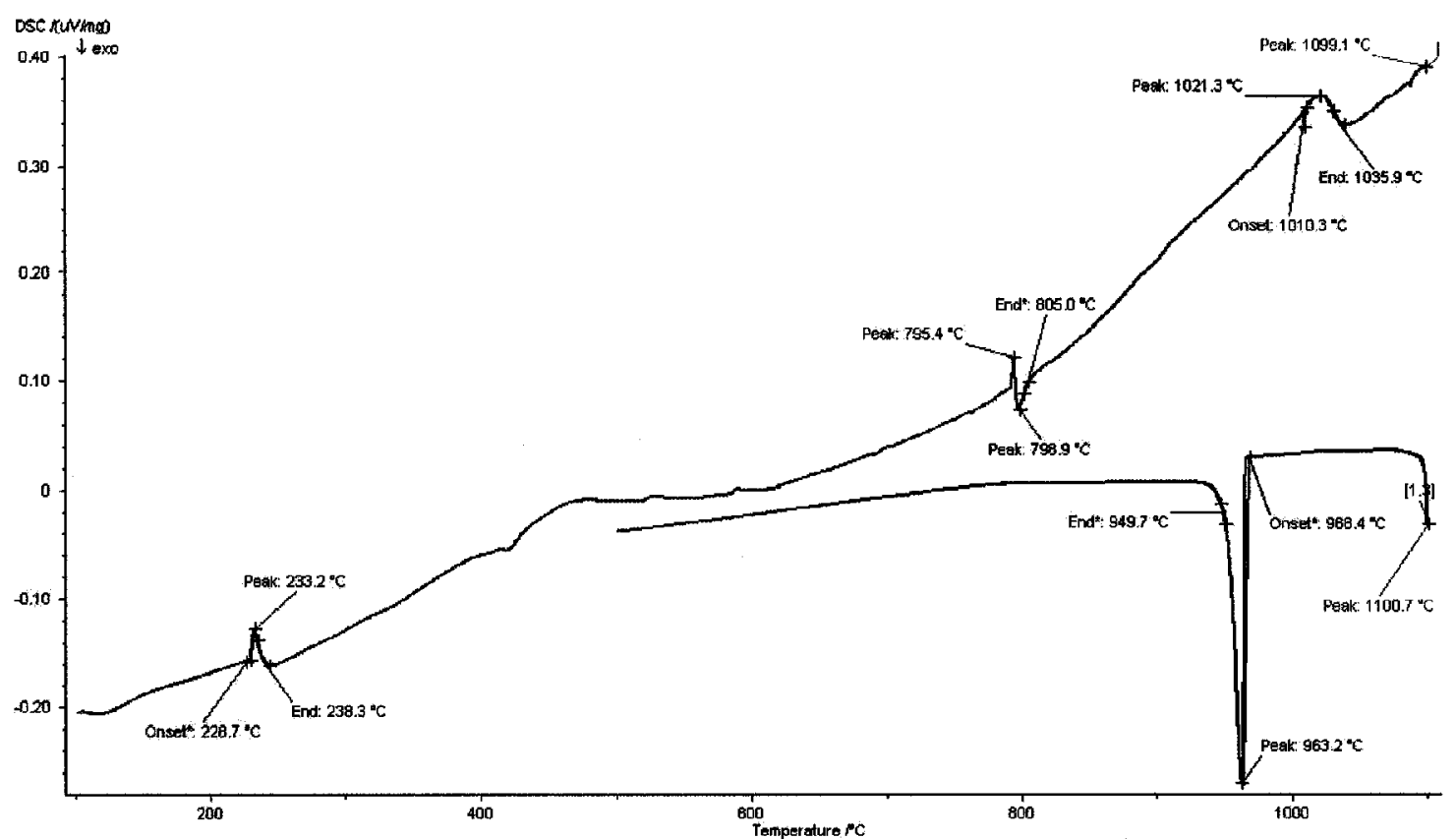

(a)

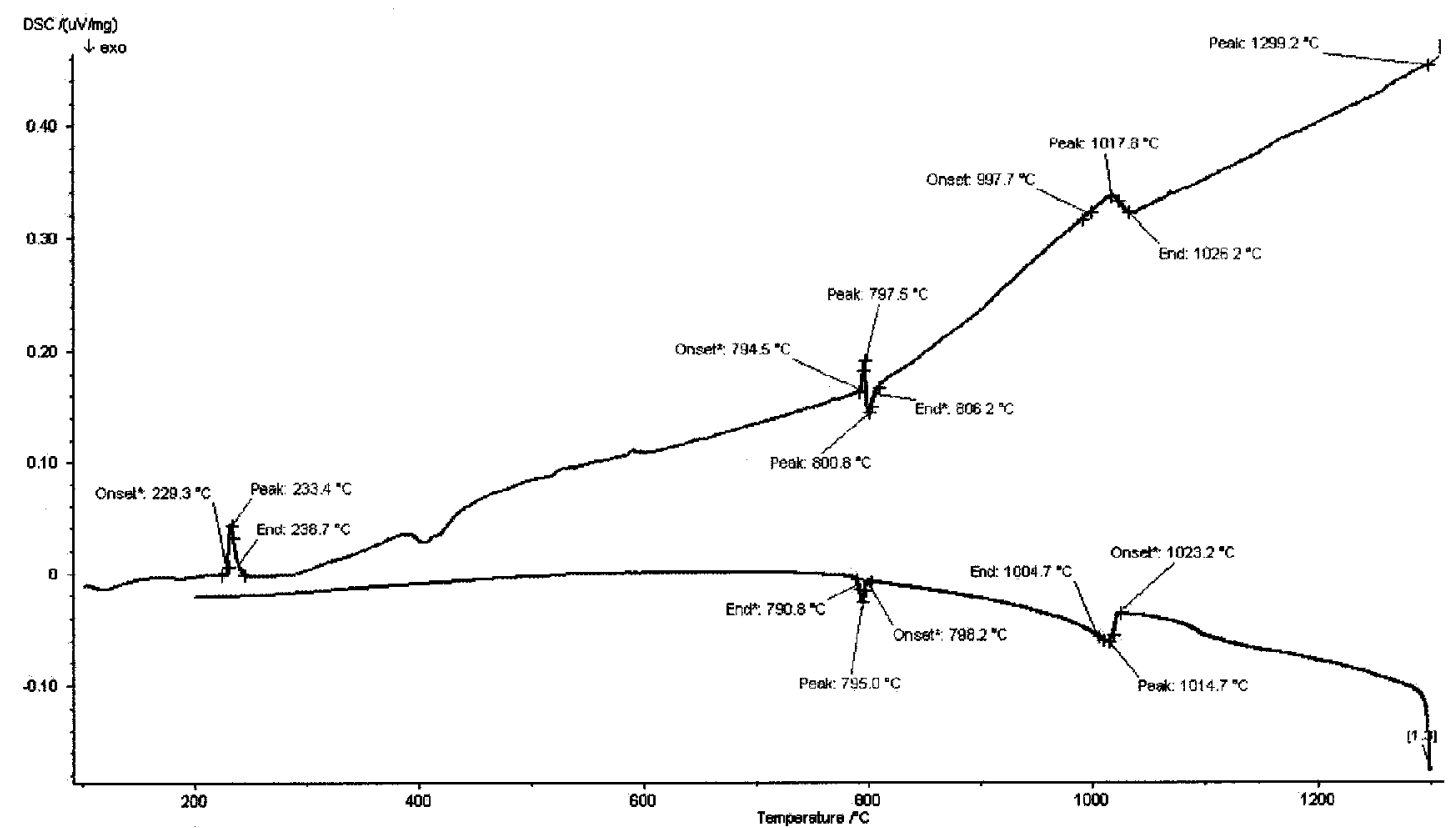

(b) 


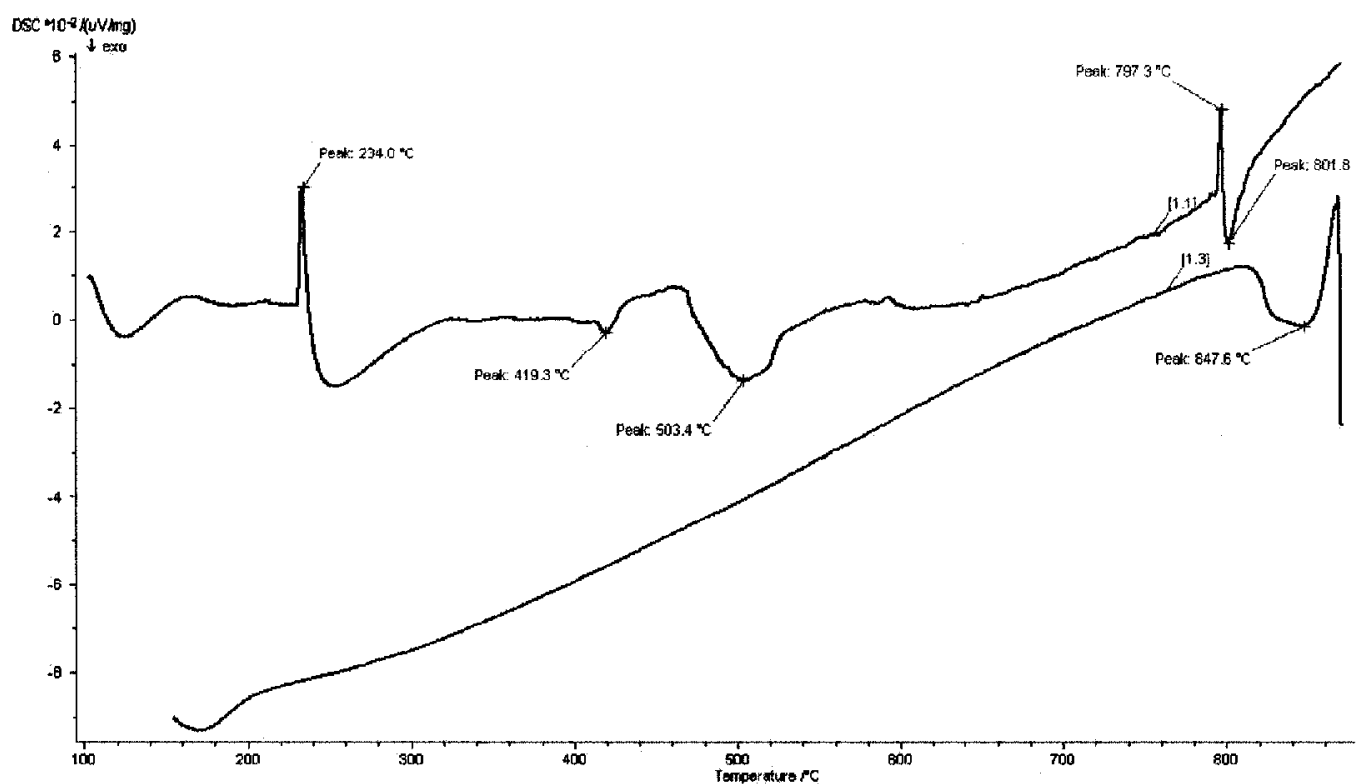

(c)

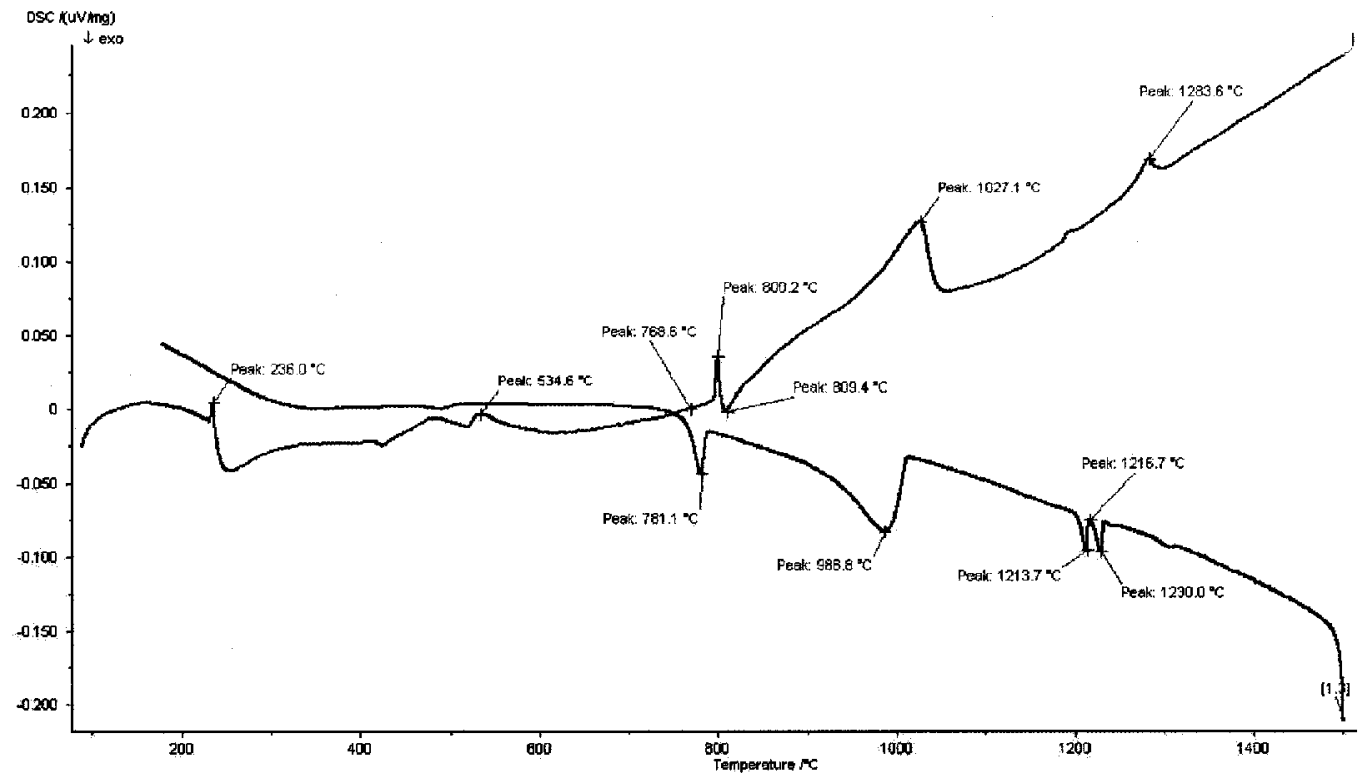

(d)

Figure 3.7 DSC curves for Group 1 specimens (premixed bronze based): (a) premixed $90 / 10$ bronze powder under the ultimate temperature of $1100^{\circ} \mathrm{C}$, (b) premixed $90 / 10$ bronze with $10 \% \mathrm{~T} 401$ under the ultimate temperature of $1300^{\circ} \mathrm{C}$, (c) premixed $90 / 10$ bronze powder under the ultimate temperature of $870^{\circ} \mathrm{C}$, (d) premixed $90 / 10$ bronze with $20 \% \mathrm{~T} 401$ under the ultimate temperature of $1500^{\circ} \mathrm{C}$ 


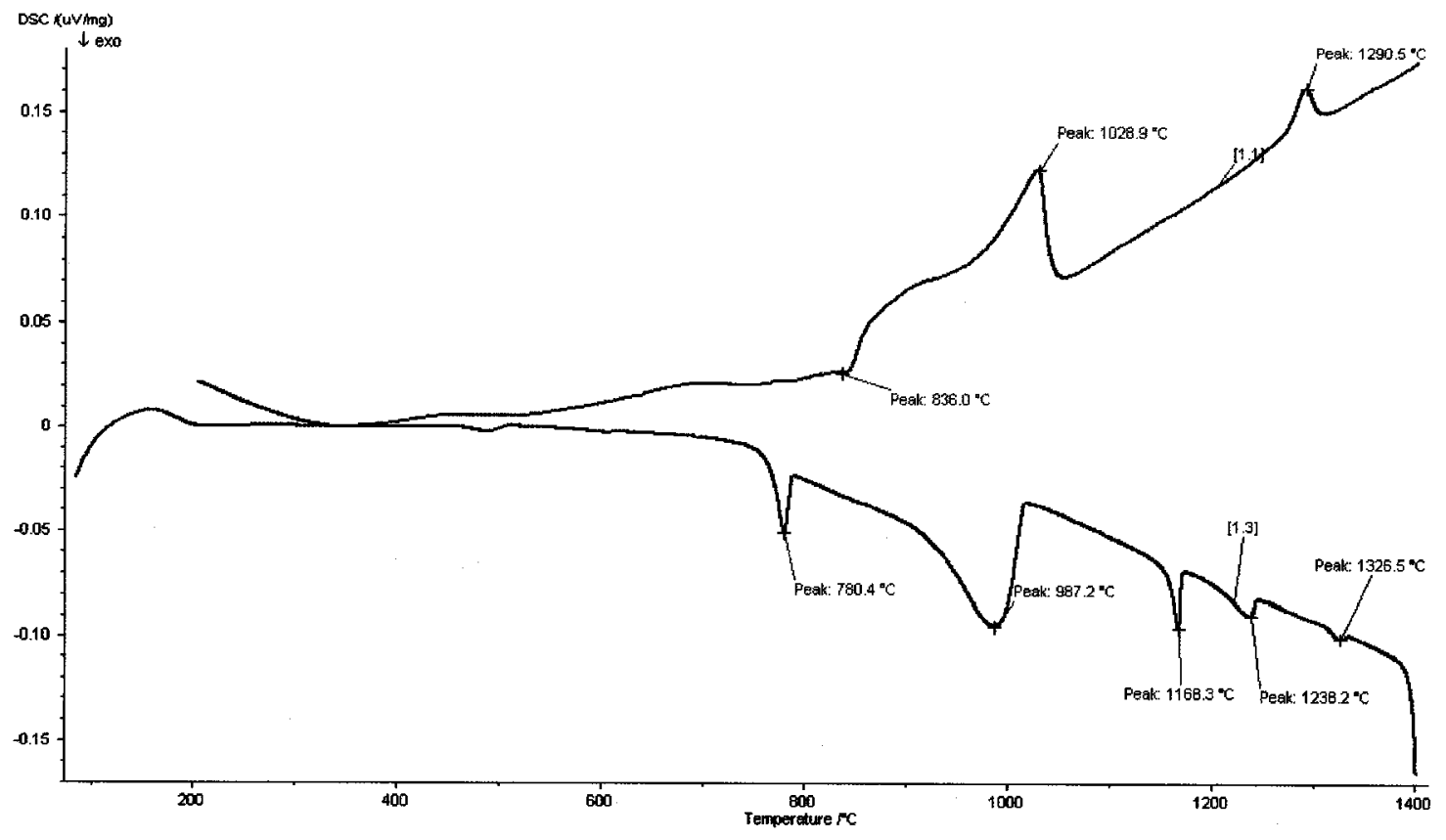

Figure 3.8 DSC curve for Group2 specimens (prealloyed bronze based), prealloyed 90/10 bronze with $20 \% \mathrm{~T} 401$ under the ultimate temperature of $1400^{\circ} \mathrm{C}$

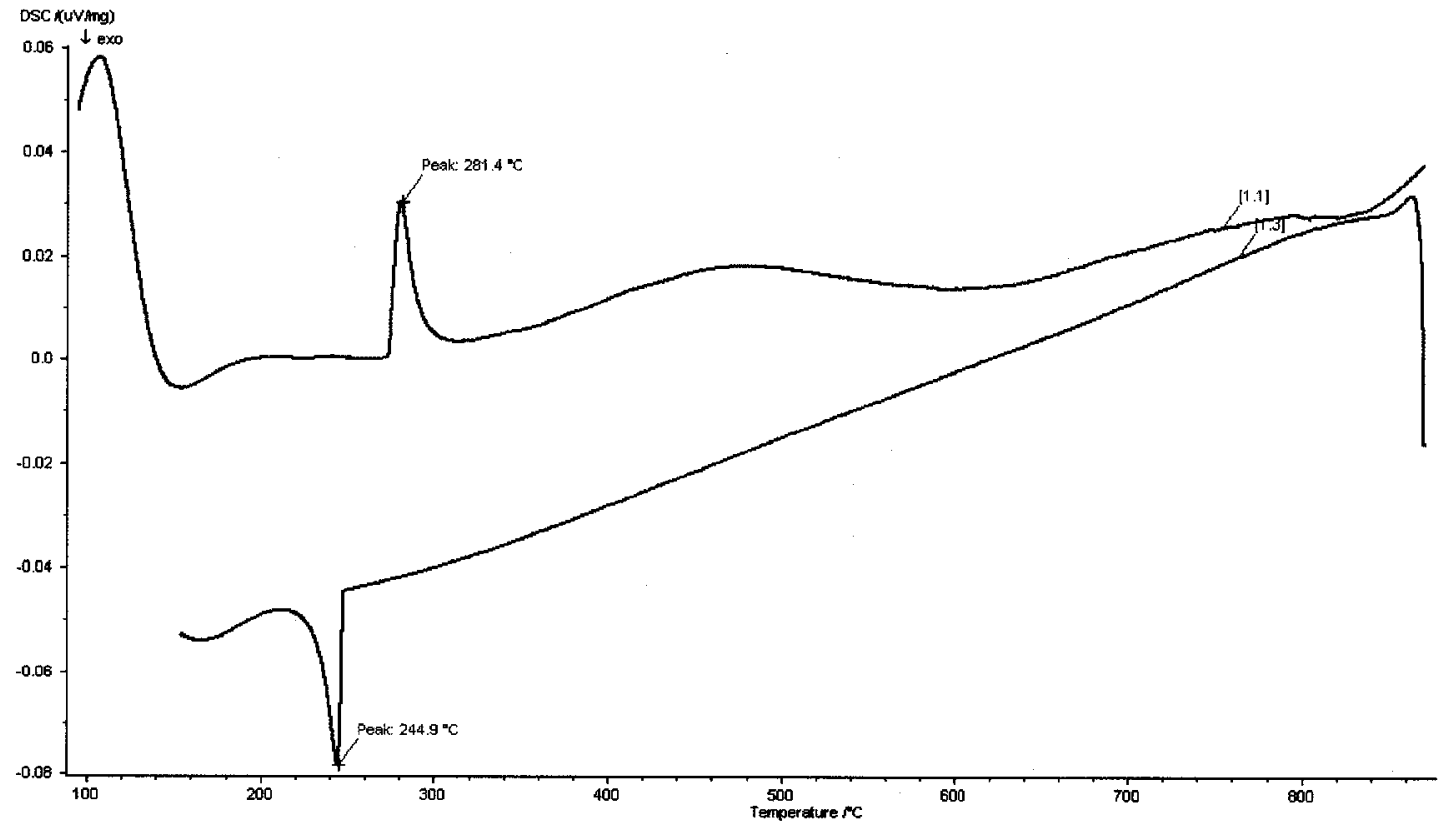

Figure 3.9 DSC curve for Group3 specimens (copper based), Cu-15\%Bi with 20\% T401 under the ultimate temperature of $870^{\circ} \mathrm{C}$ 


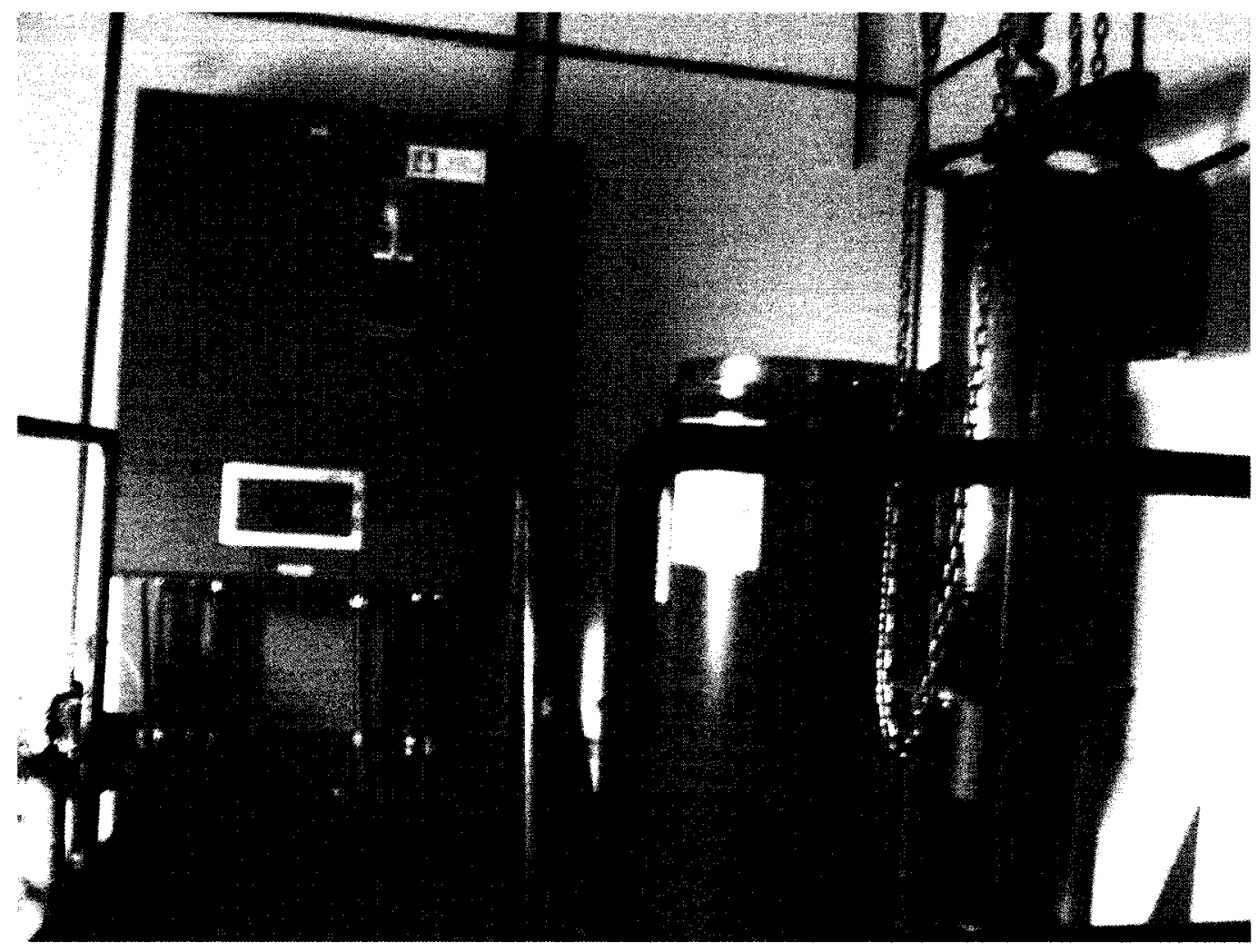

Figure 3.10 HIPping unit
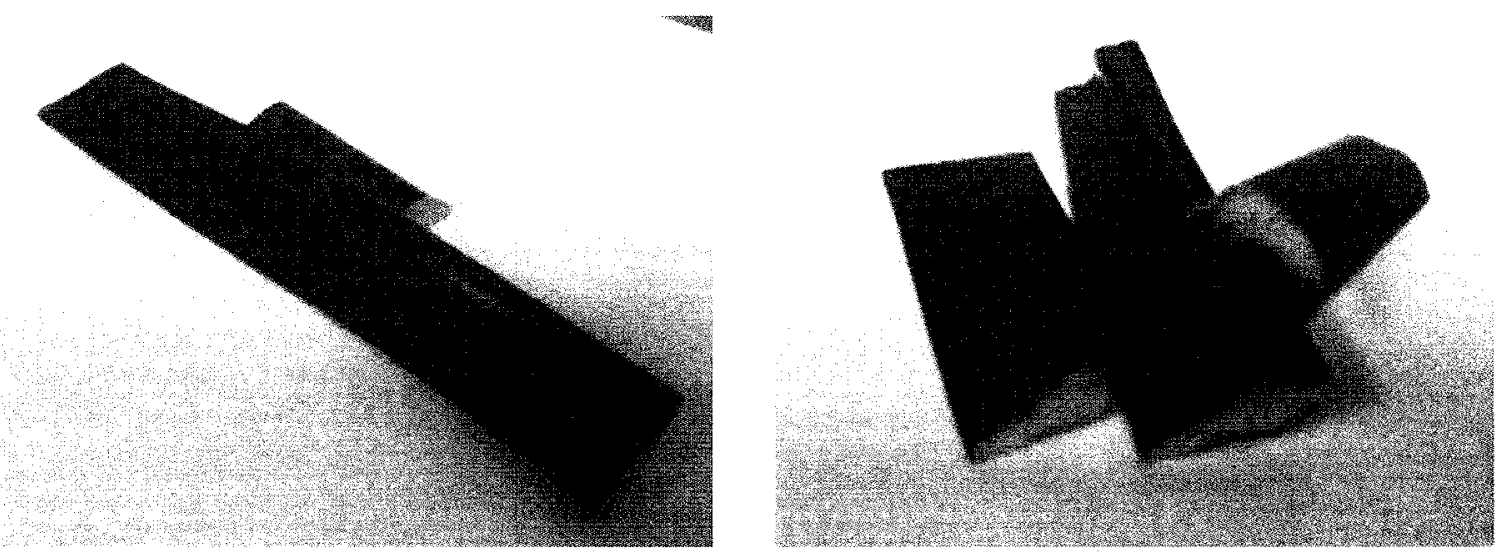

Figure 3.11 HIPped specimens 


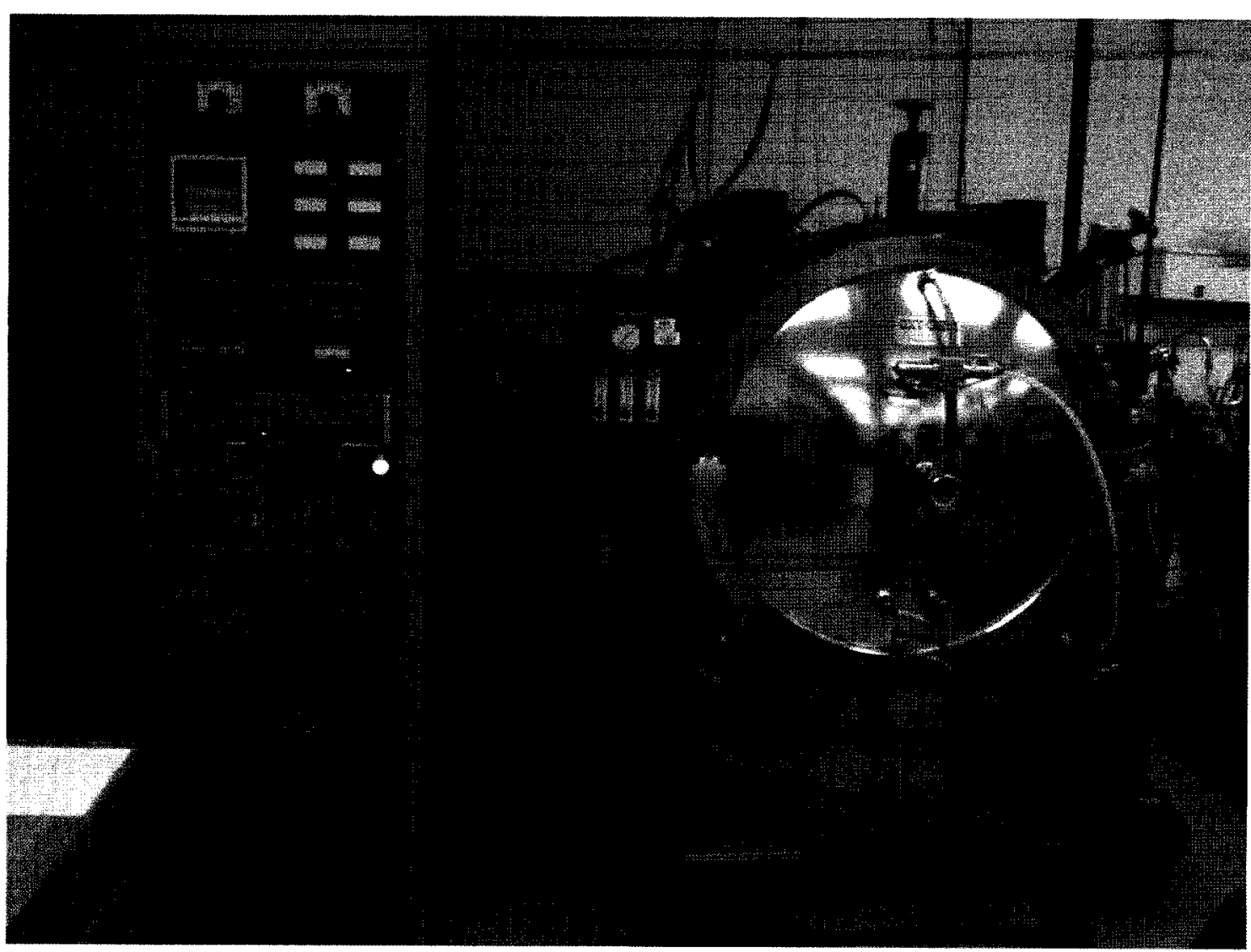

Figure 3.12 Vacuum sintering furnace 


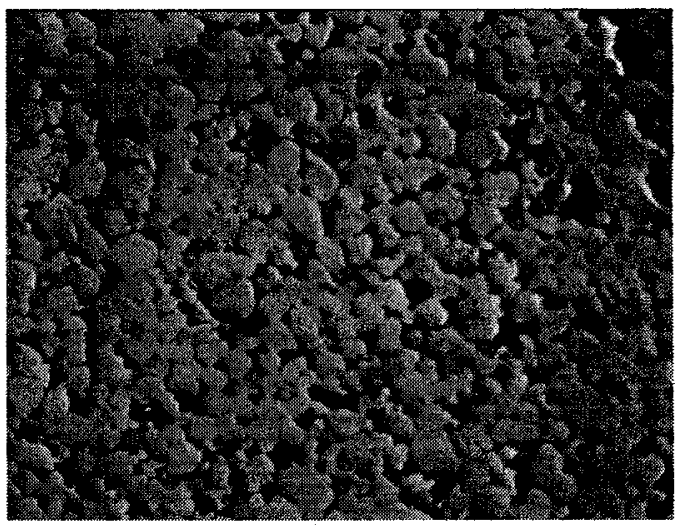

(a) Low magnification - unetched

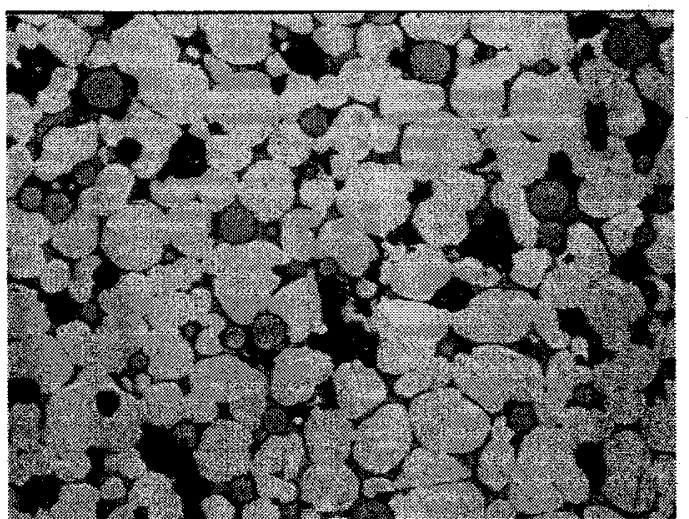

(c) High magnification - unetched

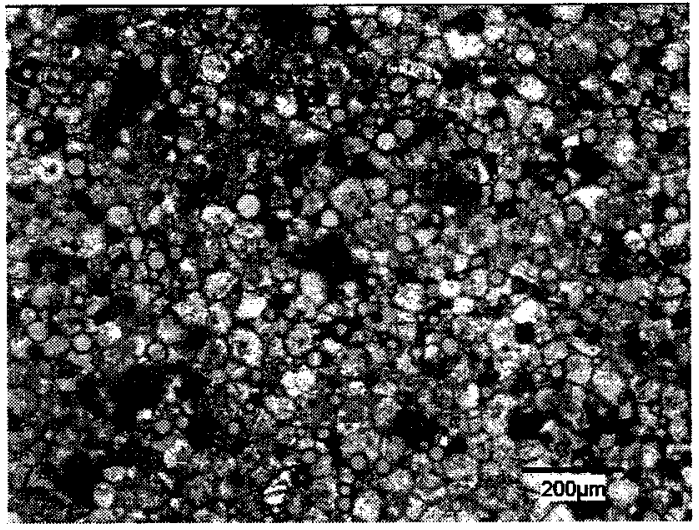

(b) Low magnification - etched

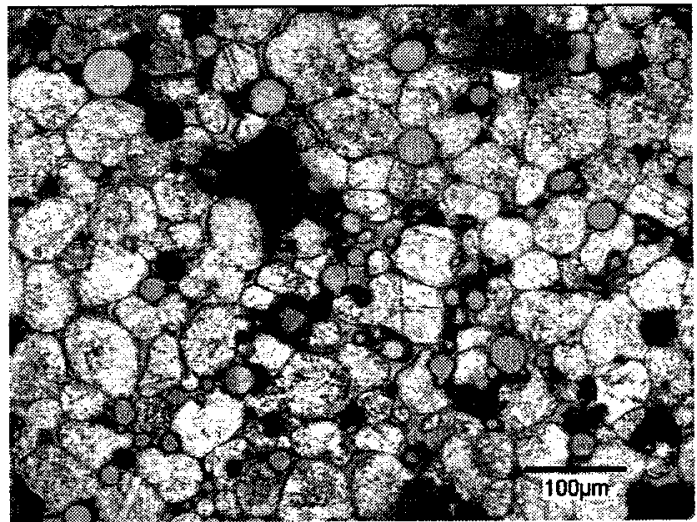

(d) High magnification - etched

Figure 4.1 Microstructures of $\mathrm{Cu}-15 \% \mathrm{Bi}$ with $10 \% \mathrm{~T}-401$ sintered for $30 \mathrm{~min}$ at $870^{\circ} \mathrm{C}$ 


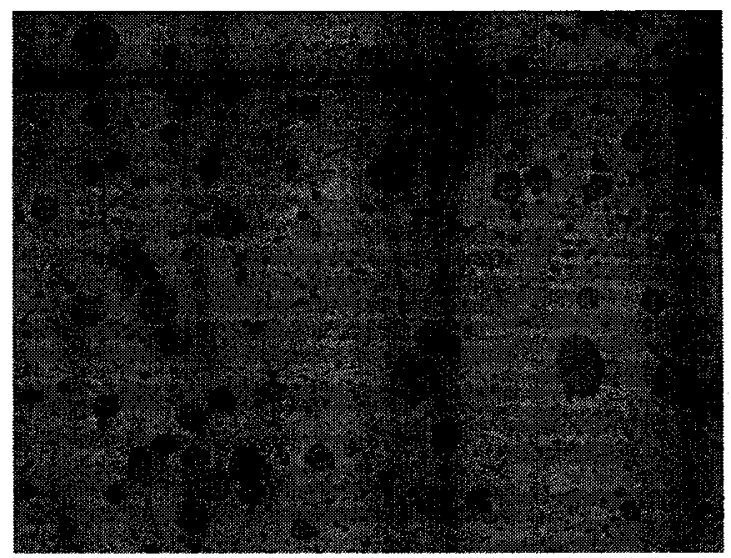

(a) Unetched

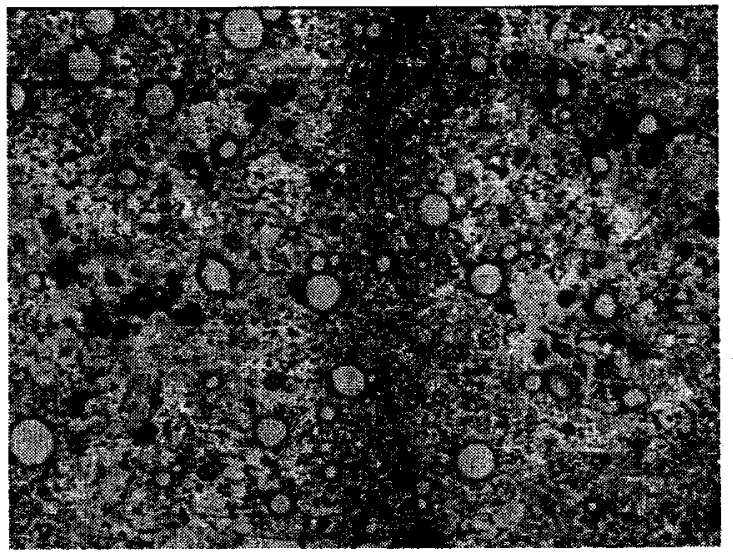

(b) Etched

Figure 4.2 Microstructures of HIPped bronze based alloy (first HIPped specimen), 90/10 premixed bronze with $10 \% \mathrm{~T}-401$, HIPped for $20 \mathrm{~min}$ at $840^{\circ} \mathrm{C}$

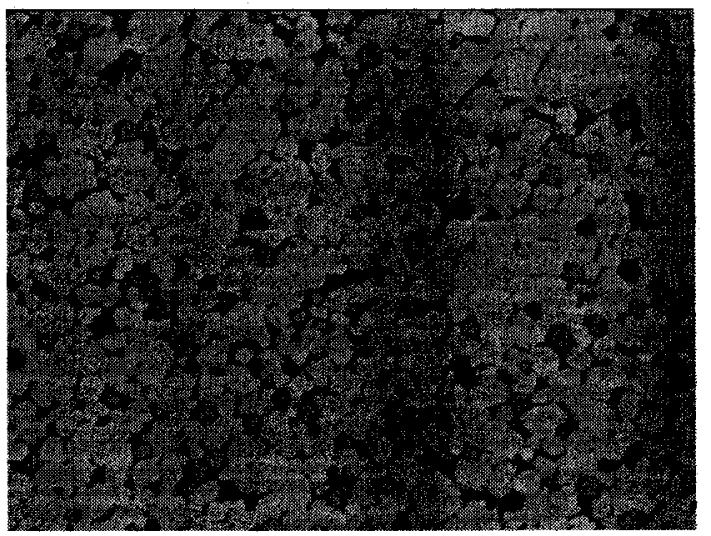

(a) Unetched

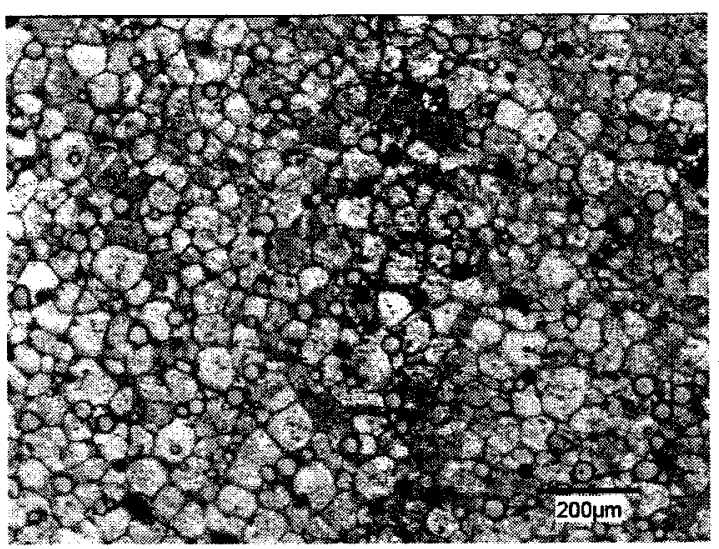

(b) Etched

Figure 4.3 Microstructures of HIPped copper based alloy (second HIPped specimen), $\mathrm{Cu}-15 \% \mathrm{Bi}$ with $10 \% \mathrm{~T}-401, \mathrm{HIPped}$ for $30 \mathrm{~min}$ at $870^{\circ} \mathrm{C}$ 


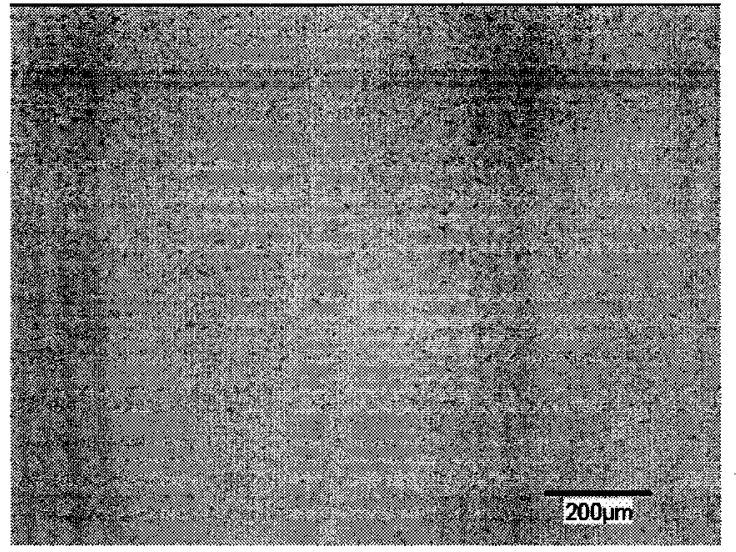

(a) Low magnification - unetched - premixed

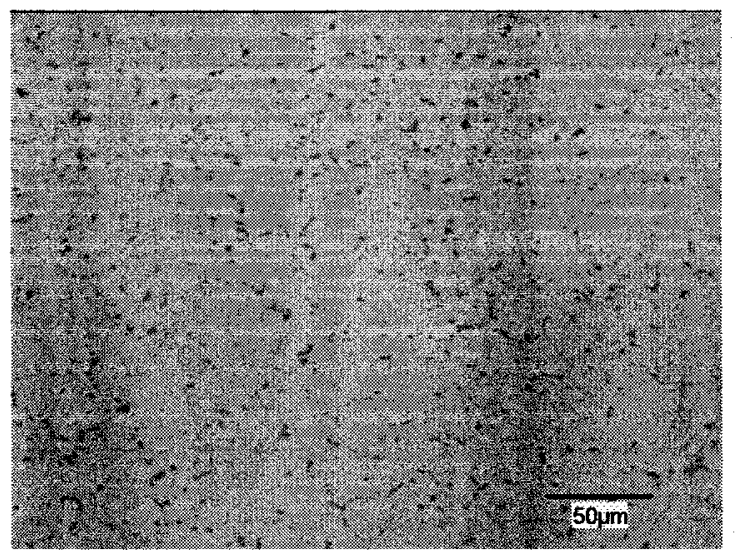

c) High magnification - unetched - premixed

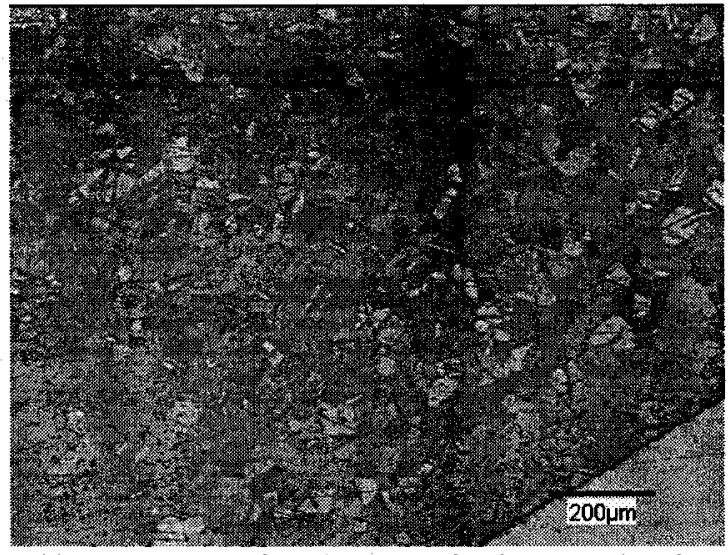

(b) Low magnification - etched - premixed

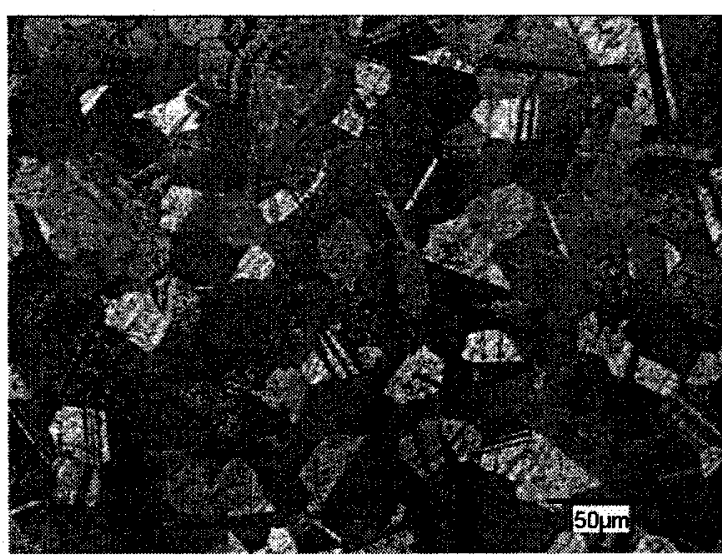

(d) High magnification - etched - premixed

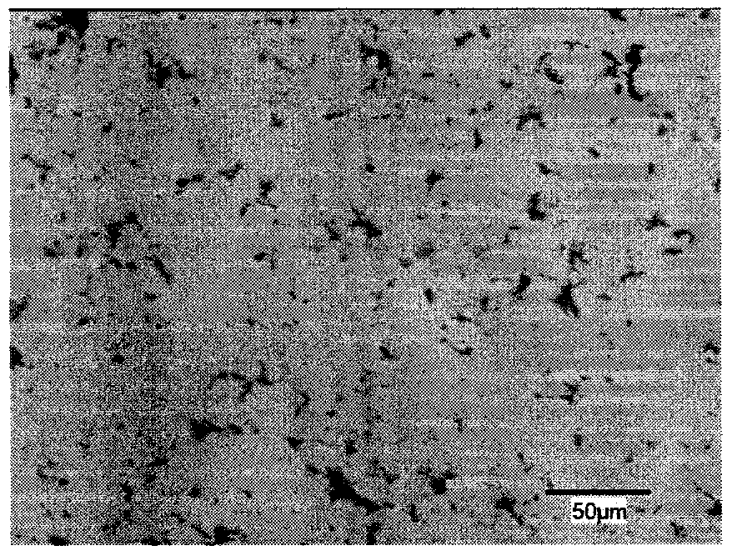

(e) High magnification - unetched - prealloyed

Figure 4.4 Microstructures of HIPped bronze based alloy (third HIPped specimens), $\mathrm{Cu}-10 \% \mathrm{Sn}, \mathrm{HIPped}$ at $870^{\circ} \mathrm{C}$ for $120 \mathrm{~min}$ under $206 \mathrm{MPa}$ pressure 


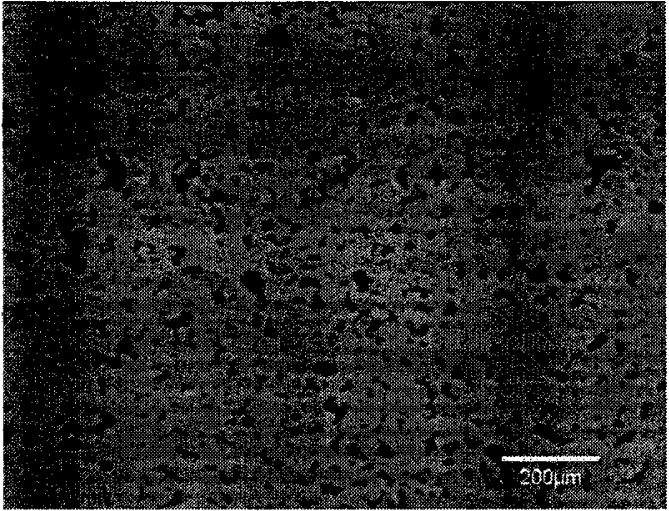

(a) Unetched

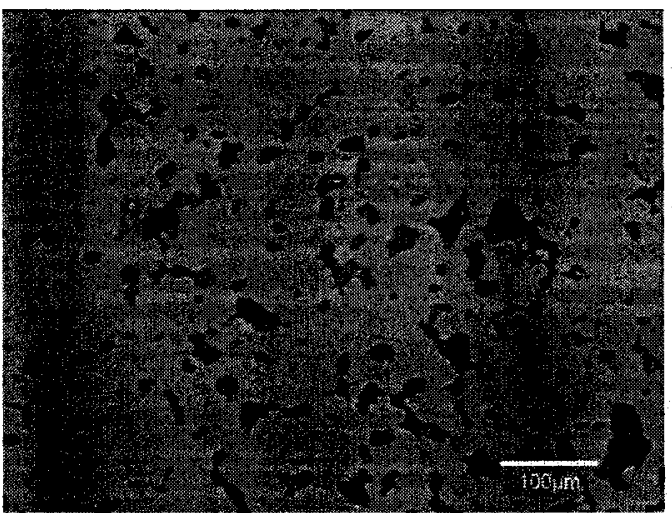

(c) Unetched

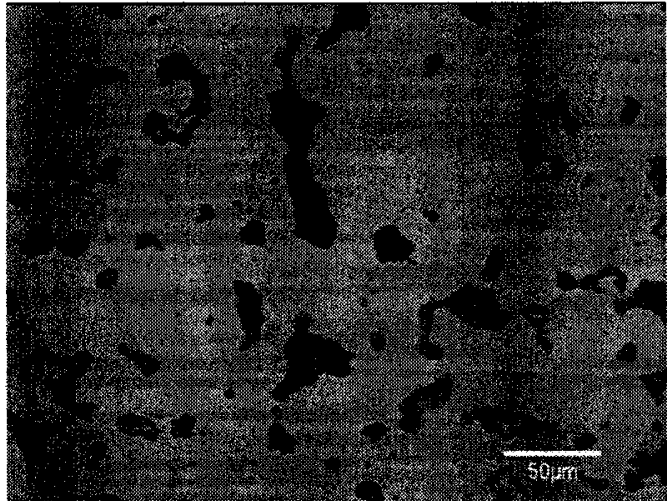

(e) Unetched

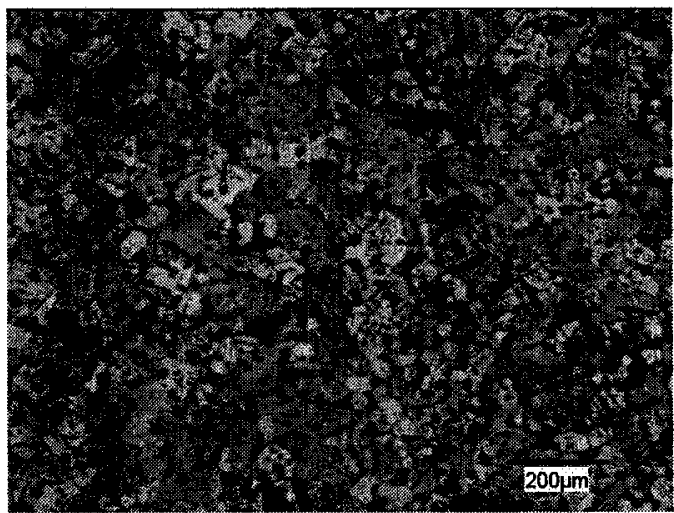

(b) Unetched - edge

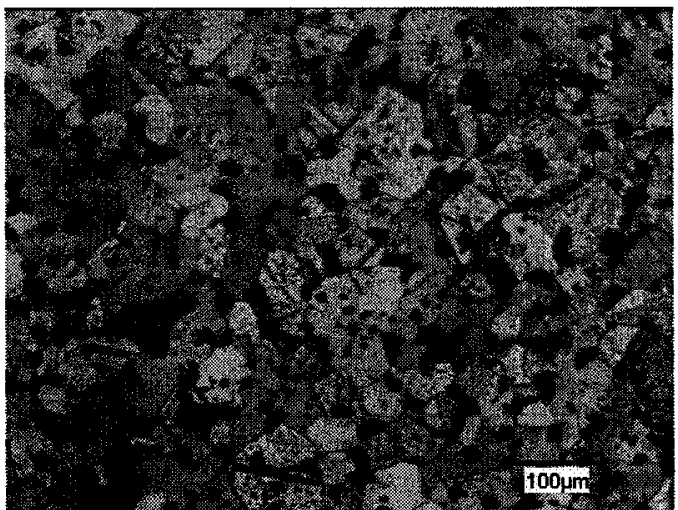

(d) Etched

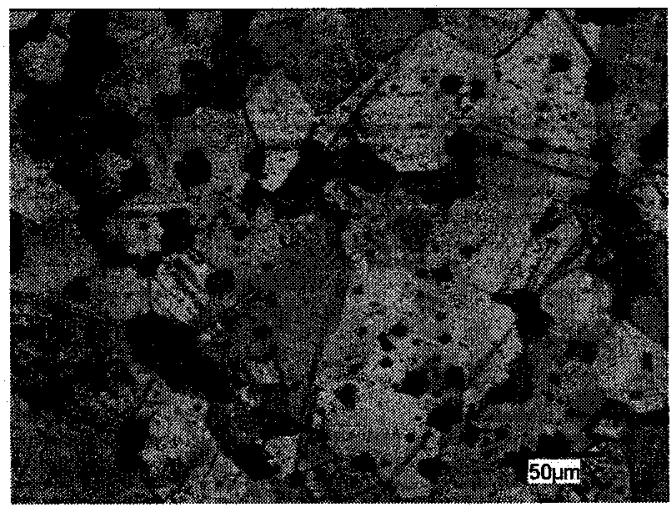

(f) Etched 


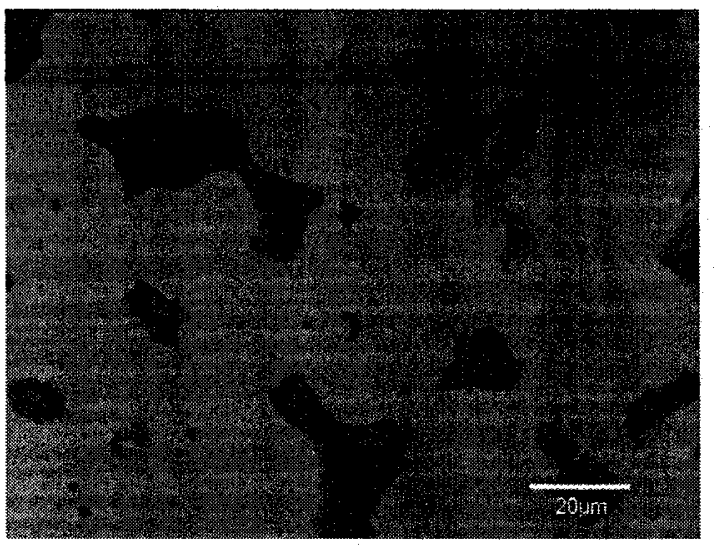

(g) Unetched

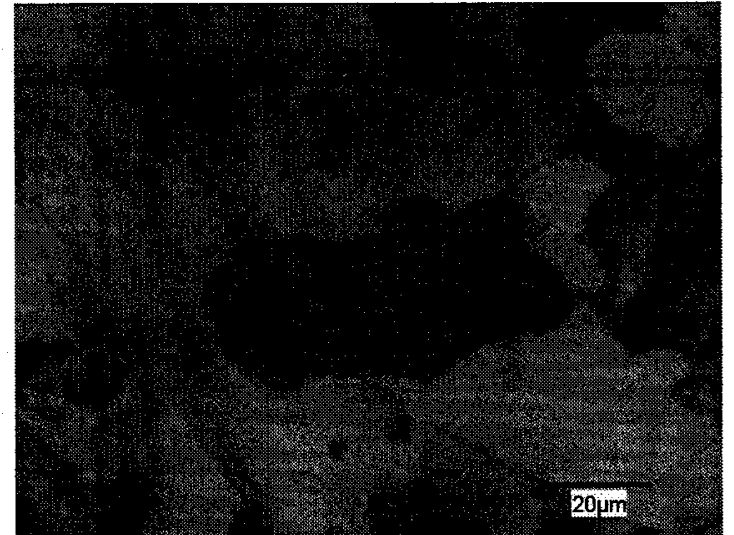

(h) Etched

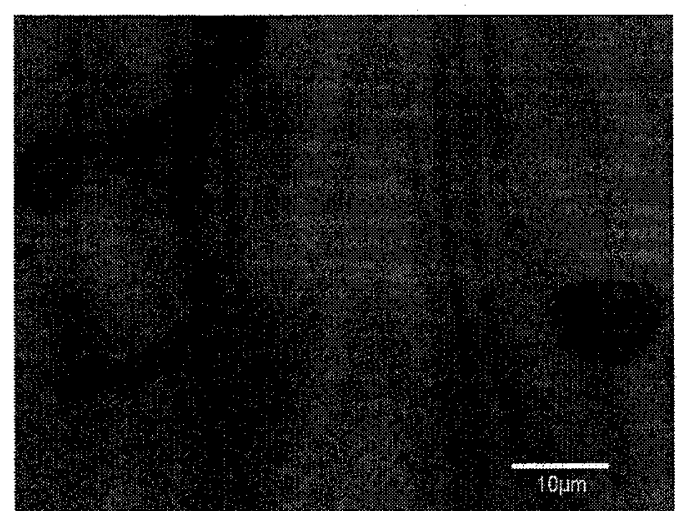

(i) Unetched

Figure 4.5 Microstructures of premixed bronze (specimen MG1) 


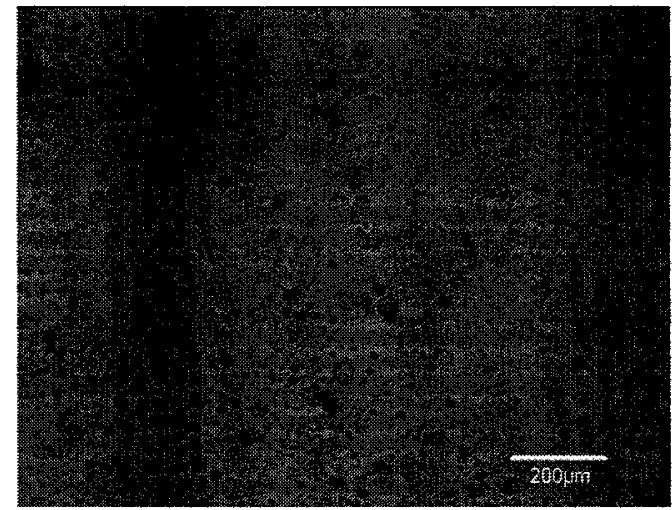

(a) Unetched

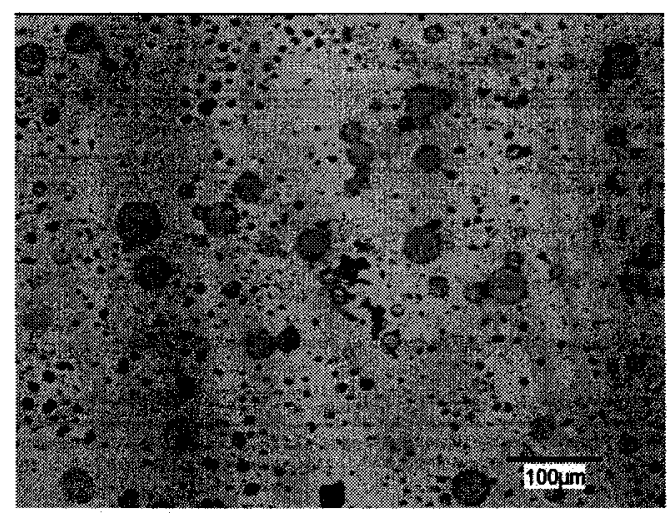

(c) Unetched

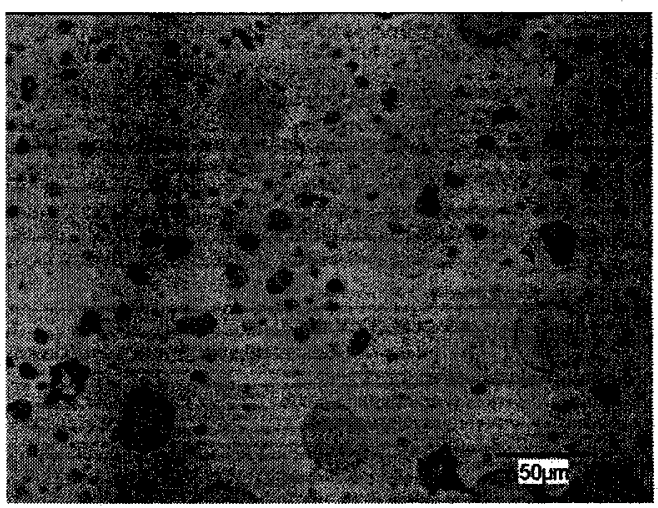

(e) Unetched

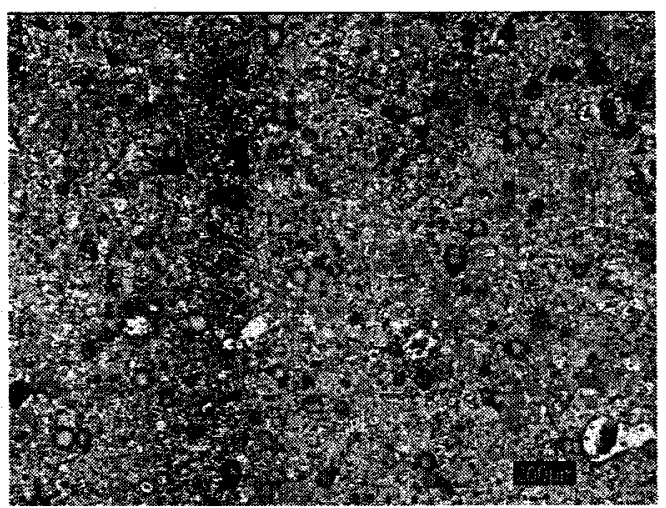

(b) Etched

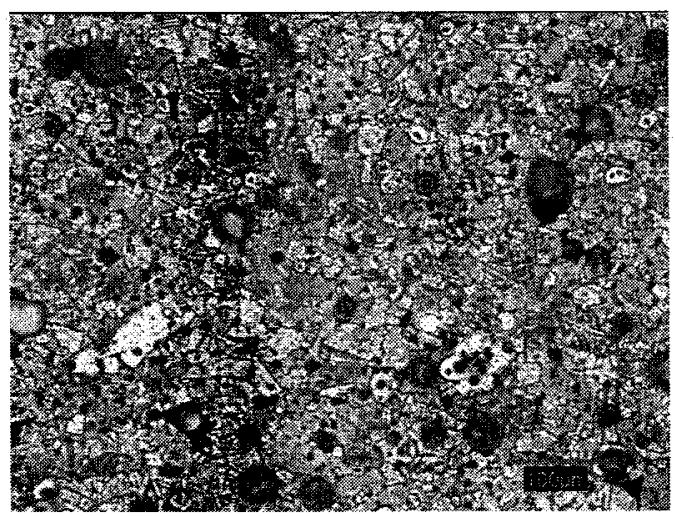

(d) Etched

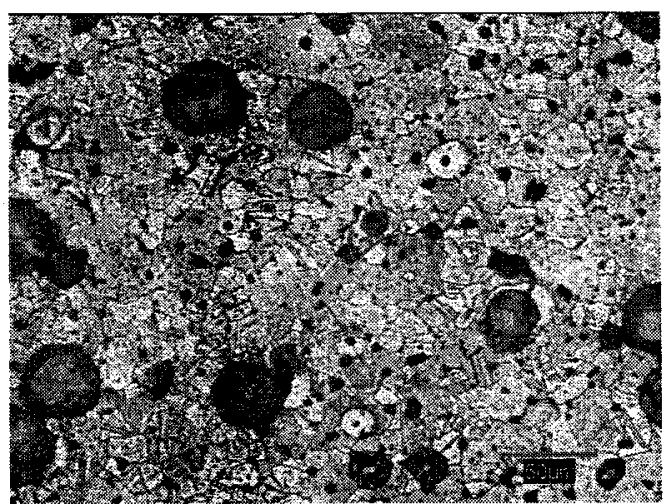

(f) Etched 


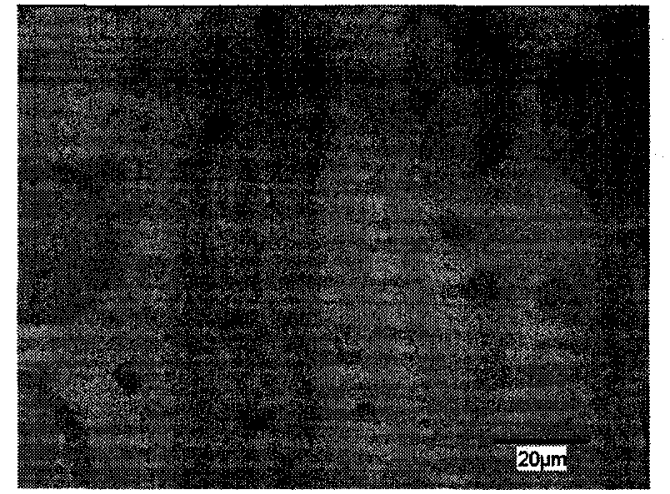

(g) Unetched

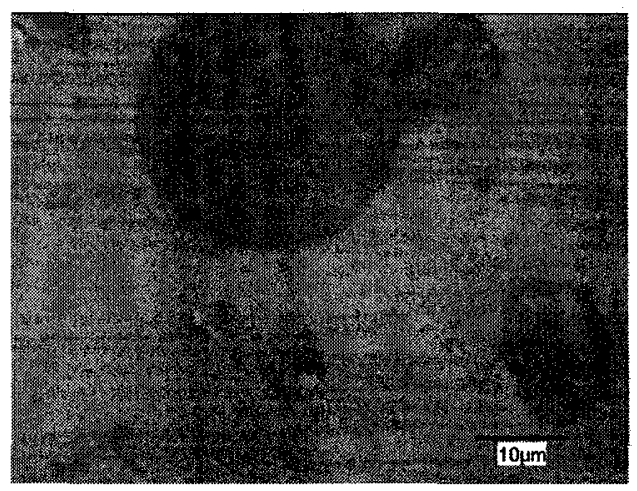

(i) Unetched

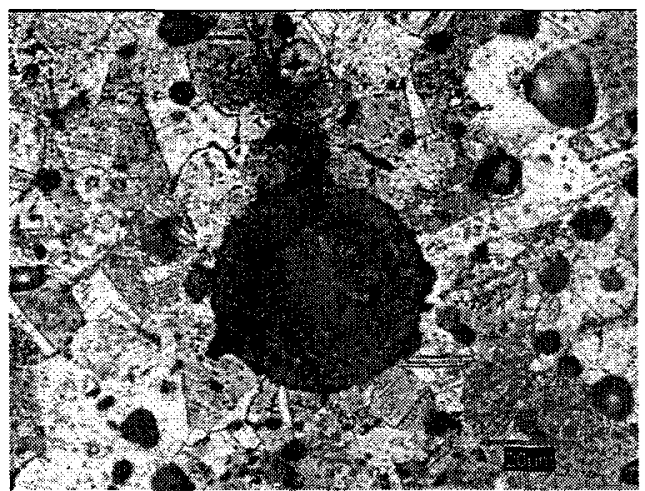

(h) Etched

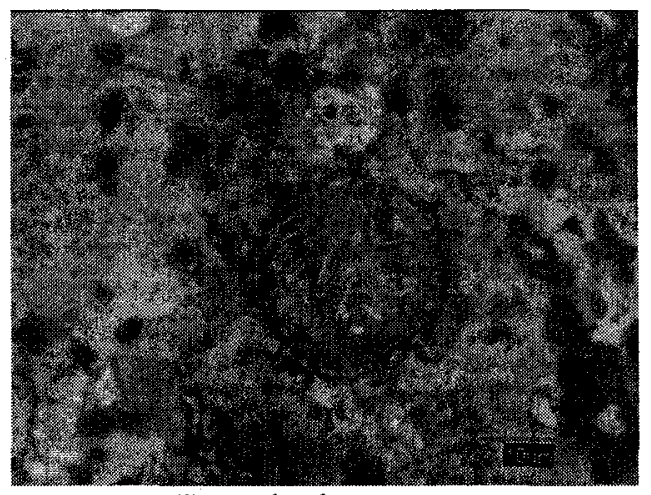

(j) Etched

Figure 4.6 Microstructures of premixed bronze with 10\% T-401 (specimen 7) 


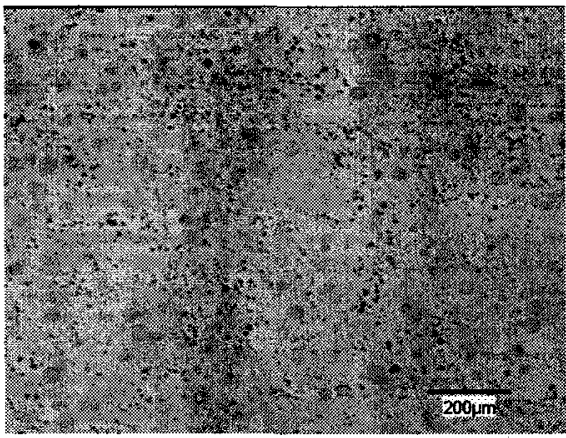

(a) Unetched

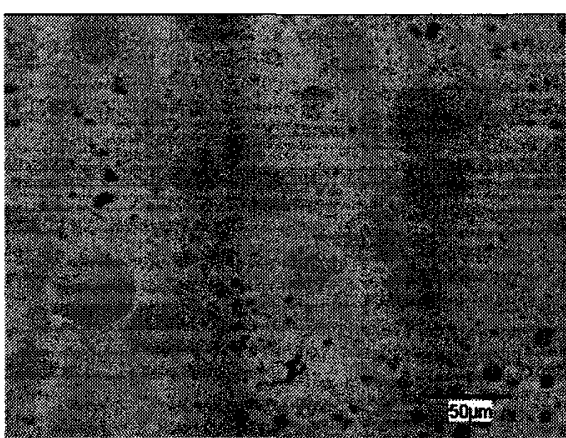

(c) Unetched

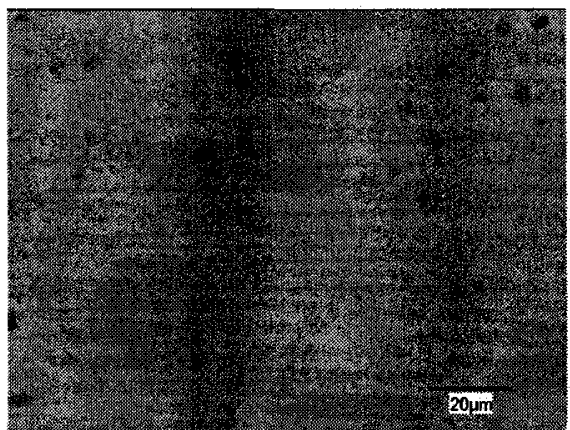

(e) Unetched

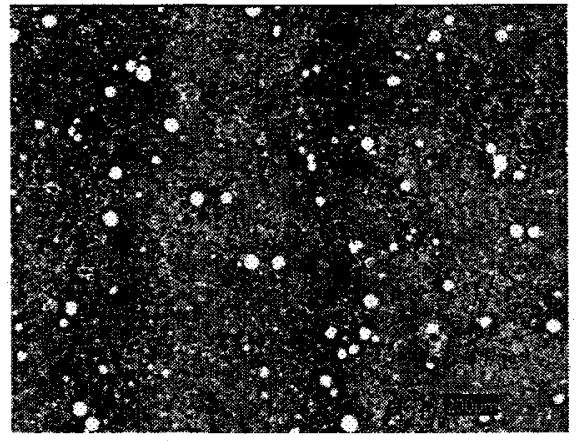

(b) Etched

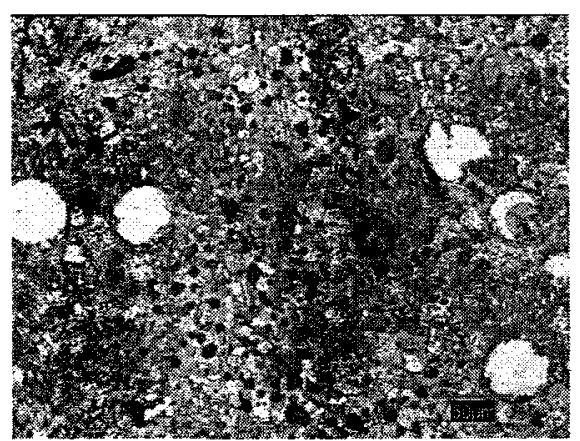

(d) Etched

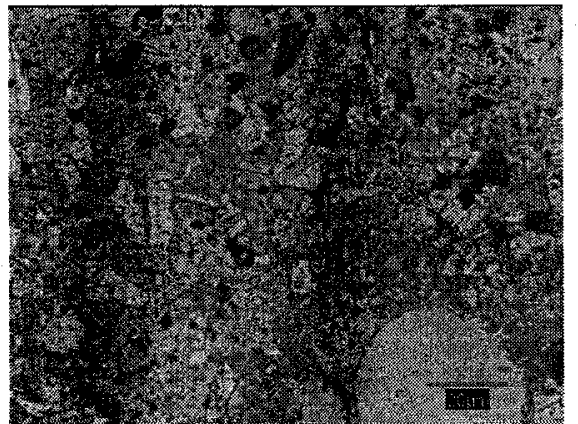

(f) Etched

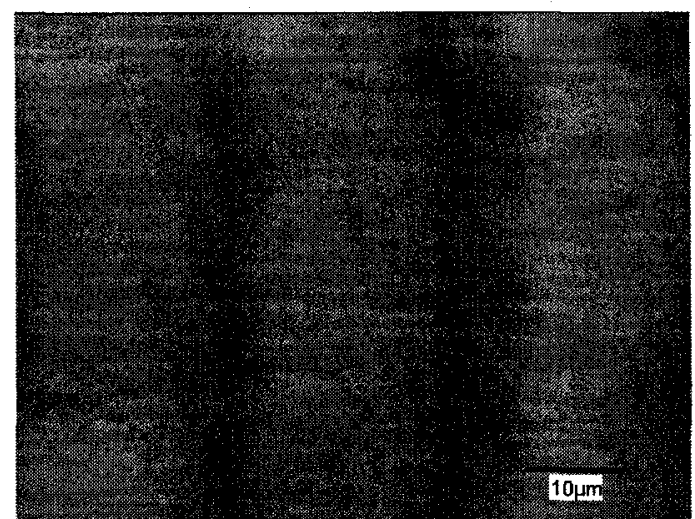

(g) Unetched

Figure 4.7 Microstructures of premixed bronze with 15\% T-401 (specimen 8) 


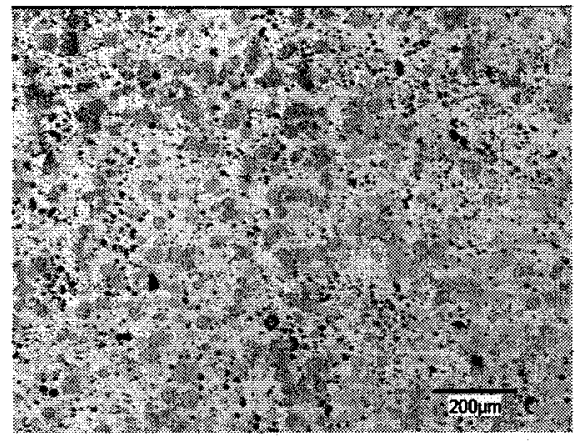

(a) Unetched

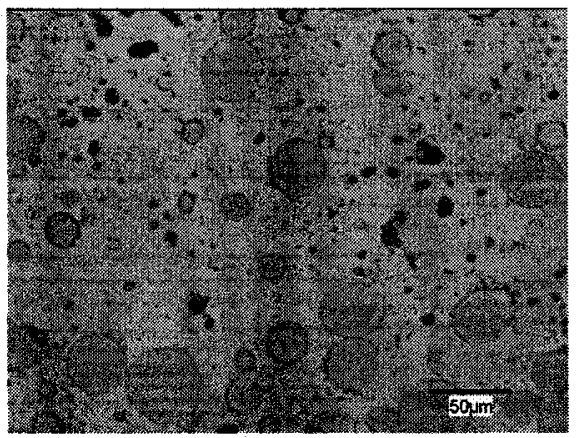

(c) Unetched

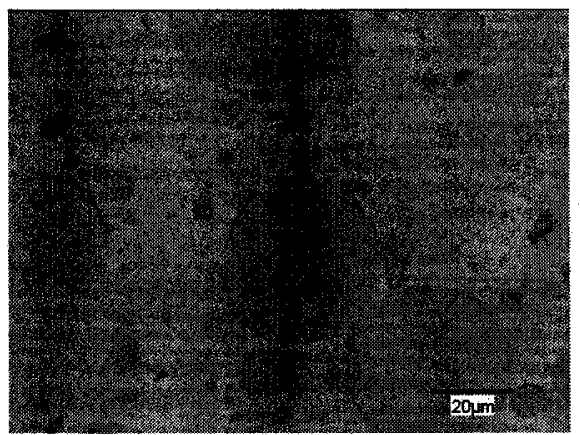

(e) Unetched

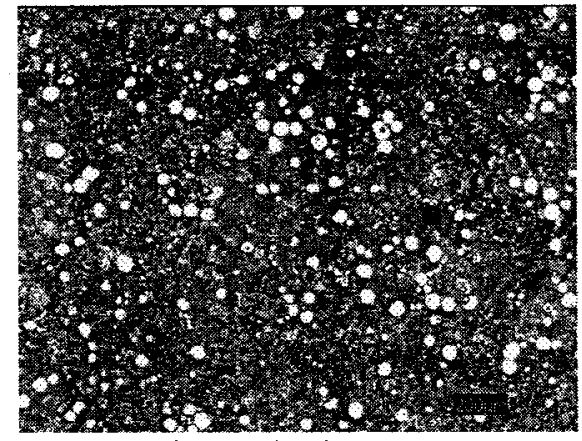

(b) Etched

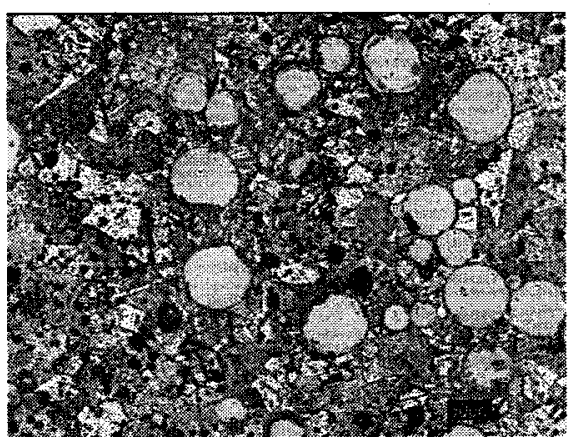

(d) Etched

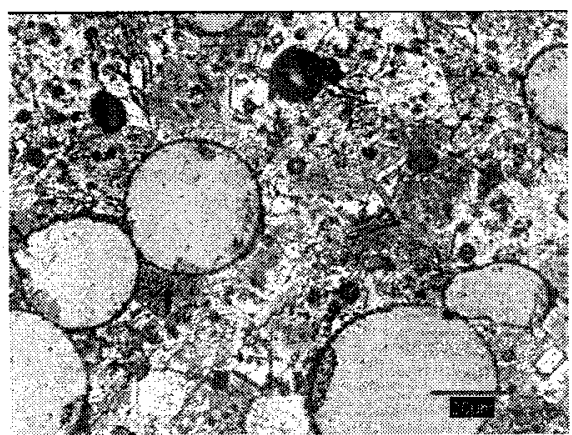

(f) Etched

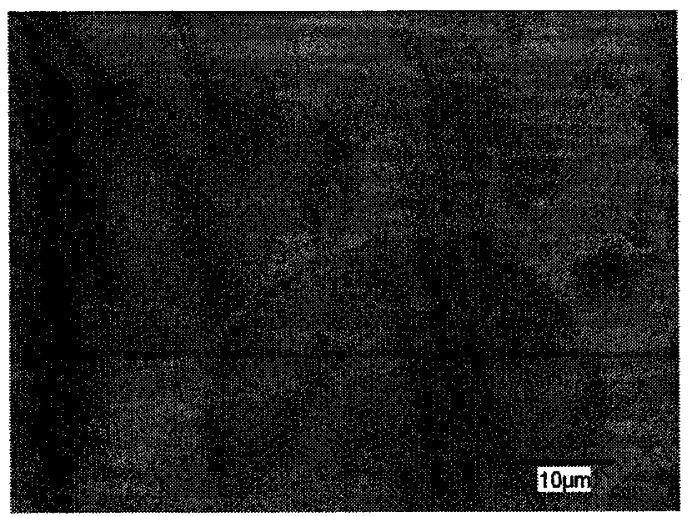

(g) Unetched

Figure 4.8 Microstructures of premixed bronze with 20\% T-401 (specimen 9) 


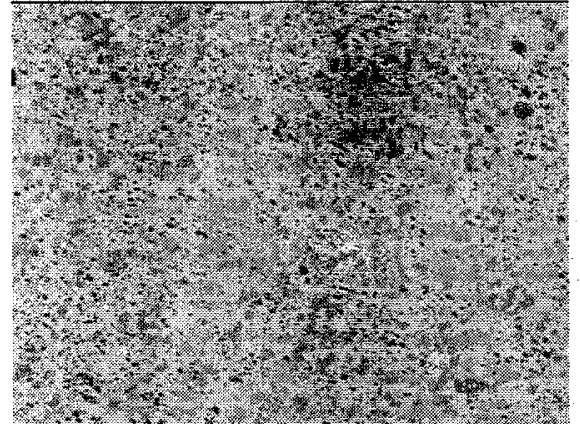

(a) Unetched

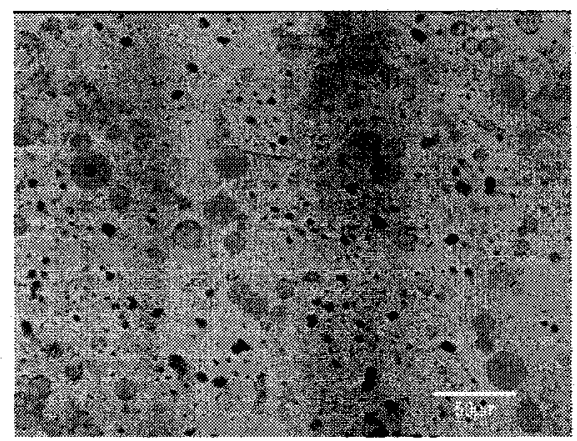

(c) Unetched

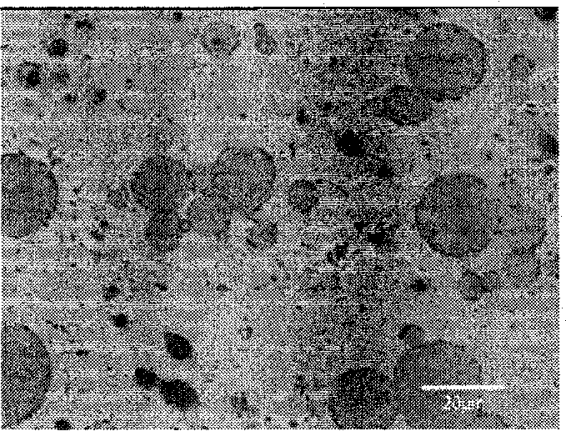

(e) Unetched

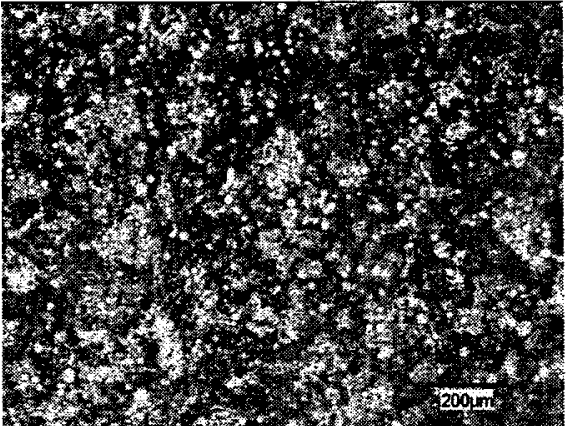

(b) Etched

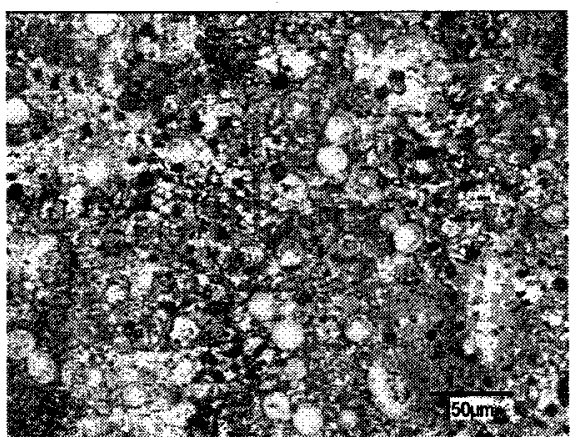

(d) Etched

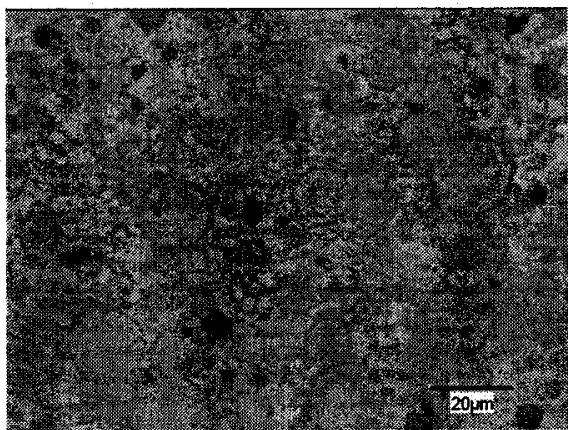

(f) Etched

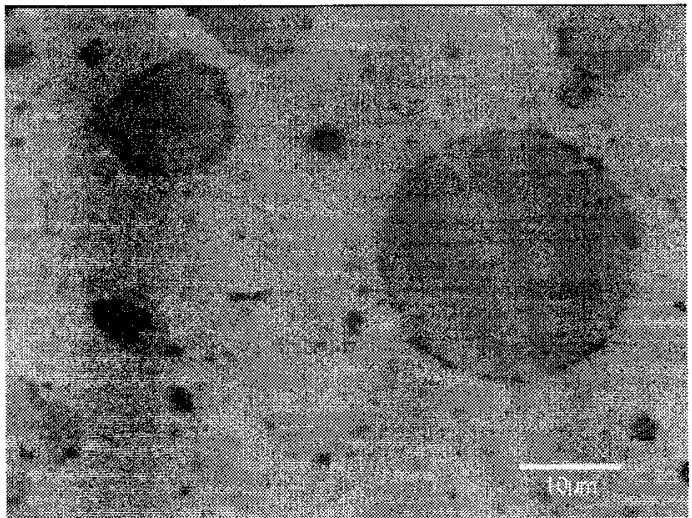

(g) Unetched

Figure 4.9 Microstructures of premixed bronze with $15 \%$ T-400C (specimen 13) 


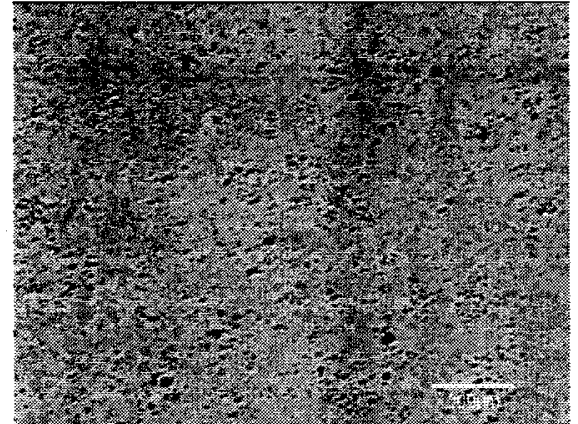

(a) Unetched

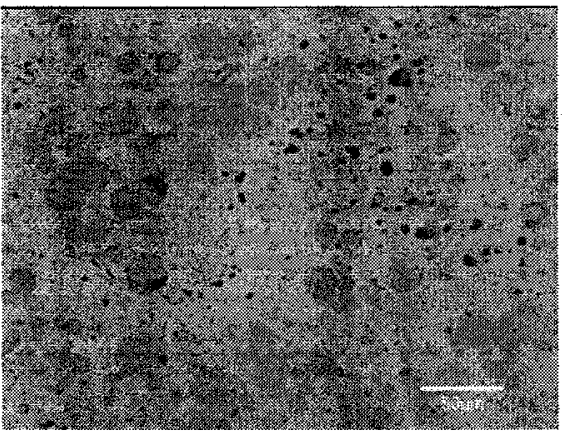

(c) Unetched

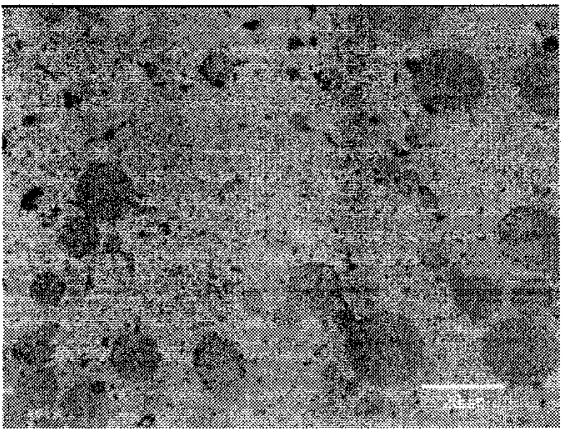

(e) Unetched

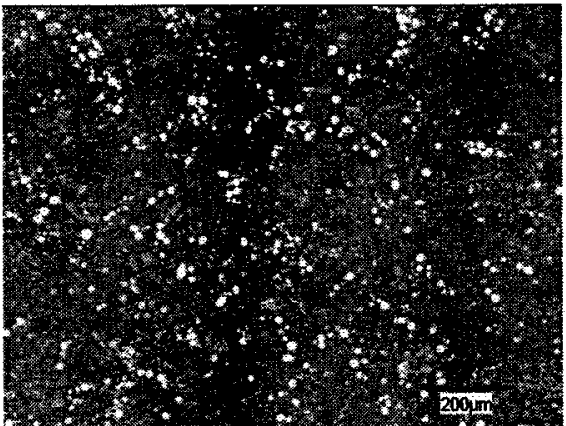

(b) Etched

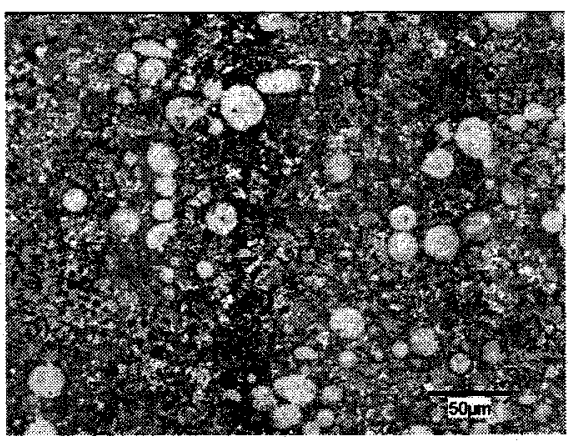

(d) Etched

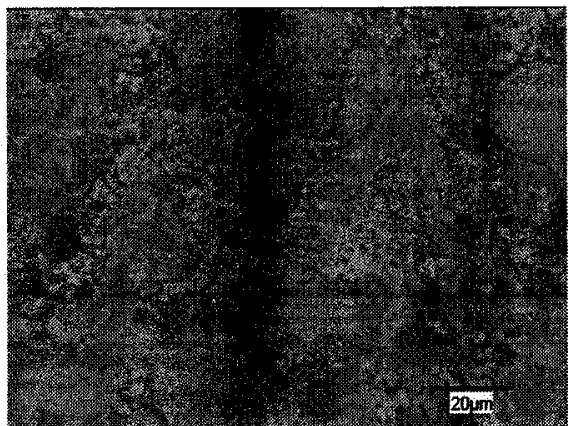

(f) Etched

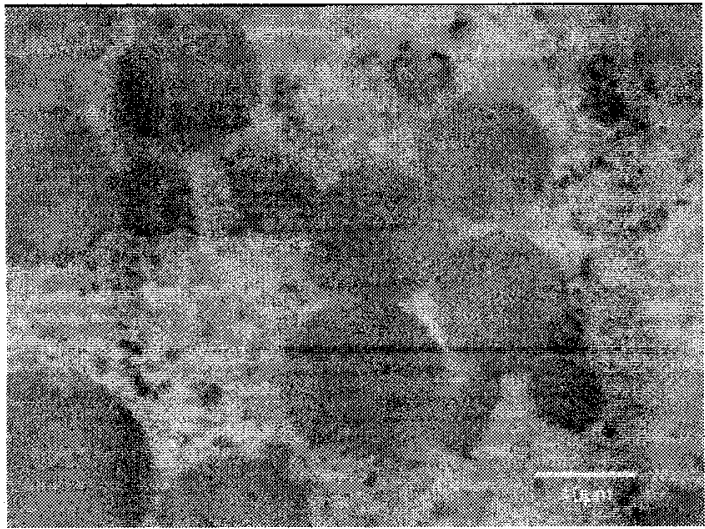

(g) Unetched

Figure 4.10 Microstructures of premixed bronze with 20\% T-400C (specimen 14) 


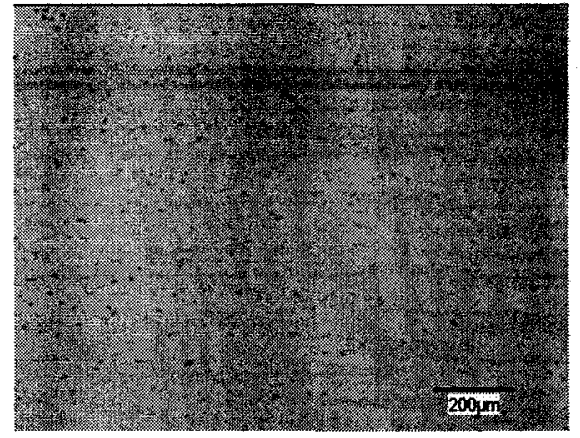

(a) Unetched

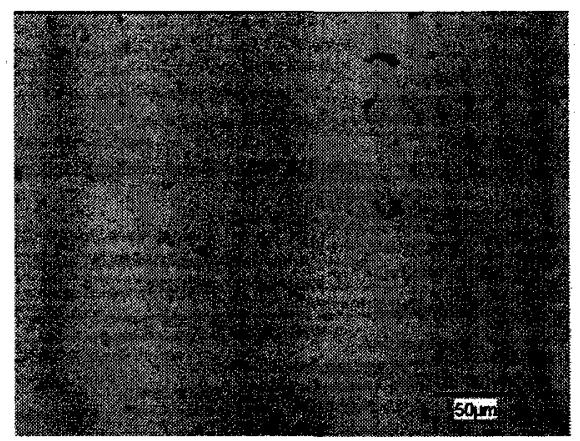

(c) Unetched

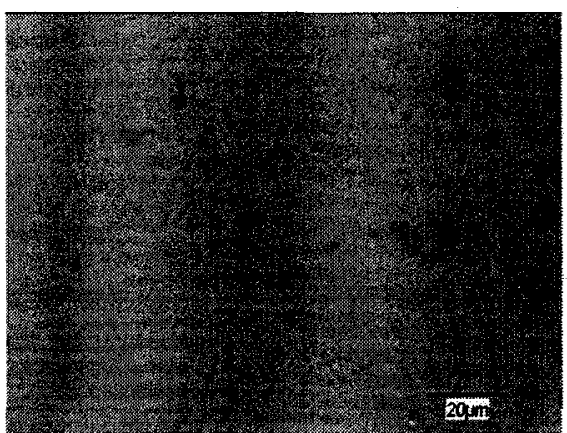

(e) Unetched

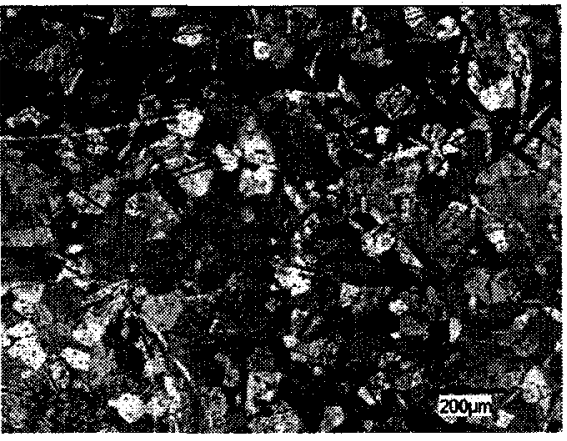

(b) Etched

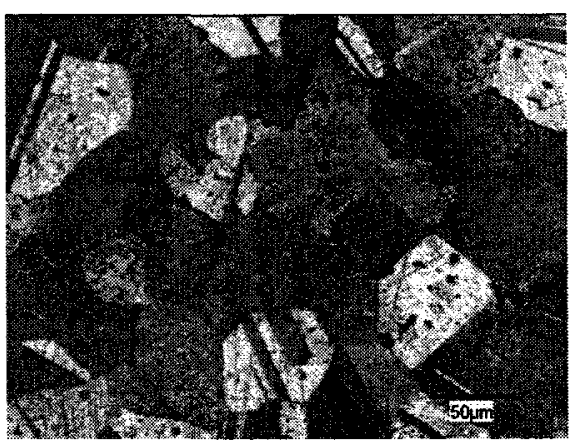

(d) Etched

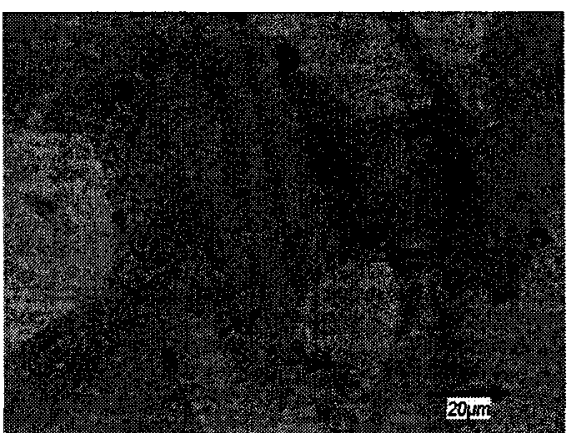

(f) Etched

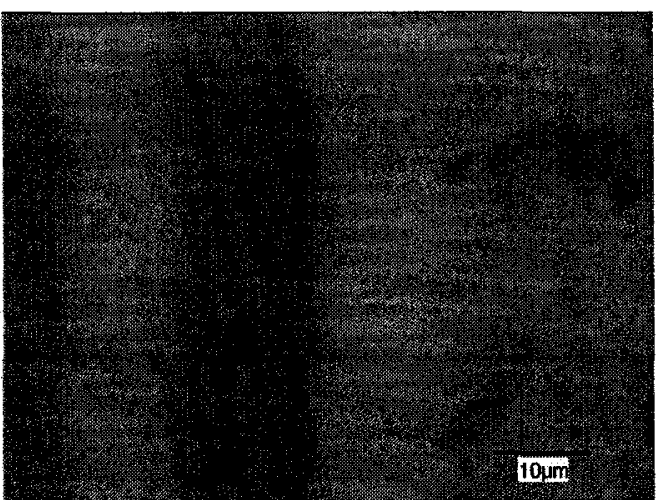

(g) Unetched

Figure 4.11 Microstructures of prealloyed bronze (specimen B409) 


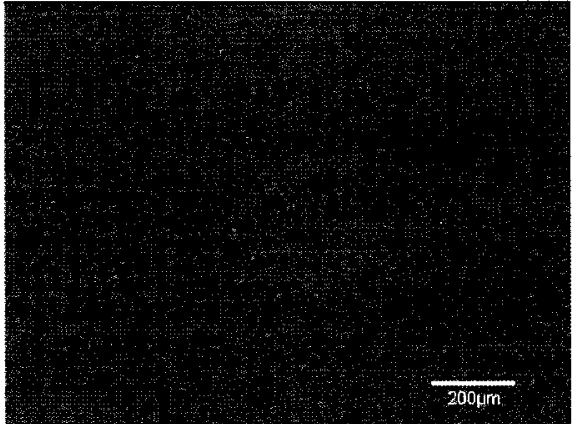

(a) Unetched

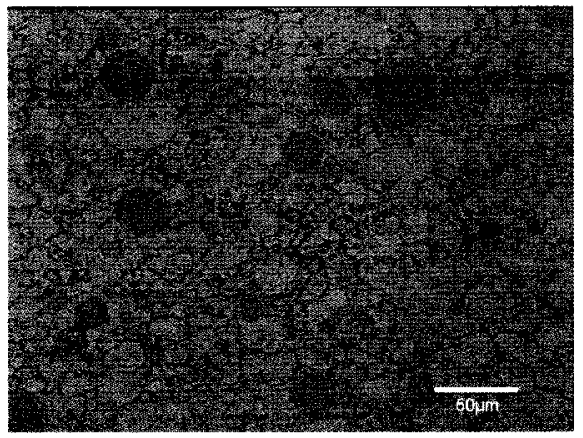

(c) Unetched

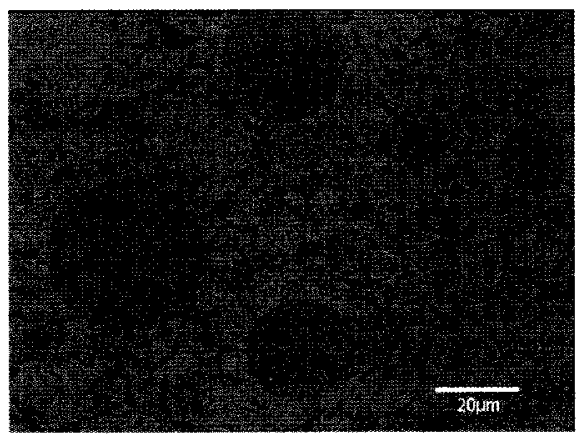

(e) Unetched

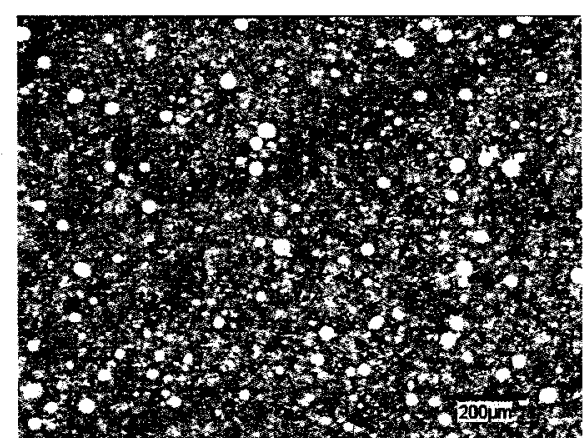

(b) Etched

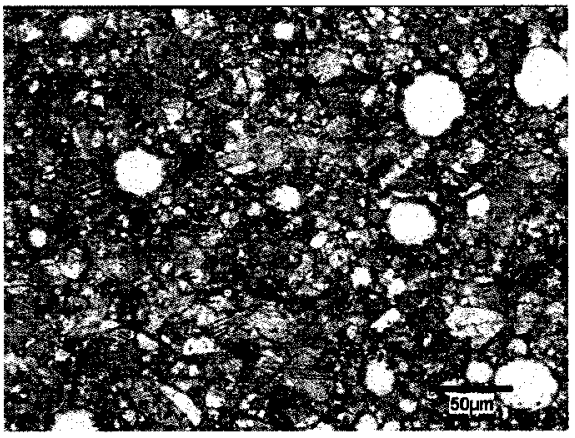

(d) Etched

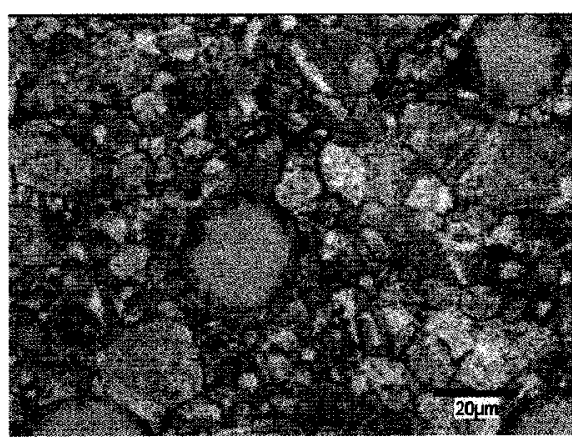

(f) Etched

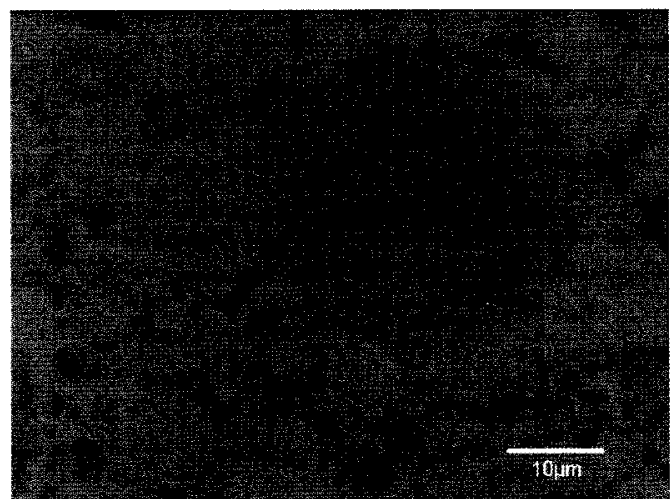

(g) Unetched

Figure 4.12 Microstructures of prealloyed bronze with 10\% T-401 (specimen 10) 


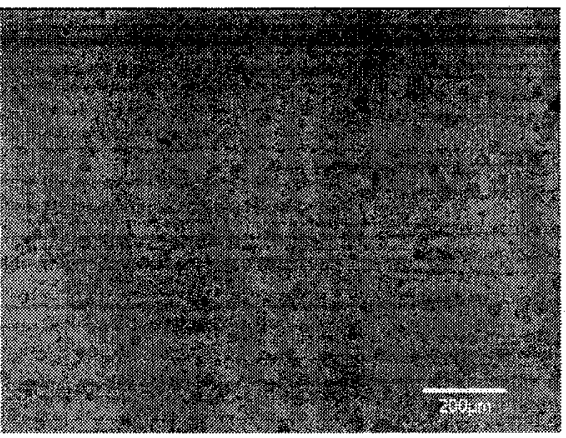

(a) Unetched

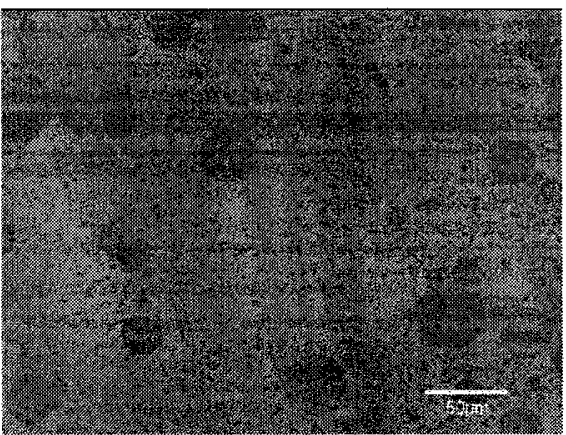

(c) Unetched

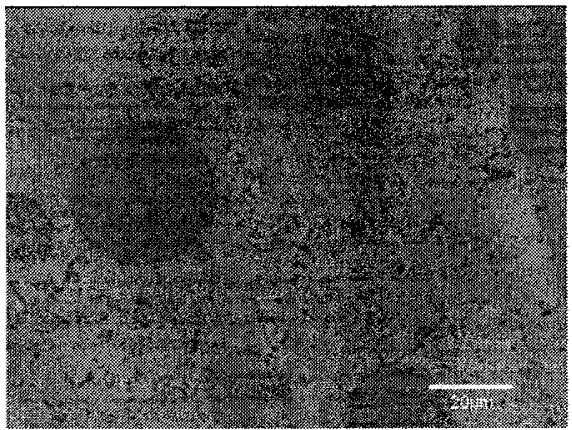

(e) Unetched

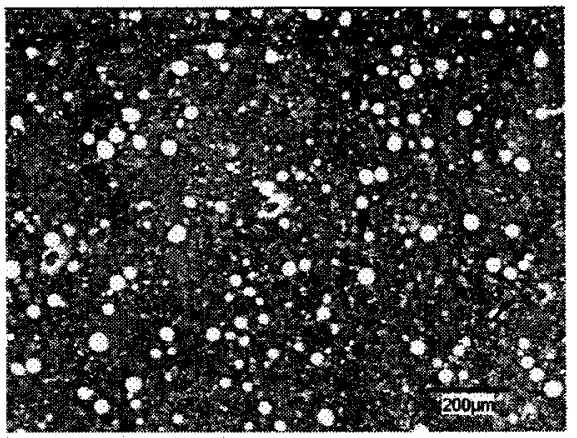

(b) Etched

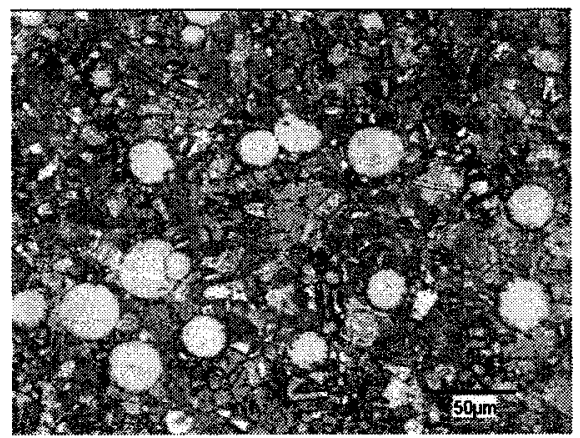

(d) Etched

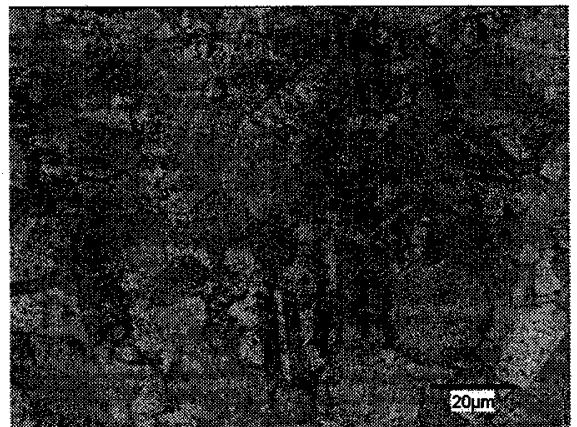

(f) Etched

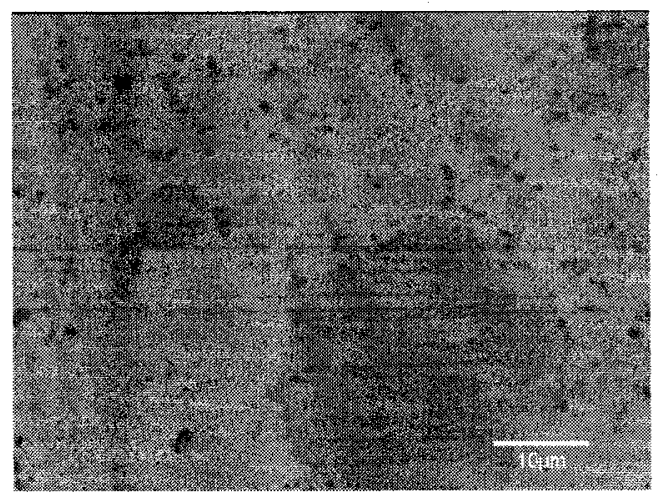

(g) Unetched

Figure 4.13 Microstructures of prealloyed bronze with 15\% T-401 (specimen 11) 


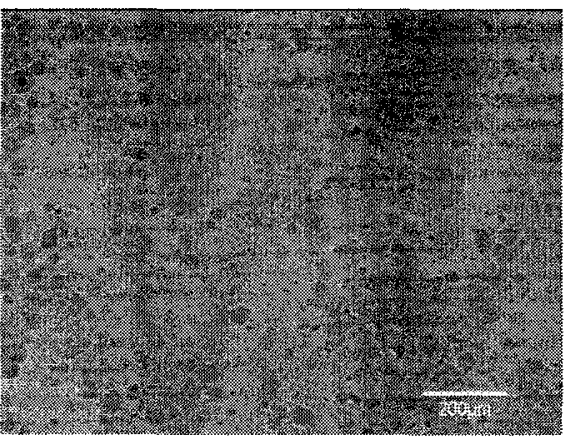

(a) Unetched

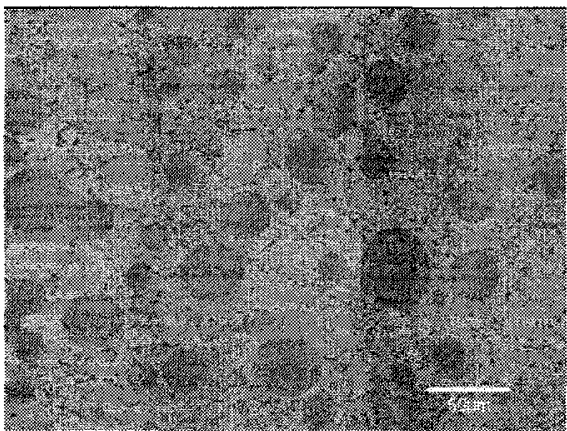

(c) Unetched

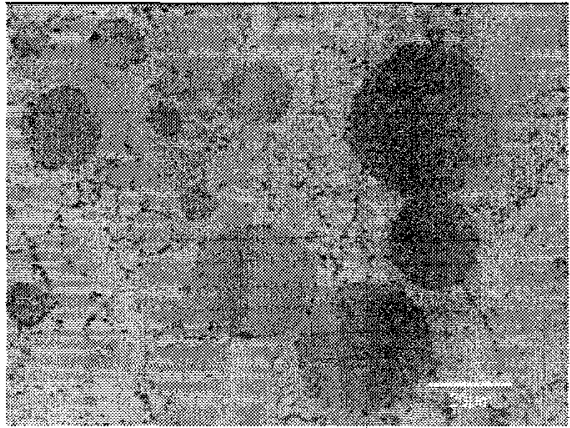

(e) Unetched

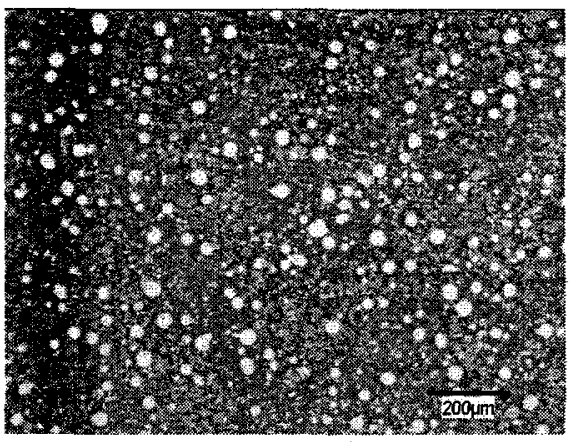

(b) Etched

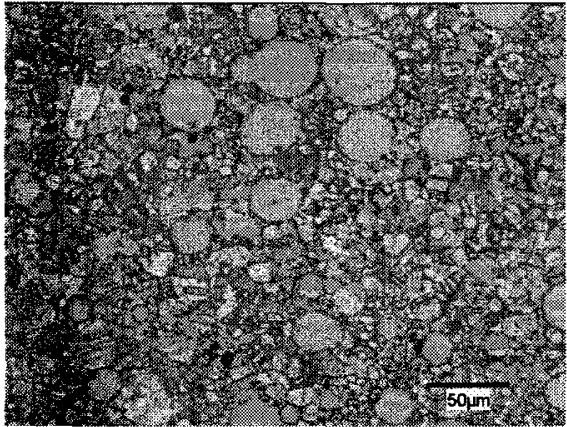

(d) Etched

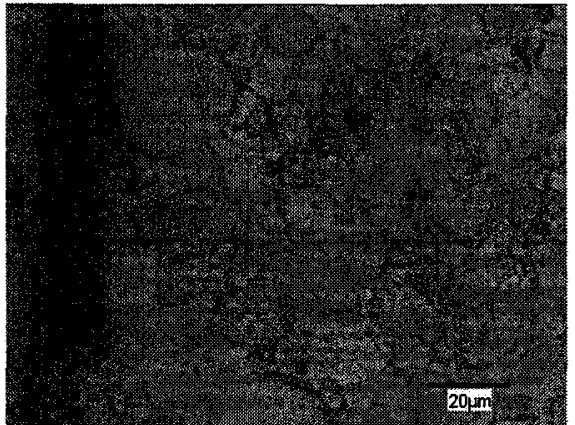

(f) Etched

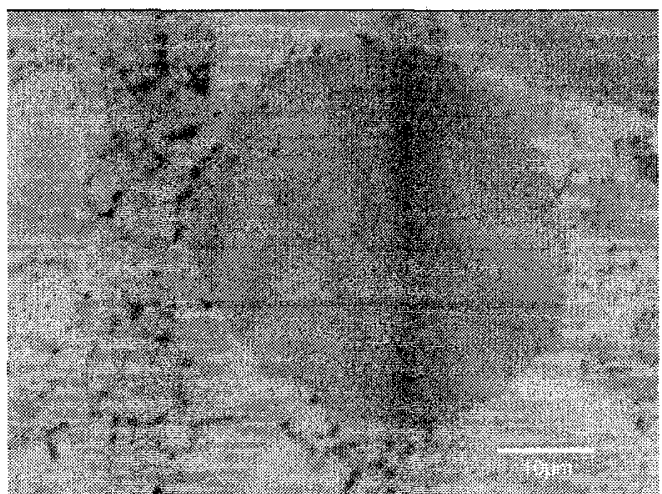

(g) Unetched

Figure 4.14 Microstructures of prealloyed bronze with 20\% T-401 (specimen 12) 


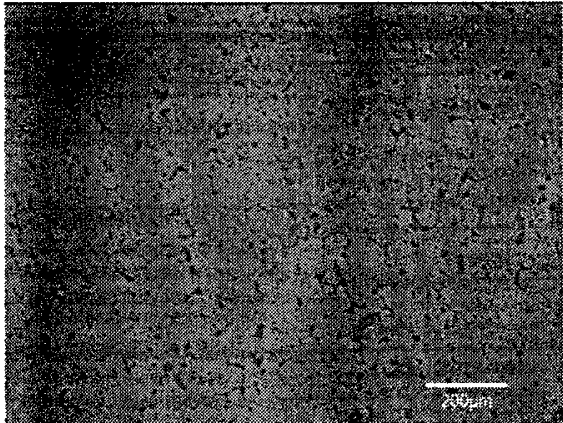

(a) Unetched - center

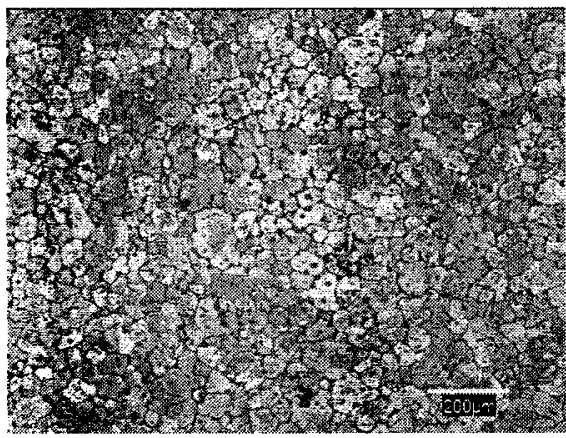

(c) Etched - center

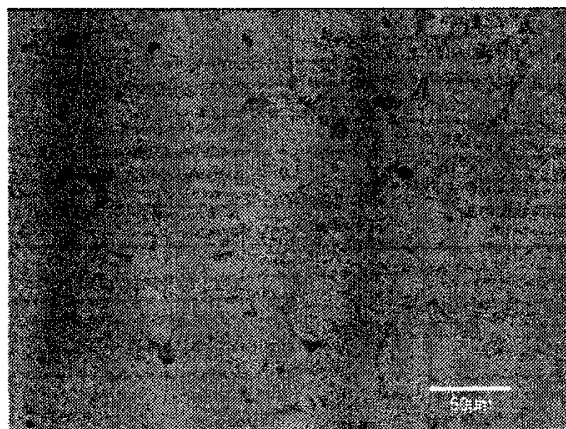

(e) Unetched

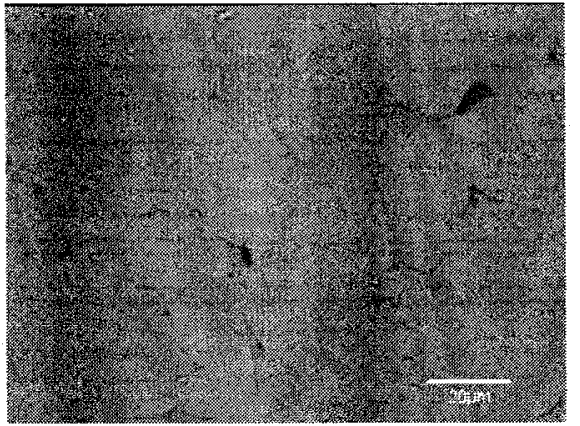

(g) Unetched

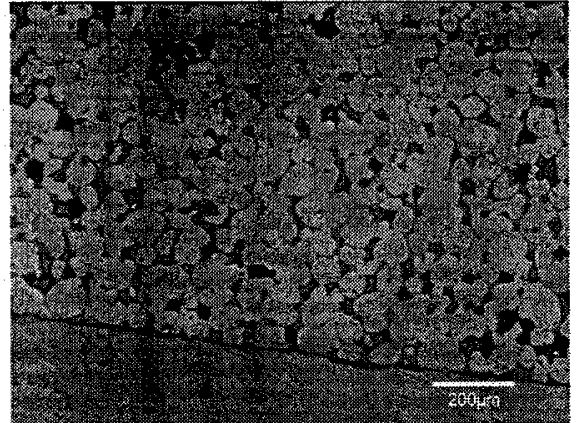

(b) Unetched - edge

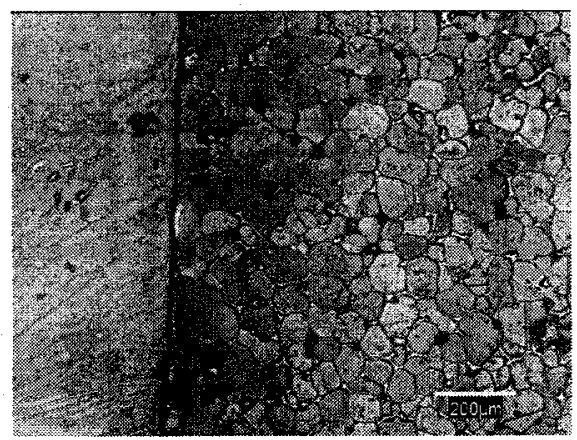

(d) Etched - edge

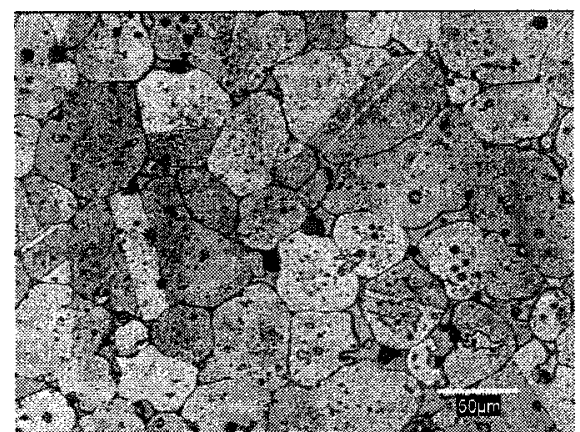

(f) Etched

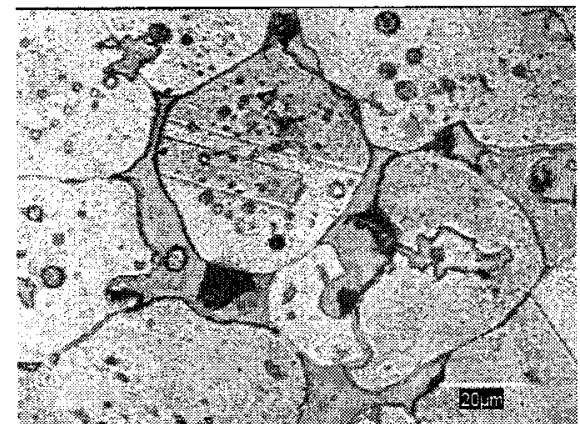

(h) Etched

Figure 4.15 Microstructures of copper-15\% bismuth (specimen 6) 


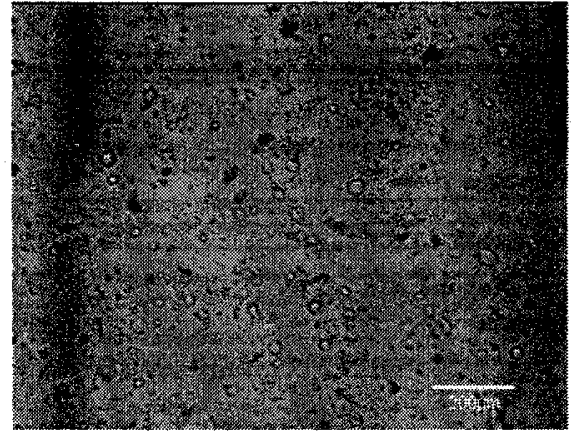

(a) Unetched

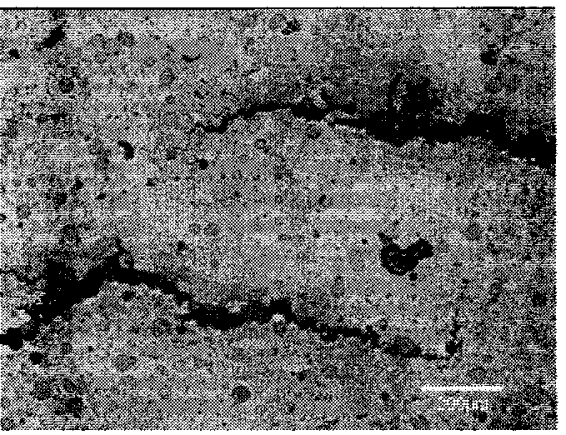

(c) Unetched

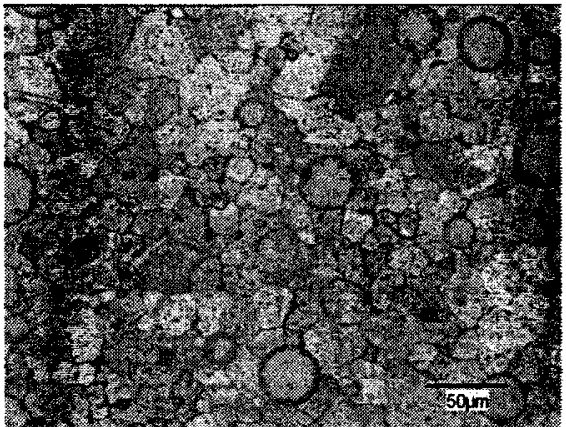

(e) Unetched

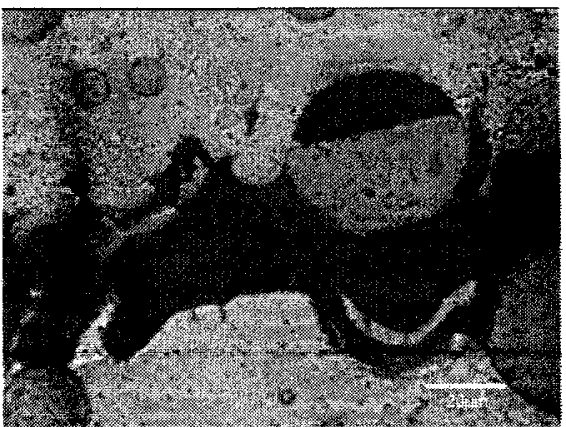

(g) Unetched

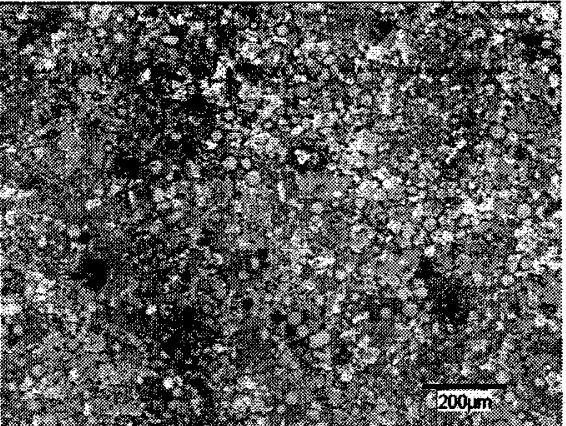

(b) Etched

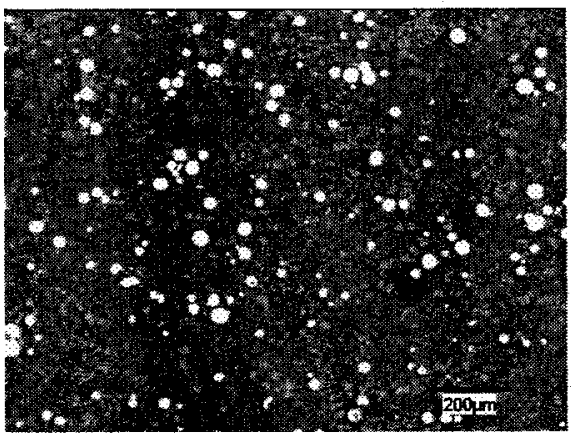

(d) Etched

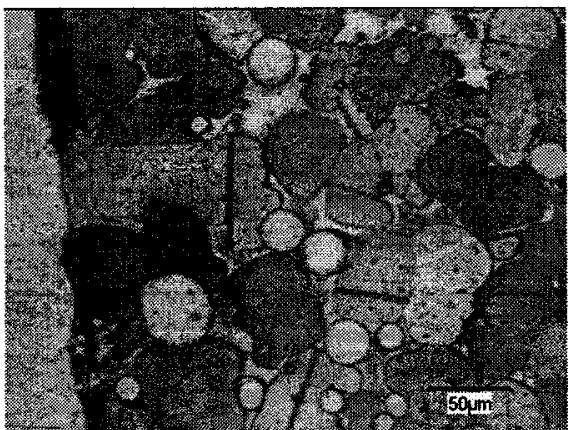

(f) Etched

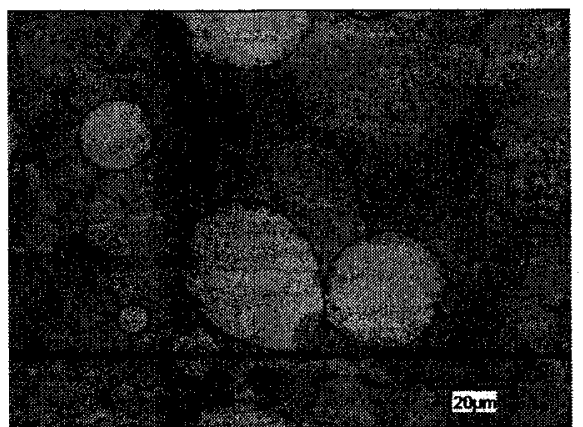

(h) Etched

Figure 4.16 Microstructures of copper-15\% bismuth with 10\% T-401 (specimen 16) 


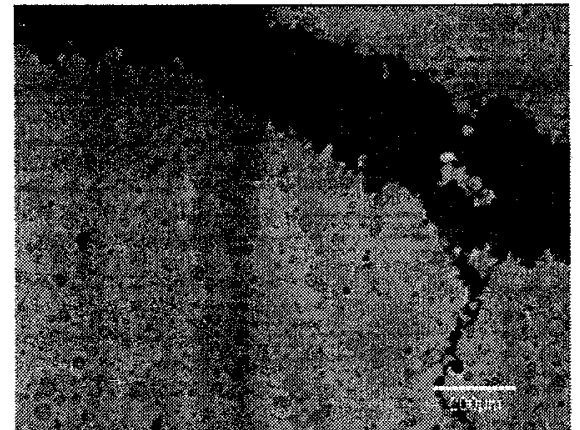

(a) Unetched

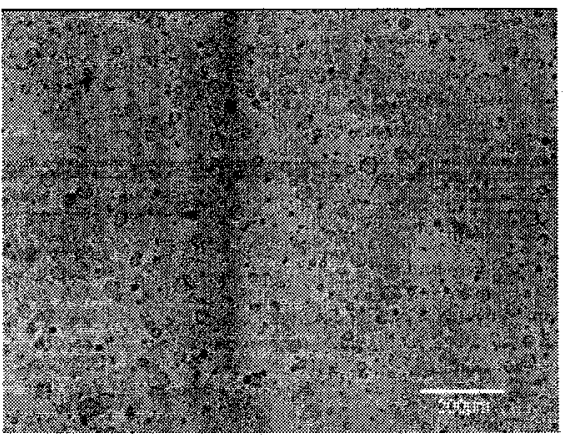

(c) Unetched

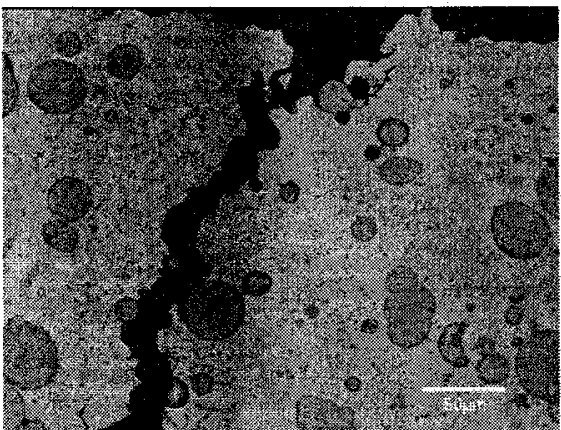

(e) Unetched

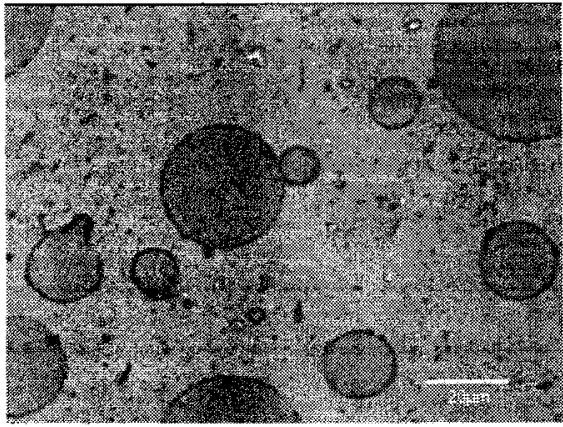

(g) Unetched

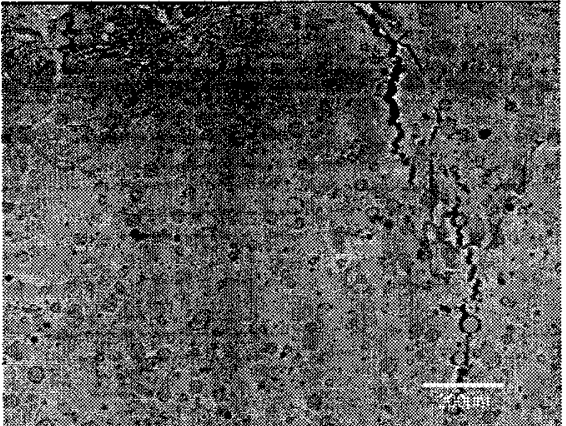

(b) Etched

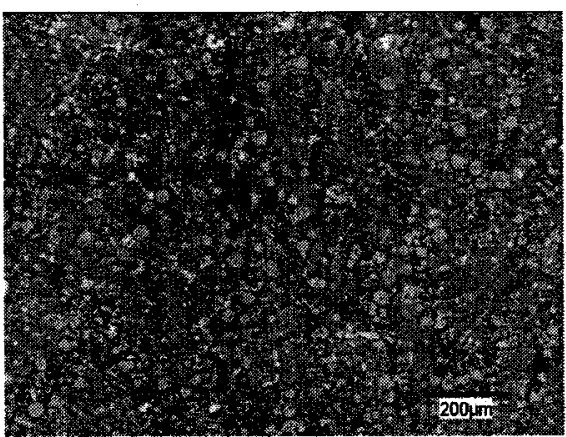

(d) Etched

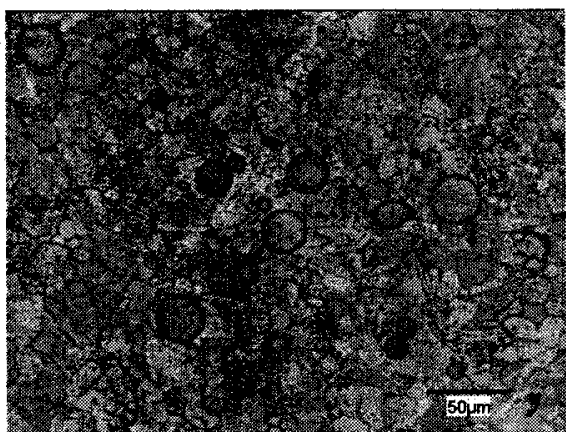

(f) Etched

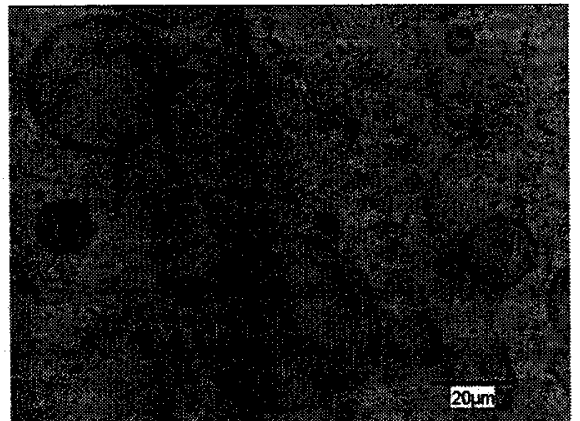

(h) Etched

Figure 4.17 Microstructures of copper-15\% bismuth with 15\% T-401 (specimen 17) 


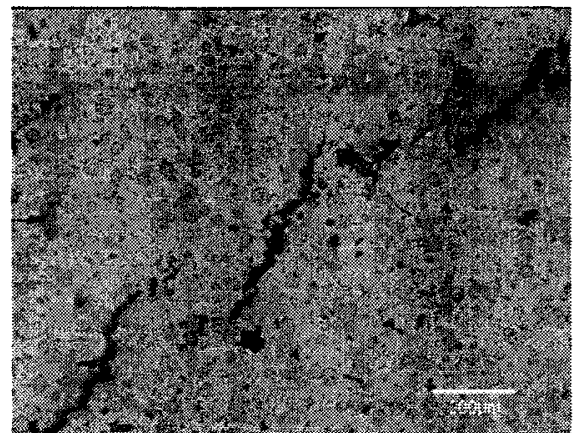

(a) Unetched

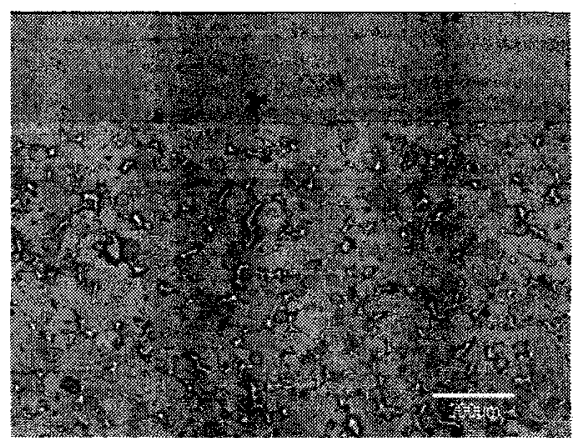

(c) Unetched

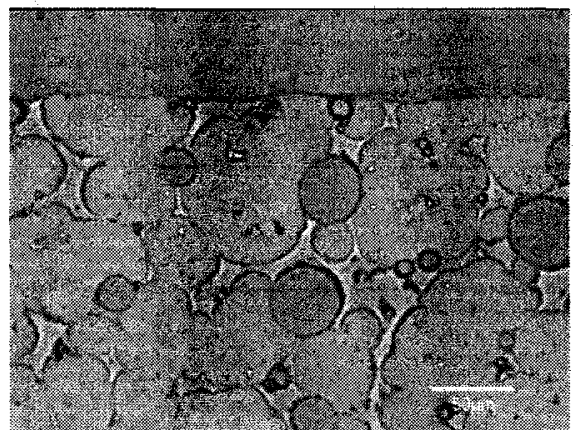

(e) Unetched

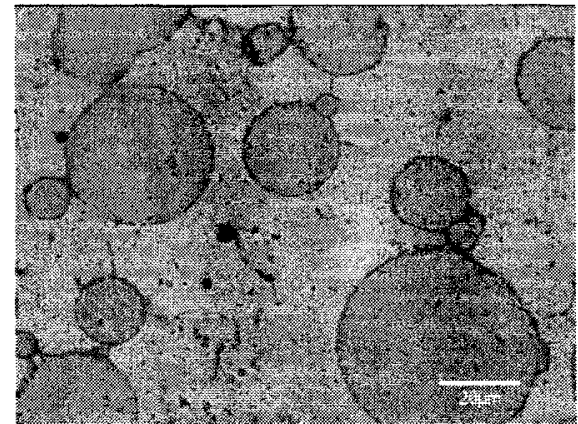

(g) Unetched

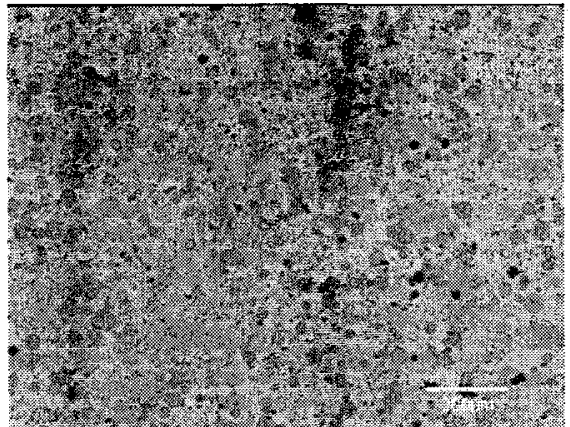

(b) Etched

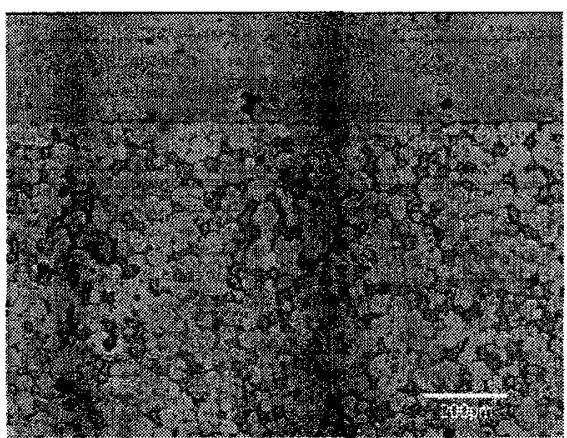

(d) Etched

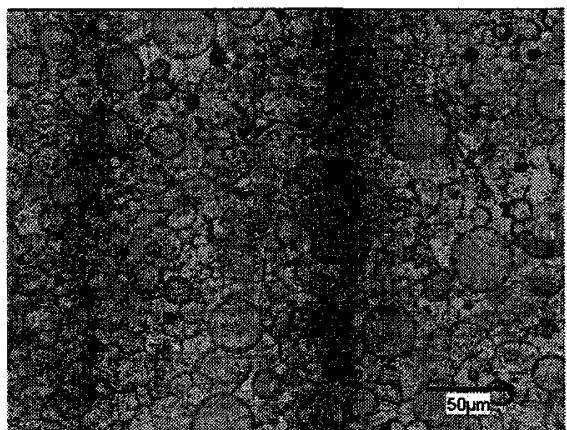

(f) Etched

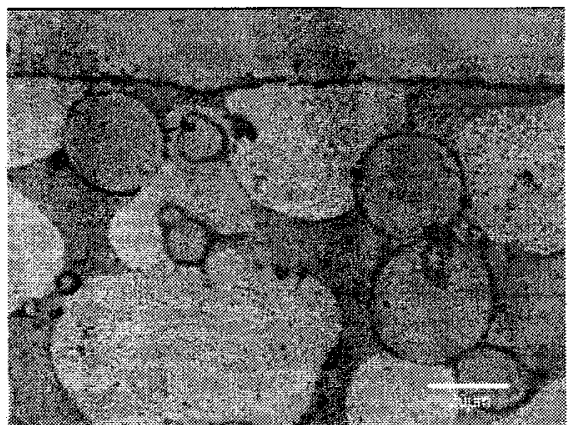

(h) Etched 


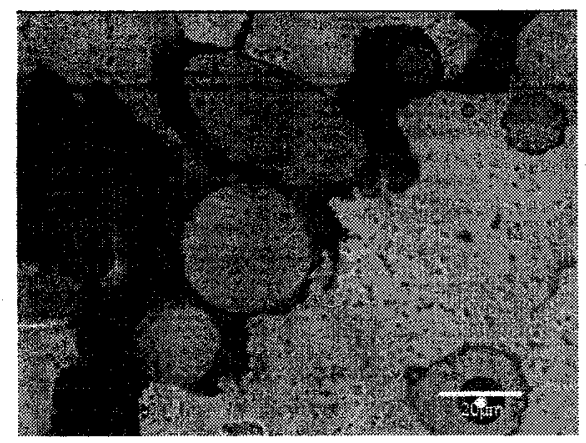

(i) Unetched

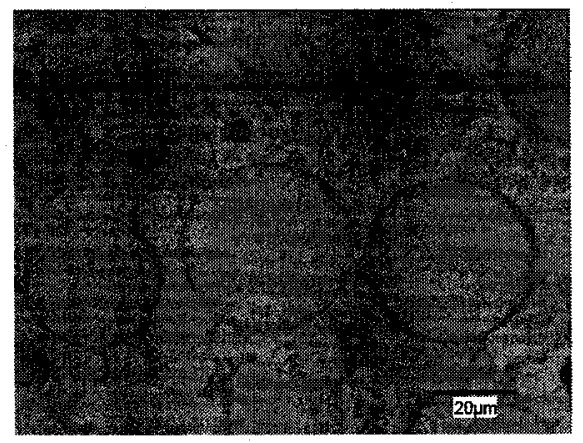

(j) Etched

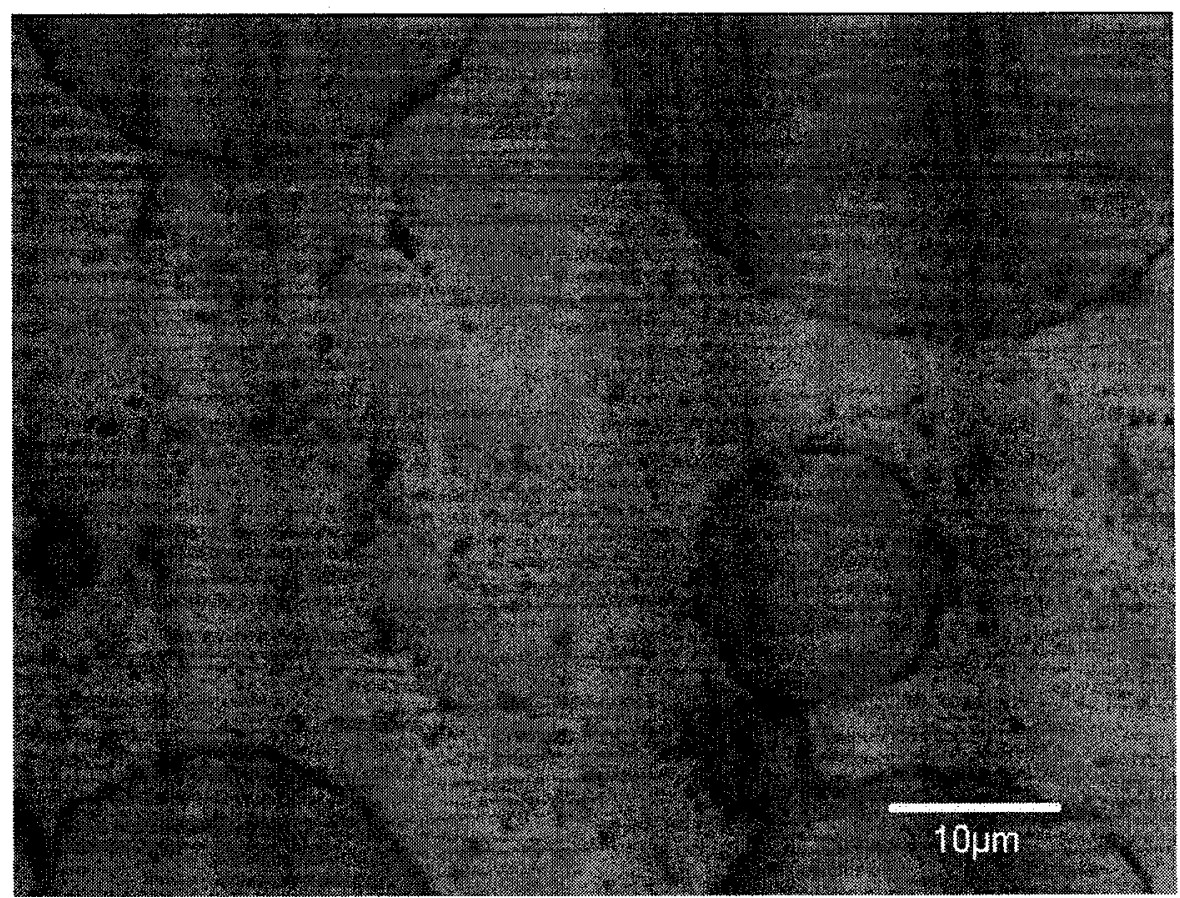

(k) Unetched

Figure 4.18 Microstructures of copper-15\% bismuth with 20\% T-401 (specimen 18) 


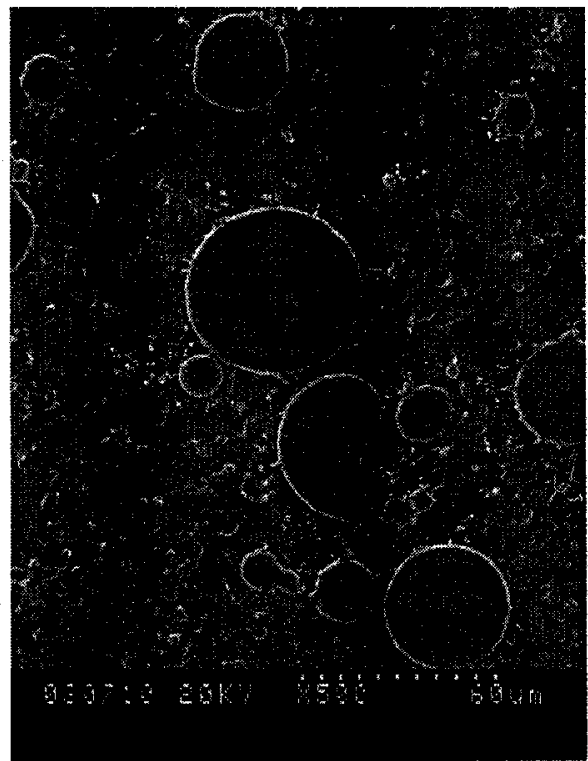

(a)

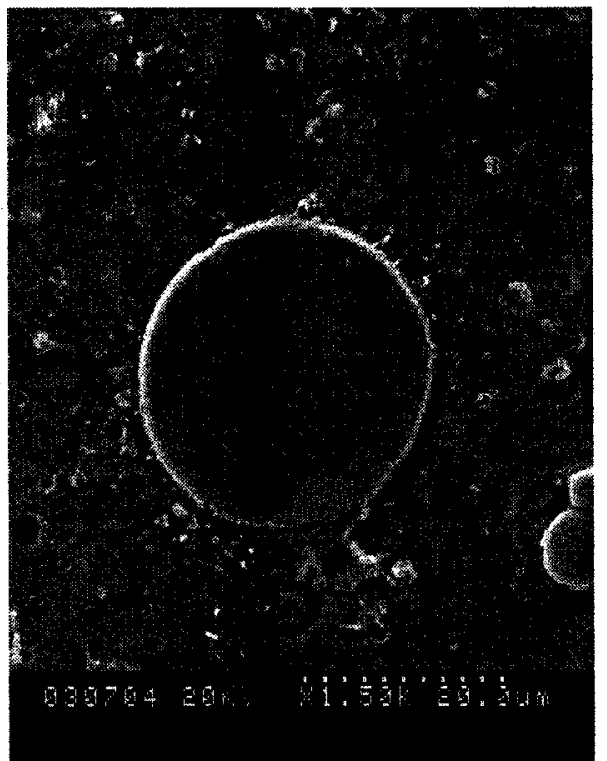

(b)

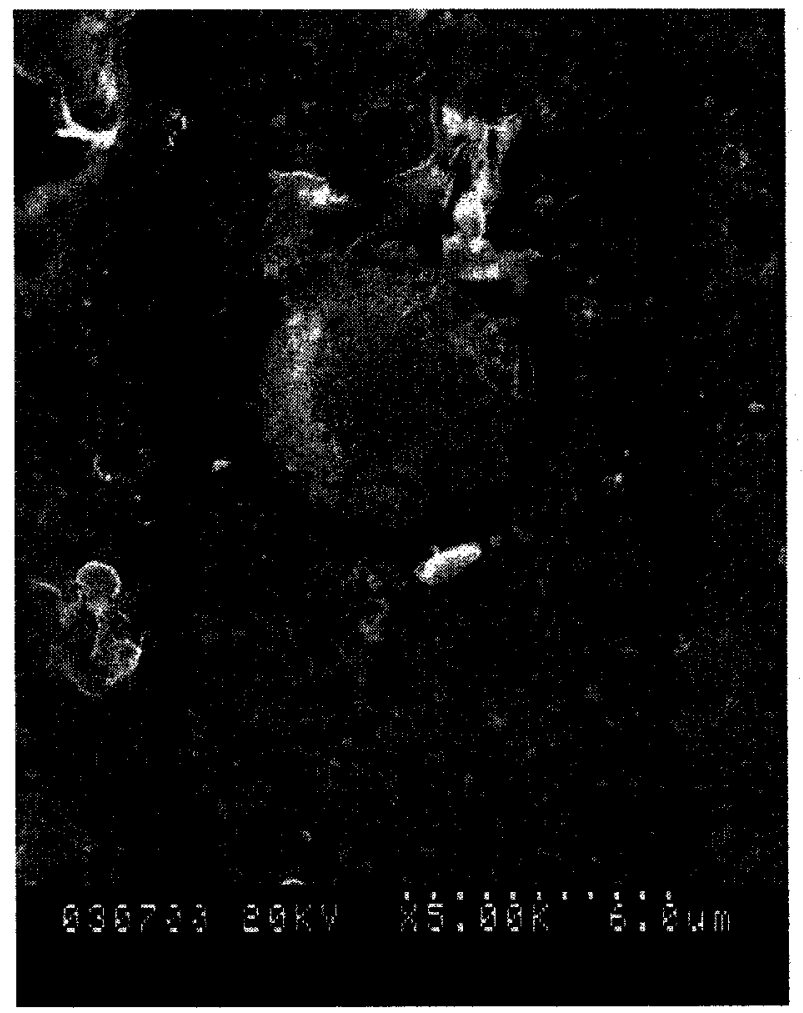

(c)

Figure 4.19 SEM images of HIPped premixed bronze with 10\% T-401: (a) Medium magnification, (b) High magnification, (c) Very high magnification 


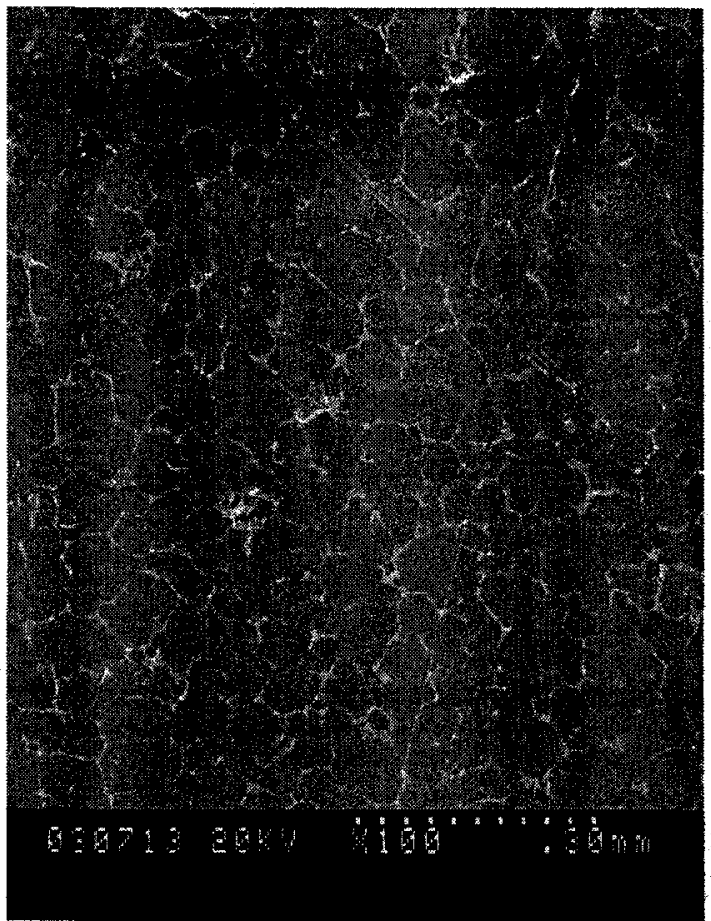

(a)

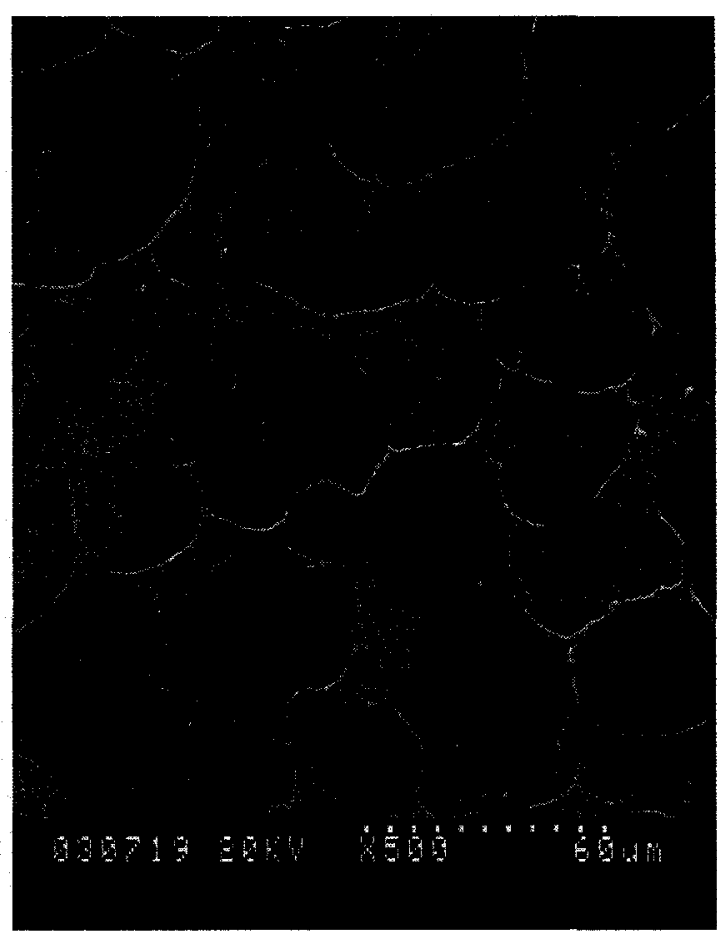

(b)

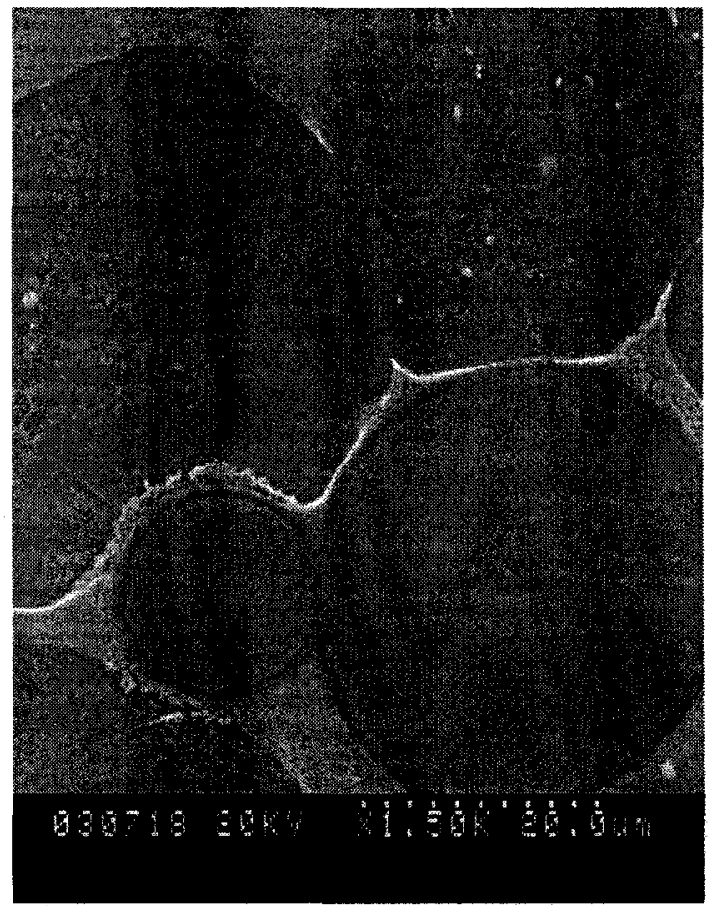

(c)

Figure 4.20 SEM images of HIPped copper-15\% bismuth with 10\% T-401: (a) Low magnification, (b) Medium magnification, (c) High magnification 


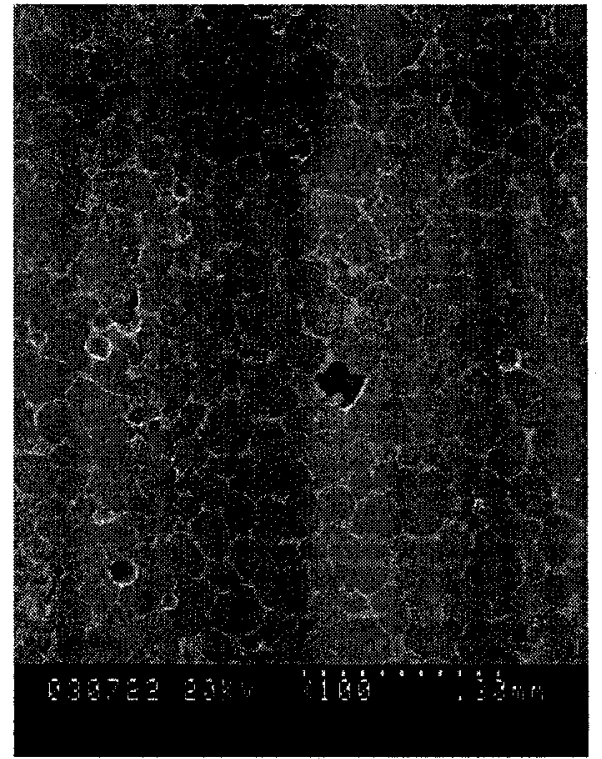

(a)

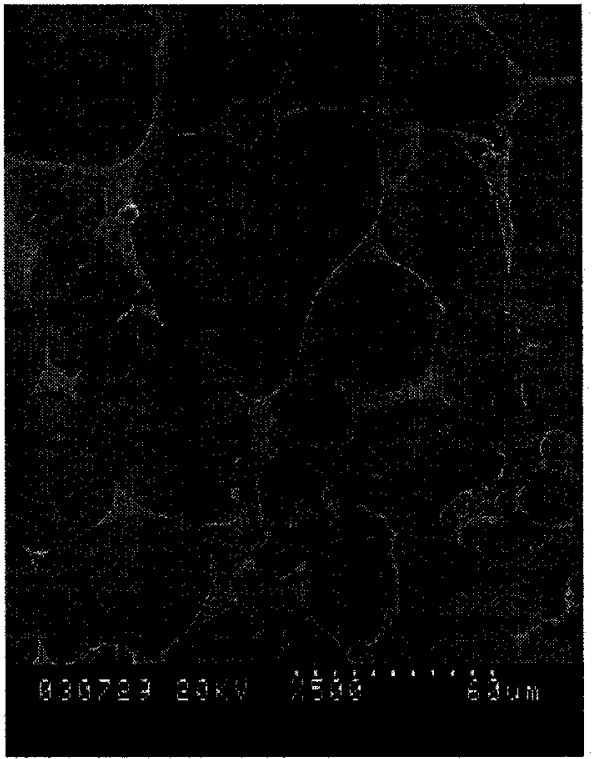

(b)

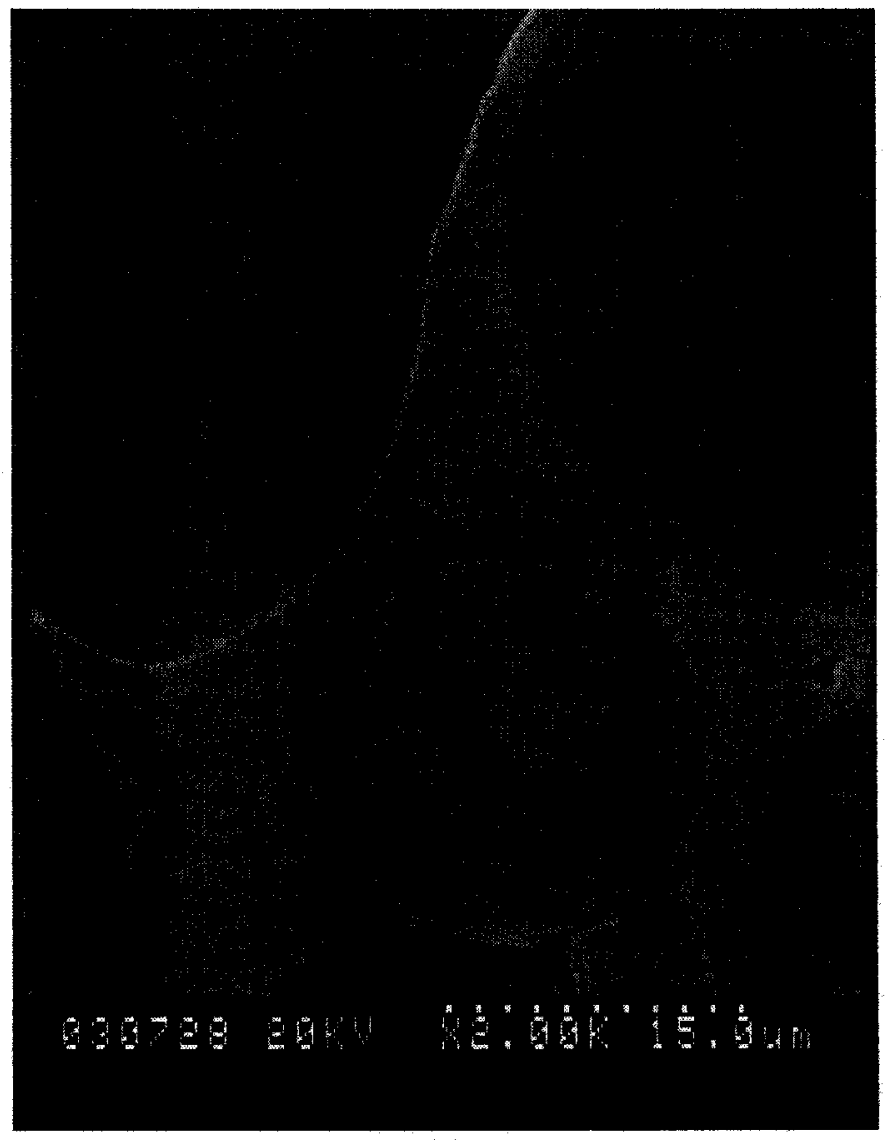

(c)

Figure 4.21 SEM images of undersintered copper-15\% bismuth with $10 \%$ T-401: (a) Low magnification, (b) Medium magnification, (c) High magnification 
kCounts

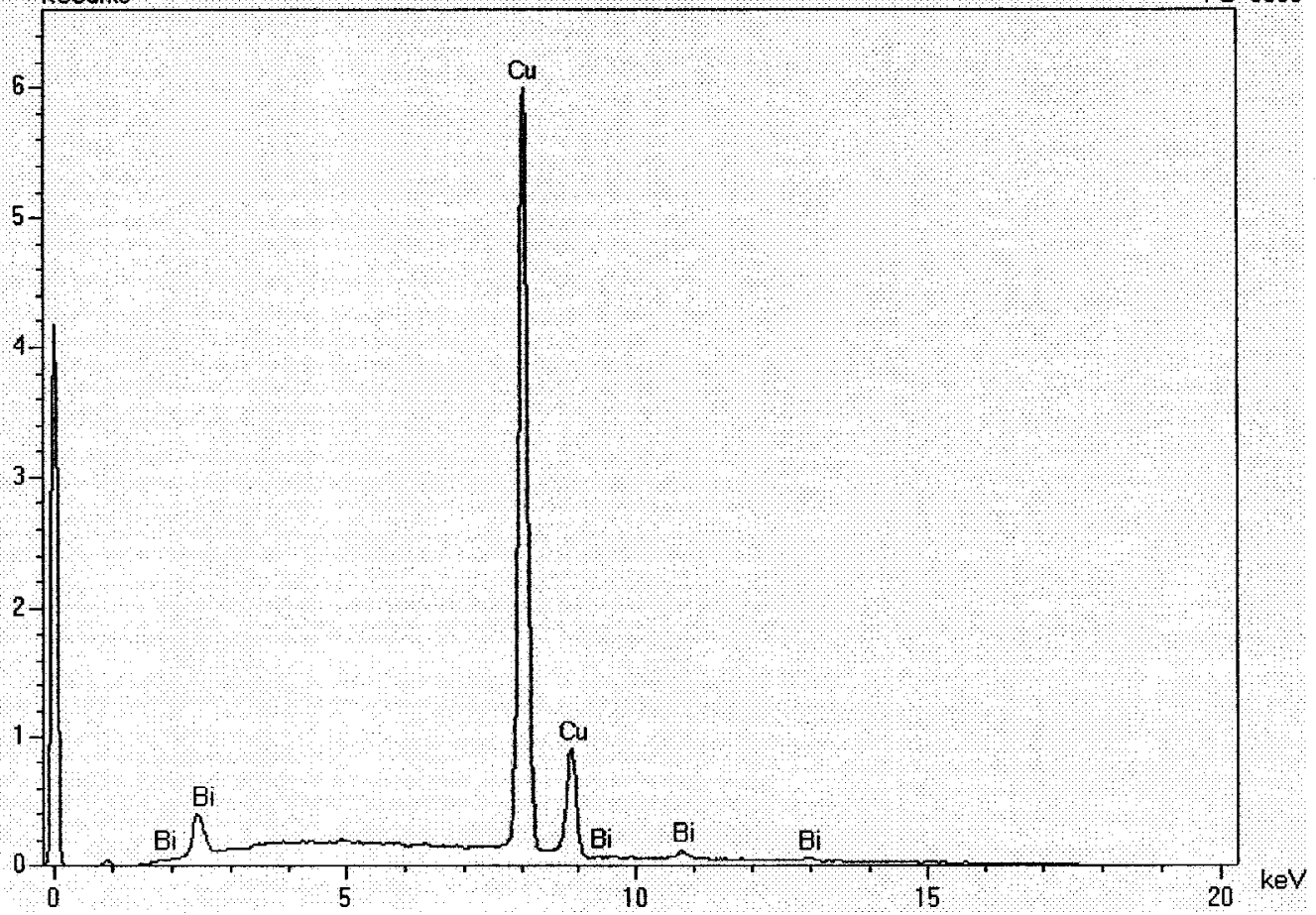

(a)

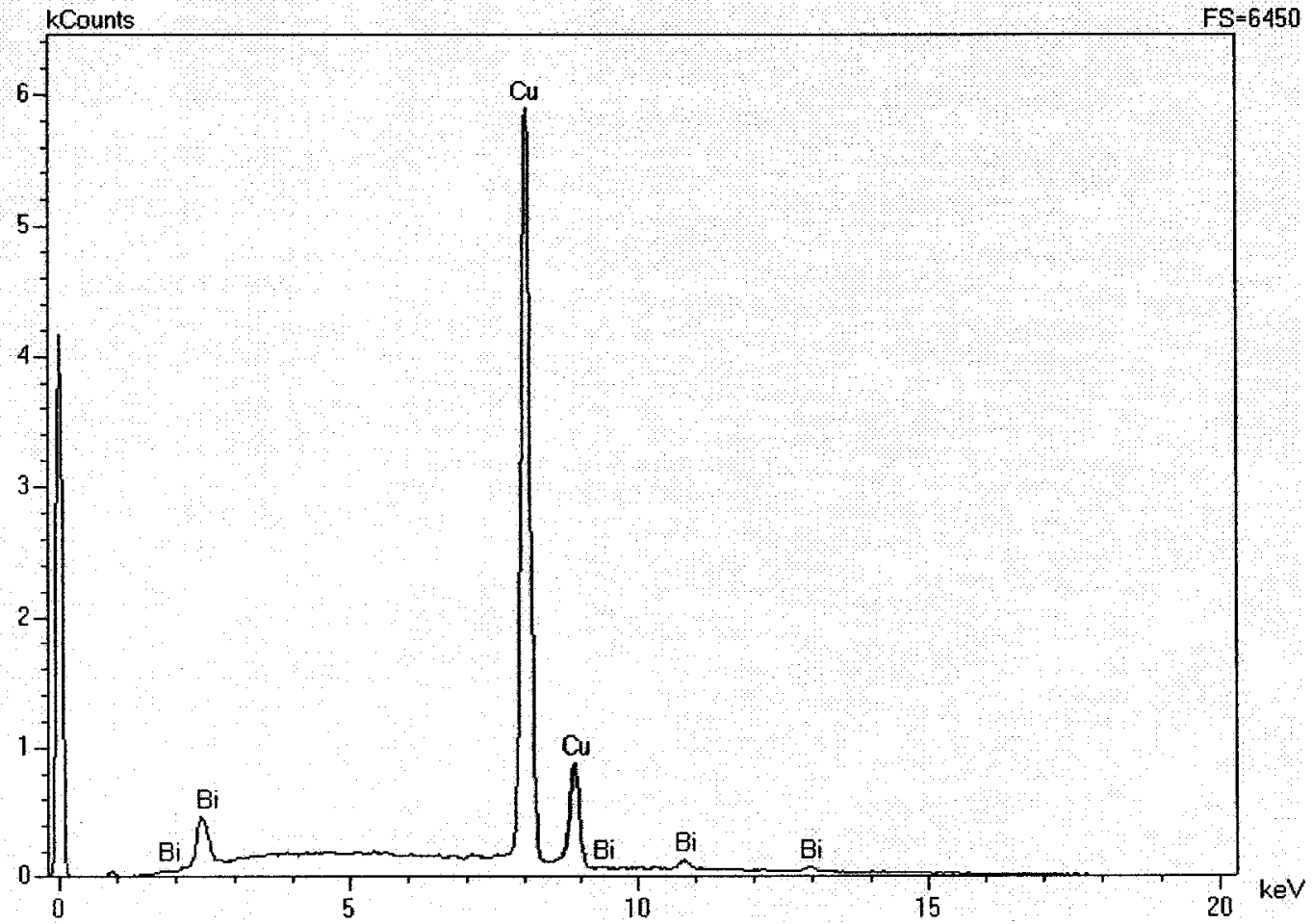

(b) 


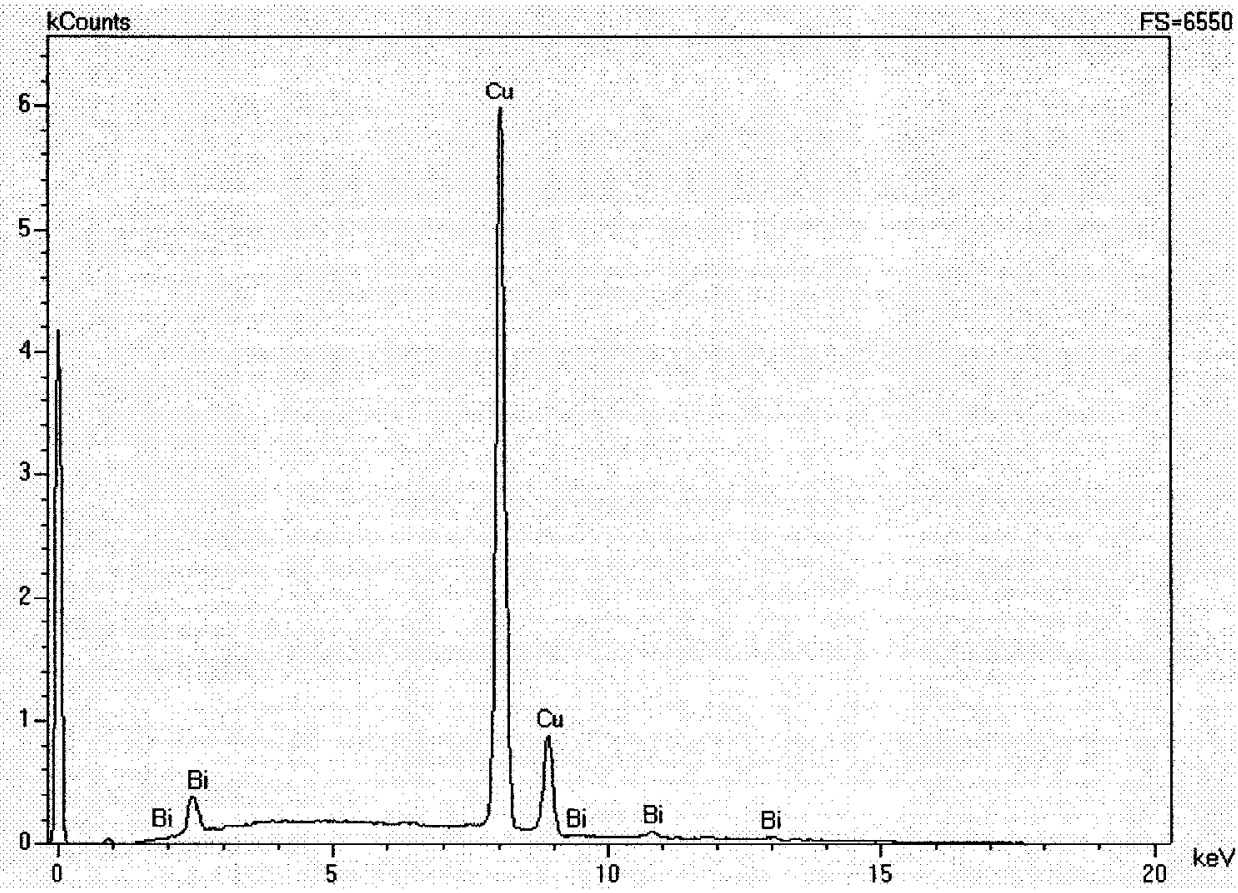

(c)

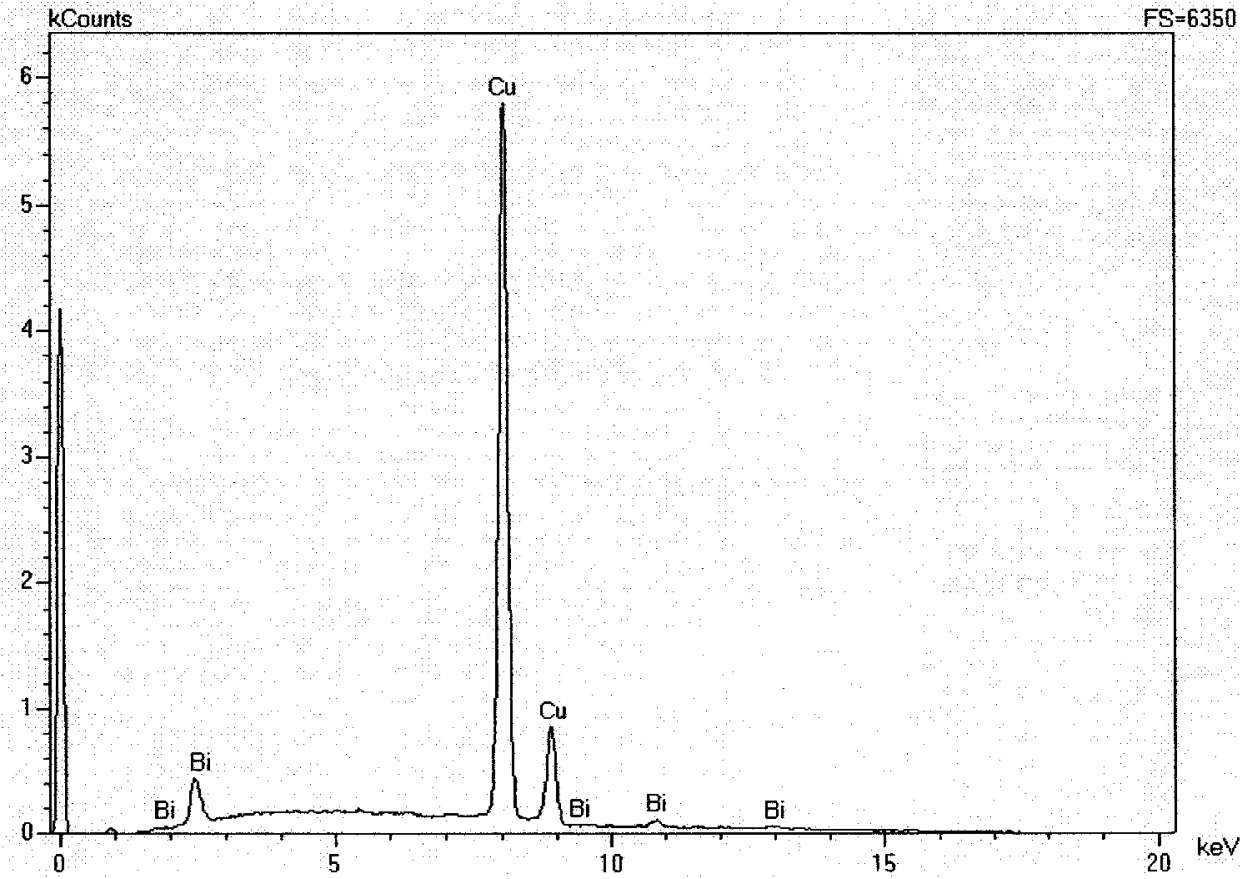

(d)

Figure 4.22 EDX patterns of composition analysis for entire microstructure of copper-15\% bismuth: (a) Test 1, (b) Test 2, (c) Test 3, (d) Test 4 


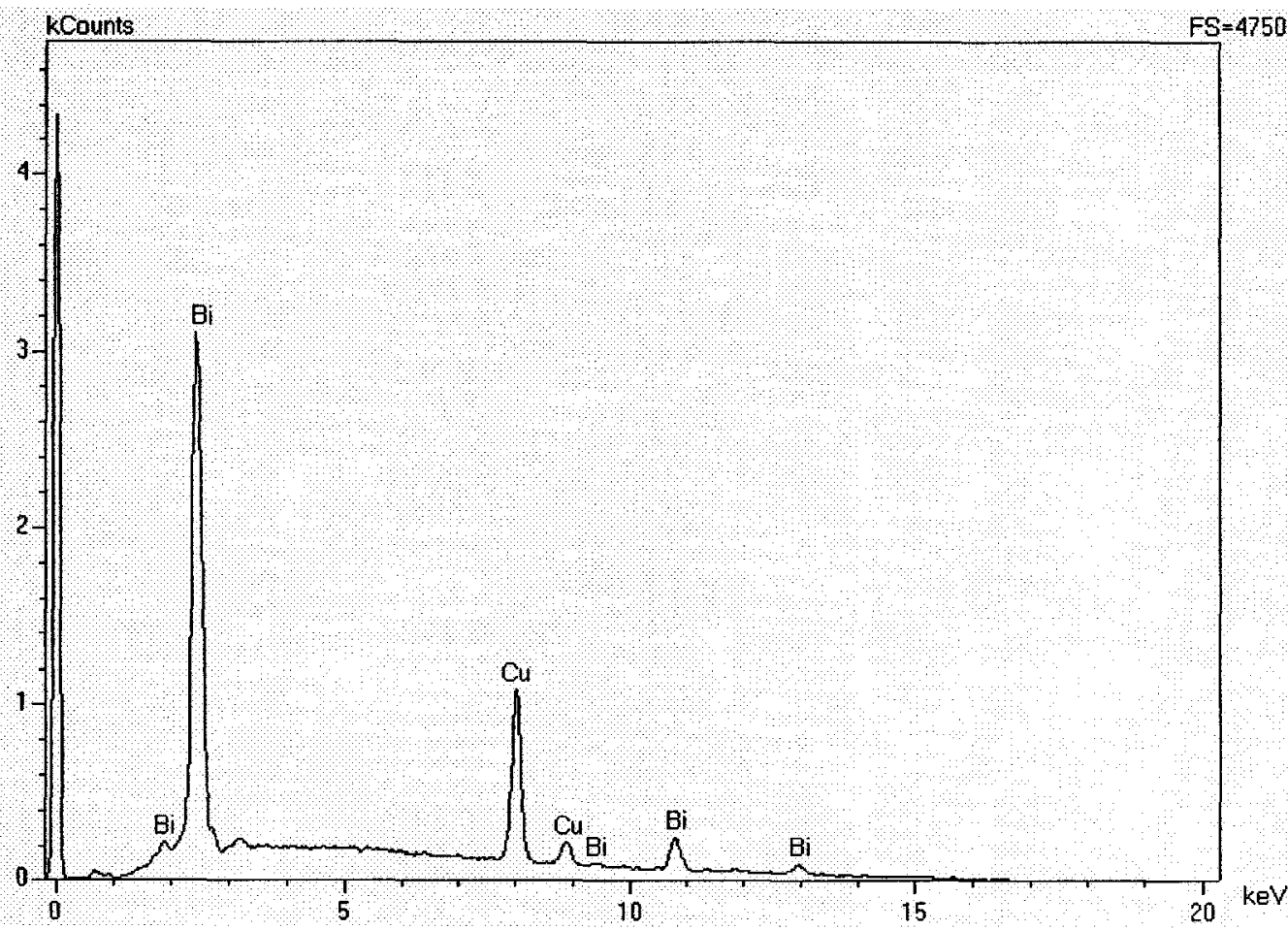

(a)

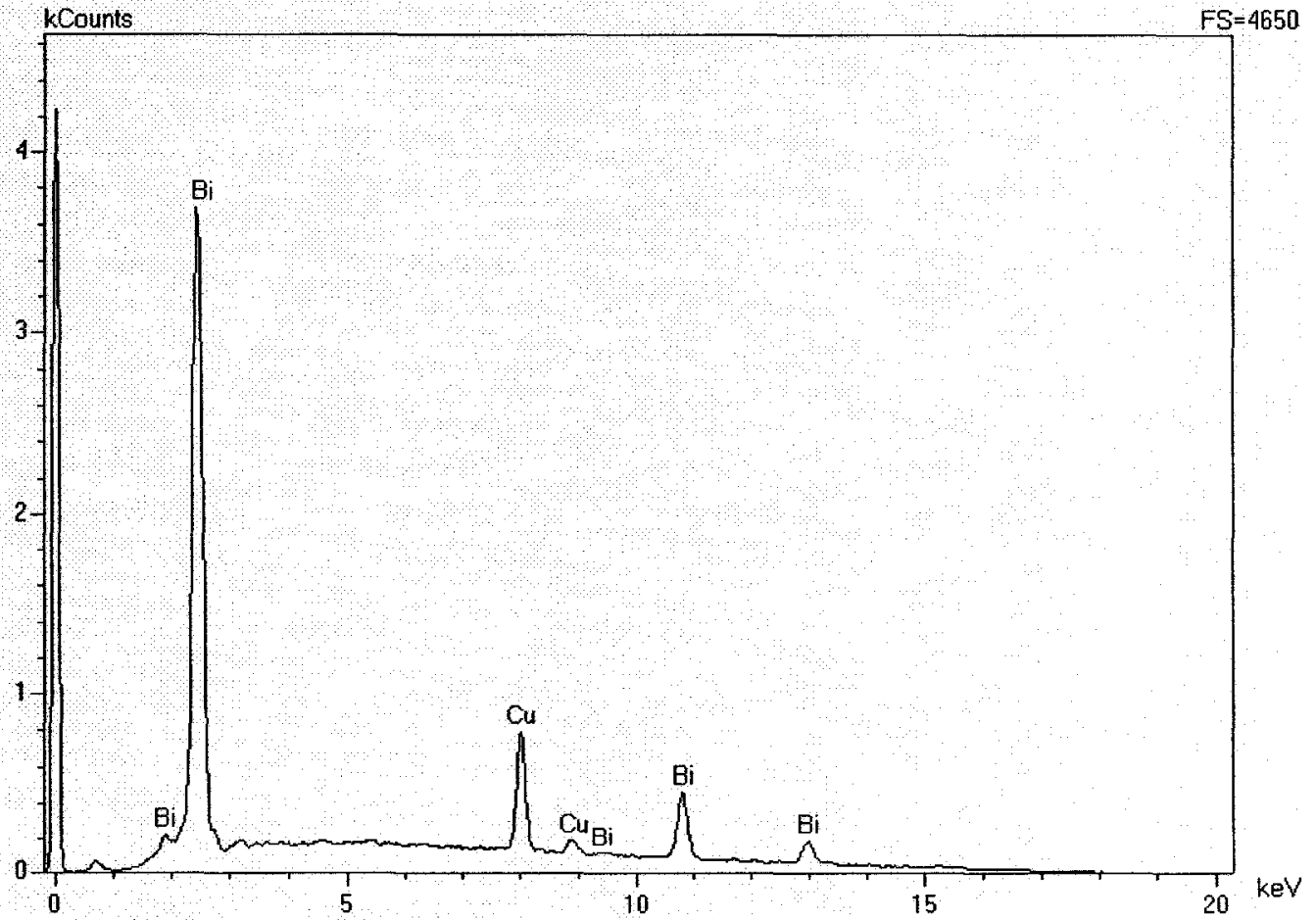

(b) 


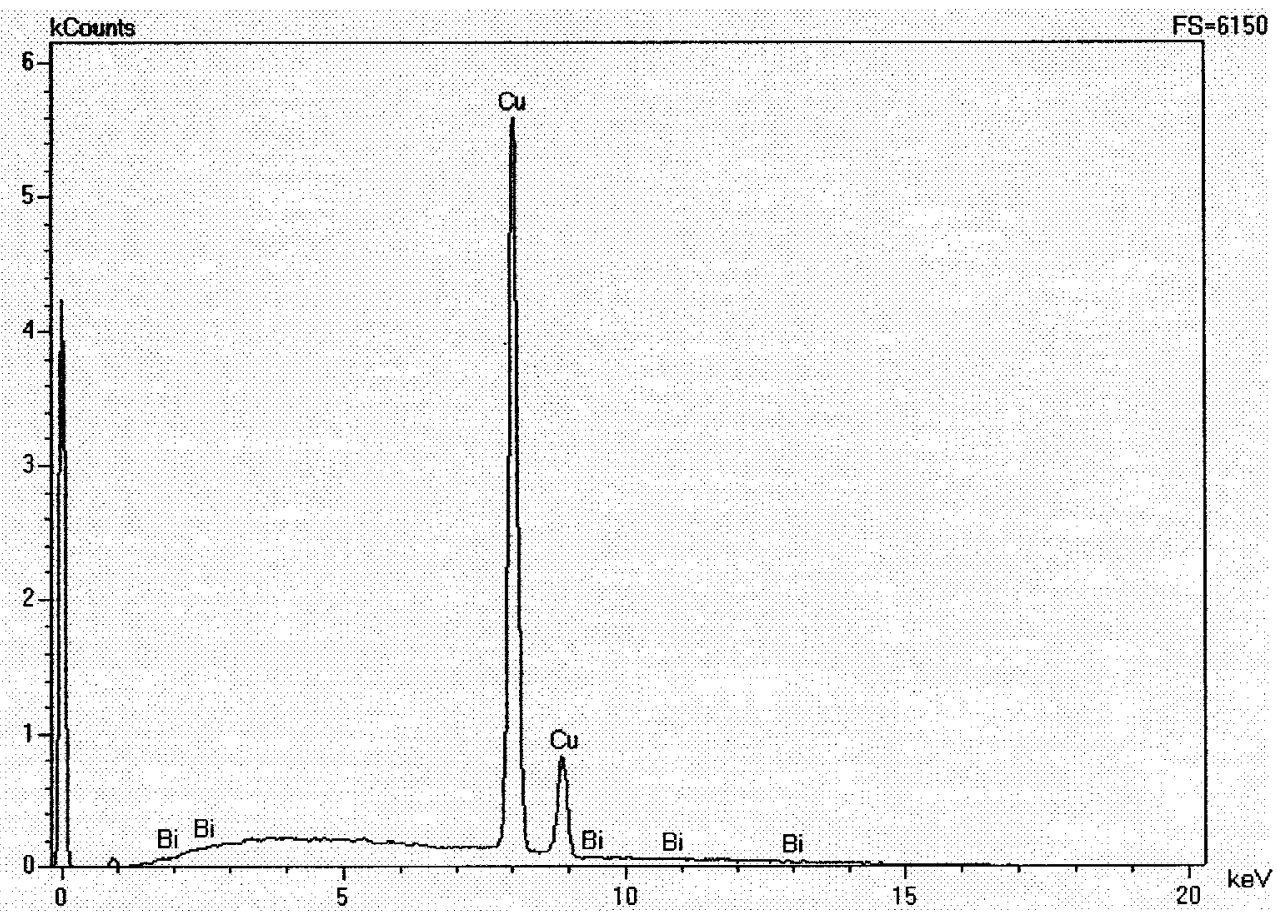

(c)

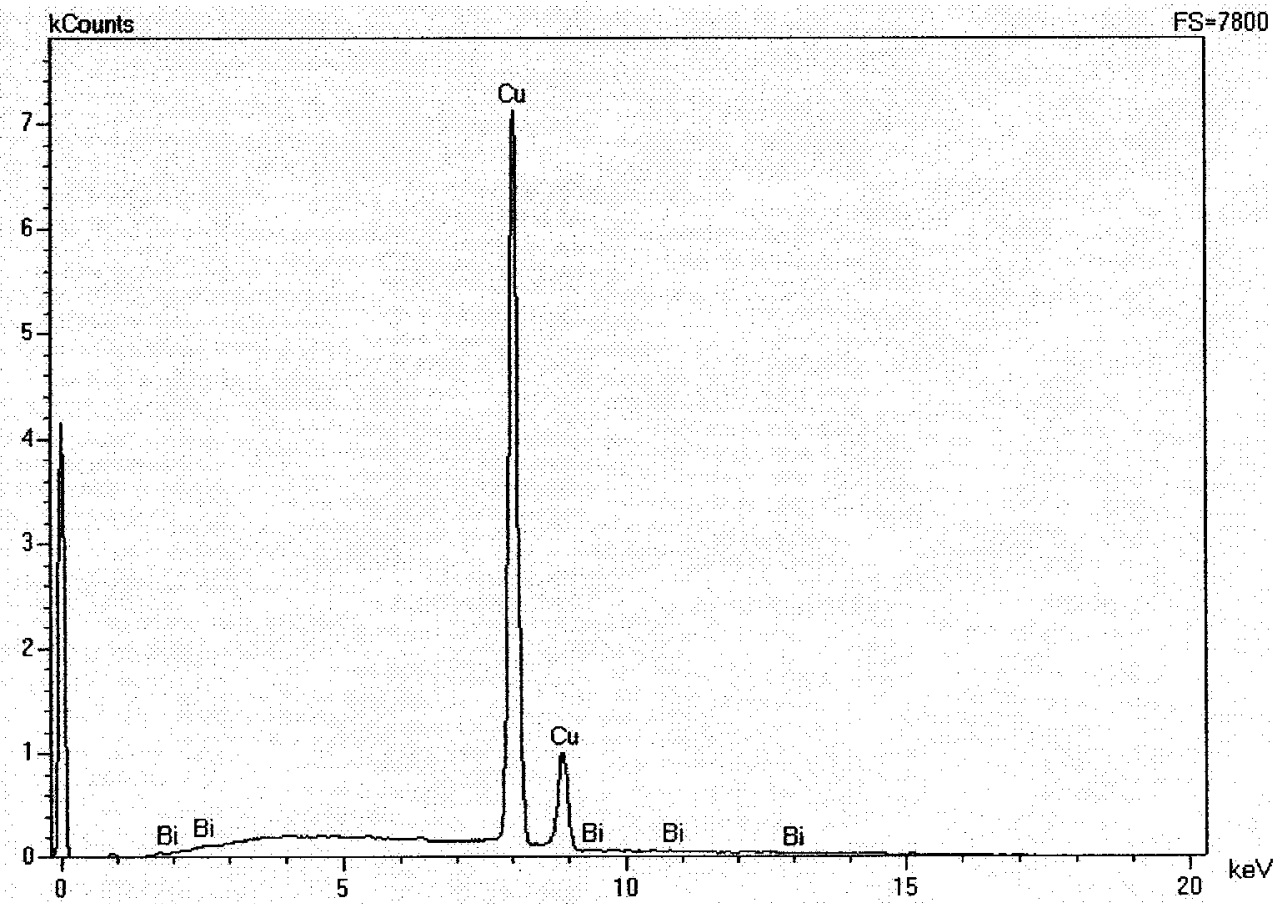

(d)

Figure 4.23 EDX patterns of composition analysis for grain boundaries of copper-15\% bismuth: (a) Test 1, (b) Test 2, (c) Test 3, (d) Test 4 


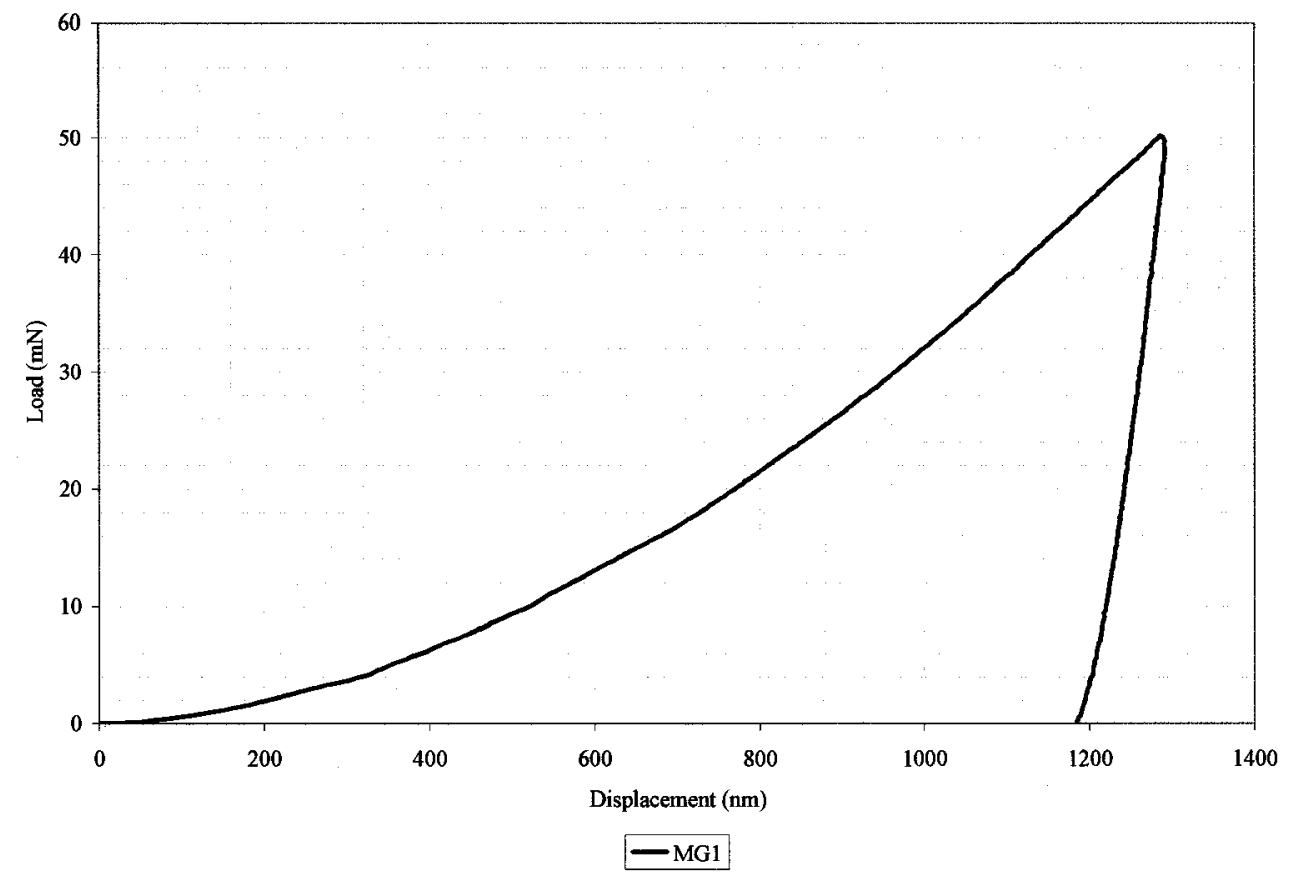

Figure 4.24 Load - displacement curves for premixed bronze (specimen MG1)

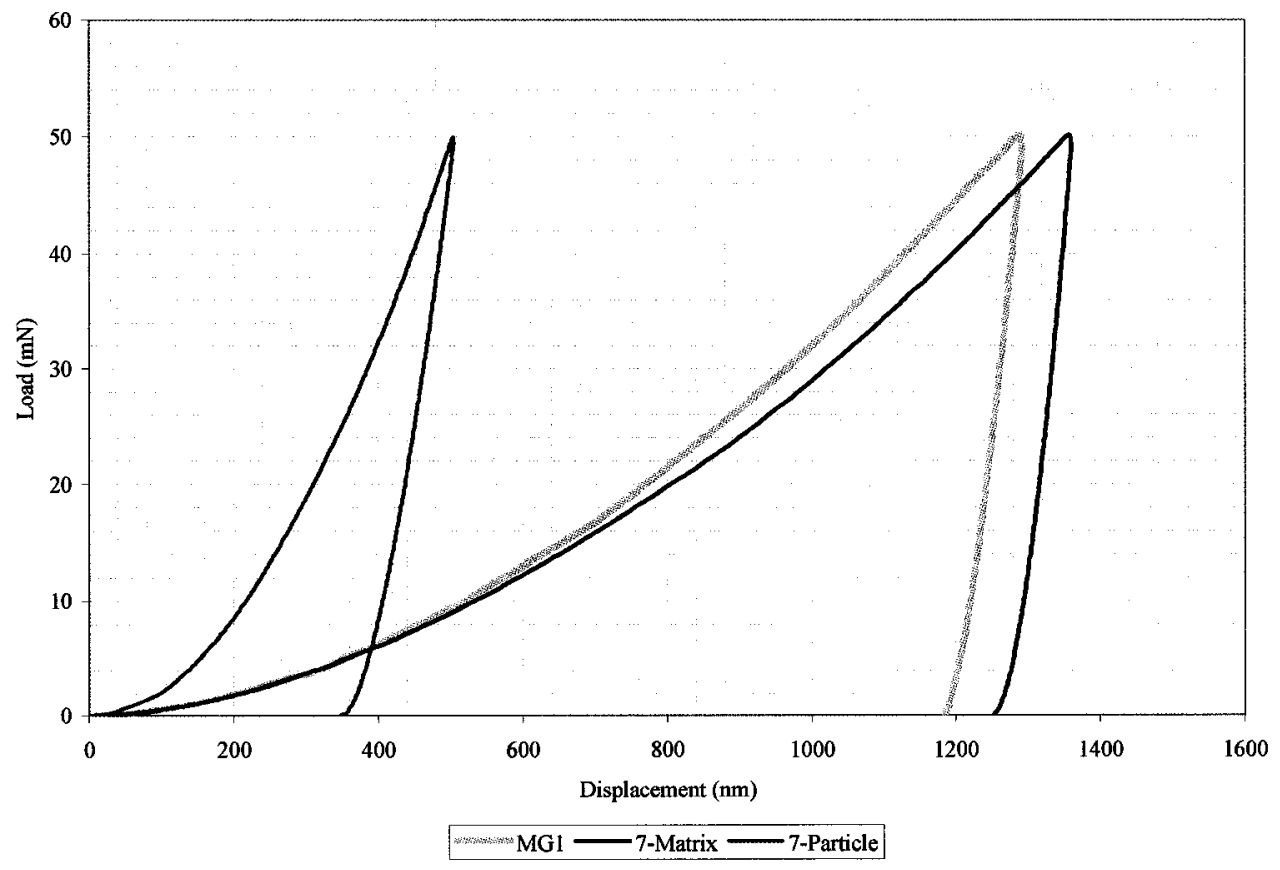

Figure 4.25 Load - displacement curves for specimen 7 


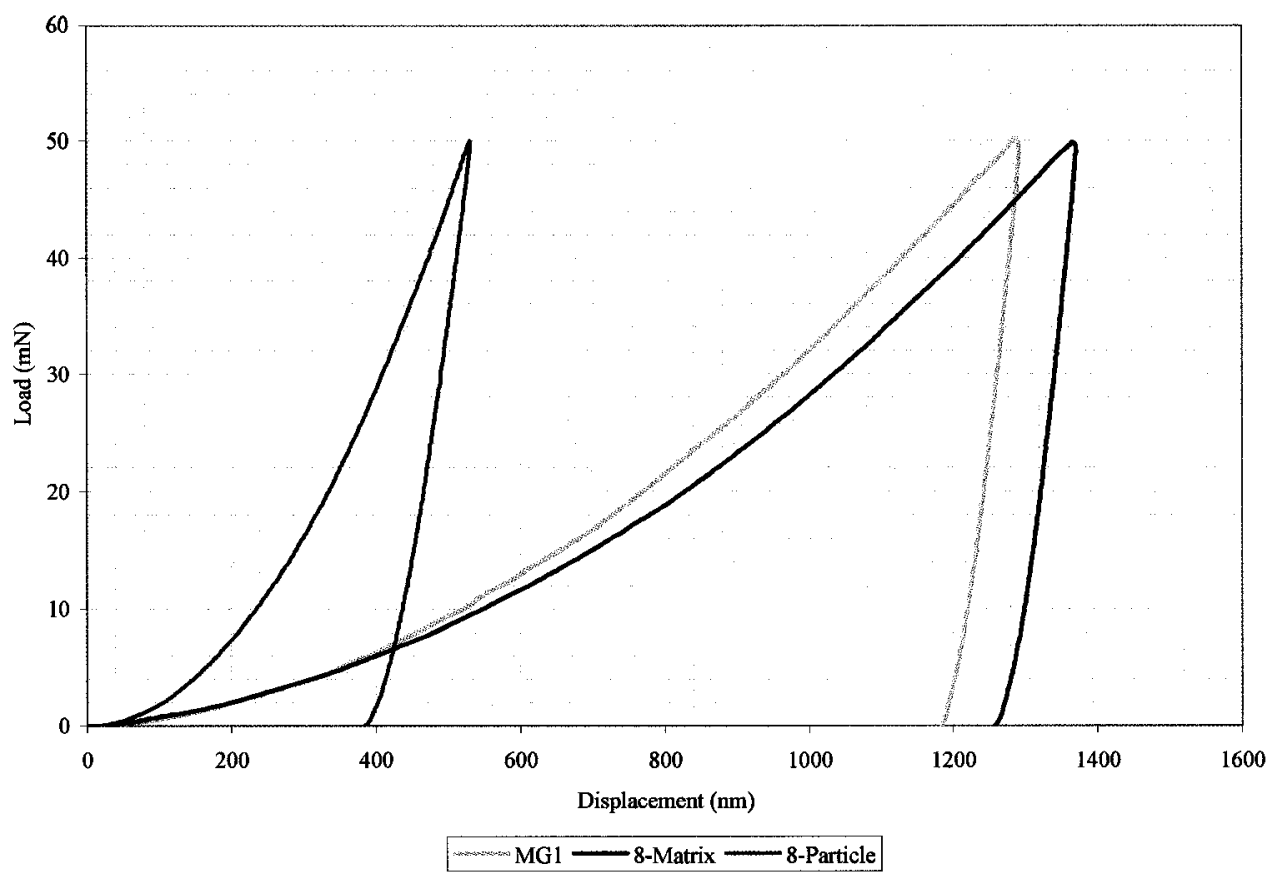

Figure 4.26 Load - displacement curves for specimen 8

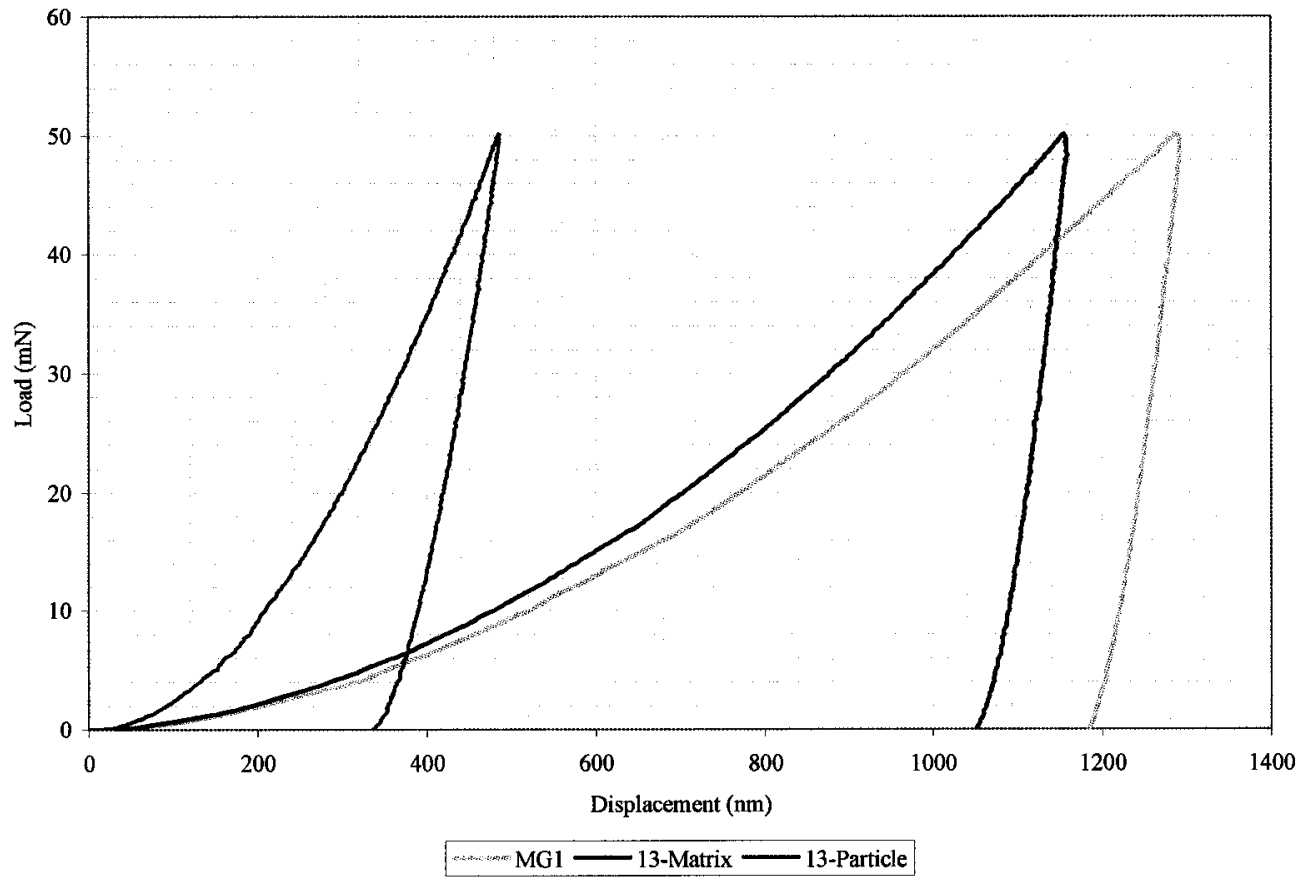

Figure 4.27 Load - displacement curves for specimen 13 


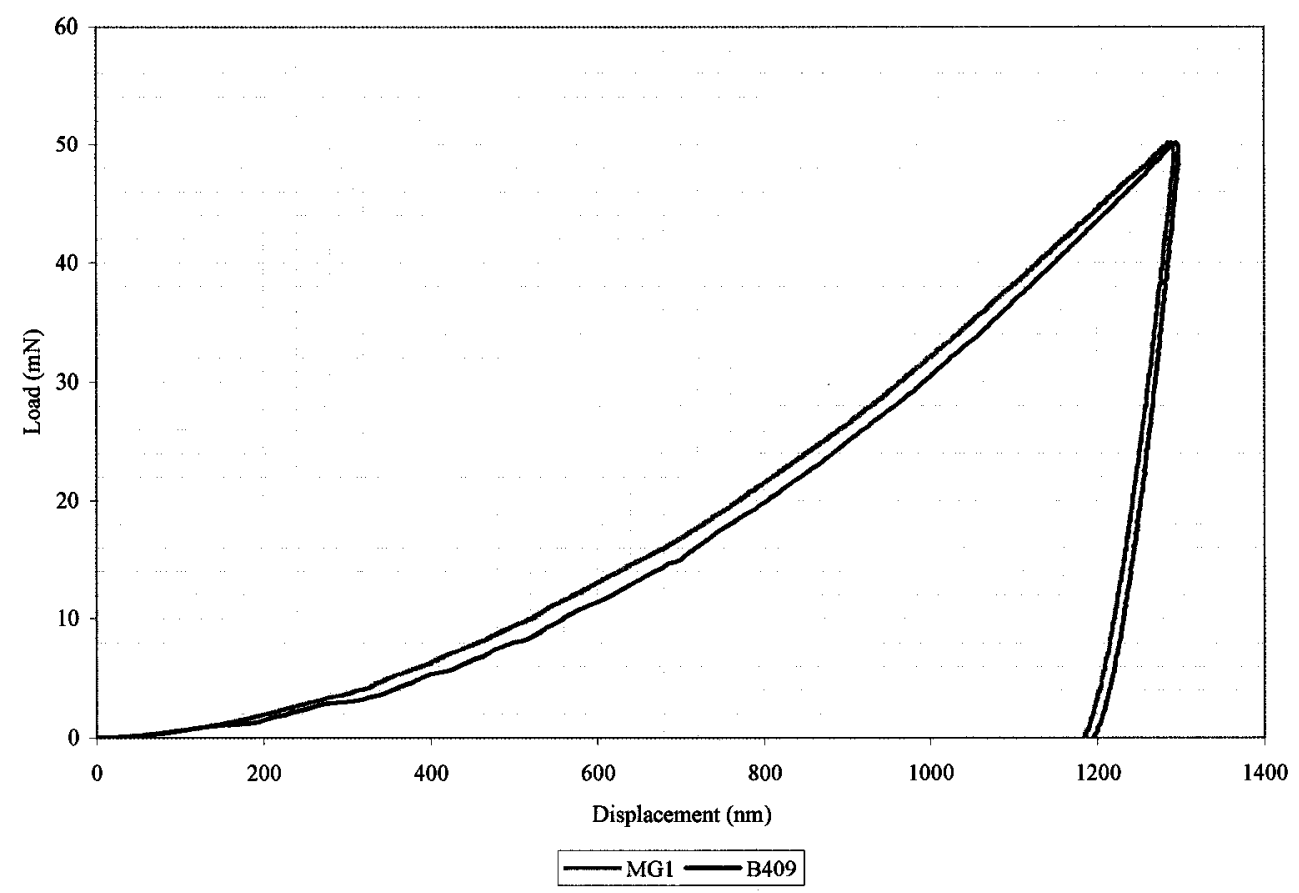

Figure 4.28 Load - displacement curves for prealloyed bronze (specimen B409)

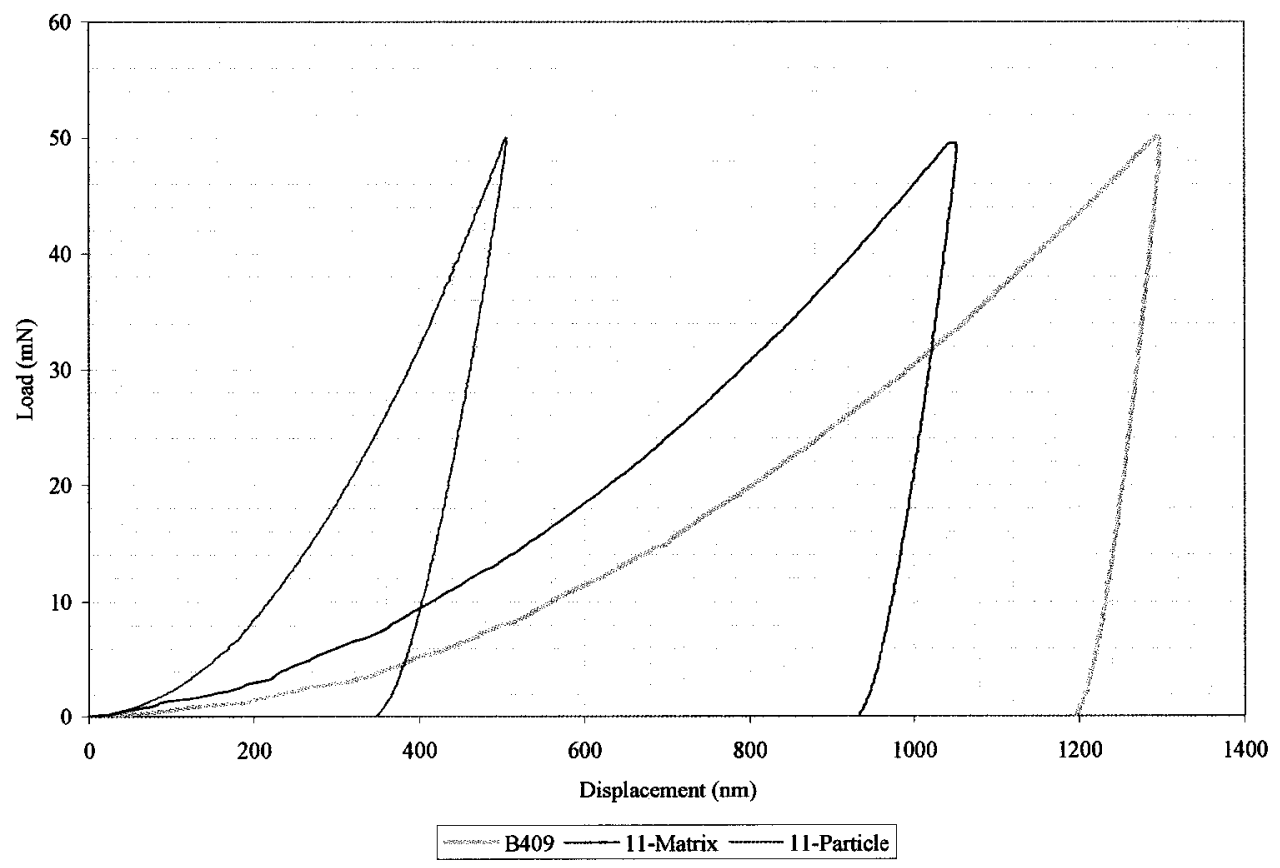

Figure 4.29 Load - displacement curves for specimen 11 


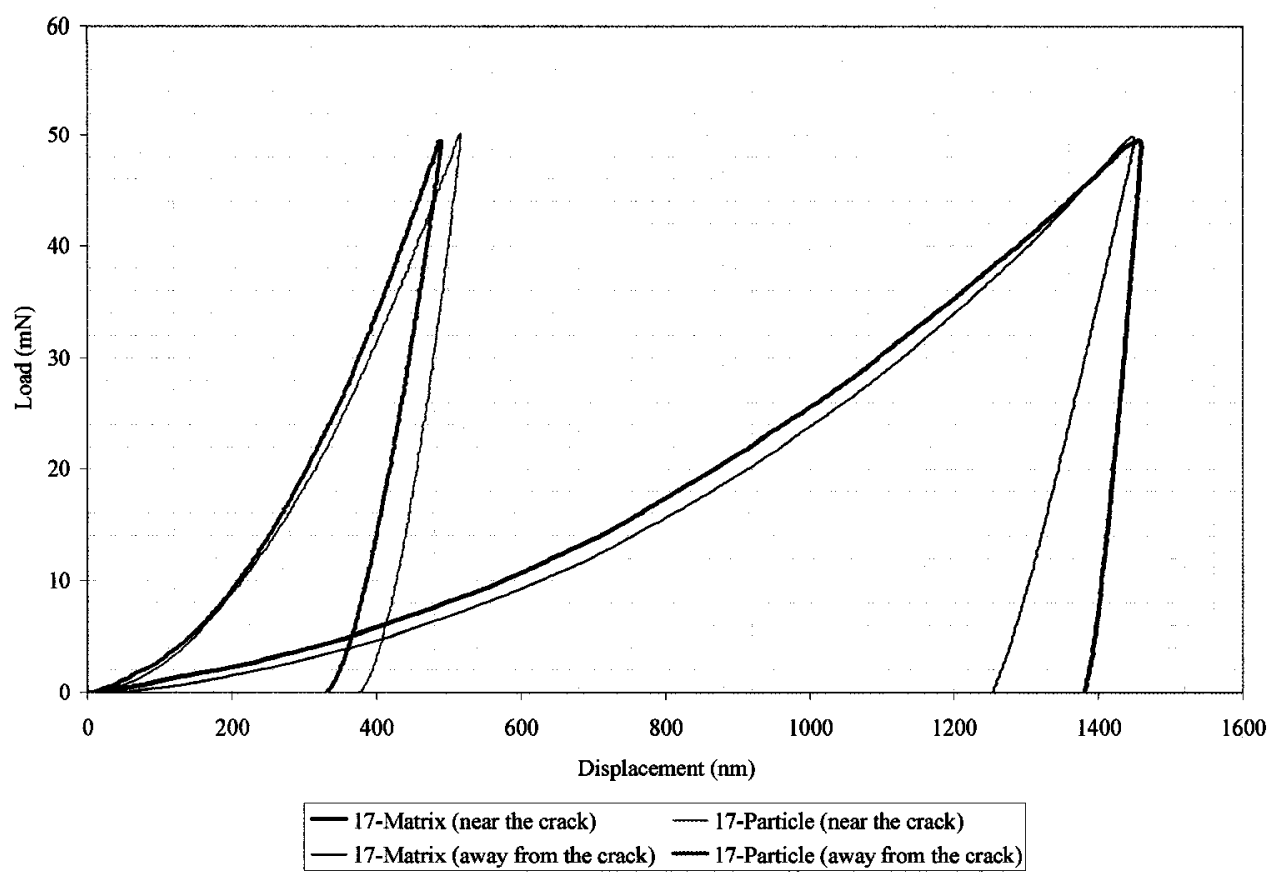

Figure 4.30 Load - displacement curves for specimen 17
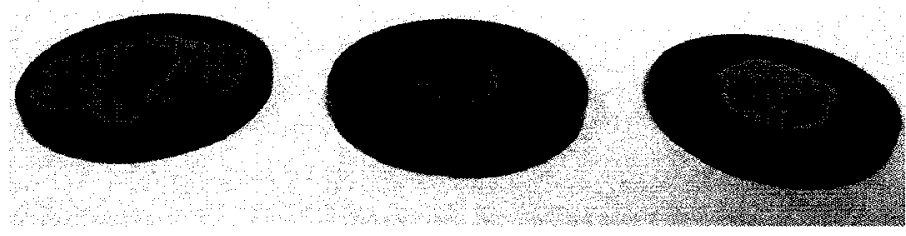

Figure 4.31 Specimens for nano indentation and wear tests

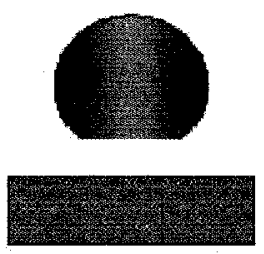

(a)

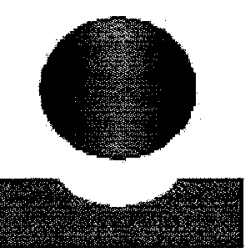

(b)

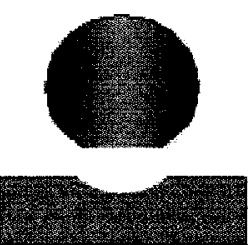

(c)

Figure 4.32 Three possible situations for differing wear of ball and flat disk specimens: (a) only the ball wears, (b) only the disc wears, (c) both the ball and disk wear 

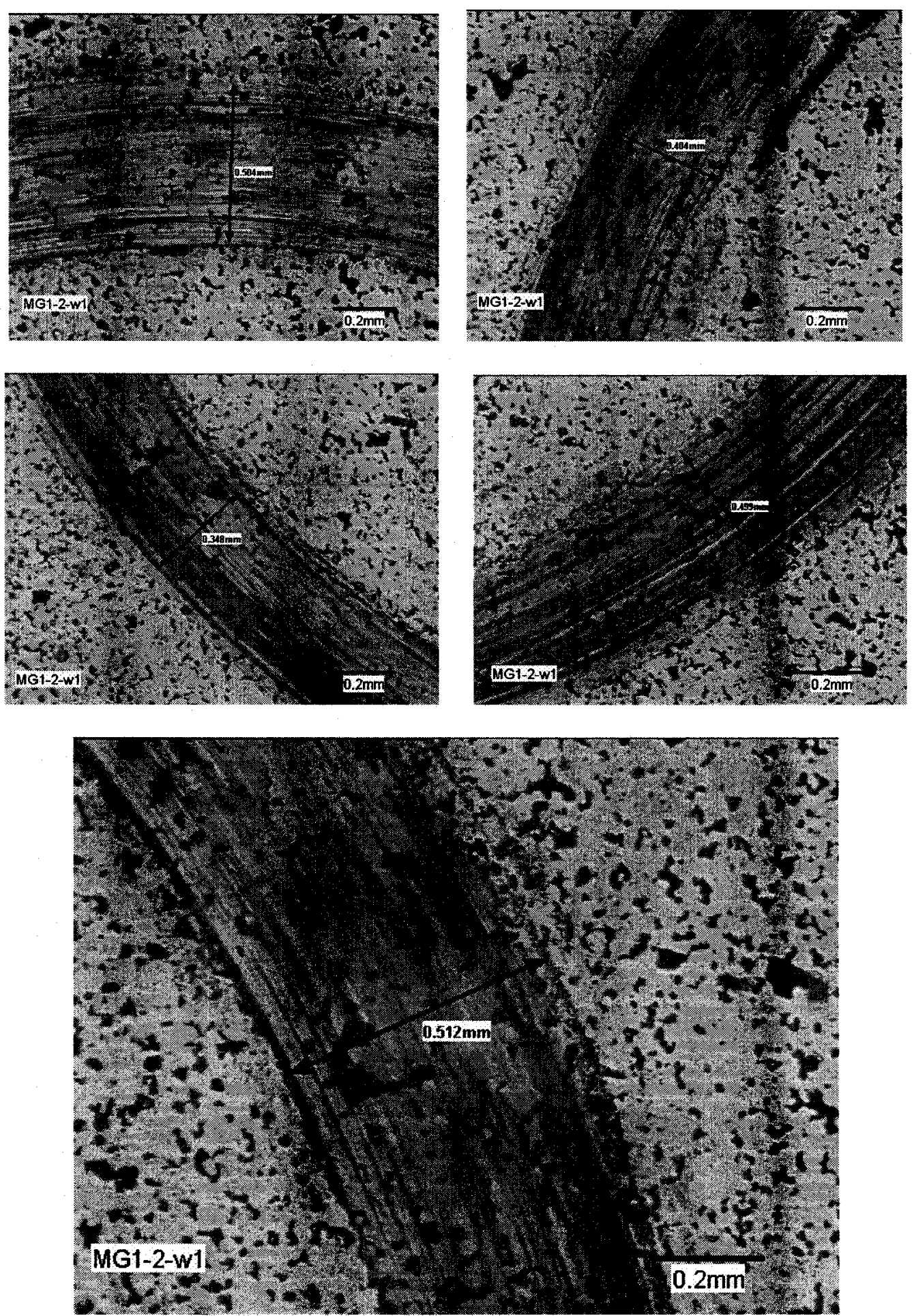

(a) 

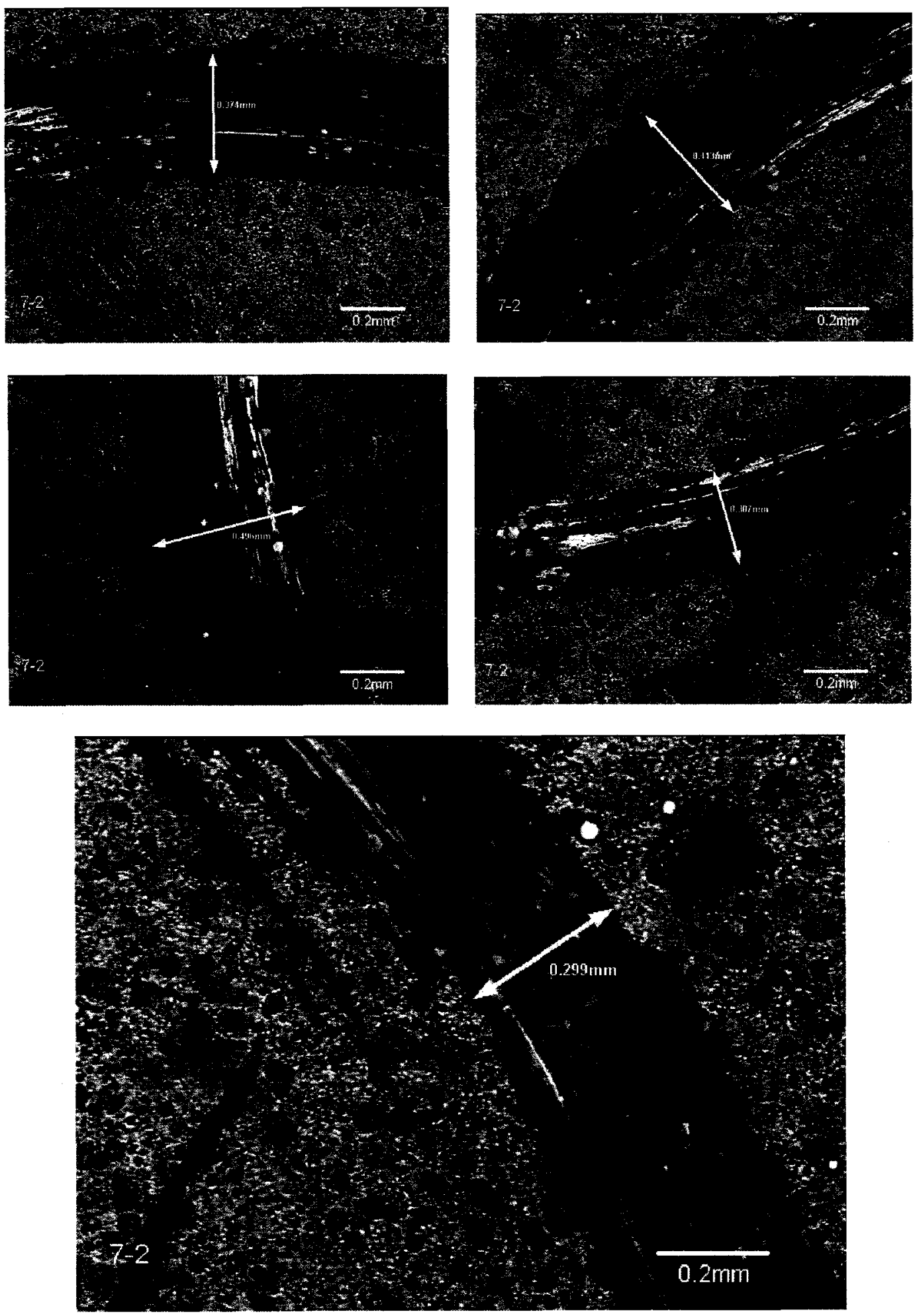

(b) 

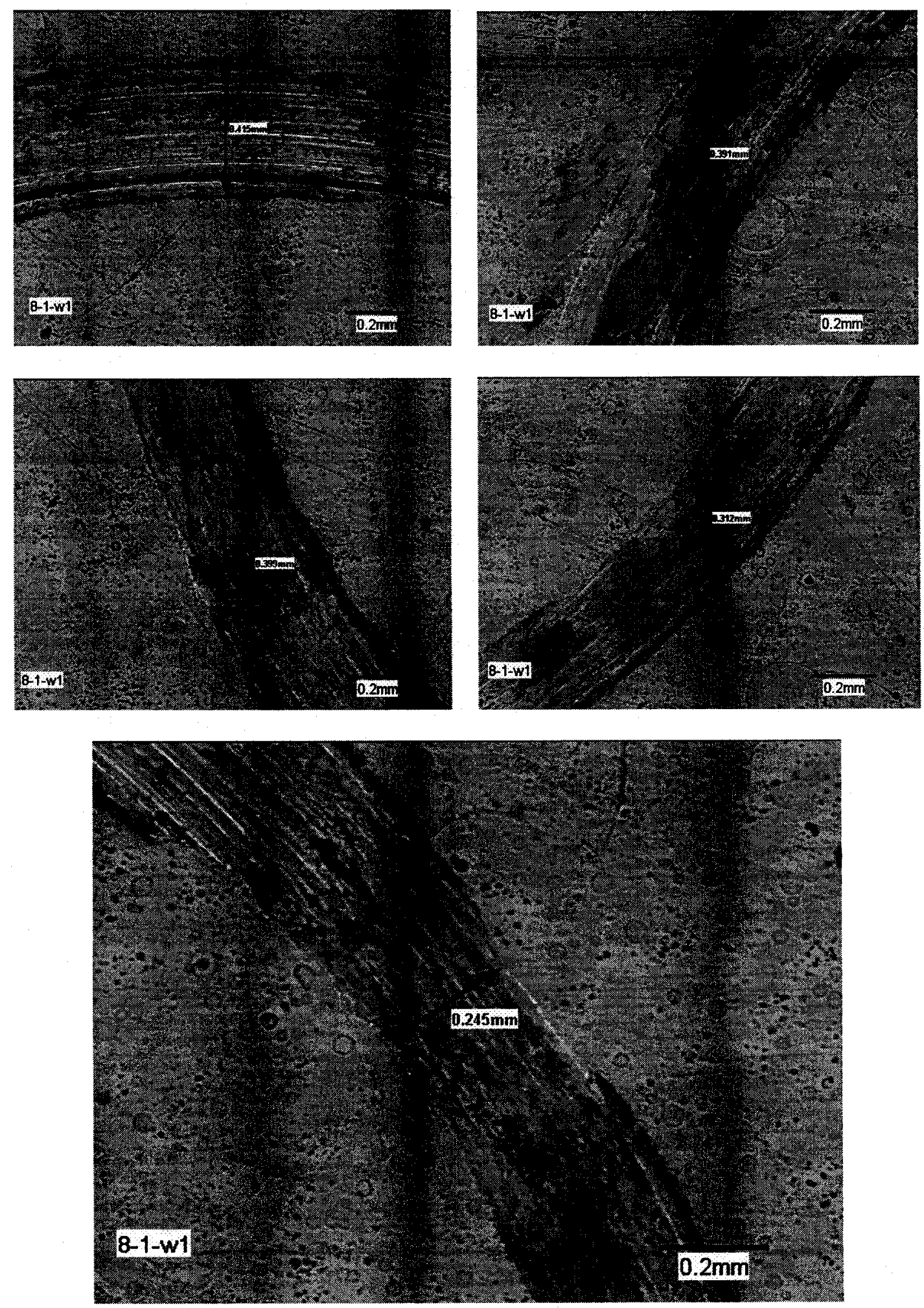

(c) 

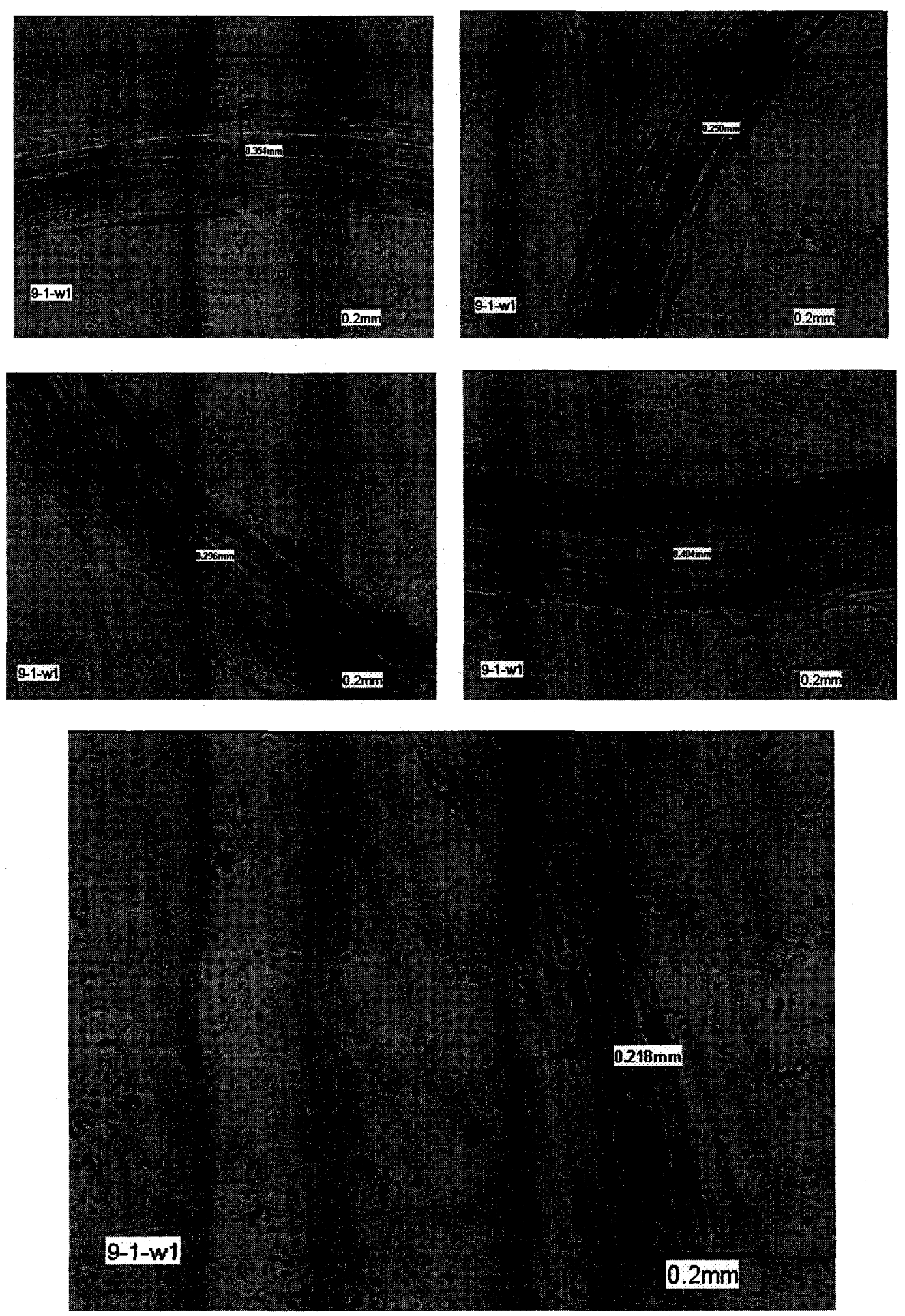

(d) 

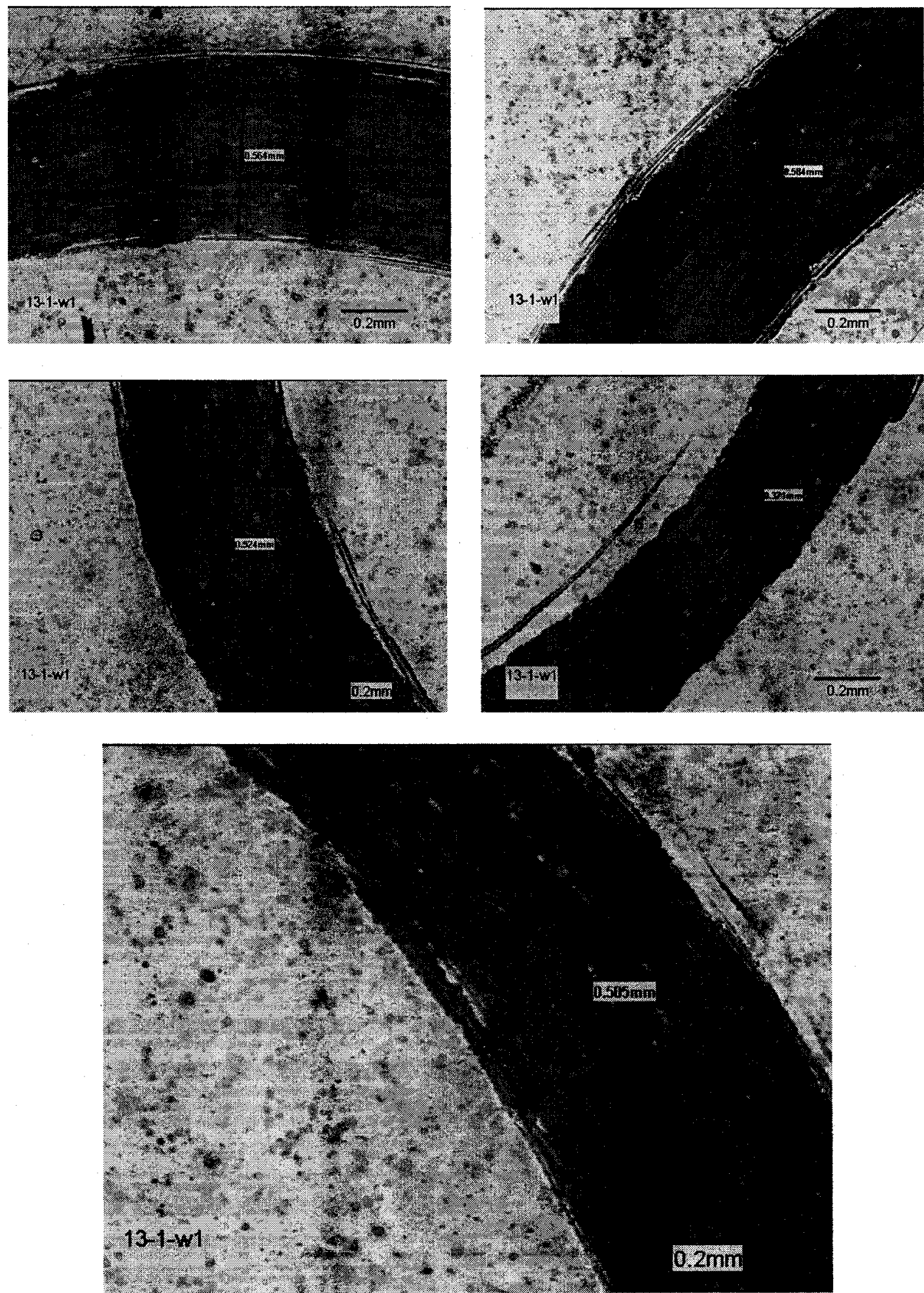

(e) 

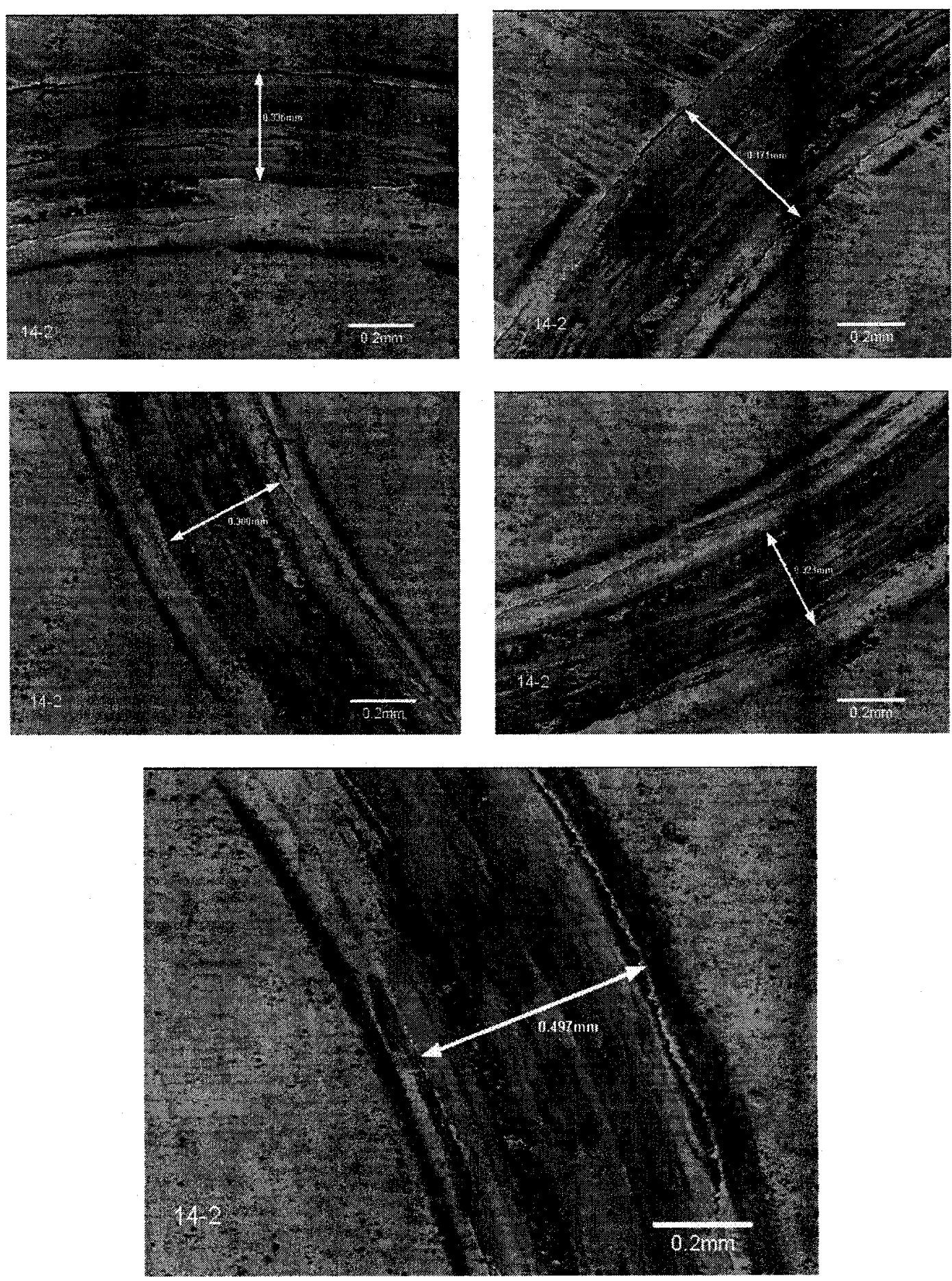

(f)

Figure 4.33 Worn surfaces for premixed bronze based specimens:

(a) specimen MG1, (b) specimen 7, (c) specimen 8, (d) specimen 9, (e) specimen 13, (f) specimen 14 

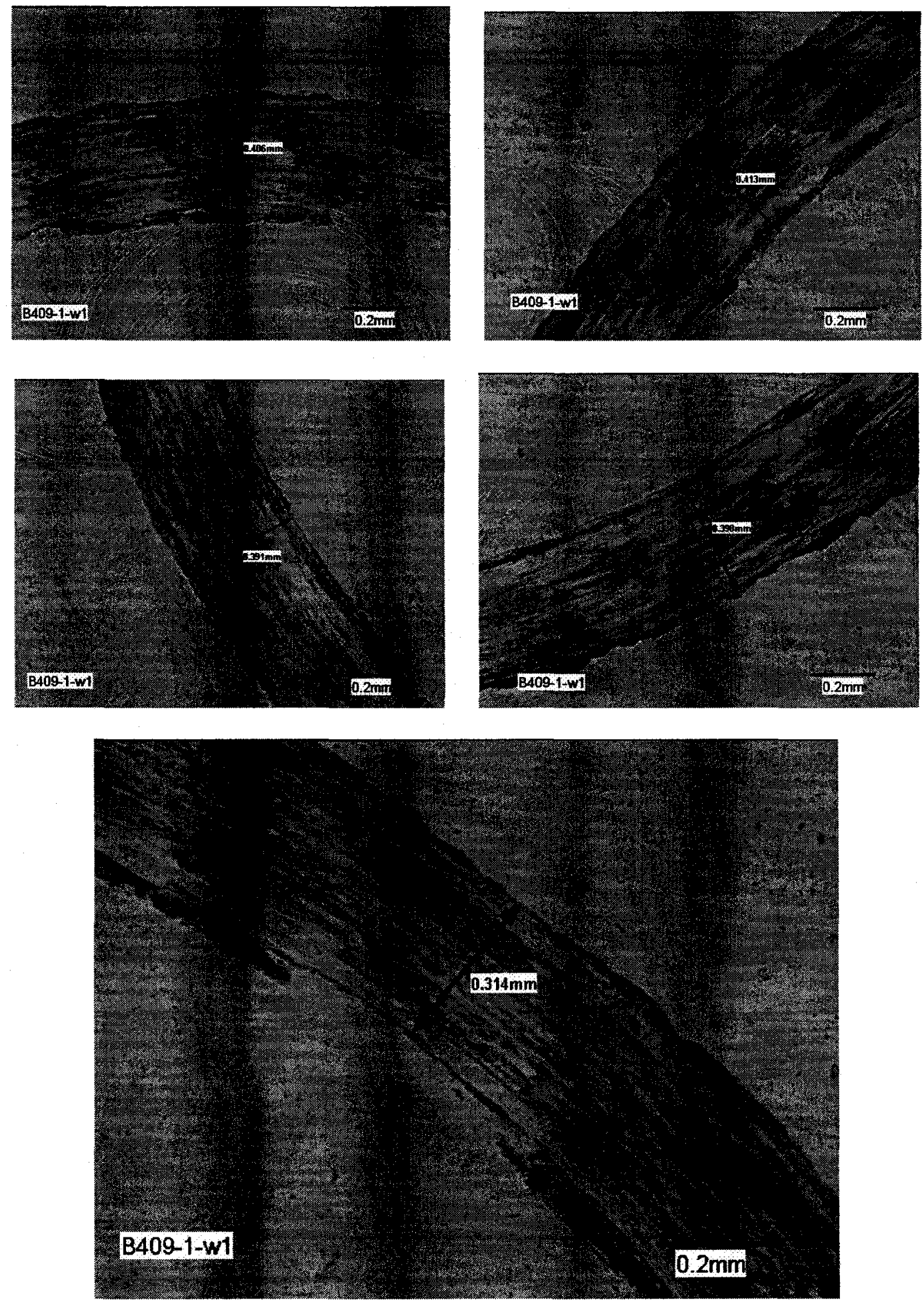

(a) 

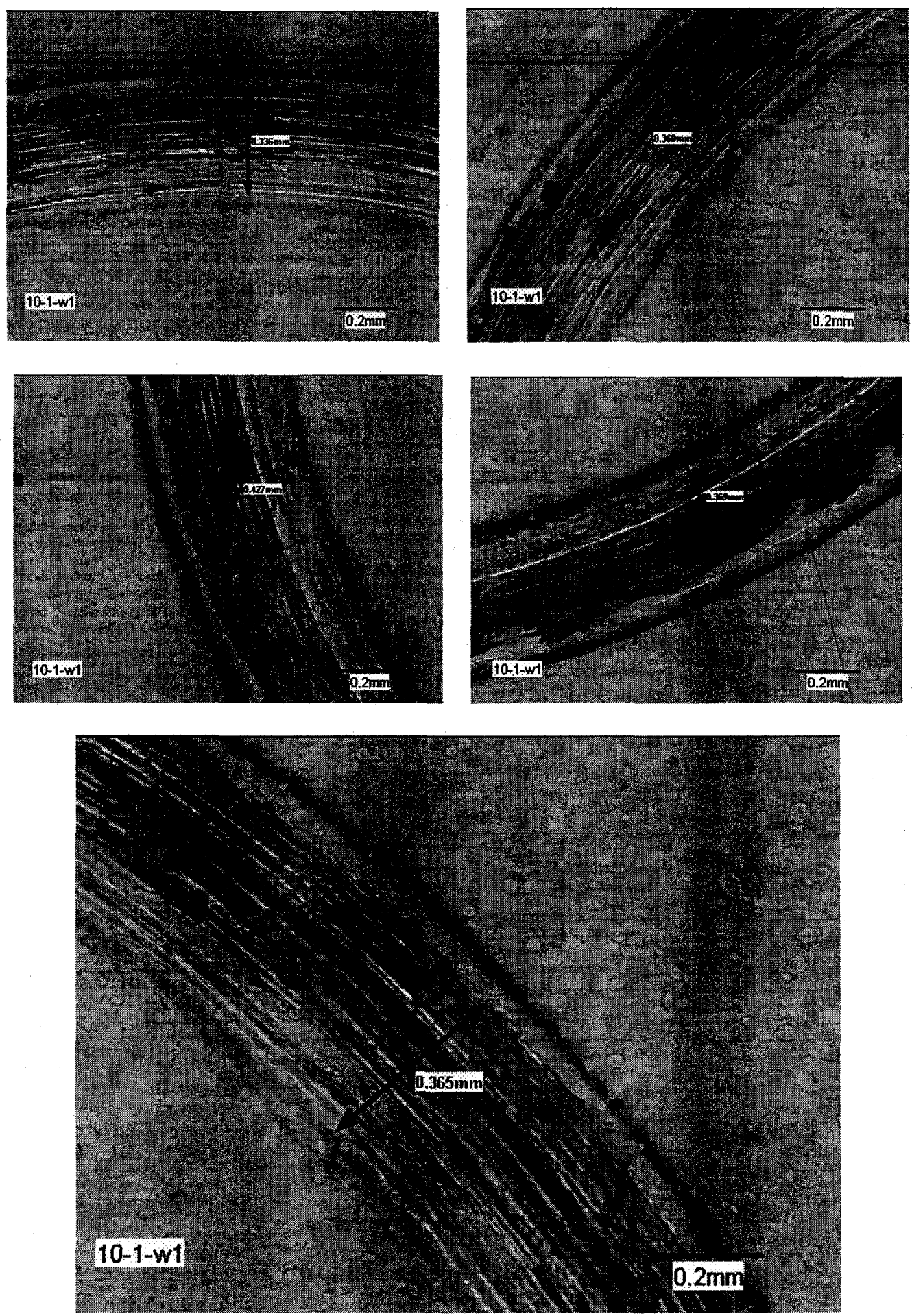

(b) 

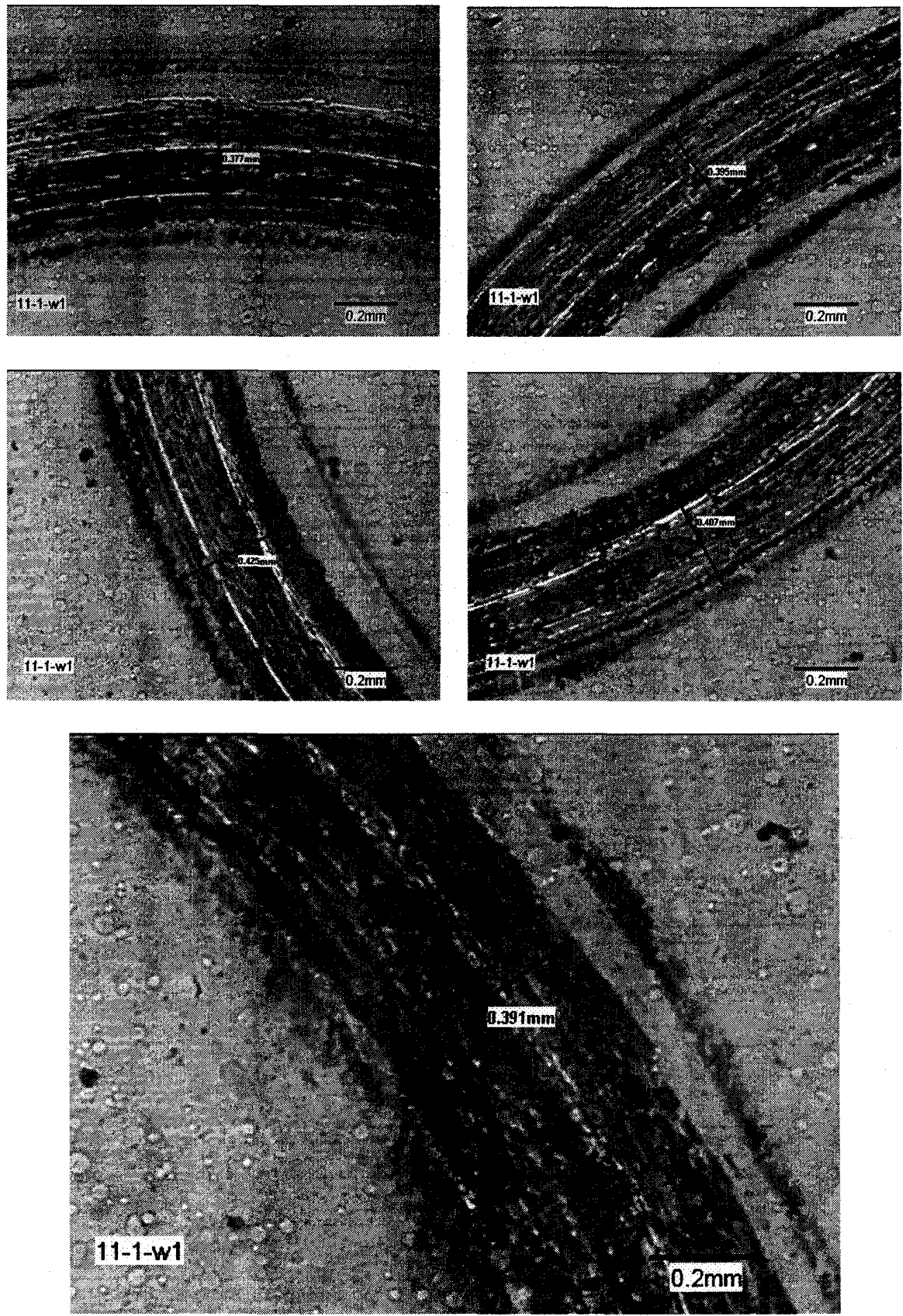

(c) 

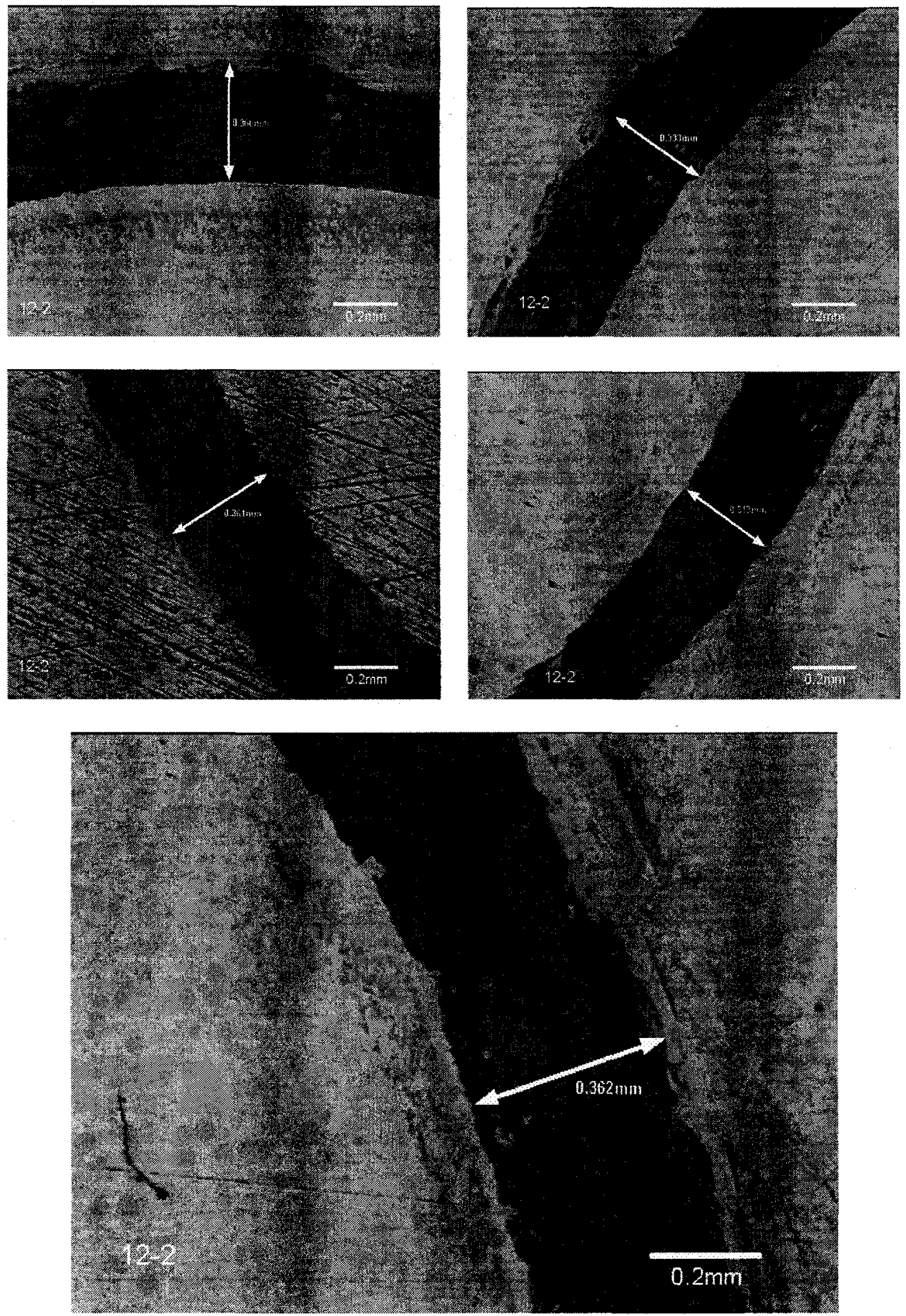

(d)

Figure 4.34 Worn surfaces for prealloyed bronze based specimens: (a) specimen B409, (b) specimen 10, (c) specimen 11, (d) specimen 12 


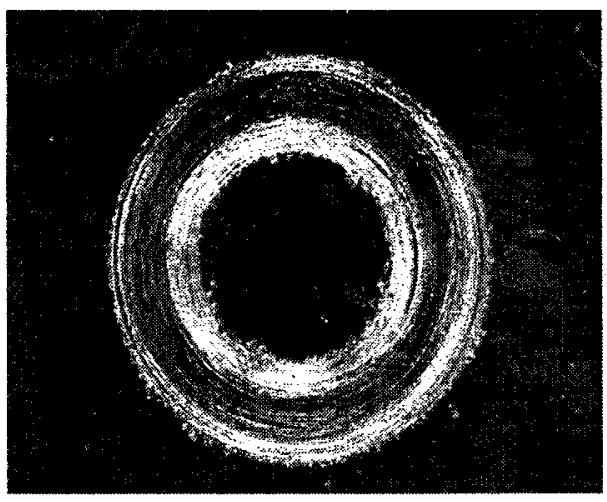

(a)
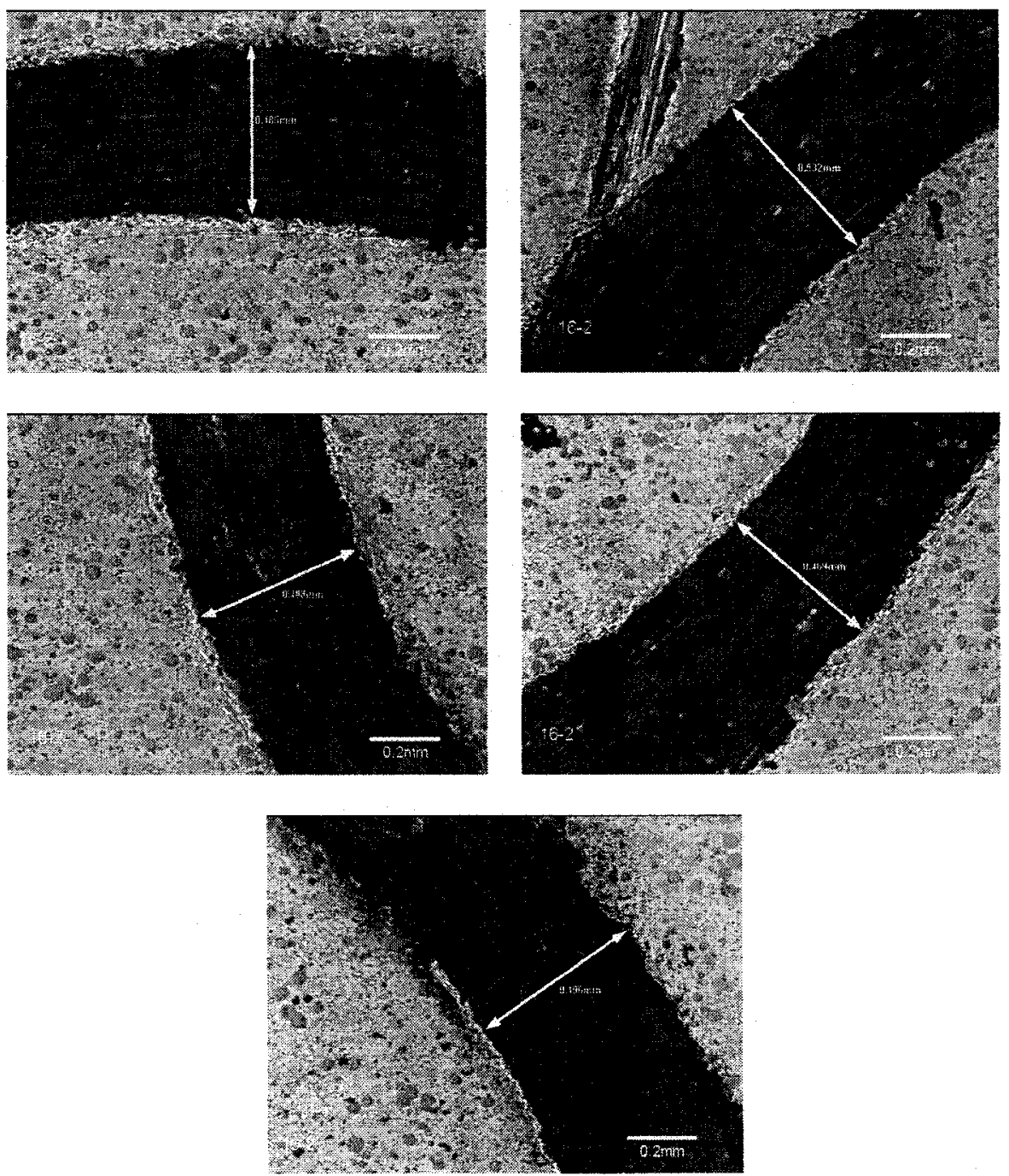

(b) 

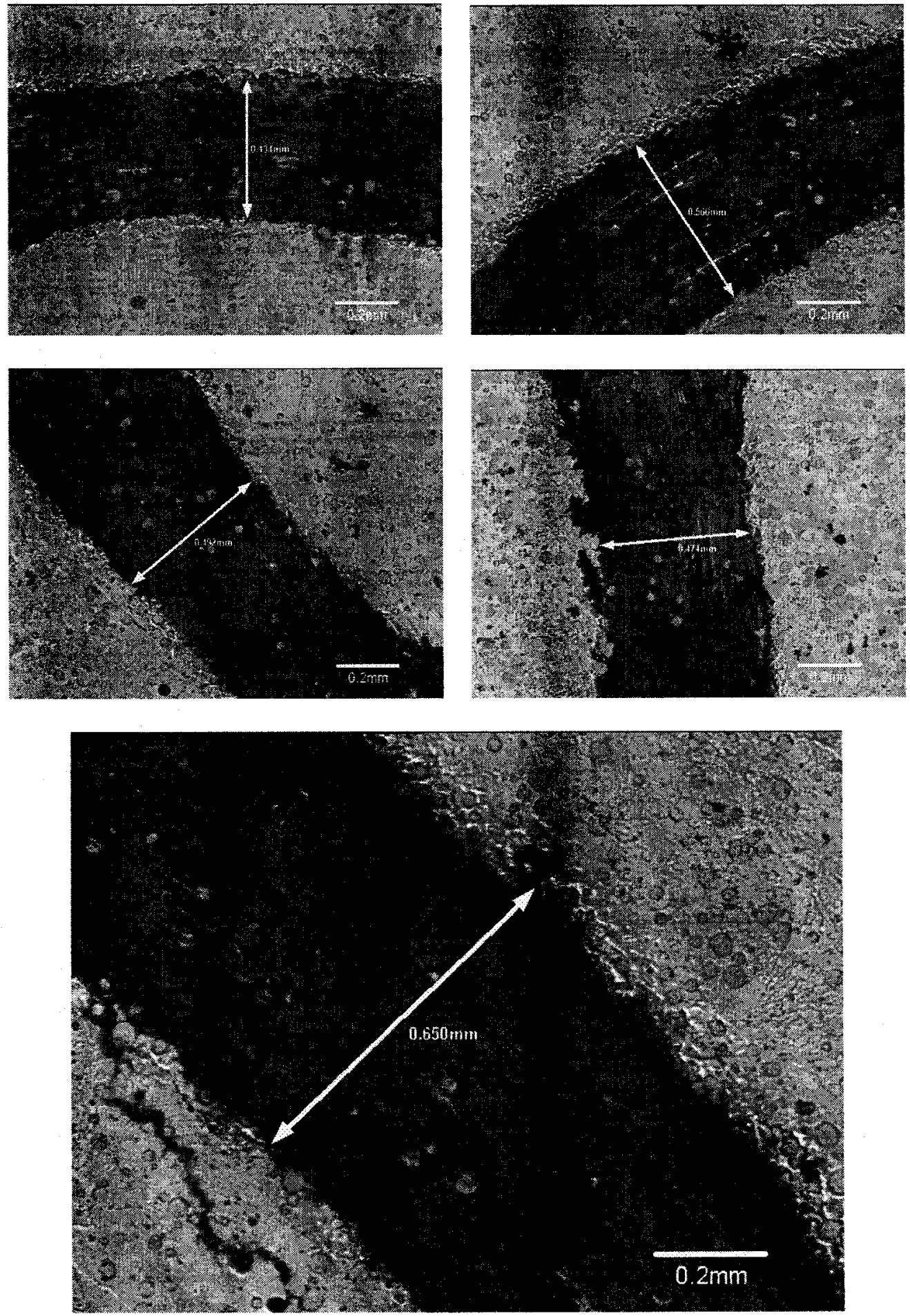

(c) 

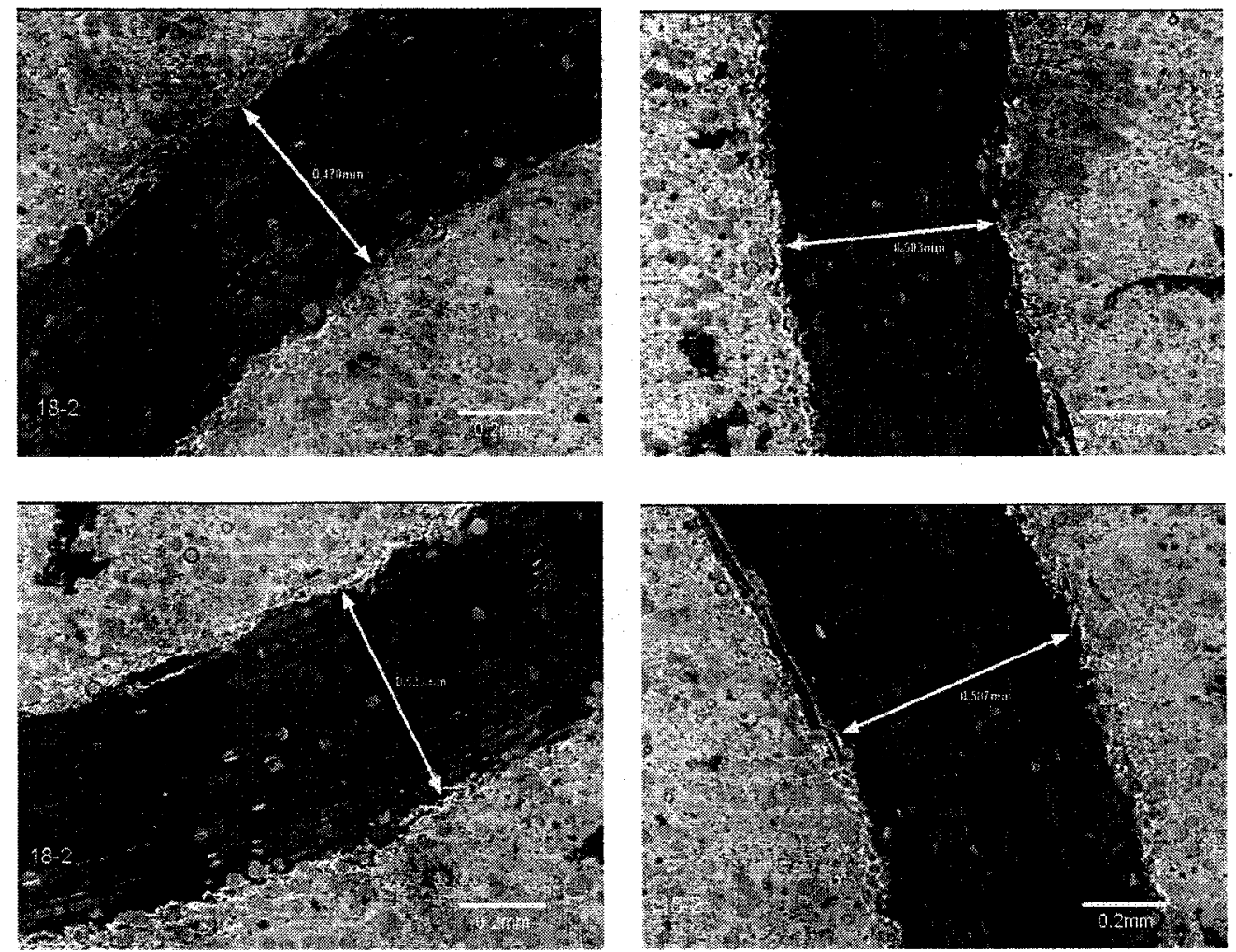

(d)

Figure 4.35 Worn surfaces for copper based specimens:

(a) specimen 6, (b) specimen 16, (c) specimen 17, (d) specimen 18 


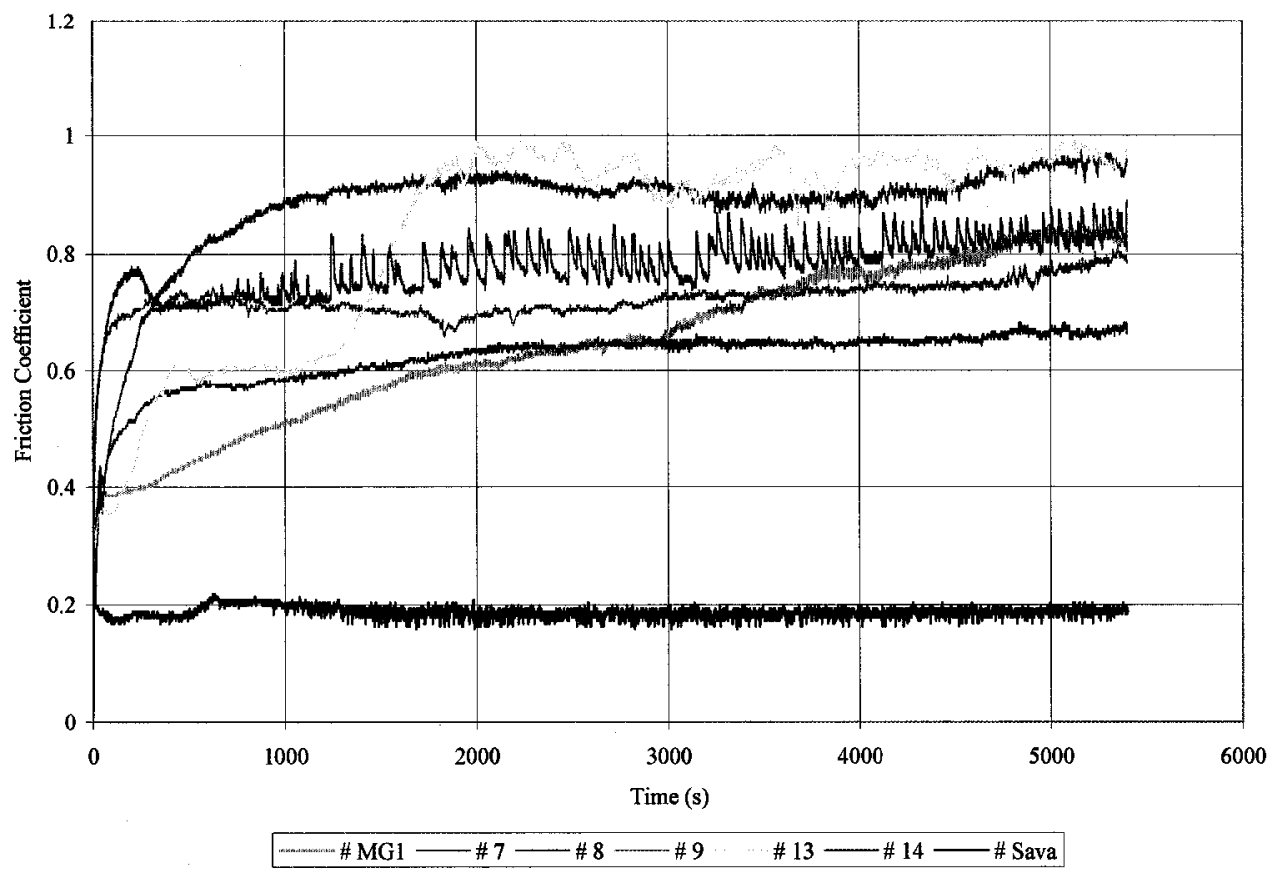

Figure 4.36 Variations of friction coefficient versus time for premixed bronze based materials

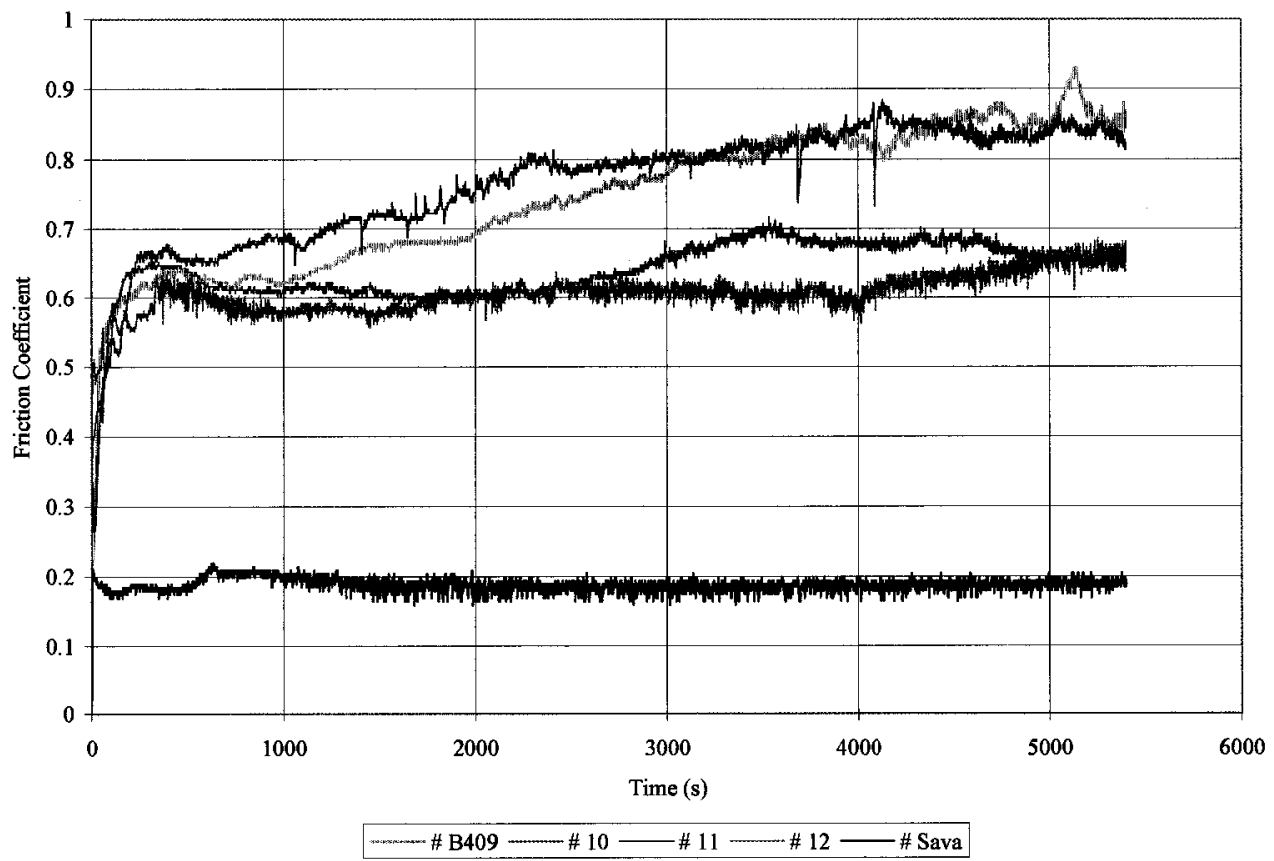

Figure 4.37 Variations of friction coefficient versus time for prealloyed bronze based materials 


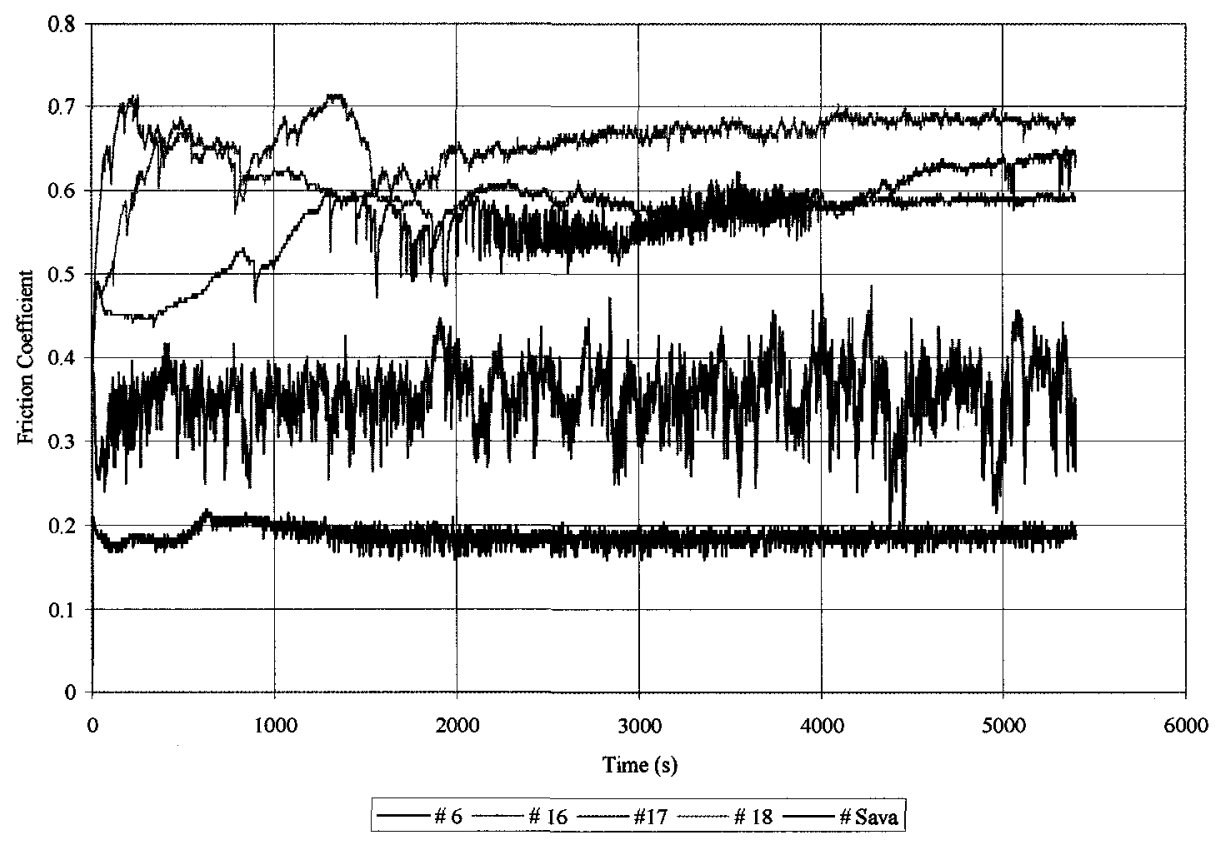

Figure 4.38 Variations of friction coefficient versus time for copper based materials

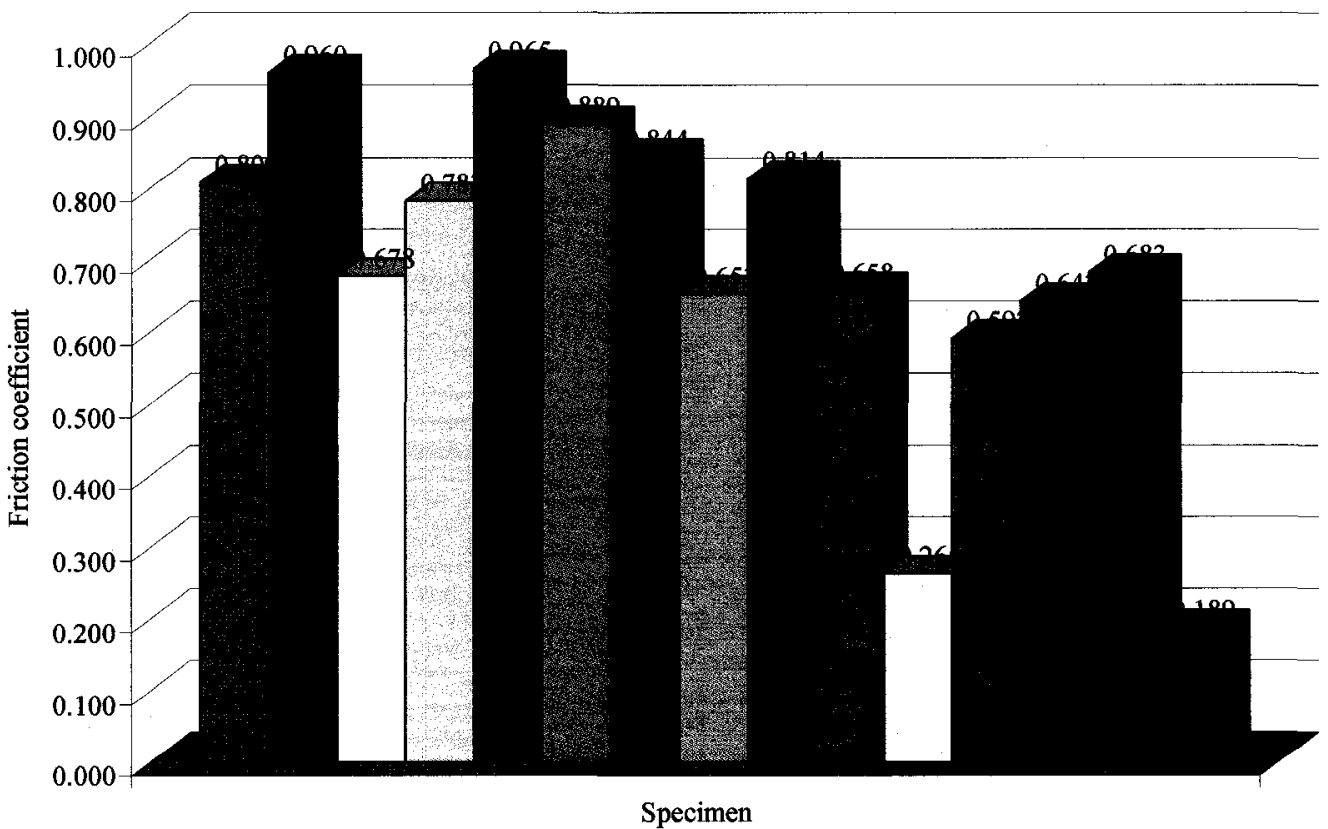

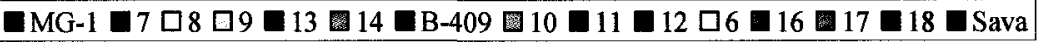

Figure 4.39 Friction coefficient at $t=5400 \mathrm{~s}$ 


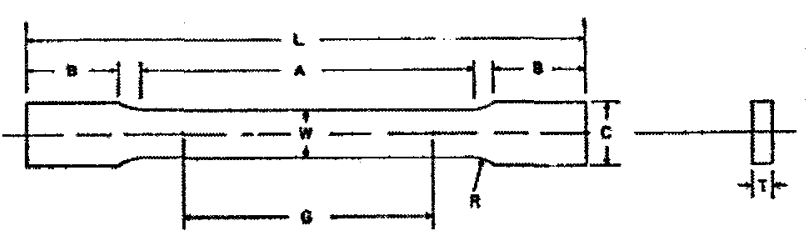

\begin{tabular}{|c|c|c|c|}
\hline \multicolumn{4}{|c|}{ Dinensions } \\
\hline & \multicolumn{2}{|c|}{ Standard specimens } & \multirow{2}{*}{$\begin{array}{c}\text { Subsize Specinen } \\
y \text {-in. Wide }\end{array}$} \\
\hline & Plate-Type, 1, is in. Whe & Shexel-Type, t/2-in Wide & \\
\hline & in. & in. & in. \\
\hline G-Gage length (Note 1 and Note 2) & $8.00 \pm 0.01$ & $2.000 \pm 0.005$ & $1.000 \pm 0.003$ \\
\hline $\begin{array}{l}\text { W-Width (Note } 3 \text { and Note 4) } \\
T-\text { Thickness (Note 5) }\end{array}$ & $13 / 2+36 .-4$ & $\begin{array}{l}0.500 \pm 0.010 \\
\text { thitckness of materia: }\end{array}$ & $0.250 \pm 0.005$ \\
\hline R-Radils of thet, min (Note 6) & 1 & $3 / 2$ & $1 / 4$ \\
\hline$L-$ Ovef-all kength, (Note 2, Note 7 and Note a) & 18 & 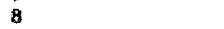 & 4 \\
\hline A-Length of reduced section, min & 9 & $2 \% / 4$ & $1 \%$ \\
\hline B-Length of grip section, (Note B) & 3 & 2 & $1 \%$ \\
\hline C-Width of gip section, approximate (Note 4 and Note 9) & 2 & $3 / 4$ & 36 \\
\hline
\end{tabular}

Norz 1-For the 1/2-in. wide specimen, punch marks for measuring elongation anter fracture shall be made on the flat or on the edge of the specimen and within the reduced section. Either a set of nine or more punch marks 1 in. apart, or one or more pairs of punch marks 8 in. apart may be used. Nore 2-When elongation measureanents of $1 / 2$-in. wide specimens are not required, a minimum length of reduced section $(A)$ of $21 / 4$ in. may be used with all other dimensions sinvilar to those of the plate-type specimen.

NoTE 3-For the three sizes of specimens, the ends of the reduced section shall not differ in width by wore than $0.004,0.002$ or 0.001 in., respectively. Also, there may be a gradual decrease in width from the ents to the center, but the width at each end shall not be more than $0.015,0.005$, or 0.003 in. respectively, larger than the widh at the center.

Nore 4-For each of the three sizes of specinens, narrower widhs ( $W$ and $C$ ) may be wsed when necessary. In such cases the width of the reciuced section should be as large as the width of the material being tested pernits; however, unless stated specifically, the requirements for elongation in a product specification shall not apply when these narrower specimens are used.

NOTE 5 -The dimension $T$ is the thickness of the test specimen as provided for in the applicable material specifications. Mininum thickness of 1 1/2-in. wide specimens shall be $3 / 16$ in. Maximum thickness of $1 / 2$-in. and $3 / 4$-in. wide specimens shall be $3 / 4$ in. and $1 / 4$ in., respectively.

NoTr 6-For the 13/2-in. wide specimen, a $1 / 2$-in. minimum radius at the ends of the reduced section is permitied for steel specinens under 100 o00 psi in tensile strength when a profile cutter is ased to machime the reduced section.

Norz 7-The dimeasion shown is suggested as a minimum. In determining the ninimum length, the grips must not extend in to the transition section between Dinwensions $A$ and $B$, see Note 9 .

Norx 8 -To aid in obtaining axial fonce application curing tesfing of $3 / 4-\mathrm{in}$. wide specimens, the over-sll length should be as layge as the material will pernit, up to 8.00 in.

Norn 9 -It is desirable, if possible, to make the length of the grip section large enough to allow the specimen to extend into the grips a distance equal to two thirds or nore of the length of the grips. If the thickness of $1 / 2$-in. wide specinens is over $3 / 3$ in., longer grips and correspondingly longer grip sections of the specimen may be necessary to prevent faihure in the grip section.

Note 10-For the three sizes of specimens, the ends of the specimen shall be symmetrical in width with the renter line of the reduced section within $0.10,0.05$ and $0.005 \mathrm{in}$, respectively. However, for neferee testing and when required by product specifications, the ends of the $1 / 2$-in. wide specimen shall be symmetrical within 0.01 in.

Note 11 - For each specimen type, the radii of all fillets skall be equal to each other within a tolerance of 0.05 in. and the centers of curvature of the two fillets at a particular end shall be located across from each other (on a line penpendicular to the centerline) within a tolerance of 0.10 in.

Notr 12 -Specimens with sides parallel turoughout their length are permitted except for referee festing, provided: (a) the above tolenances are ased (b) an adequate number of marks are provided for determination of elongation; and ( $c$ ) when yield strength is determined, a suitable extensometer is nsed. If the fracture occurs at a distance of less than $2 W$ from the edge of the gripping device, the tensile properties determined may not be representative of the material. In acceptance testing, if the properties meet the minimm reçuirements specified, no further testing is required, but if they are less than the minimun requiremerts, discard the test and retest

Figure 4.40 Rectangular tensile test specimens [63] 


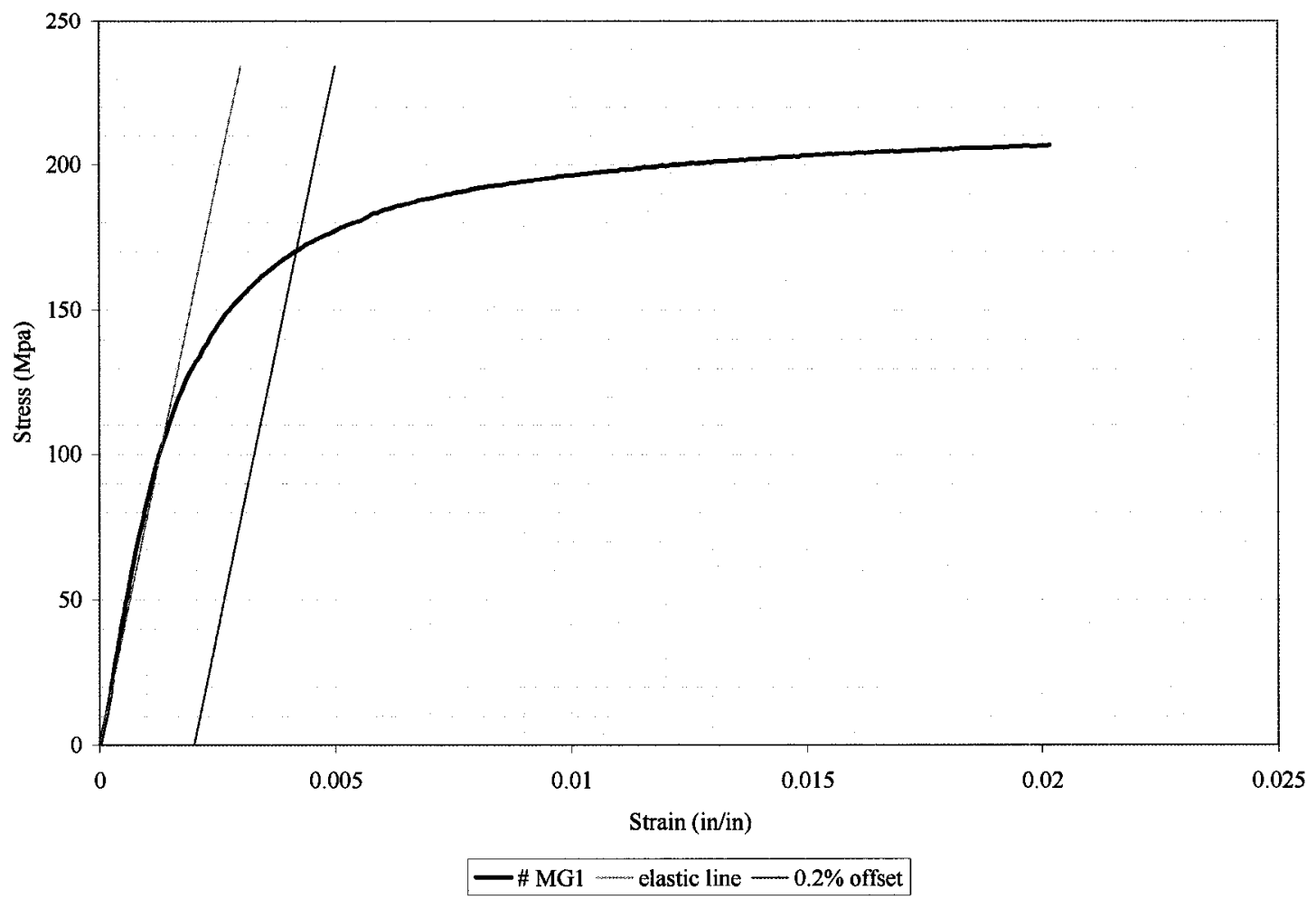

(a)

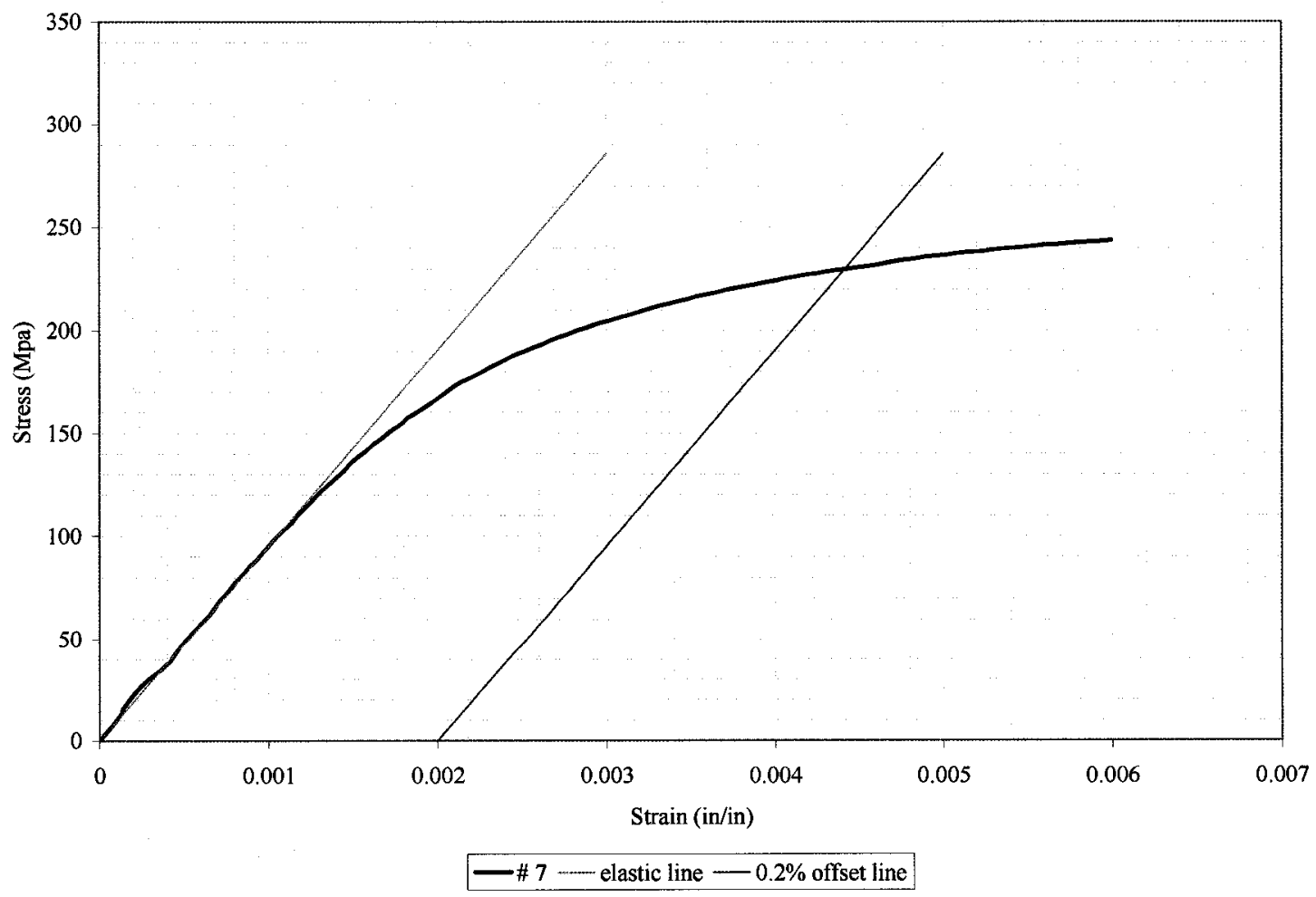

(b) 


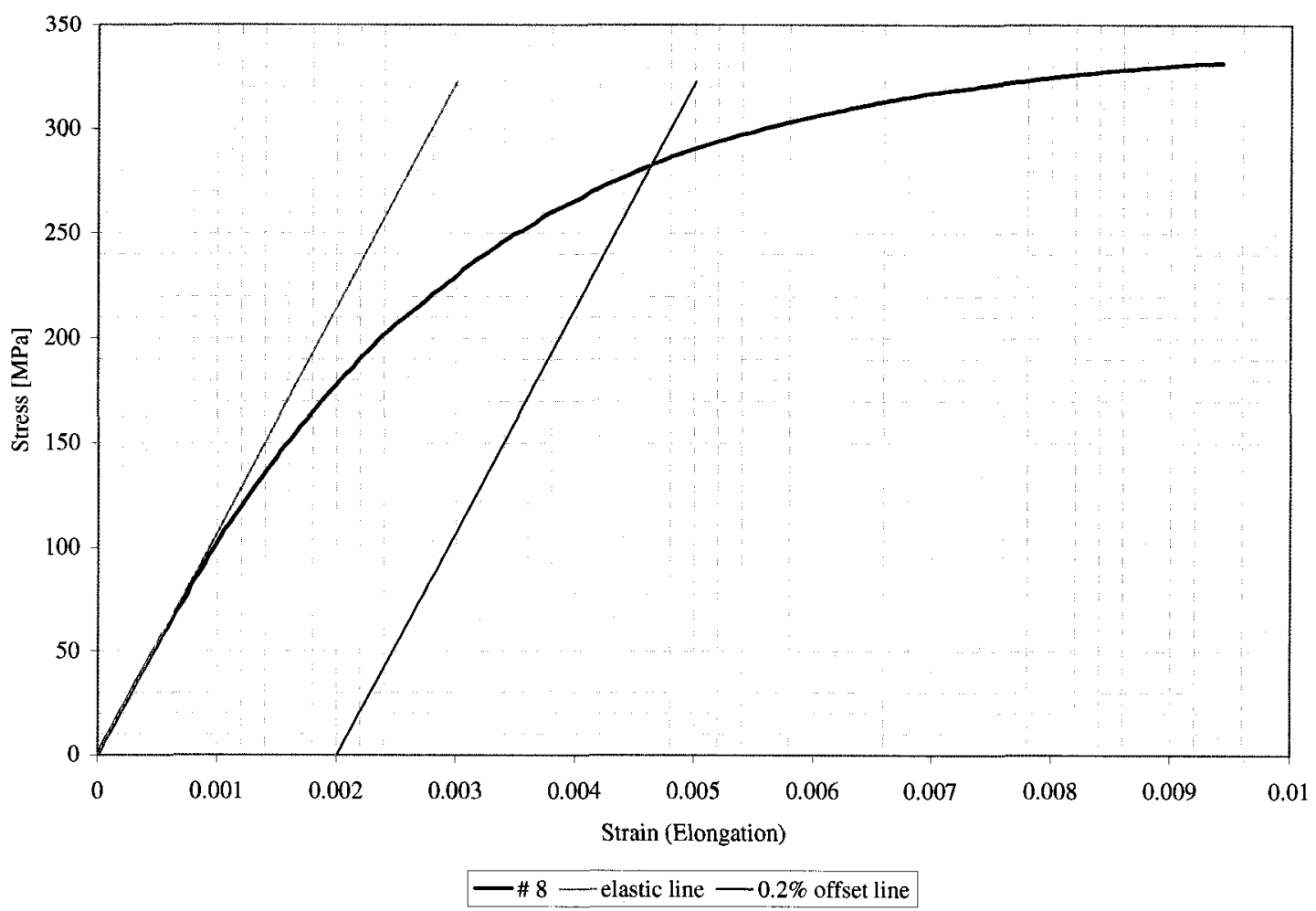

(c)

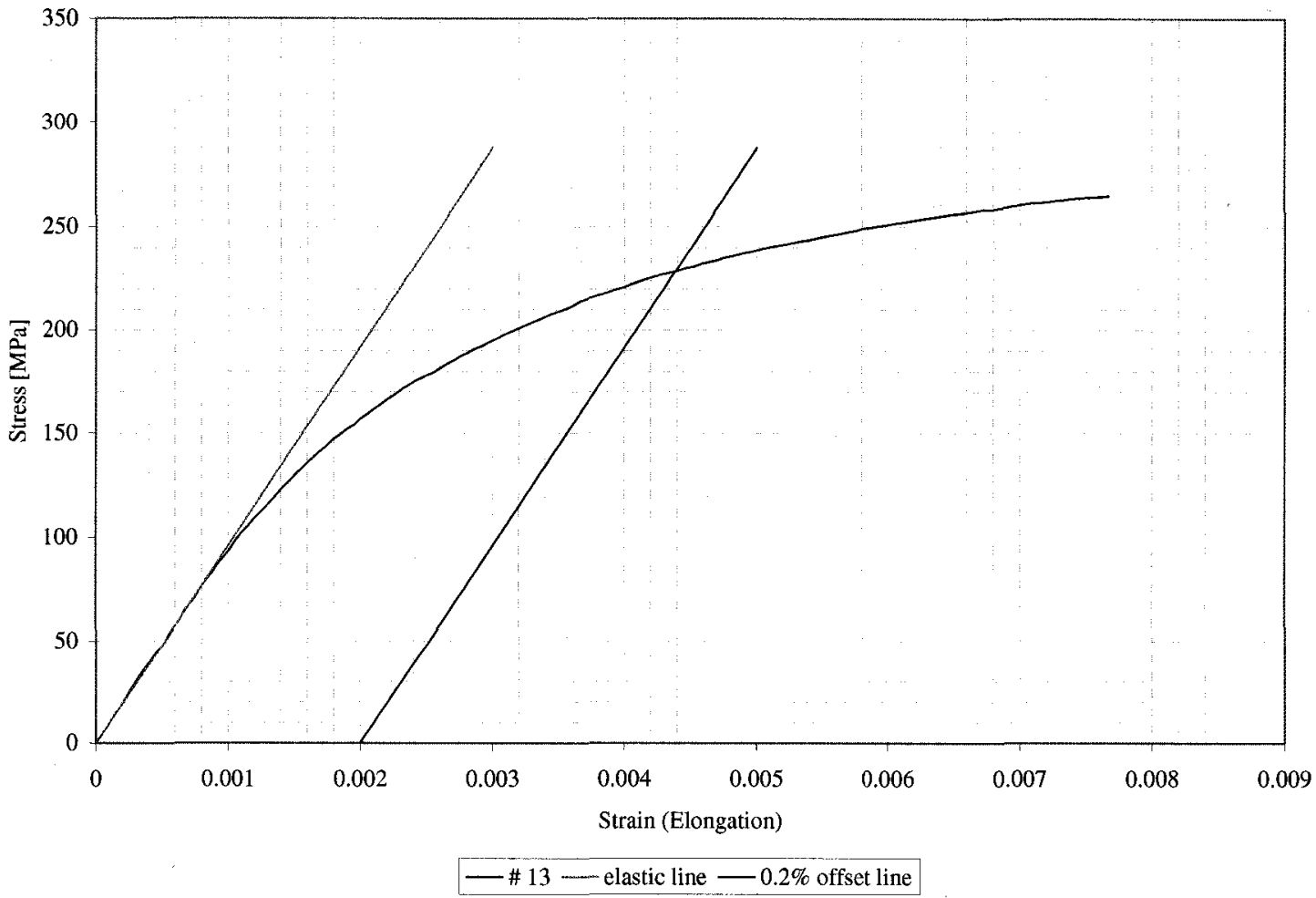

(d) 


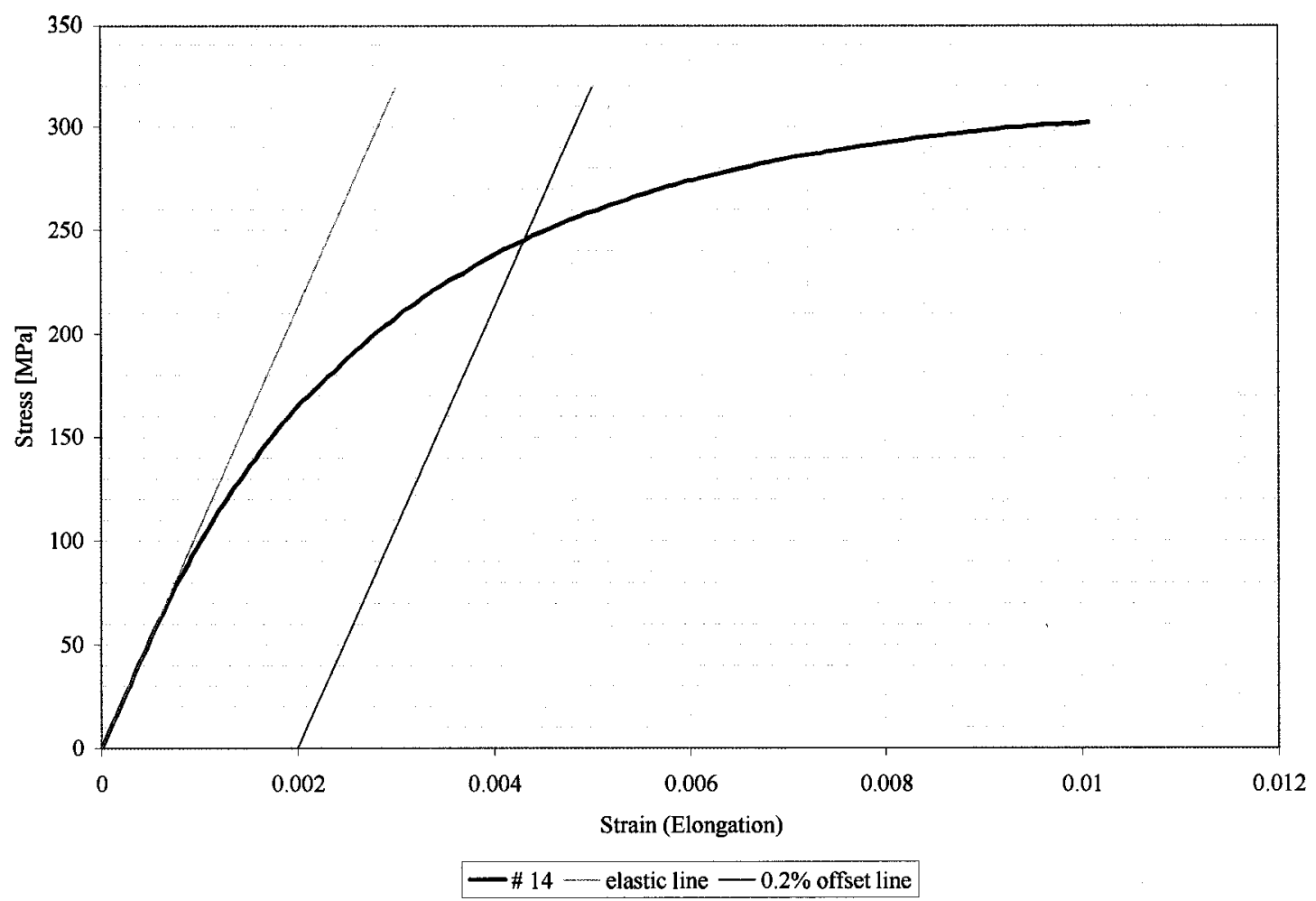

(e)

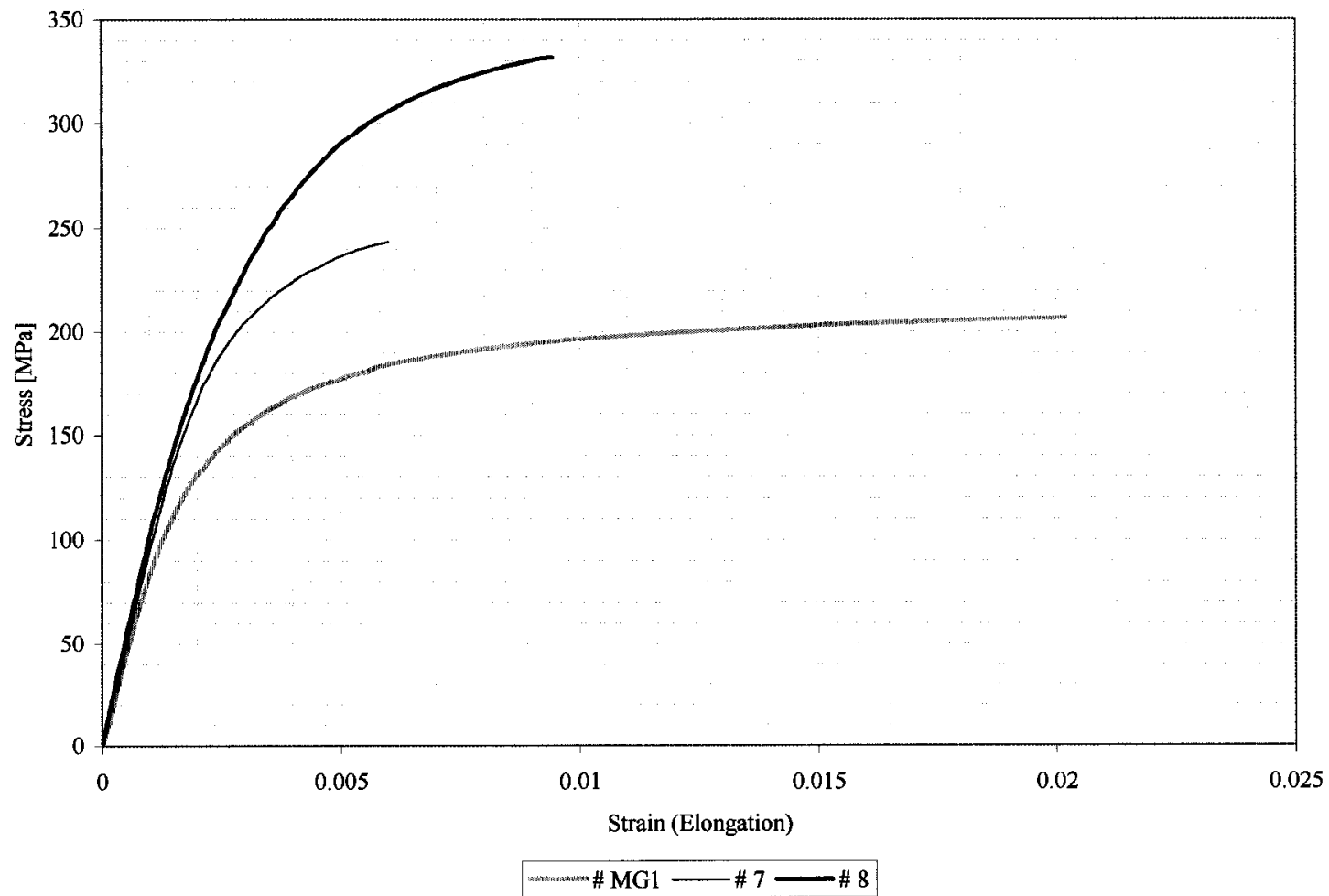

(f) 


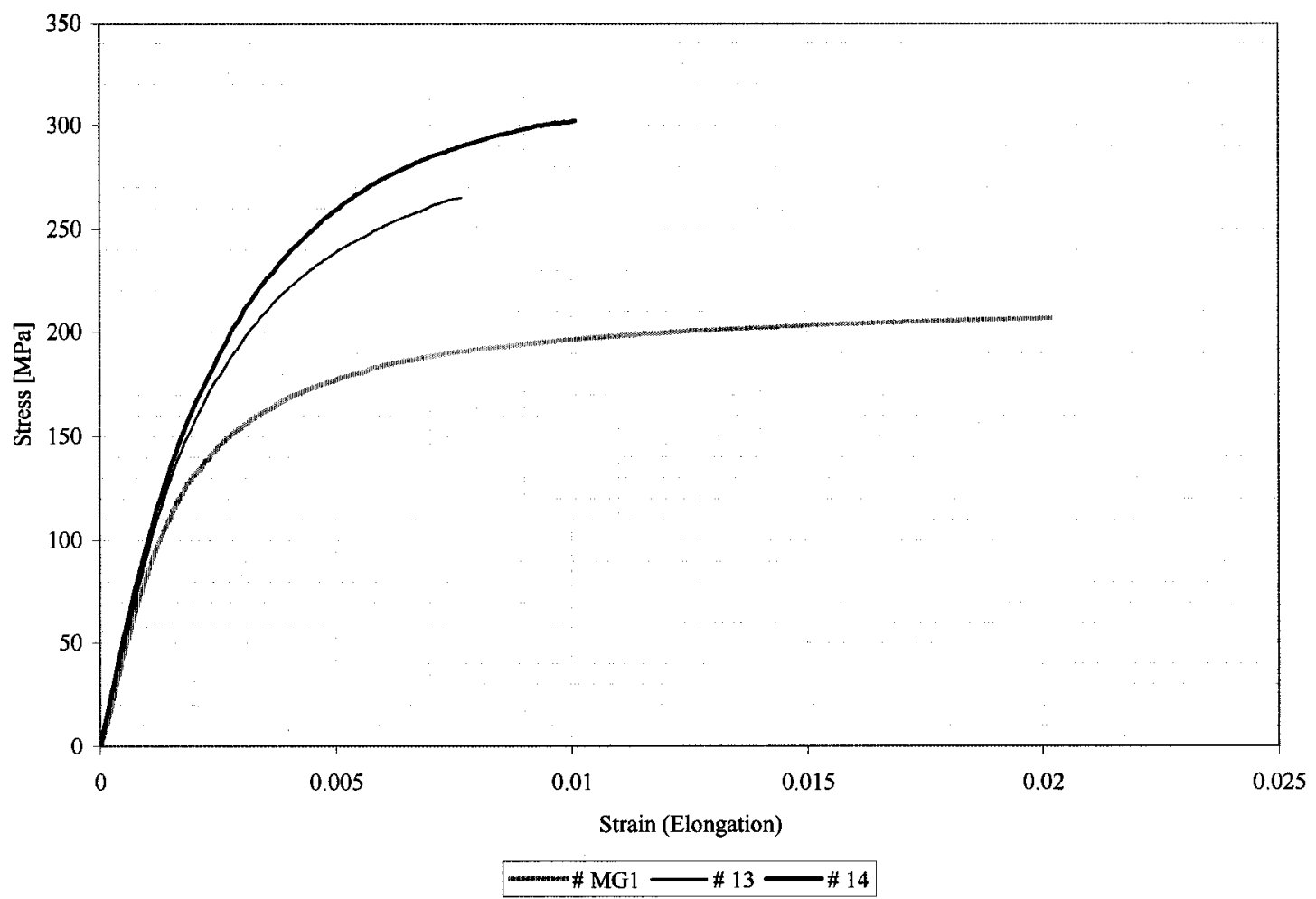

(g)

Figure 4.41 Stress - strain curves for Groupl specimens (premixed bronze based): (a) specimen MG1, (b) specimen 7, (c) specimen 8, (d) specimen 13, (e) specimen 14, (f) specimens MG1, 7, and 8, (g) specimens MG1, 13, and 14 


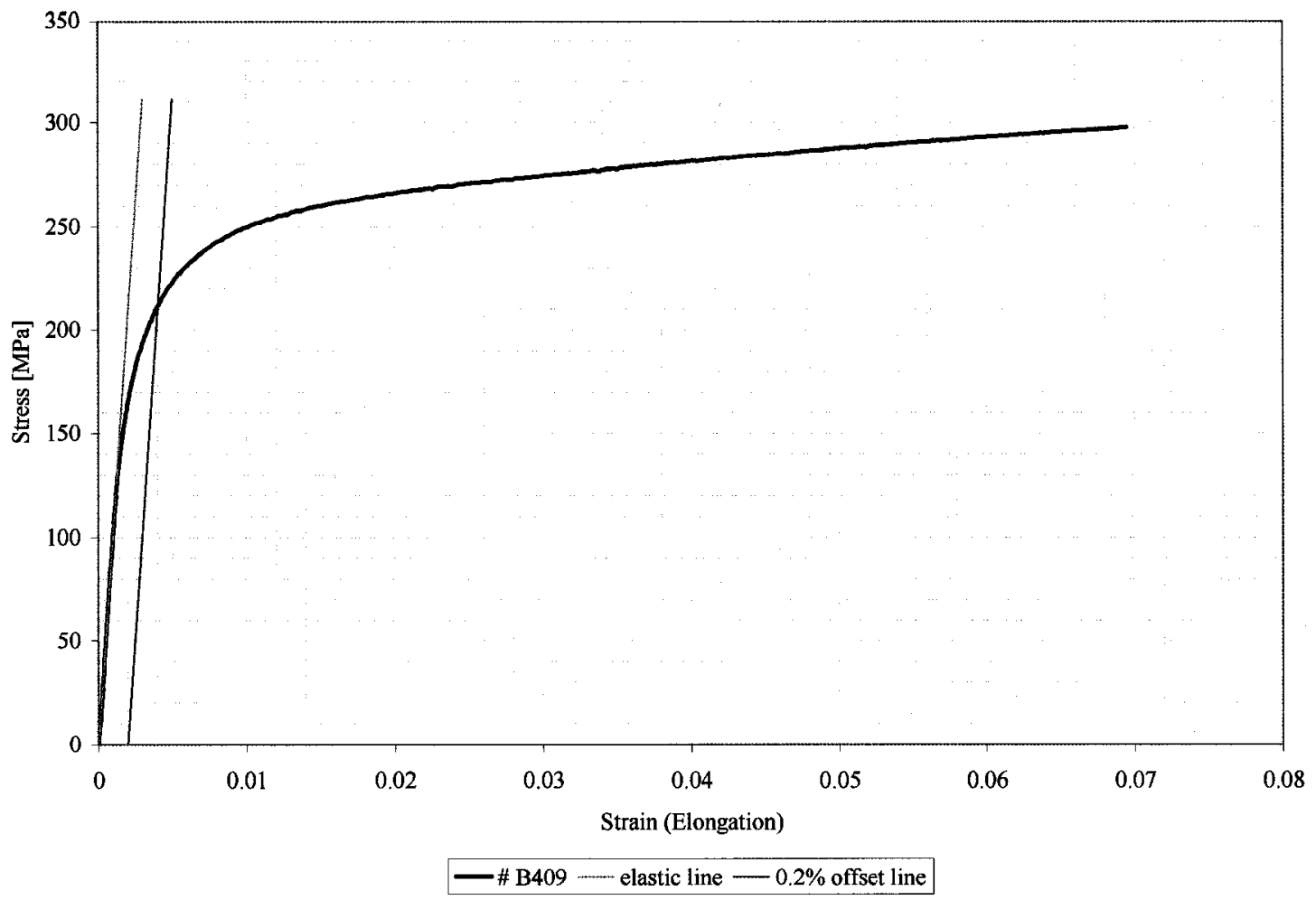

(a)

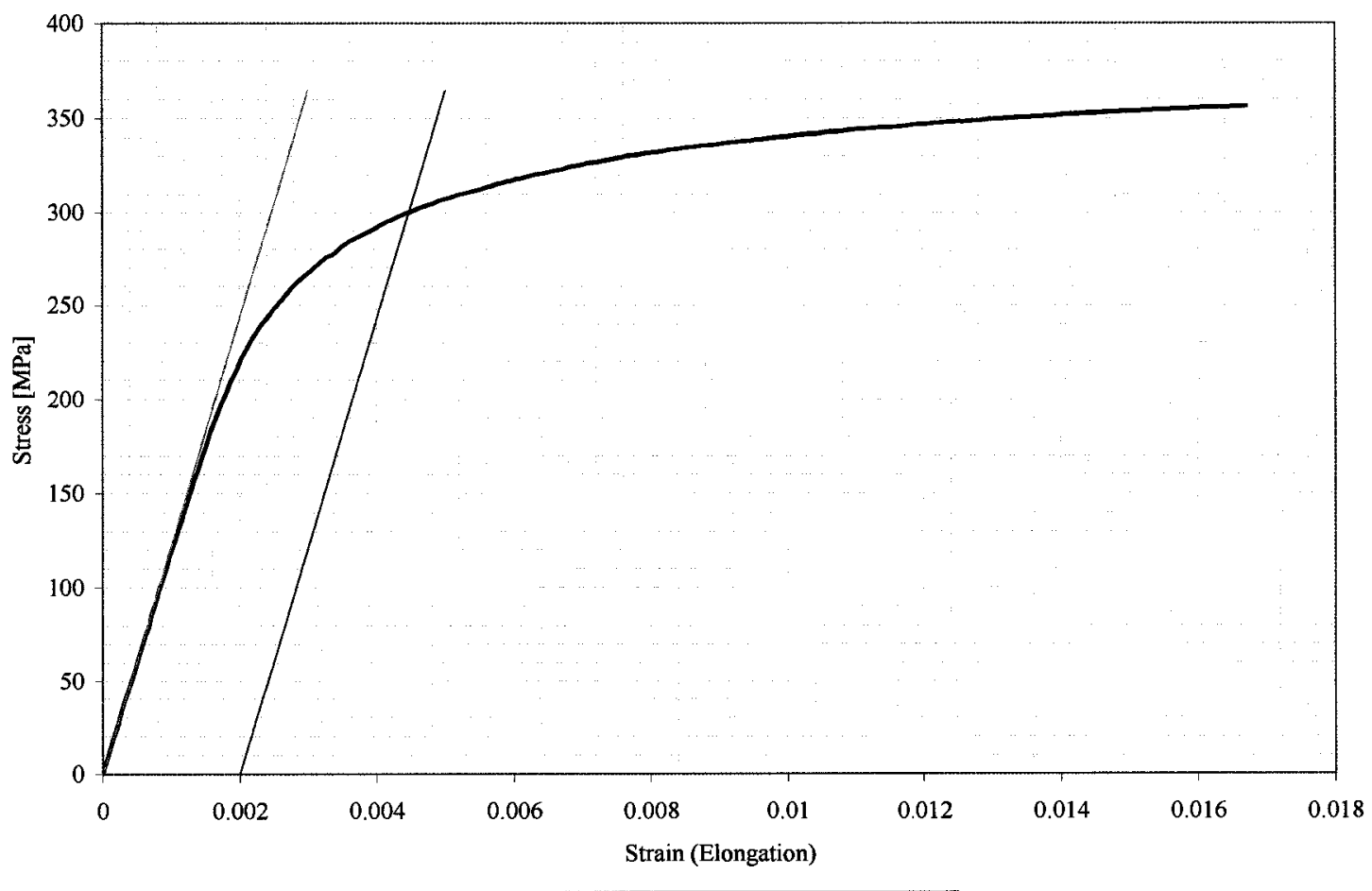

-\# 10 - elastic line - $0.2 \%$ offset line

(b) 


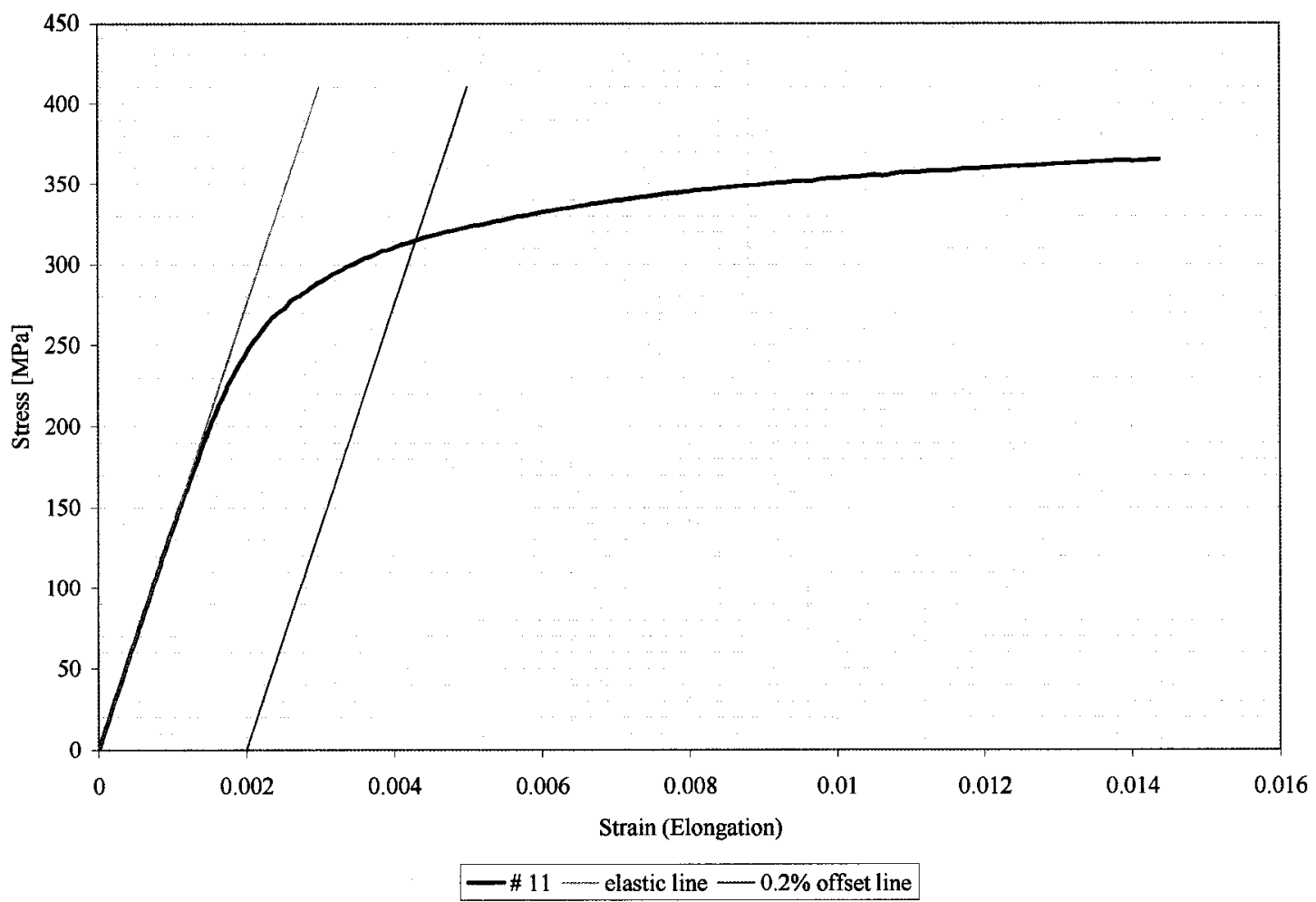

(c)

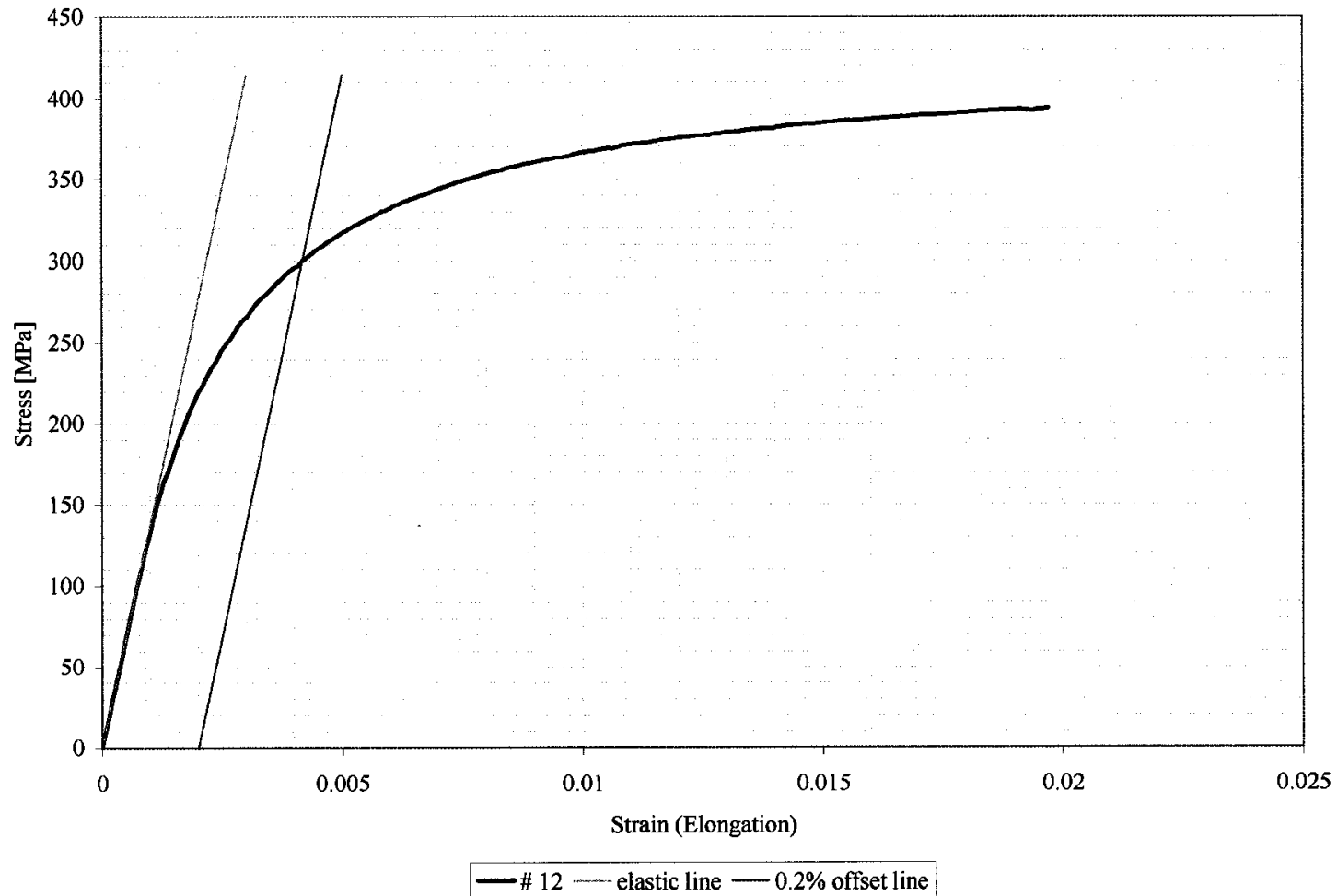

(d) 


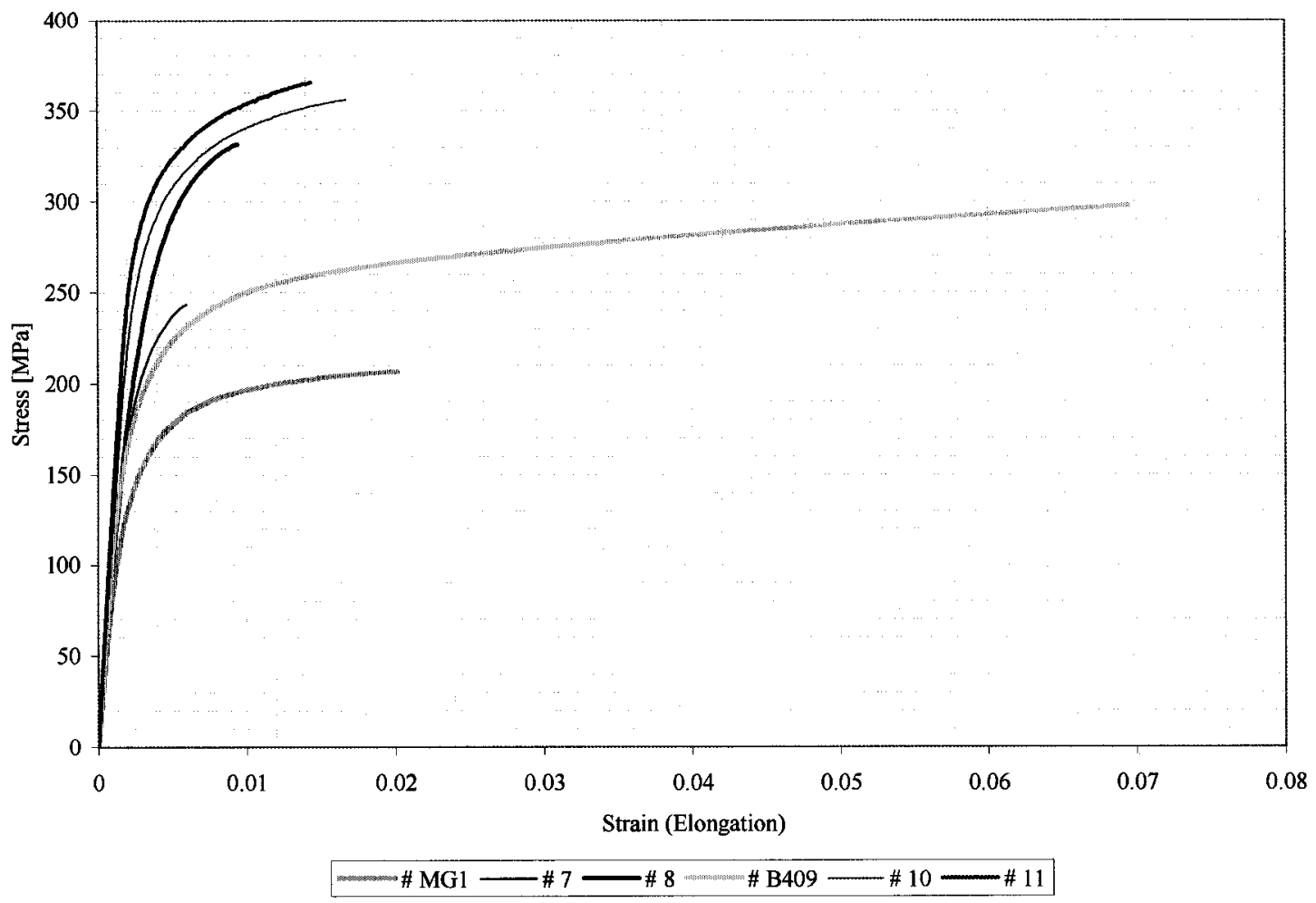

(e)

Figure 4.42 Stress - strain curves for Group 2 specimens (prealloyed bronze based):

(a) specimen B-409, (b) specimen 10, (c) specimen 11, (d) specimen 12,

(e) specimens B-409, 10, 11, 12, MG1, 7, and 8 


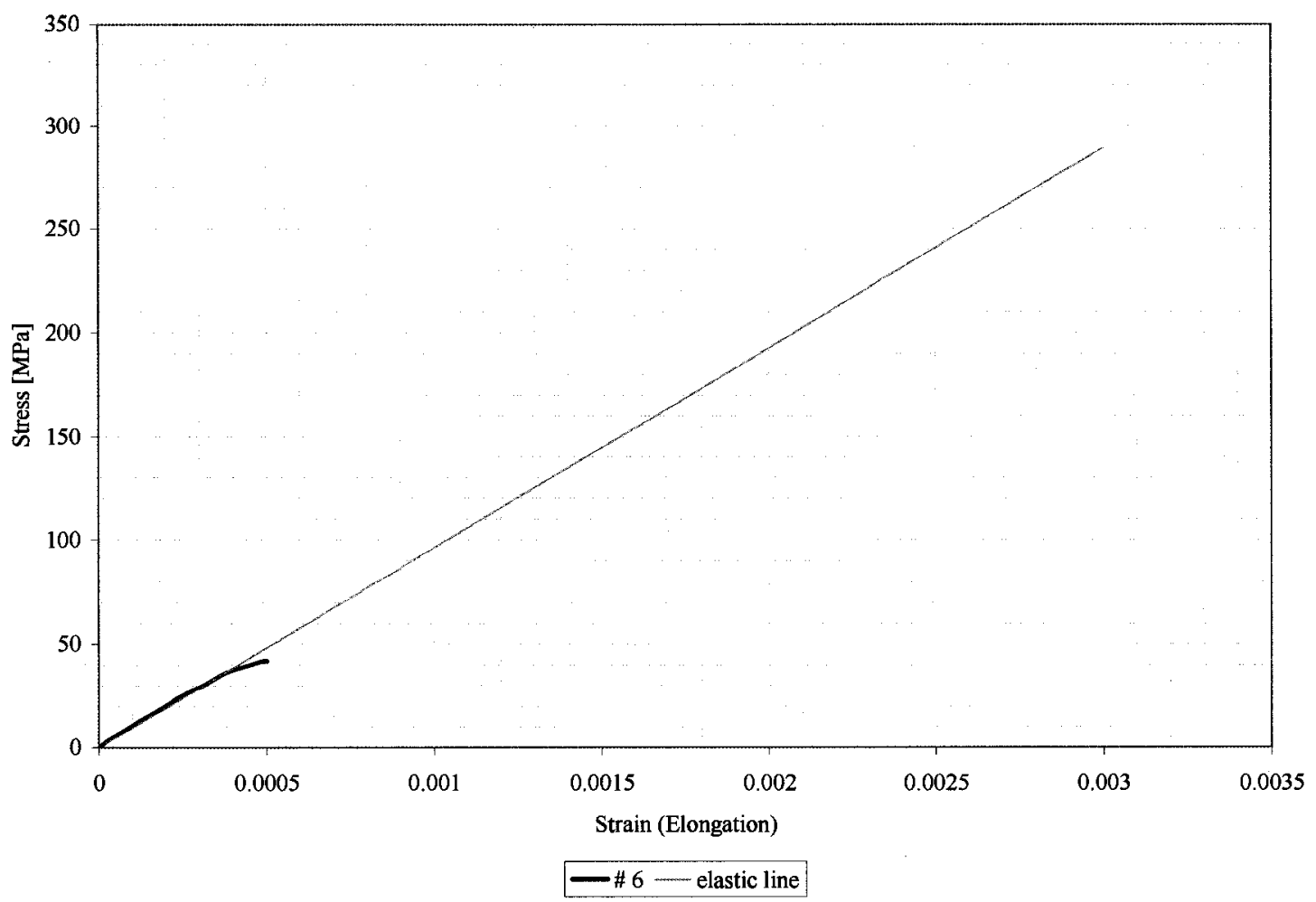

(a)

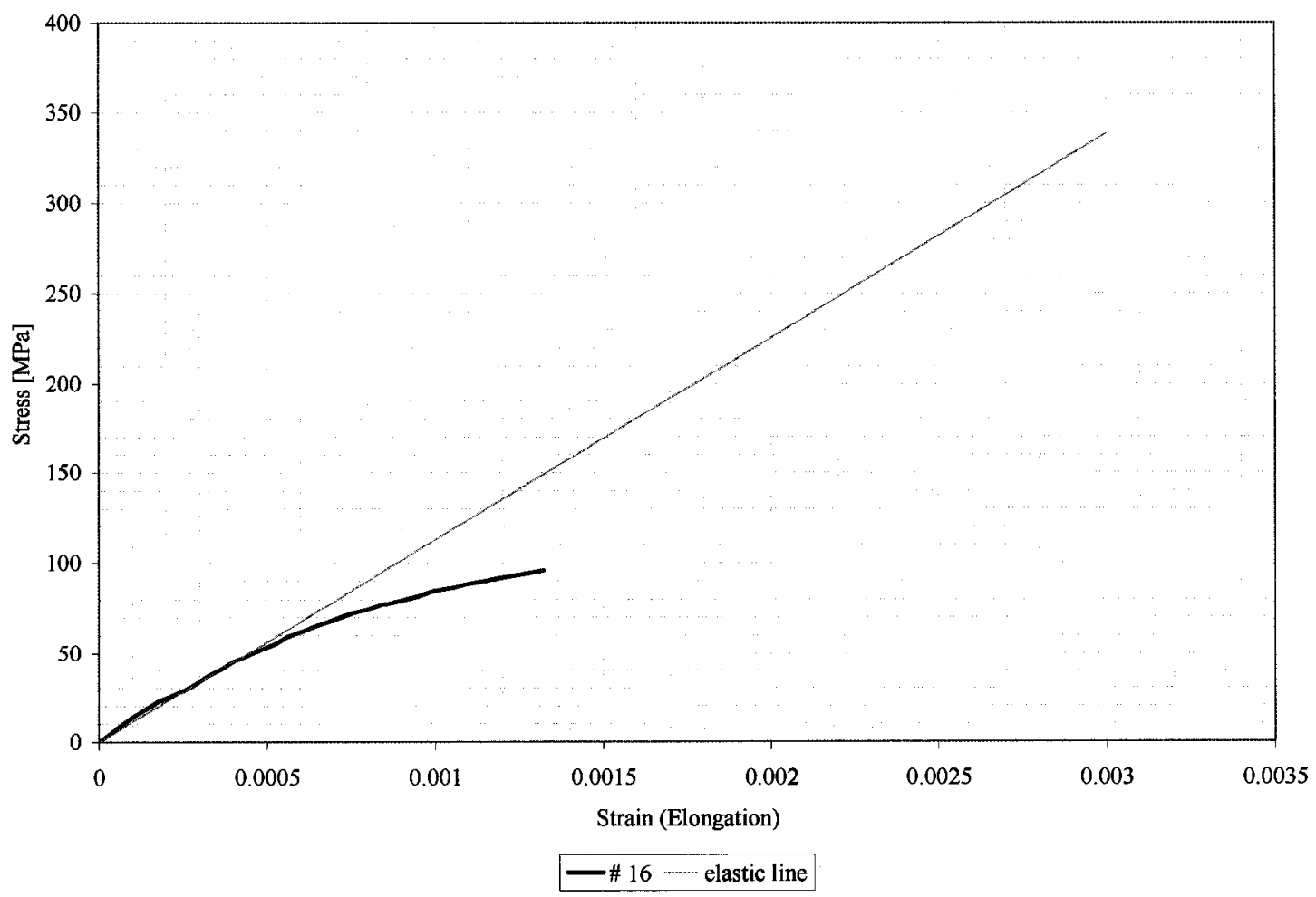

(b) 


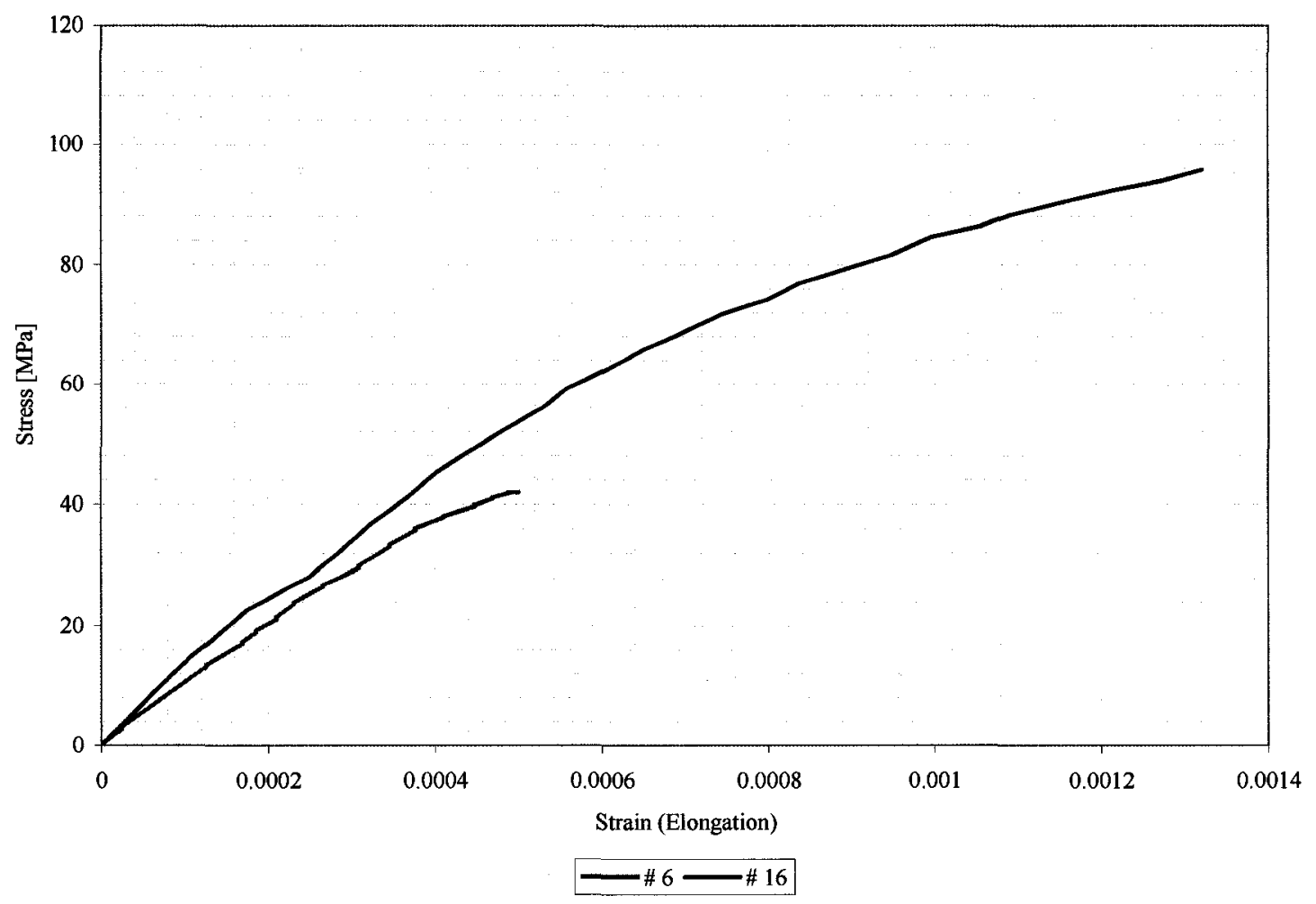

(c)

Figure 4.43 Stress - strain curves for Group 3 specimens (copper based):

(a) specimen 6, (b) specimen 16, (c) specimens 6 and 16 


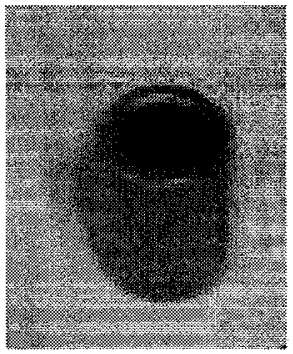

Figure 4.44 Sintered bronze bearing sample

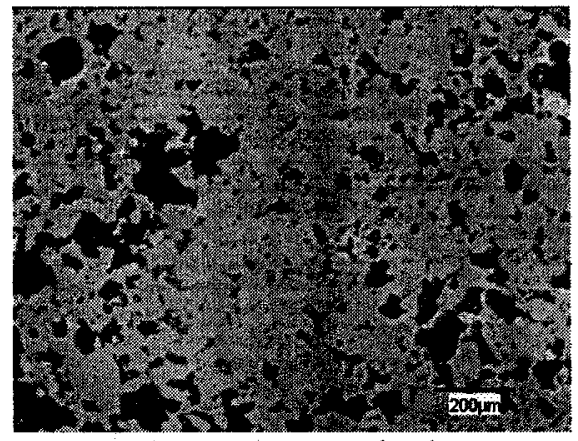

(a) X50-unetched

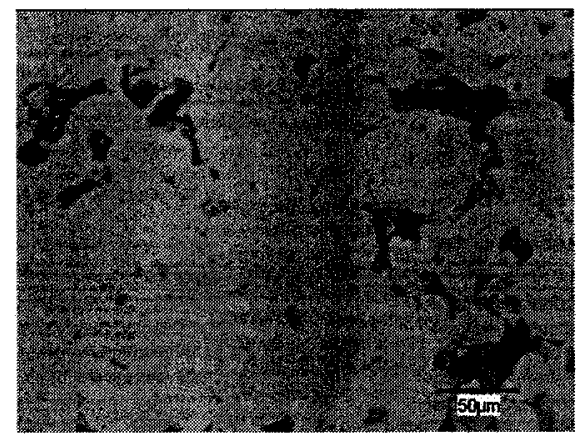

(c) X200 - unetched

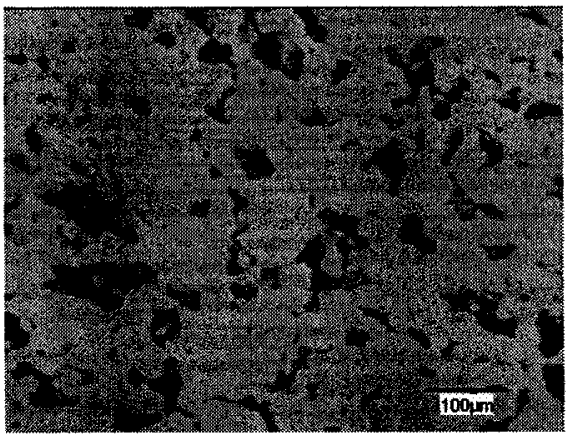

(b) X100-unetched

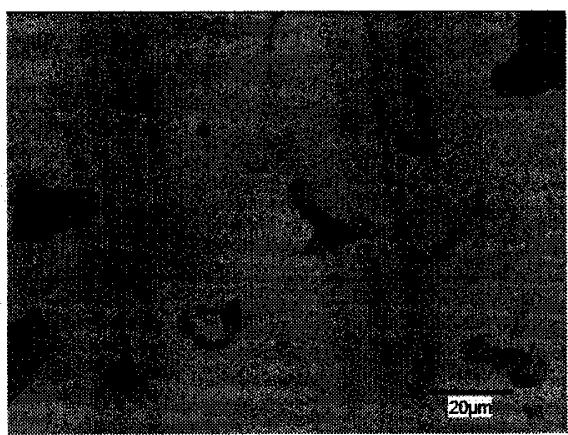

(d) X500 - unetched

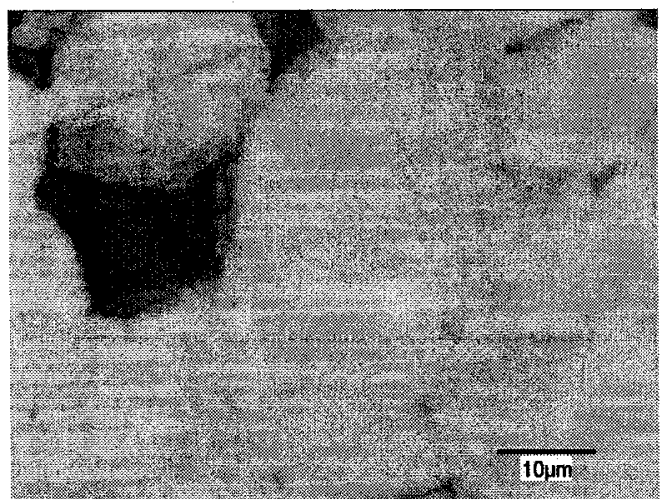

(e) X1000 - unetched

Figure 4.45 Microstructures of sintered bronze bearing sample 


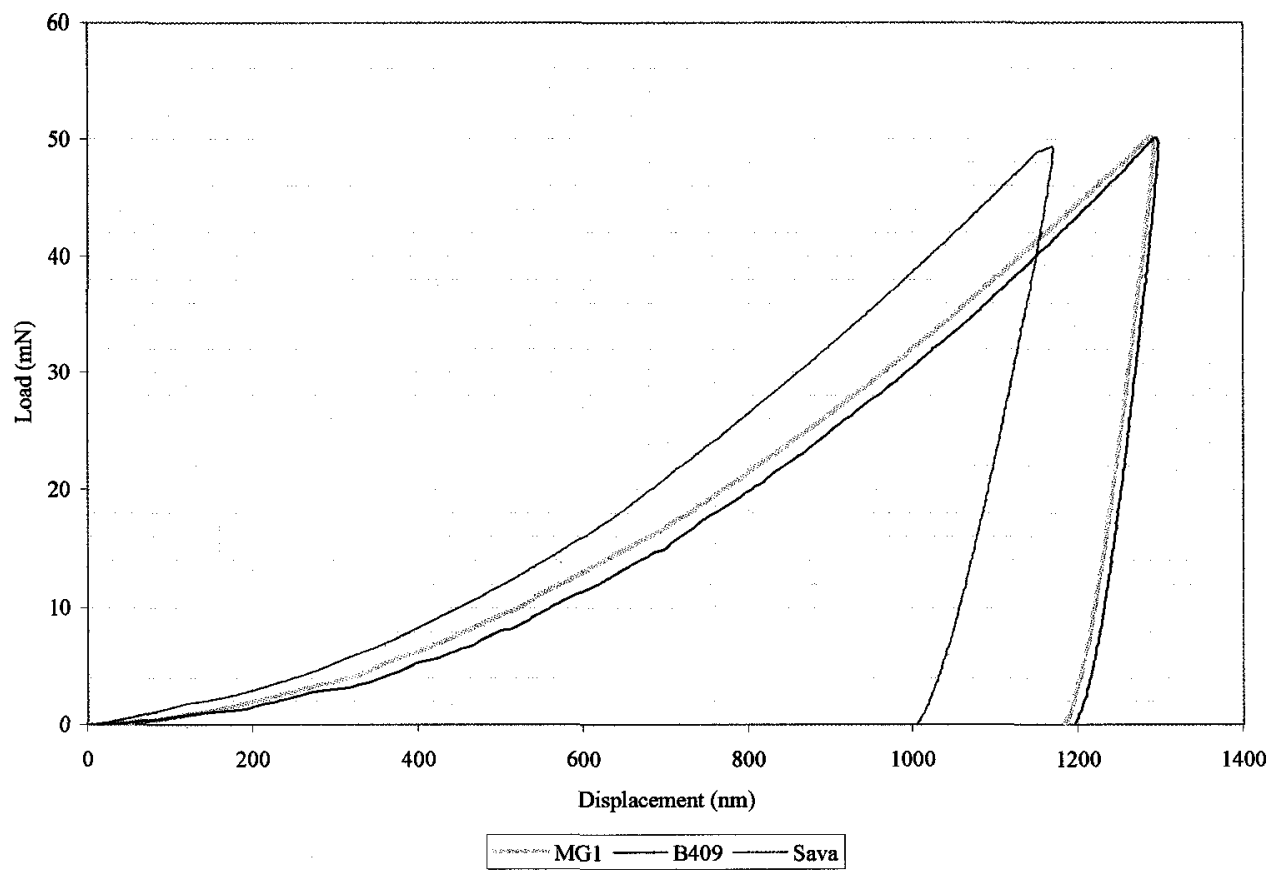

Figure 4.46 Load - displacement curves for sintered bronze bearing sample in comparison with specimens MG1 and B-409

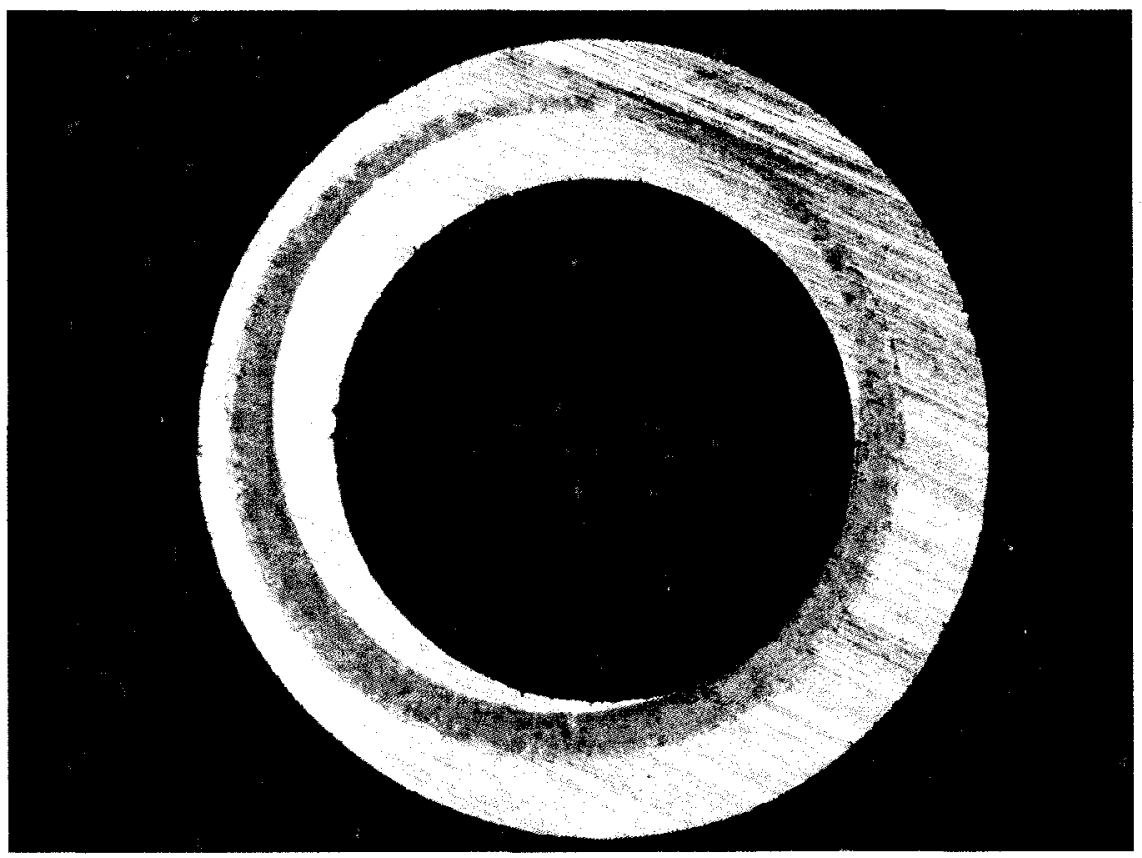

Figure 4.47 Worn surface of sintered bronze bearing sample 


\section{Appendix A}

Technical and safety data sheets for premixed bronze powder (MG1)

MATERIAL SAFETY DATA SHEET R2

$\begin{array}{lll}\text { UNITED STATES BRONZE POWDER, INC. } & \text { HMIS RATING: } \\ \text { P.O. BOX 31, 408 ROUTE 202 } & \text { HEALTH: } & 1 \\ \text { FLEMINGTON, NJ 08822 } & \text { FLAMMABILITY: } & 0 \\ \text { TELEPHONE: } 908-782-5454 & \text { REACTIVTYY: } & 0 \\ \text { Issue Date: } \quad 10 / 11 / 00 & \text { PERS. PROTECTION: } & \\ \text { Supersedes: } \quad 01 / 18 / 99 & & \end{array}$

SECTION I. MATERIAL IDENTIFICATION

Material Name:

ROYAL PREMIX HRONZE POWDER

Item Number:

HG-1, HG-2, HG-3, KB-1, KB-1-M, KB-2, KB-20, KB-20-7, KB-3, LG, LG-0 LG-1, M4000, M5000, M6000, MG, MG-1, MG-2, MG-3, PRC-1B, ROC-1, ROC-1A, ROC-1B, ROC-2B, SB 1, TB-1, TB-2

CAS Number: MIXTURE

SECTION II. INGREDIENTS AND EXPOSURE LIMTS

\begin{tabular}{|c|c|c|c|c|c|c|}
\hline Ingredient & CAS Number & $\%$ & TWA & $\begin{array}{l}\text { ACGIH } \\
\text { STEL }\end{array}$ & $\begin{array}{l}\text { TLV } \\
\text { TWA }\end{array}$ & $\begin{array}{r}\text { OSHA PEL } \\
\text { STEL }\end{array}$ \\
\hline & & & \multicolumn{4}{|c|}{ (ALL Units $=\mathrm{mg} / \mathrm{m} 3)$} \\
\hline COPPER & $7440-50-8$ & $87.5-90.5$ & 1 & - & 1 & - \\
\hline TIN & $7440-31-5$ & $9.5-10.5$ & 2 & - & 2 & * \\
\hline Organic Lubricant & Various & $<1$ & & $\mathrm{~N} / \mathrm{A}$ & & N/A \\
\hline
\end{tabular}

SECTION III PHYSICAL DATA

Appearance and Odor: Reddish color, odorless

Boiling Point:

Evaporation Rate:

Vapor Pressure (I $\mathrm{mm} \mathrm{Hg}$ ):

Specific Gravity:

Water Solubility $(\%)$ :

Melting Point:

Vapor Density (air $=1$ ):

$\%$ Volatile by Volume:

Molecular Weight:

COPPER
$4653^{\circ} \mathrm{F}\left(2567^{\circ} \mathrm{C}\right)$
N/A
$2962^{\circ} \mathrm{F}\left(1628^{\circ} \mathrm{C}\right)$
8.92
NSOLUBLE
$1981^{\circ} \mathrm{F}\left(1083^{\circ} \mathrm{C}\right)$
N/A
N/A
63.54

TIN

$4100^{\circ} \frac{1}{\mathrm{~F}\left(2260^{\circ} \mathrm{C}\right)}$

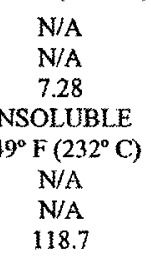

N/A

INSOLUBLE

$449^{\circ} \mathrm{F}\left(232^{\circ} \mathrm{C}\right)$

N/A

118.7

Flash Point: N/A

$\begin{array}{lccc} & \mathrm{Cu} & \mathrm{Sn} \\ \text { Limits: } & \text { LEL } \%: & \text { N/A } & 0.19 \mathrm{oz} / \mathrm{tt} 3 \\ \text { LEL } \%: & \text { N/A } & \text { N/A }\end{array}$

Extinguishing Media: Foam, CO2, Dry Chemical, and Water Fog

Page 1 of 3 
MATERIAL SAFETY DATA SHEET

Material is stable. Hazardous polymerization will not occur.

Chemical incompatibilities: Strong alkalies, chlorates, bromates, mineral acids.

Hazardous decomposition products: Decomposition may yield hydrogen and noxious copper compounds.

\section{SECTION VI. HEALTH HAZARD INFORMATION}

Target Organs: $\quad$ Respiratory system, nasal septum, skin, eyes, gastrointestinal, kidneys, liver, cardiovascular system.

Primary entry routes: Inhalation, ingestion, skin or eye contact.

Health effects:

Copper dusts and mists are eye and mucous membrane irritants, primary skin imitants and skin sensitizers. Acute exposure may cause metallic taste and nasal ulceration and perforation. Prolonged skin contact may result in imitation and metal-fume fever, metallic taste, and discoloration of the skin and hair. Ingestion of copper powder compounds may cause vomiting and collapse. Hemolysis, jaundice, anuria, hypotension, and convulsions characterize acute

First Aid: poisoning.

Eye Contact:

Immediately wash the eyes with large amounts of water, occasionally lifting the lower and upper lids. Seek medical attention immediately. Contact lenses should not be worn.

Skin contact: Inhalation: Flush contaminated skin with water. Get medical attention if irritation occurs/persists Move the exposed person to fresh air at once. If breathing has stopped, perform artificial respiration. Keep the affected person warm and at rest. Get medical attention as soon as possible.

Ingestion: $\quad$ Emergency treatment - dilute with water or milk. Remove by gastric lavage (i.e. stomach tube) unless patient is vomiting. Get medical attention as soon as possible.

\section{SECTION VII. SPILL, LEAK AND DISPOSAL PROCEDURES}

Spill/leak procedures: Sweep gently to avoid dust cloud formation.

Disposal:

Dispose of in accordance with local, state, and federal regulations.

SECTION VIII. SPECIAL PROTECTION INFORMATION

Personal Protective Equipment:

Goggles: $\quad$ Safety goggles with side shields, if needed.

Gloves: $\quad$ Required for those with extreme sensitivity

Respirator: Wear supplied air respirator under confined or enclosed spaces, if needed.

Workplace considerations: Eyewash fountains, soap and water wash station.

Ventilation: Sufficient ventilation, in volume and pattern, should be provided to keep air contamination below current applicable OSHA permissible limits.

SECTION DX. SPECIAL PRECAUTIONS

Special handing/storage: None 
MATERIAL SAFETY DATA SHEET

$\mathbf{R 2}$

SECTIONX. CARCINOGENITY STATUS

1. NTP: Not Listed

2. IARC: Not Listed

3. OSHLA: Not Listed

SECTION XI. SECTION 313 SUPPLIER NOTIFICATION

This product contains the following toxic chemicals subject to the reporting requirements of Section 313 of the Emergency Planning and Community Right-To-Know Act of 1986 and of 40 CFR 372:

$\begin{array}{lll}\text { CAS\# } & \text { Chemical Name } & \text { Percent by Weight } \\ 7440-50-8 & \text { Copper } & \frac{99 \%}{}\end{array}$

This information must be included in all MSDS"s that are copied and distributed for this material.

SECTION XII. EMERGENCY CONTACT

\section{Chemtrec: 800-424-9300}

To be used "ONLY IN THE EVENT OF CHEMICAL EMERGENCIES INVOLVING A SPILL, LEAK, FIRE, EXPOSURE, OR ACCIDENT INVOLVING CHEMICALS."

\section{DISCLAIMER OF LIABILITY}

The information provided is based on data furnished to us by our suppliers or determined by us in our facilities at the time that this product was formulated. Although believed to be reliable, the information and products are intended for use by skilled persons at their own risk. Users should make their own determinations as to the suitability of the produce for their particular use or purpose. NO WARRANTY OF MERCHANTABILITY, FITNESS FOR ANY PARTICULAR

PURPOSE, OR ANY OTHER WARRANTY IS EXPRESSED OR IS IMPLIED REGARDING THE ACCURACY OF COMPLETENESS OF THIS NFORMATION. Seller assumes no responsibility for events resulting or damages incurred from the used of this product and any obligations between seller and buyer are to be controlled by the terms and conditions contained in seller's acknowledgement forms.

Page 3 of 3 


\section{Appendix B}

Technical and safety data sheets for prealloyed bronze powder (B-409)

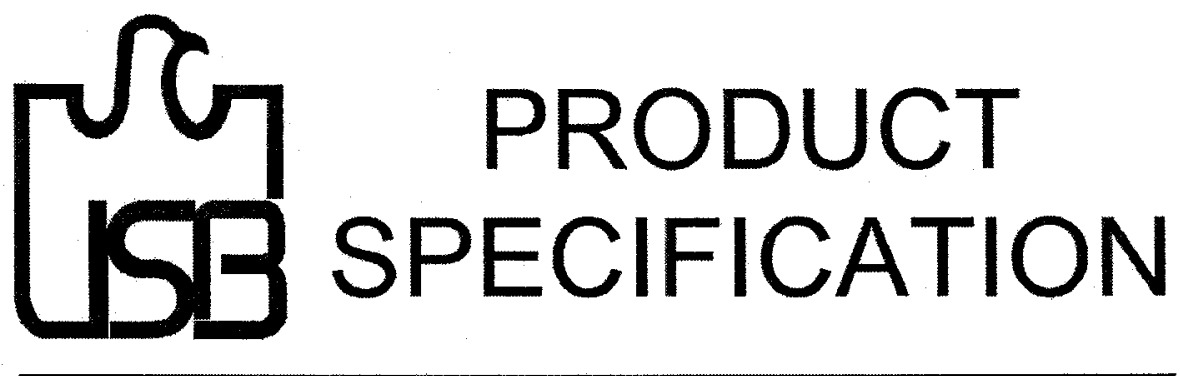

B-409

\section{PRE-ALLOYED BRONZE POWDER}

NOMINAL CHEMISTRY

Copper, \%

Tin, $\%$

APPARENT DENSITY, $\mathrm{g} / \mathrm{cm} 3$ :

SCREEN ANALYSIS:
Remainder

$9-11$

4.2 (minimum)

0.0

Trace (maximum)

1.0 (maxinum)

Remainder

95(minimum)

September 2001

Company Name:

Company Representative:

Date: 
MATERIAL SAFETY DATA SHEET

B3-1

UNITED STATES BRONZE POWDERS, INC

P.O. BOX 31, 408 ROUTE 202

FLEMINGTON, NJ 08822

HMIS RATING

HEALTH :

FLAMEABILITY:

REACTIVITY:

TELEEPHONE : $\quad 908-782-5454$

PERS. PROTECTION.

SECTION I. MATERIAL IDENTIFICATION

Material Name: BRONZE POWDER

Item Number: B-401, B-402, B-406, B-408, B-409, B-409TR, B-419. $B-432$

SPHERICAL BRONZE: $22 / 36,30 / 44,36 / 44$

$36 / 60,85 / 120,85 / 150,85 / 200,89 / 11,100 / 240$

$120 / 200,170 / 300$, SBP90/10 - 325, LF5, SBP80/20-240

CAS Number:

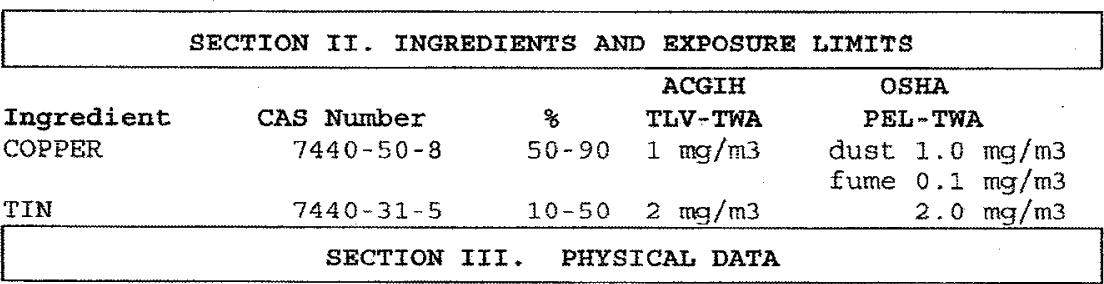

Appearance and Odor: Reddish to gold color, odorless.

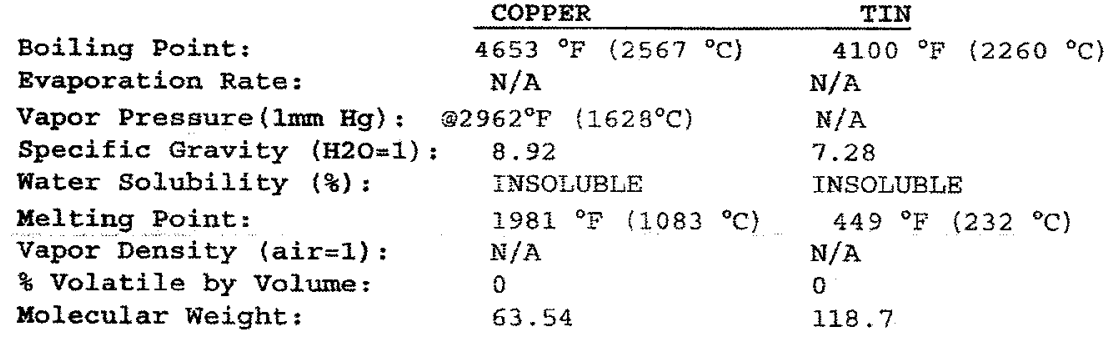

\section{SECTION IV. FIRE AND EXPLOSION DATA}

Flash Point: $N / A$

COPPER TIN TIN TI TI

UEL: :

UEL: $N / A \quad N / A$

Extinguishing media: Foam, Co2, Dry Chemical, water Fog. 
MATERTAT SAFETY DATA SHEET

B3-1

SECTION V. REACTIVITY DATA

Material is stable.

Hazardous polymerization will not occur.

Chemical incompatibilities: Strong alkalies, chlorates, bromates, turpentine, mineral acids, amines.

Hazardous decomposition products: Decomposition may yield hydrogen and noxious copper compounds.

\section{SECTION VI, HEALTH HAZARD INEORMATION}

Target organs: Respiratory system, nasal septum, skin, eyes, gastrointestinal system, kidneys, Iiver, cardiovascular system. Primary entry routes: Inhalation, ingestion, skin or eye contact.

Health effects: Copper dusts and mists are eye and mucous membrane irritants and skin sensitizers. Acute exposure may cause metallic taste and nasal ulceration and perforation. Prolonged skin contact may produce sensitization dermatitis. Exposure may result in irritation and metal-fume fever, metalic taste, and discoloration of the skin and hair. Ingestion of copper compounds may cause vomiting and collapse. Acute poisoning is characterized by hemolysis, jaundice, anuria, hypotension and convulsions.

Inorganic tin compounds are eye, mucous membrane and primary skin irritants, Acute exposure may irritate the eyes and repiratory tract. Repeated or prolonged skin contact produces dermititis. First Aid:

Eye contact: Immediately wash the eyes with large amounts of water, occasionaliy lifting the lower and upper idds. Seek medical attention immediately. Contact lenses should not be worn.

Skin contact: Flush contaminated skin with water. Seek medical attention if irritation occurs/persists.

Inhalation: If a person breathes in large amounts of this chemical, move the exposed person to fxesh air at once. If breathing has stopped, perform artificial respiration. Keep affected person warm and at rest. Seek medical attention as soon as possible.

Ingestion: Emergency treatment: dilute with water or milk. Remove by gastric lavage (i.e. stomach tube) unless patient is vomiting. Get medical atiention as soon as possible.

$$
\text { SECTION VII. SPILI, LEAK AND DISPOSAL PROCEDURES }
$$

spil1/leak procedures: Sweep gently to avoid cust cloud formation.

Disposal: Dispose of in accordance with local, state, and federal regulations. 
MATERIAL SAFETY DATA SHEET

B3-1

SECTION VIII. SPECIAL PROTECTION INFORMATION

Personal protective equipment:

Goggles: Safety goggles with side shields, if needed.

Gloves: Required for those with extreme sensitivity.

Dust Mask: Use in confined or enclosed spaces.

Workplace considerations: Eye-wash fountain, soap and water wash

station.

Ventilation: Sufficient ventilation, in volume and pattern

should be provided to keep air contamination below current

applicable osHA permissible exposure limits.

SECTION IX. SPECIAL PRECAUTIONS

Special handling/storage: N/A

SECTION $X$. CARCINOGENITY STATUS

1. NPP: Not Listed. 2.IARC: Not Listed. 3.OSHA: Not listed.

\section{SECTION XI. SECTION 313 SUPPLIER NOTIFICATION}

This product contains the following toxic chemicals subject to the reporting requirements of Section 313 of the Emergency Planning and Community Right-To-know Act of 1986 and of $40 \mathrm{CFR}$ 372:
CAS\#
$74 \frac{C A S H}{40-50-8}$
Chemical Name
Copper
Pexcent by weight $50-90 \%$

This information must be included in all MSDSs that axe copied and distributed for this material.

\section{SECTION XII. EMERGENCY CONTACT}

CHEMTREC: (800) 424-9300 TO be used "ONLY IN THE EVENT OF CHEMICAL EMERGENCIES INVOLVING A SPILL, LEAK, FIRE, EXPOSURE, OR ACCIDENT INVOLVING CHEMICALS". 


\section{DISCLATMER OF EIABETITY}

The information provided is based on data furnished to us by our suppliers or determined by us in our facilities at the time that this product was formulated. Although believed to be reliable, the information and products are intended for use by skilled persons at their own risk. Users should make their own determinations as to the suitability of the product for their particulax use or purpose. NO WARRANTY OF MERCHANTABILITY, FTTNESS FOR ANY PARTICULAR PURPOSE, OR ANY OTHER WARRANTY IS EXPRESSED OR IS IMELIED REGARDING THE ACCURACY OR COMPLETENESS OF THIS INFORMATION. Seller assumes no responsibility for events resulting or damages incurred from the use of this product and any obligations between seller and buyer are to be controlled by the texms and conditions contained in sellex's acknowledgement forms.

ISSUE DATE: $\quad 11 / 29 / 05$

REPLACES: $\quad 11 / 18 / 02$ 


\section{Appendix C}

Technical and safety data sheets for copper powder

MATERIAL SAFETY DATA SHEET

R1

UNITED STATES BRONZE POWDER, INC

P.O. BOX 31, 408 ROUTE 202

FLEMINGTON, NJ 08822

TELEPHONE: 908-782-5454

HMIS RATING

HEALTH:

FLAMMABILITY:

REACTIVTTY

PERS. PROTECTION: E

SECTION I. MATERIAL MOENTIFICATION

Material Name:

Item Number:

ROYAL COPPER POWDER

GRADES: $\quad 30,31,35,38,46,40,50,60,70,100,106,150,155,155 \mathrm{C}, 155 \mathrm{~L}, 165,165 \mathrm{~N}$,

$255,256,261,263,265,266,271,273,274,275,275 \mathrm{~L}, 275 \mathrm{U}, 276,278,279,280,290,640 \mathrm{~L}$, M1000, M1010, M1050, M1085

CAS Number: $\quad 7440-50-8$

Chemical Name: COPPER

SECTION II. INGRFDIENTS AND EXPOSURE LIMTTS

\begin{tabular}{|c|c|c|c|c|c|c|}
\hline Ingredient & CAS Number & 9 & TWA & $\begin{array}{c}\text { ACGIH } \\
\text { STEL }\end{array}$ & $\begin{array}{l}\text { TLV } \\
\text { TWA }\end{array}$ & $\begin{array}{r}\text { OSHA PEL } \\
\text { STEL } \\
\end{array}$ \\
\hline & & & & ALL Units & $=\mathrm{mg} / \mathrm{m} 3$ & \\
\hline COPPER & $7440-50-8$ & $>99$ & 1 & - & 1 & 1 \\
\hline
\end{tabular}

SECTION MI. PHYSICAL DATA

Appearance and Odor:

Reddish color, adorless

Boiling Point

COPPER

Evaporation Rate:

$4653^{\circ} \mathrm{F}\left(2567^{\circ} \mathrm{C}\right)$

N/A

Vapor Pressure ( $1 \mathrm{~mm} \mathrm{Hg}$ ):

Speeific Gravity:

Water Solubility $(\%)$ :

(a) $2962^{\circ} \mathrm{F}\left(1628^{\circ} \mathrm{C}\right)$

8.92

INSOLUBLE

Vapor Density (air=1) :

$\%$ Volatile by Volume:

$1981^{\circ} \mathrm{F}\left(1083^{\circ} \mathrm{C}\right)$

Molecular Weight:

N/A

$N / A$
63.54

SECTION IV. FIRE AND EXPLOSION DATA

Flash Point: $\quad$ N/A

Limits: LEL\%: N/A N/A

Extinguishing Media: Foan, CO2, Dry Chemical, Water Fog

Page 1 of 3 
MATERIAL SAFETY DATA SHEET

R1

\section{SECTON V. REACTIVITY DATA}

Material is stable. Hazardous polymerization will not occur.

Chemical incompatibilities: Strong alkalies, chlorates, bromates, and mineral acids.

Hazardous decomposition products: Decomposition may yield hydrogen and noxious copper compounds.

$$
\text { SECTION VI. HEALTH HAZARD INFORMATION }
$$

Target Organs: $\quad$ Respiratory system, nasal septum, skin, eyes, gastrointestinal, kidneys, liver, cardiovaseular system.

Primary entry routes: Inhalation, ingestion, skin or eye contact.

Health effects: $\quad$ Copper dusts and mists are eye and mucous membrane irritants, primary skin irritants and skin sensitizers. Acute exposure may cause metallic taste and nasal viceration and perforation. Prolonged skin contact may result in irritation and metal-fume fever, metallic taste, and discoloration of the skin and hair. Ingestion of copper powder compounds may cause vomiting and collapse. Hemolysis, jaundice, anuria, hypotension, and convulsions characterize acute

First Aid: poisoning.

Eye Contact:

Immediately wash the eyes with large amounts of water, occasionally lifting the lower and upper lids. Seek medical attention immediately. Contact lenses should not be worn.

Skin contact: $\quad$ Flush contaminated skin with water. Get medical attention if irritation occurs/persists.

Inhalation: $\quad$ Move the exposed person to fresh air at once. If breathing has stopped, perform artificial respiration. Keep the affected person warm and at rest. Get medical attention as soon as possible.

Ingestion: $\quad$ Emergency treatment - dilute with water or milk. Remove by gastric lavage (i.e. stomach tube) unless patient is vomiting. Get medical attention as soon as possible.

SECTION VII. SPILL, LEAK AND DISPOSAL PROCEDURES

Spill/heak procednres: Sweep gently to avoid dust cloud formation.

Disposal: $\quad$ Dispose of in accordance with local, state, and federal regulations.

$$
\text { SECTION VIII. SPECIAL PROTECTION INFORMATION }
$$

Personal Protective Equipment:

Goggles: $\quad$ Safety goggles with side shields, if needed.

Gloves: $\quad$ Required for those with extreme sensitivity.

Respirator: Wear supplied air respirator under confined or enclosed spaces, if needed.

Workplace considerations: Eye-wash fountain, soap and water wash station.

Ventilation: $\quad$ Sufficient ventilation, in volume and pattern, should be provided to keep air contamination below current applicable OSHA permissible limits.

\section{SECTION IX. SPECIAL PRECAUTIONS}

Special handling/storage: None 
MATERIAL SAFETY DATA SHEET

$\mathbf{R 1}$

SECTION $X$. CARCINOGENITY STATUS

1. NTP: Not Listed

2. IARC: Not Listed

3. OSFA: Not listed

SECTION XI. SECTION 313 SUPPLIER NOTIFICATION

This product contains the following toxic chemicals subject to the reporting requirements of Section 313 of the Emergency Planning and Community Right-To-Know Act of 1986 and of 40 CFR 372:
C.AS\#
$7440-50-8$
Chemical Name
Copper
Percent by Weight
$>99 \%$

This information must be included in all MSDS's that are copied and distributed for this material.

SECTION XII. EMERGENCY CONTACT

\section{Chemtrec: $800-424-9300$}

To be used "ONLY IN THE EVENT OF CHEMICAI EMERGENCIES INVOLVNG A SPILL, LEAK, FIRE, EXPOSURE, OR ACCIDENT INVOLVING CHEMICALS."

\section{DISCLAIMER OF LIABILITY}

The information provided is based on data furnished to us by our suppliers or determined by us in our facilities at the time that this product was formulated. Although believed to be reliable, the information and products are intended for use by skilled persons at their own risk. Users should make their own determinations as to the suitability of the produce for their particular use or purpose. NO WARRANTY OF MERCHANTABILITY, FITNESS FOR ANY PARTICULAAR

PURPOSE, OR ANY OTHER WARRANTY IS EXPRESSED OR IS IMPLIED REGARDING THE ACCURACY OF

COMPLETENESS OF THIS INFORMATION. Seller assumes no responsibility for events resulting or damages incurred from the used of this product and any obligations between seller and buyer are to be controlled by the terms and conditions contained in seller's acknowledgement forms. 


\section{Appendix D}

Technical and safety data sheets for bismuth powder

MATERIAL SAFETY

PRODUCT 101,201,301

DATA SHEET

NAME BISMUTH POWDER

DATE REV. SEPTEMBER 2003

Manufacturer's name \& address:

ACuPowder International LLC

901 Lehigh Avenue

Union, NJ 07083

Tel: $908-851-4500$, Ext $530-$ Emergency: $908-851-4519$

Product name \& Synonyms: BISMUTH POWDER

INGREDIENTS

\begin{tabular}{|l|c|c|c|}
\hline Material or component & $\begin{array}{c}\text { CAS } \\
\text { Number }\end{array}$ & $\%$ & $\begin{array}{c}\text { Threshold limit value } \\
\text { OSEA PEL }\end{array}$ \\
\hline Bismoth & $7440-69-9$ & 100.00 & Not known \\
\hline & & & \\
\hline
\end{tabular}

Chemicals listed as carcinogen or possible carcinogen:

\begin{tabular}{|l|l|l|l|}
\hline \multicolumn{1}{|c|}{ YeS } & NO & & \\
\hline NTP & $\mathrm{X}$ & & \\
\hline IARC & $\mathrm{X}$ & & \\
\hline OSHA & $\mathrm{X}$ & Section 313 information - see Page 3 \\
\hline
\end{tabular}

CEIEMICAL \& PHYSICAL PROPERTIES

\begin{tabular}{|l|l|l|l}
\hline Boiling Point: & Melting point:
\end{tabular}

\begin{tabular}{|l|l|l|l|l|}
$1560^{\circ} \mathrm{C}$ & $271^{\circ} \mathrm{C}$ & None & N.A. \\
\hline $\begin{array}{l}\text { Specific gravity } \\
\text { (water = 1) } 9.8\end{array}$ & $\begin{array}{l}\text { Vapor pressure } \\
\text { (mmHg): N.A. }\end{array}$ & N.A. & N.H: \\
\hline
\end{tabular}

Appearance and odor: Gray and odorless Other:

FIRE \& EXPLOSION HAZARDS

\begin{tabular}{l|l|l}
\hline Flash point (method): & Ignition temp:
\end{tabular}

N.A. N.A. N.A. N. N. N. N

Extinguishing media: Class D extinguisher, dry sand or other inert material. Do not use Class " $A$ ",

" $B$ ", or " $C$ " extinguishers or halogenated agents.

Special fire fighting procedures: Gently cover the burning powder and form a ring around it with the sand or other inert material. Allow to cool.

Unusual fire \& explosion hazards: When beated or in contact with acid, can emit toxic fumes. Can be flammable and explosive when in a dust cloud, depending on the concentration of the powder in a given area and the size range of the powder. 


\section{ACUTE HEALTH EFFECTS / ROUTES OF ENTRY}

Inhalation: Foul breath, metallic taste, gingivitis.

Skin contact: Possible exfoliative dermatitis.

Eye contact: Possible irritation.

Ingestion: Stomatitis, diarrhea, headache, fever, theumatic pains.

Supplemental information: Black line may form on gums in the mouth.

\section{FIRST AID PROCEDURES}

Inhalation: Remove from exposure. Get medical advice.

Skin contact: Wash affected skin with soap and water.

Eye contact: Flush eyes with water at least 15 minutes. Consult a physician.

Ingestion: Consult a physician immediately.

REACTIVITY

\begin{tabular}{|l|l|l|l|l|l|}
\hline \multicolumn{2}{|l|}{ Product corrosive: } & \multicolumn{2}{l|}{ Stability: } & Thazardous polymerization: \\
\hline Yes & No X X & Unstable & Stable X & IMay occur & /Will not occur X \\
\hline
\end{tabular}

Conditions and materials to avoid: Acids, halogens, nitrates, perchloric acid.

Haxardous decomposition products: May react with acids to form toxic fumes.

\section{SPILLS, LEAKS, HANDLING \& STORAGE}

Spill \& leak procedures: Wear protective clothing, goggles and a NIOSH approved respirator. Sprinkle moderately with damp sand and collect for disposal avoiding dust clouds as much as possible.

Waste disposal method: Put in a closed container for disposal.

(Disposer must comply with Federal, state or local waste disposal laws)

Handling and storage methods: Store in a cool, dry place avoiding contact with heat and acids. Avoid creating dust clouds.

BISMUTH POWDER 101, 201,301

Page 2 of 3 
Rev. $9 / 03$

BISMUTH POWDER 101, 201, 301

SPECLAL PRECAUTIONS

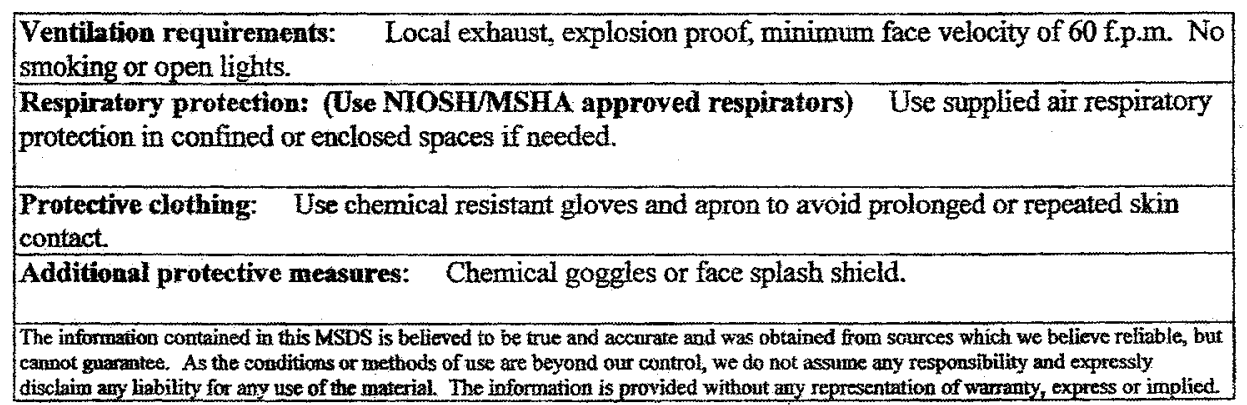

\section{CHRONIC AFFECTS}

Available data on Bismuth exposure is limited, especially of pure metallic bismuth. Studies have shown that chronic exposure may result in anemia, "Lead Line" on gums, possible uicerative stomatitis.

PRE-EXISTING CONDITIONS AGGRAVATED

Pre-existing respiratory, stomach.

TRANSPORTATION

DOT - Not Regulated

Page 3 of 3 